Portland State University

PDXScholar

Spring 6-4-2019

\title{
Next Generation Science Standards and Physics First: a Case Study of High School Teachers' Beliefs and Practices
}

Stephen Godfrey Scannell

Portland State University

Follow this and additional works at: https://pdxscholar.library.pdx.edu/open_access_etds

Part of the Curriculum and Instruction Commons, Educational Leadership Commons, and the Science and Mathematics Education Commons

Let us know how access to this document benefits you.

\section{Recommended Citation}

Scannell, Stephen Godfrey, "Next Generation Science Standards and Physics First: a Case Study of High School Teachers' Beliefs and Practices" (2019). Dissertations and Theses. Paper 5002.

https://doi.org/10.15760/etd.6878

This Dissertation is brought to you for free and open access. It has been accepted for inclusion in Dissertations and Theses by an authorized administrator of PDXScholar. Please contact us if we can make this document more accessible: pdxscholar@pdx.edu. 
Next Generation Science Standards and Physics First: A Case Study of High School

Teachers' Beliefs and Practices

by

Stephen Godfrey Scannell

A dissertation submitted in partial fulfillment of the requirements of the degree of

\author{
Doctor of Education \\ In \\ Educational Leadership: Curriculum and Instruction
}

Dissertation Committee:

Samuel Henry, Chair

Dannelle D. Stevens

Cary Sneider

Gwen Shusterman

Portland State University

2019 
(C) 2019 Stephen Godfrey Scannell 


\begin{abstract}
This dissertation is a case study of a school district in the Pacific Northwest that developed three-year high school science curricula using a Physics First course sequence (Physics, Chemistry, Biology), with the crosscutting concept Patterns as the central theme of the courses. The purpose of the study was to examine the impact of the implementation of the $9^{\text {th }}$ grade course, Patterns Physics, on teacher practice and beliefs about science teaching and determine whether this new approach facilitated teacher classroom practices and beliefs congruent with those expressed in A Framework for K-12 Science Education (NRC, 2012) and the Next Generation Science Standards (NGSS Lead States, 2013). Results from this study indicate that the implementation of Patterns Physics positively impacted teacher confidence in teaching the NGSS science and engineering practices. Professional development that provided teachers multiple opportunities to engage with the curriculum - in the role of a student, in professional discussions with colleagues, and over several years were critical to support a change in practice consistent with three-dimensional (3D) teaching called for by the Framework and NGSS. Teacher participants viewed the Patterns PCB (Physics, Chemistry, and Biology) sequence as an appropriate course sequence, with strong agreement that a $9^{\text {th }}$ grade physics course needs to be tailored to the needs of students, such as added support for students with minimal mathematics skills. The NGSS, with an emphasis on 3D learning (science content knowledge, crosscutting concepts, and science and engineering practices), had a significant positive impact on instructional practice.
\end{abstract}




\section{Dedication}

I dedicate this dissertation to Heather, Rachel and Nathaniel. You have been patient, supportive, and have provided unwavering love through this entire journey. Thank you.

I also dedicate this dissertation in the memory of two mentors who had a significant influence on me. Dr. Ron Narode was my advisor through the first phases of my doctoral journey. Ron was an amazing teacher and mentor who provided important guidance in both academics and in life. Dr. David Hamilton was my high school physics and chemistry teacher. I did not know at the time that I wanted to teach high school science, but he was certainly a model on how to do it right. I was very fortunate to reconnect with him when I began teaching; he was instrumental in my early professional growth with science inquiry and utilizing technology in teaching physics, and he was an example of how to continue to develop professionally throughout one's career. 


\section{Acknowledgements}

I would like to acknowledge the support, encouragement and inspiration of many colleagues, PSU faculty, friends and family who have supported me through my doctoral journey.

I am especially grateful to the members of my committee. Each one of them has had a significant impact on me, and I was very fortunate to have a committee of scholars with diverse skills and talents that supported me in completing this dissertation and degree. Samuel Henry, Ph.D., my advisor and committee chair, has been wonderful in supporting my work. As someone who was at the table when our state adopted the Next Generation Science Standards, he provided unique perspectives germane to this dissertation. In our meetings together, I was inspired by our conversations and left the meetings feeling motivated to take the next steps. I am grateful for his help and support.

Dannelle D. Stevens, Ph.D. has been generous with her time and efforts in supporting my development in academic writing. I am grateful for her consultations on focused writing and writing strategies, and especially for her tips and tricks with using Zotero as I finalized this document. It was largely through working with Dannelle that I began to enjoy the writing process. In part from her encouragement, and with some of the many writing strategies she has shared, I plan to continue to write and develop as an academic writer.

I am truly grateful to Cary Sneider, Ph.D. whom I have been fortunate to work with on several projects in addition to this dissertation over the past ten years. Cary was 
extremely generous with his time and expertise in all phases of this dissertation. I have truly appreciated his support and his ability to help me focus on what is most important. Cary helped me find my voice as a science educator and to design and carry out this study in a way that aligned with my own professional goals as well as with an eye to the broader impacts. I am extremely grateful for the time, energy and patience he has generously provided over the years.

I am also grateful to Gwen Shusterman, Ph.D. who served as the graduate representative on my committee. Gwen brought a unique perspective as a science educator with expertise in chemistry to this project. I am grateful for her thoughtful input.

I would also like to recognize Joanne Cooper, Ph.D. who led the writing support class of which I was a part for many years. The writing class was truly a place where one could get re-centered, as well as share the trials and tribulations of the doctoral process with other students. Joanne's openness about her own doctoral and professional journey, and her journey as a writer were helpful to me. I would also like to thank all of the students who were in the writing class, and in particular Alfonso Garcia Arriola, Ed.D. (2017 graduate), who was my writing partner for several years. Alfonso and I shared many drafts of writing with each other, as well as supporting each other through each phase of the research process. I truly valued his unique perspective. I would also like to thank Moti Hara, Ph.D. who made two semesters of statistics fun, enjoyable, and a chance to explore many of the tools in SPSS. Moti's assistance, several years after taking his courses, with SPSS and providing guidance on the statistics used in this study was truly valuable to me. I would also like to thank Jennifer Wells, Ed.D., my former 
colleague from the Center for Science Education, who met with me during the research design phases, mid-way during the data analysis phase to review my initial coding of the qualitative data, and edited the final version of this document.

I would like to recognize the contributions of the research participants in District A as they were invaluable to this project. I was impressed by the professionalism and dedication to science teaching I witnessed when meeting with these teachers. The number of survey participants and quality of responses to my survey indicated a high level of professionalism that I greatly appreciated. I would also like to recognize those teachers who participated in interviews. They were willing to take the time to participate and share their stories. Their contribution, through sharing their experiences in their classrooms, building and district professional development, and their own teaching experiences was invaluable to this study.

I would also like to recognize Bradford Hill and Susan Holveck, DEd. These two District A TOSAs were always available to discuss Patterns Physics and their experiences in providing professional development and curriculum design.

I would like to thank my parents, Alice and John Scannell, for their continued support throughout my life and throughout this doctoral journey. My mother in particular has been a wonderful sounding board as we had many conversations about doing research. The survey developed for use in this study began at her kitchen table where she shared her expertise in designing surveys. Our conversations, sometimes late at night on the phone, helped me focus on what I was trying to do and helped me think of things in new ways. 
And a special recognition and thank you to my wife Heather and children Rachel and Nathaniel. This dissertation would not have been possible without your longstanding support. Thank you for supporting me throughout this entire process and in understanding that it was something that I needed to do. Heather, I am looking forward to spending more time together. Rachel and Nathaniel — the heart of my research is to better understand the learning process. Being part of your lives as you have grown into the people you are has been one of the joys of my life. You have often provided useful insights and suggestions in areas related to this work (i.e. writing strategies, time management, school-life balance, taking time to play, etc.) which I have applied to my own life and in persisting and completing the dissertation. Thank you! 
Table of Contents

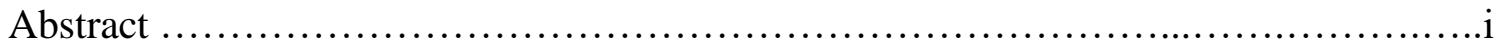

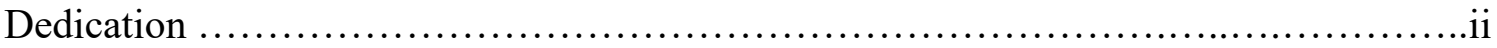

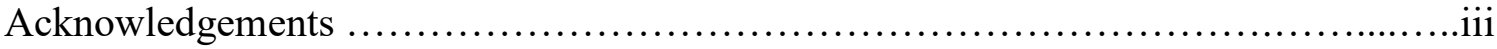

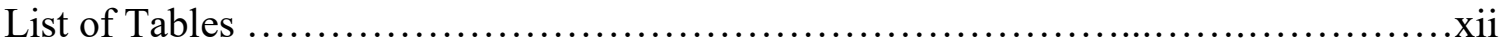

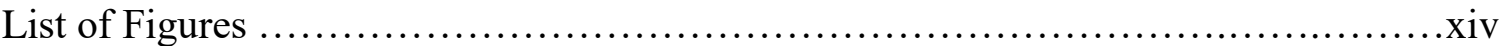

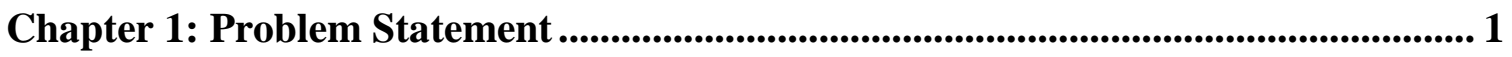

Background of the Problem ..................................................................................... 5

Characteristics of the Next Generation Science Standards .................................. 5

High School Science Course Sequencing ...................................................... 9

Challenges in Professional Development ....................................................... 11

Statement of the Research Problem ........................................................................... 12

Significance of the Research Problem ............................................................. 14

Presentation of Methods and Research Questions ..................................................... 17

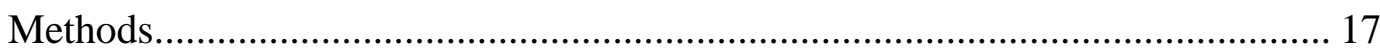

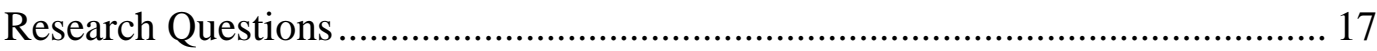

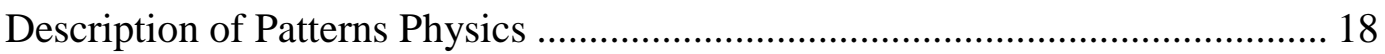

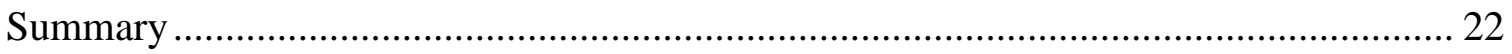

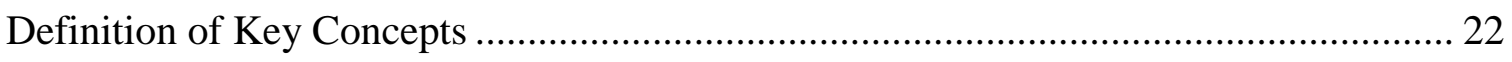

Chapter 2: Literature Review ............................................................................... 24

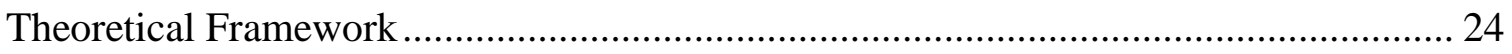

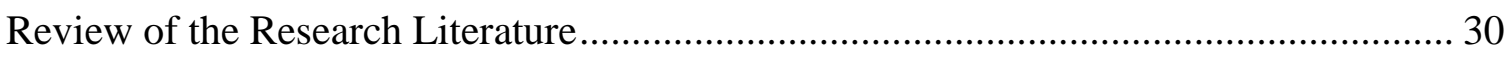

Change in Teaching Practice Due to NGSS .................................................... 30

What is the Relationship Between Science and Engineering?.......................... 31

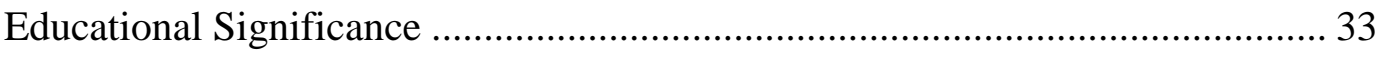

The Challenges of Implementing the Engineering Practices ............................. 35

High School Science Course Sequences and Physics First ................................ 37

Enrollment in Physics First programs.................................................. 40

Influence of educational research on Physics First.............................. 41

Research on the impact of Physics First ............................................. 45 
Patterns Physics in the Context of Physics First...................................... 52

Describing the Challenges, and Teacher Beliefs and Professional Development 55

Teacher beliefs about inquiry-based practices ..................................................... 57

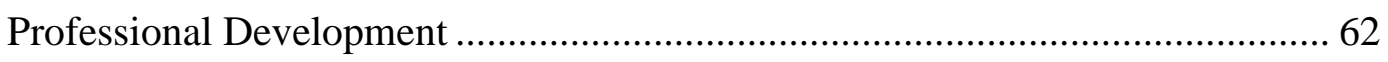

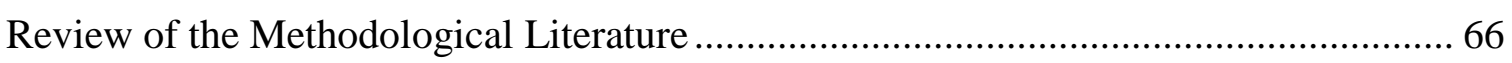

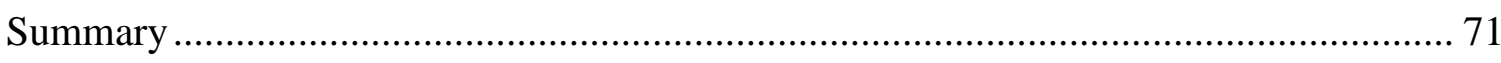

Chapter 3: Methods ............................................................................................................. 72

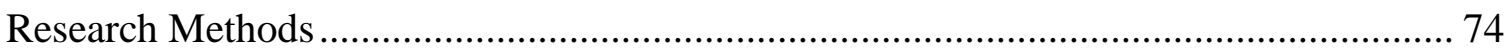

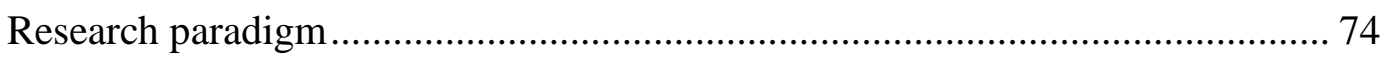

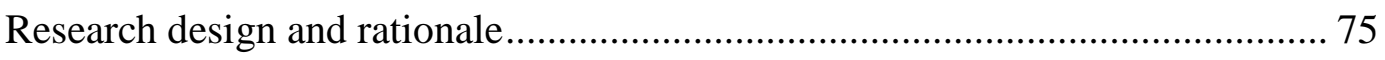

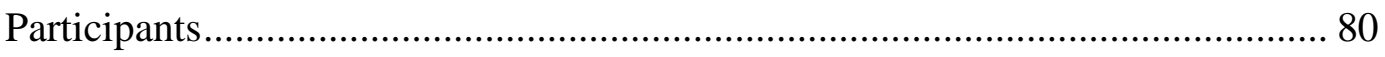

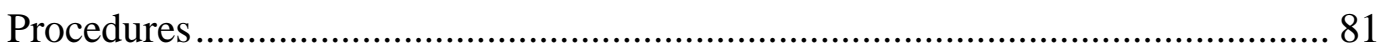

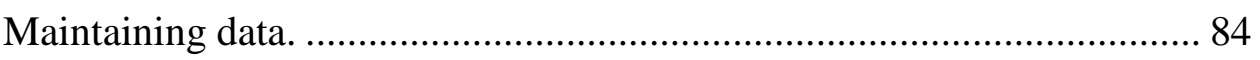

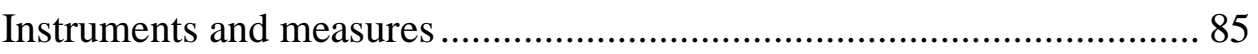

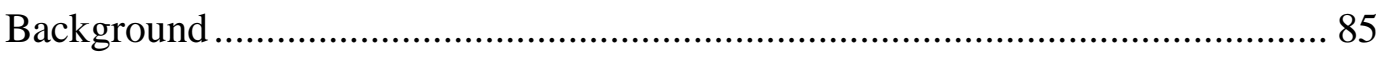

Development of the Patterns Physics Impact Survey (PPIS).................... 90

Course sequence and views of Physics at the 9th grade.......................... 91

Change in confidence in engaging students in science and engineering .. 92

PD Impact and recommendations.......................................................... 97

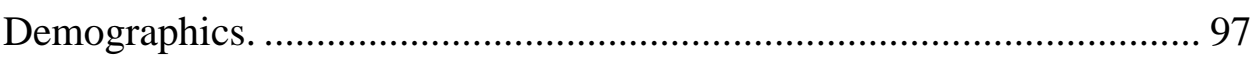

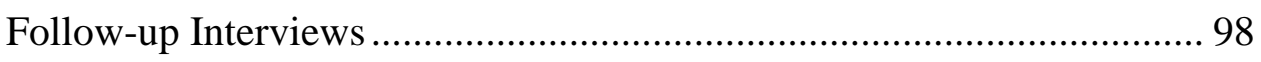

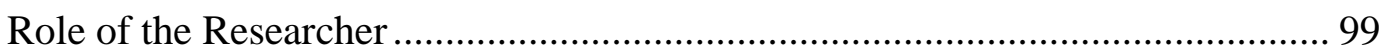

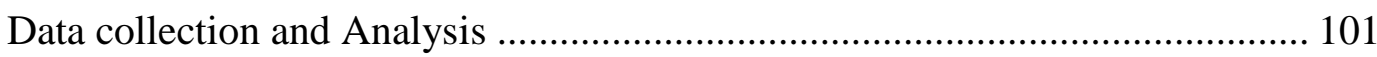

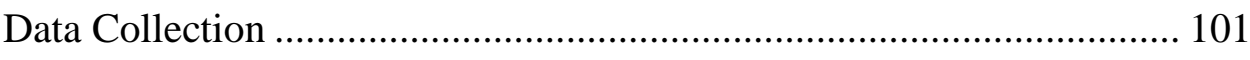

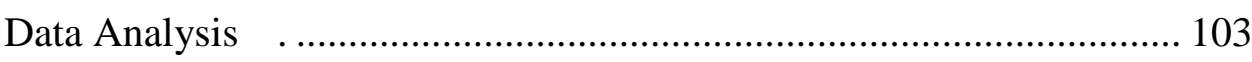

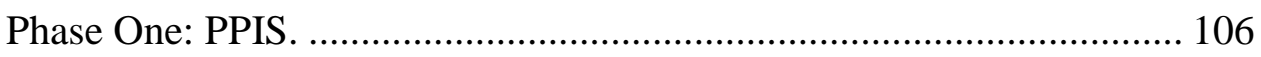

Phase Two: Interview Analysis. ........................................................... 108

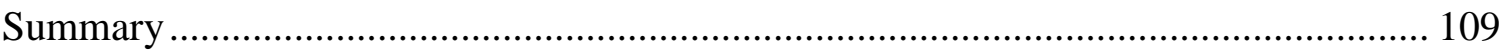

Chapter 4: Results.................................................................................................................... 110

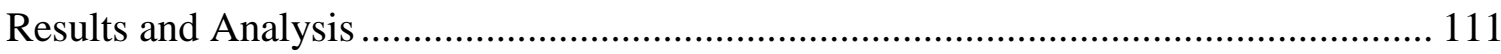

Phase One: Patterns Physics Impact Survey ……………………………......... 111

Demographics of District A Survey Participants.................................... 113 


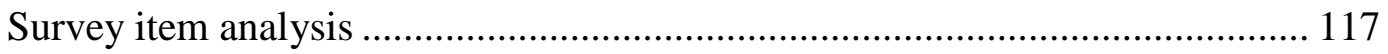

Patterns Physics and Physics First ....................................................... 117

Qualities of a 9th grade Physics Course. .............................................. 125

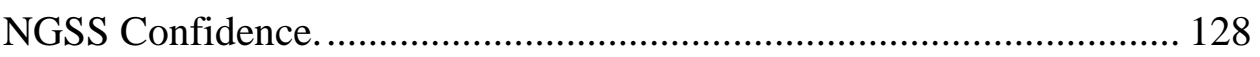

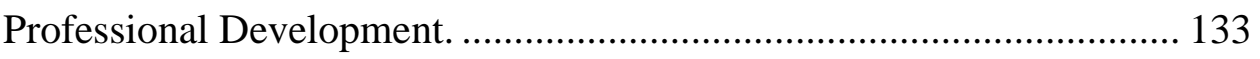

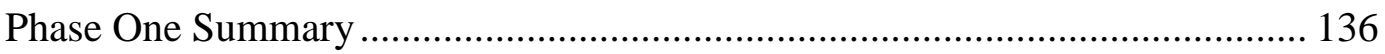

Finding one: District A high school science teachers strongly support

Patterns Physics and the PCB course sequence. ..................................... 136

Finding two: Teaching experience and district training in Patterns Physics improved confidence in teaching the NGSS science and engineering practices.

Finding three: Multiple opportunities for Professional Development provided over a significant timespan were critical in supporting Patterns Physics and NGSS implementation.

Finding four: Whatever sequence they prefer, teachers are aware of the need to adjust the curriculum to meet the needs of struggling students. 137

Phase Two: Interview Analysis and Results ..................................................... 137

Experience and Views of Interview Participants ................................... 139

Phase Two: Findings through Categories and Themes ...................................... 144

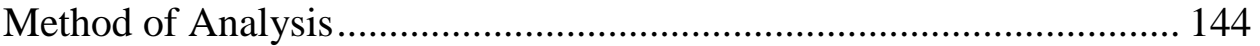

Category 1: Descriptions of Practice. ………………………………...... 145

Theme 1A: Patterns .................................................................. 146

Theme 1B: Inquiry ………………………………............... 147

Theme 1C: Engineering (Data, Iteration, Constraints ................ 149

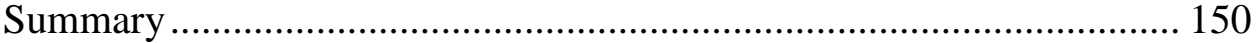

Category 2: Considerations about Patterns Physics and Physics First. .. 150

Theme 2A Nature of the course and Sequence Matters............... 151

Theme 2B: Role of Mathematics and Challenges........................ 153

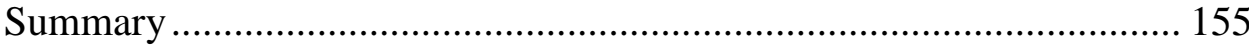

Category 3: Professional Development. ................................................ 156

Theme 3A. Qualities of Effective PD ......................................... 157

Theme 3B: Multiple opportunities and a collaborative culture .. 158

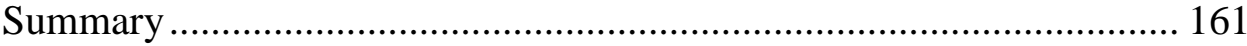

Category 4: Role of the NGSS............................................................... 161 
Theme 4A, Guiding instructional practice .................................... 163

Theme 4B, Moving science education forward: ............................ 163

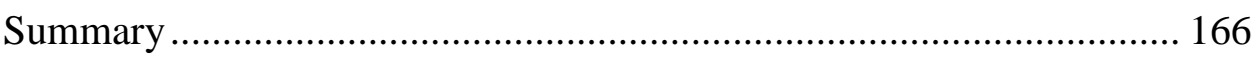

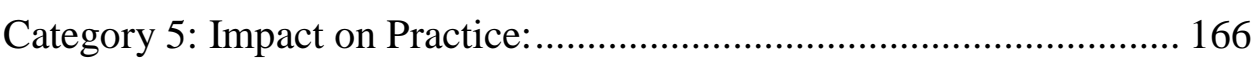

Theme 5A, Patterns as an instructional model .............................. 167

Theme 5B, Student-centered instruction: .................................... 167

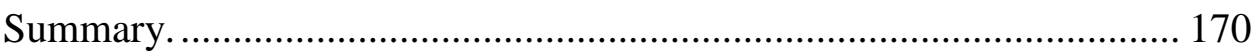

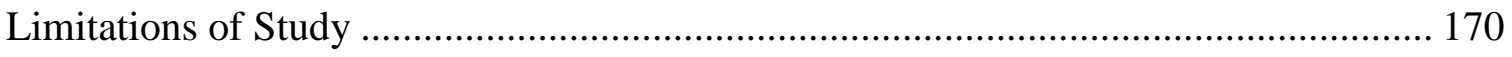

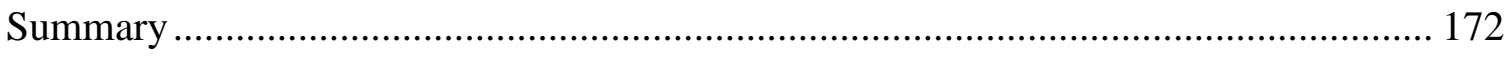

Chapter 5: Conclusions ..................................................................................................... 175

How the Data and Analysis Informs the Research Questions .................................... 177

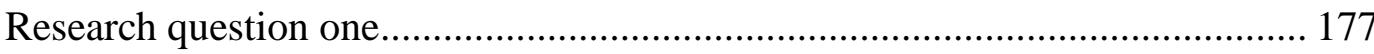

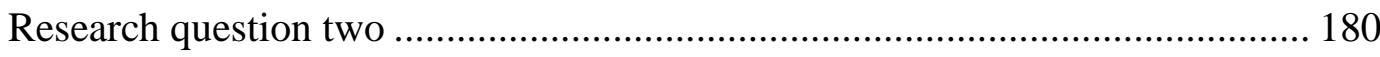

Summary. ............................................................................. 185

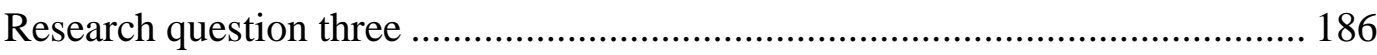

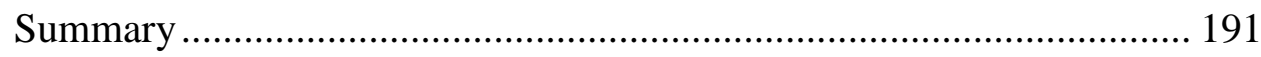

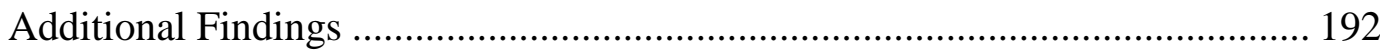

Situated in a Larger Context .................................................................................. 194

Recent history of science education reform................................................... 195

Within the context of the Physics First movement ......................................... 197

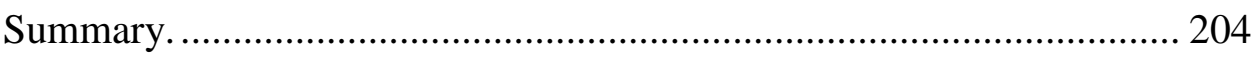

Within literature on science professional development .................................. 204

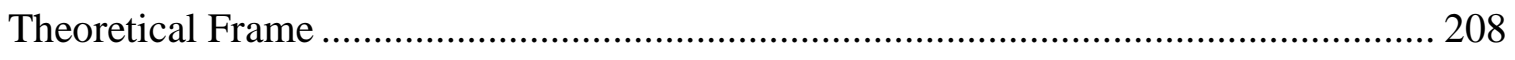

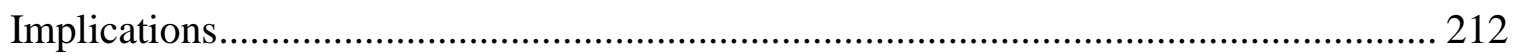

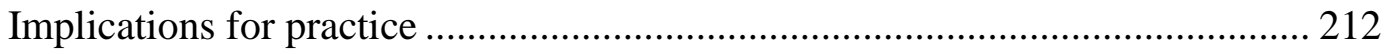

Implications for policy ...................................................................... 216

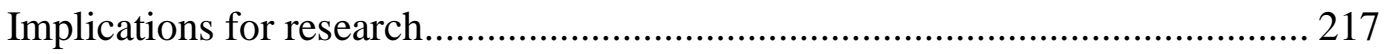

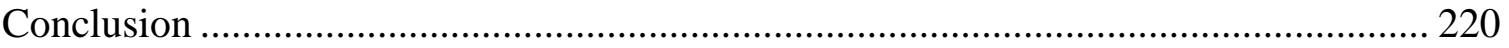

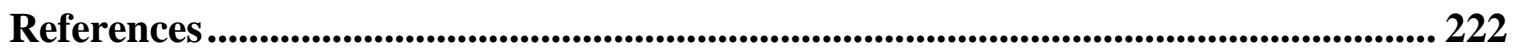

Appendix A: Patterns Physics Impact Survey (PPIS) ........................................ 240

Appendix B. Semi-structured Interview Questions ............................................ 250 
Appendix C. Interview Consent Form .............................................................. 251

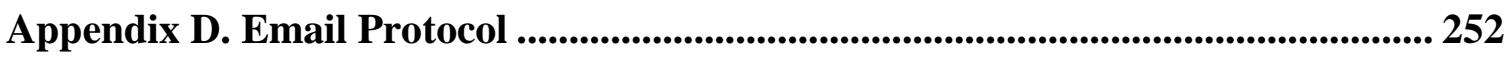

Appendix E. Proxy (TOSA) Recruitment Script .................................................. 253

Appendix F. Recruitment Script ................................................................................. 254

Appendix G. Interview Coding Matrix ......................................................................... 255 


\section{List of Tables}

Table 1 Comparison of National Science Education Standards and Next Generation

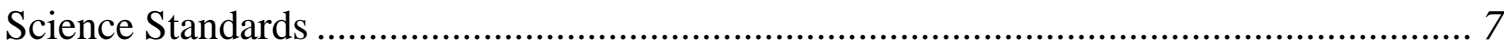

Table 2 Patterns Physics units, key science topics and engineering projects............... 19

Table 3 Comparison of Engineering and Science Practices ..................................... 33

Table 4 Research on Physics First Initiatives ......................................................... 48

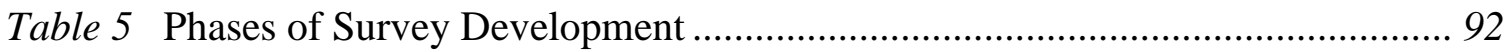

Table 6 Demographics of District A Survey Participants........................................... 98

Table 7 PPIS Survey items and interview items utilized for each research question...... 99

Table 8 PPIS Survey and interview items utilized for each research question and

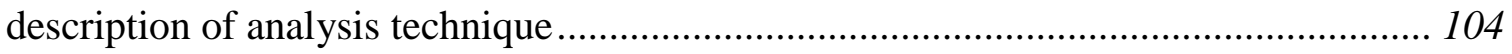

Table 9 Demographic Categories of District A Survey Participants ............................ 107

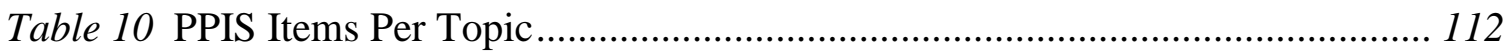

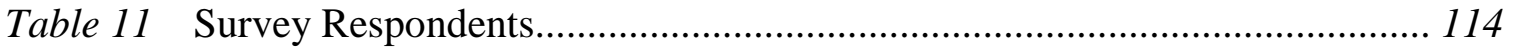

Table 12 Survey Teachers' Course Assignments and Workshop Attendance............. 116

Table 13 Best Sequence Choices by Location and Experience ................................. 123

Table 14 Best Sequence Choices by Courses Taught and Workshops Taken.............. 124

Table 15 Comparison of best sequence and Expertise........................................... 125

Table 16 Belief about $9^{\text {th }}$ Grade Physics Course .................................................... 127

Table 17 Comparison Between All teachers, Pattern Physics teachers and Patterns

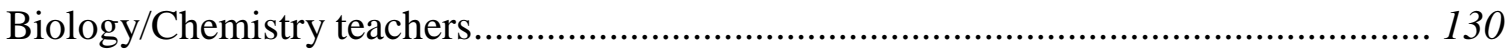


Table 18 Paired Samples T-Test Comparison for Teachers who teach both Pattern

Physics and Patterns Biology/Chemistry ............................................................ 131

Table 19 Impactful experiences for science and engineering practices...................... 133

Table 20 Phase 2- Demographics of Interviewees................................................. 138

Table 21 Categories and Themes for the interviews............................................. 145 


\section{List of Figures}

Figure 1. District A patterns PCB timeline .......................................................... 14

Figure 2. Learning arc for energy and engineering ............................................... 20

Figure 3. The interconnected model of professional development ............................. 25

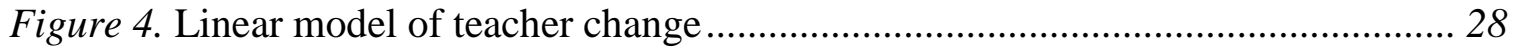

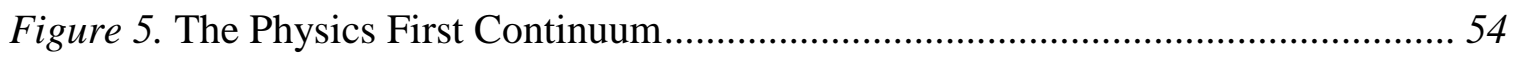

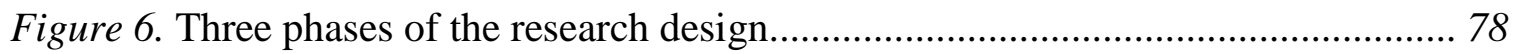

Figure 7. Development of the patterns physics impact survey (PPIS) .......................... 90

Figure 8. Integration of success and motivation items to confidence construct.............. 95

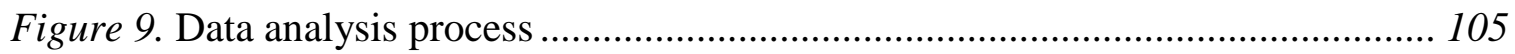

Figure 10. Preferred Course Sequence ….......................................................... 118

Figure 11. Prompts for PPIS confidence items .................................................. 128

Figure 12. Scannell revision of Clark and Hollingsworth (2002), Interconnected Model

for Professional Growth.................................................................................. 211 


\section{Chapter 1: Problem Statement}

The April 2013 release of the Next Generation Science Standards (NGSS) promoted significant reform of science education in the United States (U.S.). The NGSS were developed to update state science standards, based on standards released in the 1990's, to take advantage of the latest research on how students learn science. They also addressed the latest advancements in science and are consistent with the Common Core English Language Arts/Literacy and Mathematics Standards, released in 2010 (NGSS Lead States, 2013).

The NGSS standards were developed through a collaborative process among 26 states, the National Research Council (NRC), the National Science Teachers Association (NSTA), the American Association for the Advancement of Science (AAAS), and Achieve, a non-profit organization in charge of coordinating the second phase of the NGSS development. Since their release in 2013, twenty states including Oregon and the District of Columbia, have fully adopted NGSS. The NGSS are written as performance expectations that indicate what students should know and be able to do at the end of instruction and are organized to build students' understanding of science over time.

There are several significant differences from past standards: the addition of engineering to the traditional science practices, the elevation of crosscutting concepts (concepts that are found throughout science such as patterns, cause and effect, systems and modeling), and the integration of these with traditional science content into a construct called 3D (3-dimensional) learning. The goals for 3D learning are for students to "have gained sufficient knowledge of the practices, crosscutting concepts, and core 
ideas of science and engineering to engage in public discussions on science-related issues, to be critical consumers of scientific information related to their everyday lives, and to continue to learn about science throughout their lives" (NRC, 2012, p. 9). In addition, students should develop an appreciation for the historical development of scientific knowledge and practices. These goals are intended for all students, not just those interested in science and engineering, or academically strong students.

While the NGSS has specific grade level standards for grades K-5, the standards are organized by grade bands for middle school (grades 6-8) and high school (grades 912), leaving the decisions about organizing standards into courses and the sequencing of those courses up to schools and school districts. Due to this development, many high school and district leaders are revisiting their science course sequences and revamping their course offerings.

The NGSS has highlighted several significant issues for science educators at the high school level that need to be addressed in order for the goals of the NGSS to be realized. First, the NGSS calls for a coherent science course sequence in which the concepts and content learned in one course are connected and built upon by another course (Bybee, 2014). Traditionally, high school science courses have been viewed as independent of each other wherein the knowledge and skills developed in one course are not explicitly taught in a manner intended to impact student performance in other courses (Sadler \& Tai, 2001). Therefore, science course sequences need to be reevaluated and courses revamped to provide coherence between courses. 
Equity for all students is also an issue related to course sequencing. If all students are to be well prepared for college and career, then all students must take appropriate courses and those courses must be coherently aligned for students to achieve that goal. In contrast, a review of a large school district in California in the year 2000 found that students could choose from a multitude of science course options and sequences. However, only one-third of graduating seniors had taken the appropriate course work to attend a state college (Bess \& Bybee, 2004).

Second, the NGSS reinforces the importance of an inquiry-based approach to teaching and learning. While the reform efforts of the 1990's intended to make science teacher practices more constructivist in nature through an emphasis on inquiry-based instruction, this goal had limited success (Capps, Crawford, \& Constas, 2012; Demir \& Abell, 2010; Marshall, Horton, Igo, \& Switzer, 2009; Ozel \& Luft, 2013). So, in addition to continued work on inquiry-based instruction, the NGSS expands on this strategy adding engineering as both a content area and as a performance expectation, while raising the profile of crosscutting concepts to be on equal footing. In essence, while previous standards had each of these components, they were often separate, so instruction and assessment happened separately, if at all. The NGSS combines these constructs so that students are focused on understanding applications of knowledge and skills in context versus just memorizing and reciting science facts.

The focus on an inquiry-based approach in conjunction with engineering has been shown to have a positive effect on the learning of science for groups historically underserved in science education (NGSS Lead States, Appendix D, 2013). Engineering 
activities give students from diverse groups an opportunity to draw on knowledge and skills acquired through their own experiences, and those of their culture, into the activities thus providing relevance to their own lives. Key to this engagement strategy is providing students with opportunities to develop a sense of meaning as they practice using multiple communication strategies (writing, speaking, drawing) to communicate ideas and results.

Meeting the goals of the Next Generation Science Standards (NGSS) requires a significant investment in teacher professional development. Much has been learned about designing and implementing professional development since the release of the National Science Education Standards (NRC, 1996). While traditional professional development can been described as "sit and get," as in teachers attend a workshop or conference to sit and listen to a speaker and take notes; it is now viewed as important for professional development to focus on the teacher as a learner, have a direct classroom application, attend to teacher knowledge, and provide a collegial environment for professional development to be effective (Garet, Porter, Desimone, Birman, \& Yoon, 2001; Rogers et al., 2007). When professional development is targeting a specific curriculum, Taylor et al. (2015) identified the following key characteristics for effective professional development "providing coherent, ongoing (i.e., multi-event) programs that mirror best practice; keeping a focus directly on learning and teaching; and providing teachers opportunities to develop deep understanding of concepts and participate in communities of reflective practice" (p. 990). With guidance from the latest research, professional 
development targeting the NGSS should be more successful than past efforts (Taylor et al., 2015).

In order to move towards a successful implementation of the NGSS, schools and school districts will need to make a significant effort. This includes modifications and reorganizations of current course offerings to include all of the standards for all of the students, and professional development for teachers to help them modify instructional practices to engage students in 3D learning. Due to the scale of these changes, these tasks will require a multi-year effort (Heller, Daehler, Wong, Shinohara, \& Miratrix, 2012).

\section{Background of the Problem}

In the next section of chapter one, I begin by providing more detailed information about the differences in past science standards and the NGSS. This will be followed by an overview of traditional course sequencing at the high school level and the reasoning behind a common Physics First course sequence. This is followed by information on the call for more professional development. I then introduce the research problem and its significance. This is followed by brief description of research methods used in this study that will be further elaborated in chapter two and chapter three. The chapter concludes with a list of key terms.

\section{Characteristics of the Next Generation Science Standards}

Although much of the scientific content involved in the NGSS is similar to that found in past standards (Benchmarks for Science Literacy, 1993; National Science Education Standards, 1996) the new standards differ from former standards in significant 
ways. First, these standards explicitly distinguish between scientific content referred to as Disciplinary Core Ideas (DCI), scientific processes referred to as Science and Engineering Practices (SEP), and general scientific concepts found throughout science, called Crosscutting Concepts (CCC).

Second, these three areas (DCI, SEP, and CCC) are integrated into each standard. The integration of these areas is necessary to provide "students with a context for the content of science, how science knowledge is acquired and understood, and how the individual sciences are connected through concepts that have universal meaning across [scientific] disciplines" (NGSS Lead States, 2013, p. xv).

Third, the standards are written as performance expectations, whereas previously, the focus was more general and content focused. Table 1 lists an Earth Science standard for grade 9-12 from the National Science Education Standards (NRC, 1996) and a comparable Earth Science Standard from the Next Generation Science Standards (NGSS, Lead States, 2013). The NSES is more general, in that the key phrase is that "students should develop an understanding of...." This wording does not indicate how an instructor would determine this or the level of detail required to meet this standard. In contrast, the key phrase from the NGSS is "Students who demonstrate understanding can...," followed by a list of what students can do to demonstrate understanding of this standard. This change from general, content-focused standards, to performance expectations provides a clearer expectation of what students should know and be able to do.

The fourth major difference is the addition of engineering in the standards. Engineering finds a place both as a Disciplinary Core Idea (DCI), alongside the 
traditional science topics_-physical science, earth and space science, and life scienceand as a "practice," alongside scientific inquiry, in a section called Science and Engineering Practices. As stated in the NGSS, "Science and engineering are integrated into science education by raising engineering design to the same level as scientific inquiry in science classroom instruction at all levels and by emphasizing the core ideas of engineering design and technology applications" (NGSS Lead States, 2013, p. xii).

Table 1

Comparison of National Science Education Standards and Next Generation Science Standards

National Science Education Standards (1996)

Grade 9-12 Earth and Space Science

"As a result of their activities in grades 9-12, all students should develop an understanding of, Energy in the earth system, Geochemical cycles, Origin and evolution of the earth system, origin and evolution of the universe" (p. 187).
Next Generation Science Standards (2013)

Grade 9-12 Earth Science

"HS-ESS1-Earth's Place in the Universe: Students who demonstrate understanding can: Develop a model based on evidence to illustrate the life span of the sun and the role of nuclear fusion in the sun's core to release energy in the form of radiation" (p. 119)

While each of these differences is significant, I think that the increased emphasis on science and engineering practices from past standards not only provides a fertile environment to support constructivist classroom practices, but to significantly change the nature of classroom practice for most teachers.

The NGSS requires teachers and educational institutions to take a fresh look at how science instruction is designed and implemented. Standards are broken down by grade level for grades 1-5 but are organized into multiple-grade groupings called grade 
bands for grades 6-8 and 9-12 — which fit the grade levels common to middle school and highs school levels. These grade bands are organized this way because different states handle standards differently and "because there is no conclusive research that identifies the ideal sequence for student learning” (NGSS, Appendix K, 2013, p. 2). While the NGSS authors provide several course maps as models for states and school districts to organize the standards into year-long courses, they make it clear that:

States and districts/local education agencies are not expected to adopt these models; rather, they are encouraged to use them as a starting point for developing their own course descriptions and sequences (p. 3).

Courses at the middle school and high school level are often organized by the traditional science topics of physical science, earth and space science and life science, but are sometimes integrated in various ways in courses typically called Integrated Science or General Science (Banilower et al., 2013). While not specifying the organizational structure in which the DCI's need to be organized into courses, the expectation is that over the 9-12 grade band, all students are prepared to meet all of the standards (NGSS, Appendix K). In addition to the disciplinary core ideas (DCI), the crosscutting concepts (CCC) and the scientific and engineering practices (SEP) need to be integrated into all science course courses; which includes having engineering as a component in all science courses. The combination of these areas, DCI, CCC, \& SEP, are called Performance Expectations (PE), which are statements that "clarify the expectations of what students will know and be able to do by the end of the grade or grade band" (NGSS, Appendix K, p. 5). 


\section{High School Science Course Sequencing}

One reason that the organizing of courses around the specific NGSS PE's is a challenge is that there has not been a standard course sequence in science at the high school level across the entire nation. While states identify standards that need to be taught, it is up to districts and schools to organize and implement courses that meet these standards. The Biology, Chemistry, Physics course sequence (BCP, Biology at the $9^{\text {th }}$ grade, Chemistry at the $10^{\text {th }}$ grade, and Physics at the $11^{\text {th }}$ grade) is recognized as the most common course sequence at the high school level in the U.S. (Gaubatz, 2013). However, in my own experience, the Physical Science course was a common $9^{\text {th }}$ grade course (typically covering both Physics and Chemistry concepts) followed by $10^{\text {th }}$ grade Biology with a two-year science requirement in my home state until 2009 (it was raised to 3 years starting with the class of 2012). This sequence resulted in many students choosing to stop taking science after the $10^{\text {th }}$ grade.

According to the 2012 National Survey of Science and Mathematics Education (Banilower et al., 2013), "virtually all schools offer at least one biology course, and nearly all offer chemistry; somewhat fewer offer physics. Environmental science and Earth/space science courses are each offered in about half of high schools" (p. 66). Each of these content areas, biology, chemistry, physics, environmental, and earth/space science has a significant presence in the NGSS at the high school grade band, therefore it is a significant challenge to design courses that will provide all students the opportunity to meet all of the NGSS performance expectations - thereby achieving the goal of the NGSS. 
To provide guidance to those in charge (at the state, district, and school levels) of developing course descriptions and course sequences, the Next Generation Science Standards: For States, By States Appendix K includes several course maps for both the 68 and 9-12 grade bands. The NGSS 9-12 course maps provide several variations on a three or four-year course sequence and include both DCI specific and integrated models. These models indicate that a variety of approaches to course sequencing are viable - that an integrated approach to organizing standards is as viable as a subject-centered approach. Either way, it will be a challenge as school districts revamp or develop courses to provide opportunities for all students to meet all of the standards, particularly if they are confined to a three-year course sequence.

Over the past twenty years, there has been a movement within the science education community to teach physics at the $9^{\text {th }}$ grade level, before students take chemistry or biology. This movement has been given the name Physics First (Lederman, 2005). The reasoning behind this movement is largely based on the ideas that physics concepts underlie those taught in chemistry and biology and for students to understand those topics they need to understand basic physics concepts (Lederman, 1998; Wilt, 2005; AAPT, 2006). Others have supported a Physics First approach with an inquirybased physics curriculum to improve student learning and have found that this particular approach improved student achievement in science (Wells, Hestenes, \& Swackhamer, 1995; Dye, Cheatham, Rowell, Barlow, \& Carlton, 2013).

I will provide more detail about the Physics First movement and the rationale and research supporting it in the next chapter. In the context of this discussion regarding 
science course sequencing, it is important point out that while some school and district leaders have chosen to teach physics in the $9^{\text {th }}$ grade this sequence is still quite rare in schools. For example, in 2005 it was estimated that Physics First programs were in only three percent of public schools and nine percent of private schools (AAPT, 2006). In a 2009 national survey of physics students that was repeated in 2013 it was estimated that $37 \%$ and $39 \%$ of all students completed a physics class in high school respectively. Of the total number of students taking high school physics, both surveys indicated that only $6 \%$ of all physics students had taken physics in the $9^{\text {th }}$ grade (White $\&$ Tesfaye, 2014a). Some school districts that had implemented a Physics First program have since dropped this approach (Cavanagh, 2006a; Hezel Associates LLC, 2009).

\section{Challenges in Professional Development}

School districts and other stakeholders will need help to prepare teachers to teach to the NGSS as "the NGSS represent a significant departure from past approaches to science education" (Bybee, 2014, p. 213). Again, while the NGSS has roots in traditional science teaching, it requires significant changes in classroom practice. However, Bybee (2014) stated that "the NGSS presents an opportunity to improve curriculum, teacher development, assessment and accountability, and ultimately student achievement. In order to bring this opportunity to reality, science teacher educators must address educational shifts in NGSS" (p. 215).

The Guide to Implementing the Next Generation Science Standards (NRC, 2015) compiled the latest research in science education to provide guidance for professional development to support teachers in transitioning their teaching practices to those required 
to effectively implement the NGSS. They make the following recommendations that professional development must: focus on specific content; be connected to teachers' instructional practice; have opportunities for active engagement; opportunities for collaboration; be of sufficient time; and have a coherent and ongoing system of support. This report recognizes the amount of effort and time it will take to change teacher practice, stating that "It will take a minimum of 3-4 years for teachers to transition to effectively teaching the new standards" (NRC, 2015, p. 20). The report also warns against the common pitfalls of underestimating both the need for changing one's practice, as well as underestimating the need for ongoing support.

\section{Statement of the Research Problem}

This dissertation research addresses the problem of how to successfully implement the NGSS at the high school level. The Next Generation Science Standards (NGSS) are the forefront of a new era of science education in which the goal is to provide effective science education for all students by emphasizing science and engineering practices to engage all students in the important concepts and content of science and engineering. While the standards have been in existence for only a few years, work has begun to improve science courses and instructional strategies to meet the performance expectations outlined in the NGSS. Early adopters have made headway in understanding how to meet these standards. One school district in the Pacific Northwest, identified as District A in this study, changed from an unstructured science course sequence (students did not take a specific course sequence, but chose from a large selection of courses that 
were often school or teacher dependent) to the non-traditional Physics First, or PCB (Physics, Chemistry, Biology) course sequence starting in the 2012-2013 school year. This new three-course sequence and the corresponding curricula was designed to meet the NGSS. Figure 1 below shows a timeline with key characteristics and events that impacted the development and implementation of the new courses to provide a context in which to place this study.

Prior to 2012, District A consisted of five-large comprehensive high schools and several smaller alternative high schools. There was no uniform science course sequence amongst the high schools in the district and students were largely free to choose which science courses to take. In analyzing their science sequence in relation to college readiness, the district found that there were over 188 different science course sequences taken by students, and that only 11 percent of students that graduated in 2010 had taken all three core discipline — physics, chemistry, and biology—courses (Manning, 2012). At the policy level, the state requirement for high school graduation changed from two years of science to three years of science beginning with the graduating class of 2012 .

While these changes began prior to the release of the NGSS, the district based much of its initial work on A Framework for K12 Science Education (NRC 2012), the foundational document of the NGSS, and had worked to incorporate the NGSS into this adoption by primarily focusing on embedding the science and engineering practices into each course curriculum and providing extensive professional development to support this change. Due to a focus of the crosscutting concept Patterns in each course, the school 
district named the courses: Patterns Physics, Patterns Chemistry, and Patterns Biology, which together are identified as Patterns PCB.

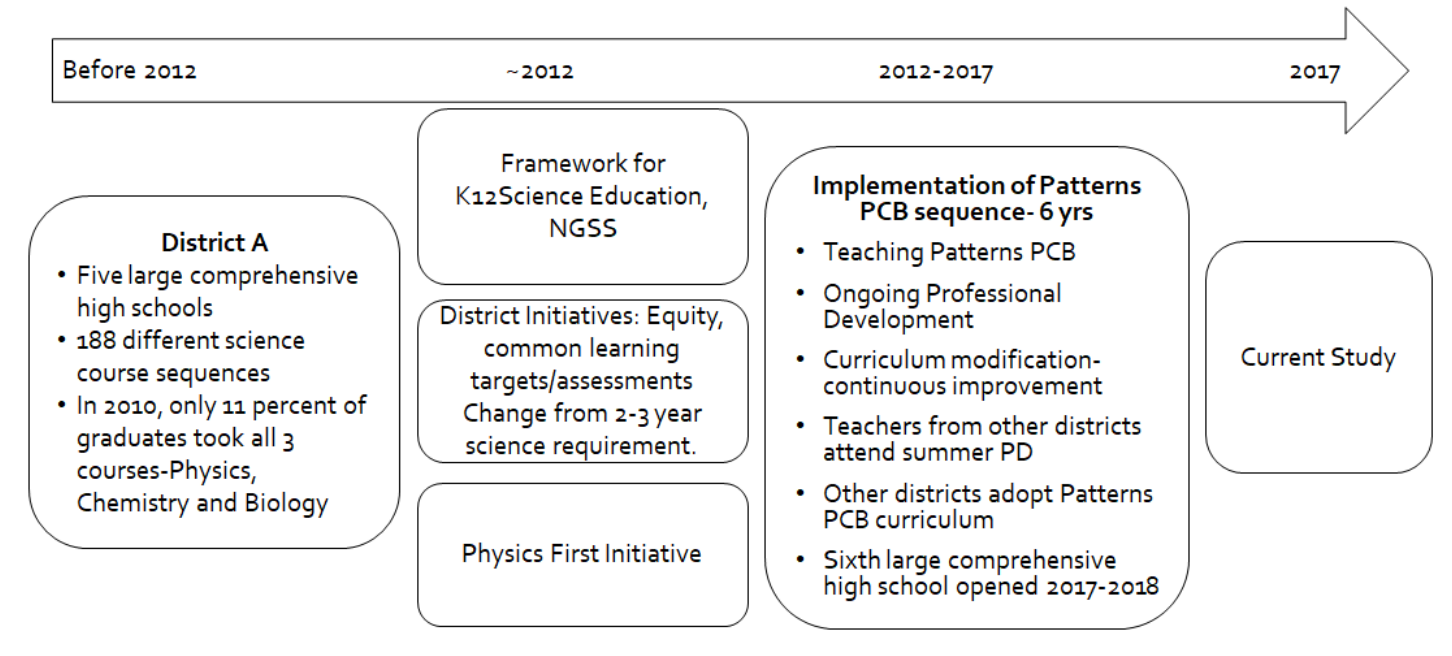

Figure 1. District A patterns PCB timeline

The purpose of the study is to examine the impact of the implementation of Patterns Physics on teacher practice and beliefs about science teaching. Does this new approach facilitate teacher classroom practices and beliefs congruent with those expressed in A Framework for K-12 Science Education (NRC, 2012) and Next Generation Science Standards (NGSS Lead States, 2013)?

\section{Significance of the Research Problem}

The problem of successfully implementing the Next Generation Science Standards (NGSS) is significant in several ways. First, the NGSS will require a significant change in teacher practice. In addition to adding engineering to the traditional science practices (also referred to as scientific inquiry), both the engineering and science practices are on equal footing with science content knowledge. While traditional science 
instruction has a focus on transmitting factual knowledge to students, and often employs lecture and other teacher centered strategies, the science and engineering practices are student centered, requiring students to participate in engaging in these practices. In addition, there is also the integration of the crosscutting concepts, such as patterns, cause and effect, systems, etc. which should now be explicitly taught.

Second, as mentioned previously, the NGSS does not prescribe a certain course sequence for high school science but instead requires that all standards are addressed over the three-year time band. The PCB sequence has received some recognition since the movement started in the late 1990's, with relentless promotion by Leon Lederman (Lederman, 1998, 2001). However, adoption rates of Physics First are still quite small with only six percent of U.S. high school students who take physics taking the course in $9^{\text {th }}$ grade.

There is controversy over whether or not physics is appropriate for the $9^{\text {th }}$ grade, as well as multiple perspectives on whether a physics course should be mathematics focused or more conceptually-based. Some think engaging students in age-appropriate mathematical thinking (typically algebra) as applied to physics is appropriate, while others think that a focus on mathematical thinking gets in the way of learning the physics concepts (Glasser, 2012; Gaubatz, 2013). In addition, most Physics-First programs are in place due to decisions made at the individual school level, with only a few school districts able to implement a district-wide Physics First program in the U.S.

Third, there are many issues with regard to providing effective professional development to teachers to support the required change in teaching practice. Traditional 
professional development, where teachers attend a workshop or conference, is unlikely to have a significant effect on changing teacher classroom practice (Loucks-Horsley, Stiles, Mundry, Love, \& Hewson, 2009). Recent research has shown that to be most effective, professional development needs to have a content focus, engage participants in active learning, have coherence with other learning activities and policies, be of sufficient duration, and provide for collective participation amongst colleagues to support interaction and discourse (Desimone, 2009). These characteristics are important because changing teacher practice to support an inquiry-based curriculum has been shown to be difficult (Bess \& Bybee, 2004; Zhang, Parker, Koehler, \& Eberhardt, 2015).

This study sought to investigate the experience of teachers in District A who had been teaching the Patterns PCB curriculum since the 2012-2013 school year, its sixth year of implementation at the time of this study. In addition to its continued implementation in District A, there had been interest from other educators in the region, as at least four school districts had adopted the Patterns PCB curriculum, and over 150 teachers from non-District A school districts participating in the Patterns Physics summer workshops. This study could be used both to improve the Patterns program in District A and to improve professional development (PD) and programs in other adopting districts. While this project is specifically designed for Patterns Physics, this project may shed light on how to best support teacher change towards meeting the goals of the NGSS in general. 


\section{Presentation of Methods and Research Questions}

Methods. A case study of high school science teachers in District A was done to inform the research questions. "A case study is an in-depth description and analysis of a bounded system" (Merriam, 2009, p. 40). This case study is bounded by the participants' perceptions and by time as only the science teachers teaching in District A at the time of this study were involved in this research.

The purpose of the study is to examine the impact of the implementation of Patterns Physics on teacher practice and beliefs about science teaching. Does this new approach facilitate teacher classroom practices and beliefs congruent with those expressed in A Framework for K-12 Science Education (NRC, 2012) and Next Generation Science Standards (NGSS Lead States, 2013)? The specific research questions were:

\section{Research Questions:}

1. To what extent have the professional development and teaching experiences affected teachers' confidence in engaging students in the practices of science and engineering?

2. Which aspects of the professional development and teaching experiences have made the greatest difference in teachers' confidence and self-reported changes in their practices?

3. How have the professional development and teaching experiences changed physics teachers' perceptions about the value of physics first?

All District A high school science teachers who were teaching in one of the district's six large comprehensive high schools were invited to participate in this study 
$(\mathrm{n}=68)$. This case study used both quantitative and qualitative data to inform the research questions. A survey was developed and given to all participants. Follow-up interviews were conducted with nine teachers who agreed to be interviewed. Acknowledgement of informed consent was provided by all participants.

\section{Description of Patterns Physics}

Designed to meet the goals outlined in A Framework for K-12 Science Education (NRC, 2012) and to meet the NGSS, Patterns Physics was organized around the crosscutting concept Patterns with the central theme: How do we find and use patterns in nature to predict the future, make data-informed decisions in the present, and understand the past? This theme was used throughout each unit and used as an anchor for student knowledge and experiences throughout the course.

The Patterns Physics curriculum consists of seven units designed to be taught at the $9^{\text {th }}$ grade. Table 2 provides a summary of each of these units:

The first unit, Patterns and Inquiry, provides three foundational experiments in which students engage in science inquiry to develop an understanding of three key mathematical patterns: linear-including the special cases of where the slope $=0$ and where the y-intercept=0; quadratic; and inverse. Hill (2013) provided an in-depth description of this unit along with the rationale for this approach and detailed descriptions of student learning progressions. According to Hill (2013), "the [Patterns] unit teaches students to make predictions, plan and conduct experiments, collect data, analyze the results, argue from evidence, and evaluate conclusions. Harnessing their own experiences students learn the value of evidence-based reasoning and data-informed decision making" 
(p. 38). The Claim-Evidence-Reasoning model (Michaels, 2008) was used to structure student explanations and discussions about the phenomena investigated. Next is a brief outline of how the units that followed were organized.

Table 2

Patterns Physics units, key science topics and engineering projects.

\begin{tabular}{|c|c|c|}
\hline Patterns Unit & $\underline{\text { Key Science Content }}$ & Engineering Task \\
\hline Unit 1 - Patterns \& Inquiry & Science practices & \\
\hline Unit 2 - Texting \& Driving & Kinematics & $\begin{array}{l}\text { Coding a spreadsheet to model complex } \\
\text { situation of texting and driving and use to } \\
\text { create an evidence-based argument. }\end{array}$ \\
\hline Unit 3 - Energy \& Engineering & $\begin{array}{l}\text { Conservation of } \\
\text { Energy }\end{array}$ & $\begin{array}{l}\text { Engineer bungee cord system and computer } \\
\text { application to predict length of cord for a } \\
\text { variety of situations. }\end{array}$ \\
\hline Unit 4 - Engineer a Shoe & $\begin{array}{l}\text { Impulse, Momentum, } \\
\text { Forces }\end{array}$ & $\begin{array}{l}\text { Engineer a shoe using data informed } \\
\text { decisions. }\end{array}$ \\
\hline Unit 5 - Waves \& Technology & Waves & $\begin{array}{l}\text { Engineering to send and receive a text } \\
\text { message. } \\
\text { Extension project: Building a guitar }\end{array}$ \\
\hline $\begin{array}{l}\text { Unit } 6 \text { - E\&M, Power } \\
\text { Production, \& Climate Science }\end{array}$ & $\begin{array}{l}\text { E\&M, Power, } \\
\text { Coulomb's Law }\end{array}$ & $\begin{array}{l}\text { Engineer wind turbines, optimize solar } \\
\text { cells, develop model for 50-year energy } \\
\text { plan }\end{array}$ \\
\hline Unit 7 - Space \& the Universe & Universal gravitation & \\
\hline
\end{tabular}

Units two through seven of Patterns Physics were designed for students to apply the skills and processes learned in the Patterns and Inquiry unit in new contexts targeted towards key science content and engineering tasks (Table 2). Units two through six each involved a unique engineering task that bookended each unit and served as the theme for the unit. Each engineering task was used to introduce each unit in which students 
identified the problem, determined criteria and constraints, accessed prior knowledge, and began to identify needed science content. Instruction then shifted to engage students in inquiry to answer critical questions and develop specific patterns of phenomena to be applied toward making evidence-based decisions for the engineering task. These concepts and patterns were then brought together for students to use in completing the engineering task.

Units were organized so that concepts were connected through a progression of learning activities and constructs called a learning arc. Figure 2 shows the learning arch for Unit 3: Energy and Engineering; the graphic illustrates the progression of learning activities and key concepts.

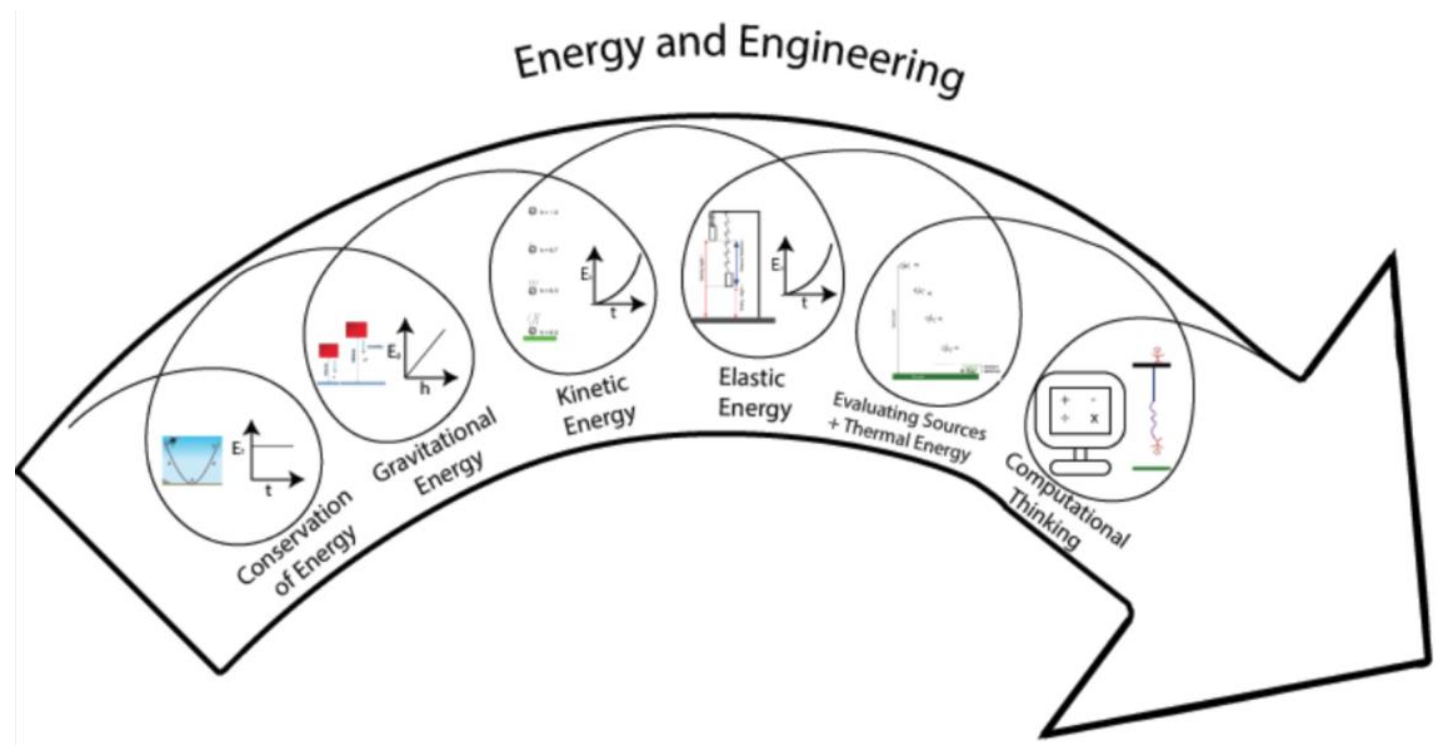

Figure 2. Learning arc for energy and engineering 
In this unit, the engineering project required students to build a bungee cord system (rubber band and string) for a successful bungee jump of a doll and to build a computer app (using Google Sheets) to correctly calculate how much string to add to their bungee cord given parameters such as the mass of their jumper, the drop height, and the safety margin for their jumper. After students explored the design challenge, identifying constraints and limitations, they engaged in inquiry experiments to understand the relationships and mathematical models between the relevant types of energy and the associated variables (i.e. Gravitational Potential Energy and height, Kinetic Energy and velocity, Elastic Energy and stretch, Energy Loss). At the end of the unit, students compiled these patterns in a way to analyze the energy transformations in a bungee jump, and then used these patterns to build the computer model, or app, in Google Sheets to calculate how much string to add to their bungee cord. To conclude, students tested their jumper and bungee cord system, reflected on their results, and could make iterations of their design in order to improve their project in some way. In this particular project, there was a physical engineering component in designing and testing the bungee cord as well as a mathematics and computational thinking component in which students developed a computer model to solve the complex problem of optimizing their bungee cord, using evidence, to meet the design requirements. The computer model could be iterated as well. This learning arc exemplifies how the Patterns Physics curriculum was organized to engage students in 3D learning - integrating science content knowledge, the crosscutting concepts, and the science and engineering practices. Throughout the school 
year, students had multiple opportunities to engage in this type of learning and built their capacity to more independently engage in the practices of science and engineering.

\section{Summary}

The purpose of the study was to examine the impact of the implementation of Patterns Physics on teacher practice and beliefs about science teaching. Does this new approach facilitate teacher classroom practices and beliefs congruent with those expressed in A Framework for K-12 Science Education (NRC, 2012) and Next Generation Science Standards (NGSS Lead States, 2013)? The lessons learned from this study provide evidence for what aspects of the professional development and the curriculum that teachers found most impactful in their own teaching practice, as well as what teachers identified as their own needs for further professional development. Results from this study will be shared with District A and provide insight into the Patterns Physics, and Patterns PCB initiative. It also provides valuable information to teachers and district leaders who are planning to, or inquiring about, adopting the Patterns Physics sequence. Finally, there may be lessons learned that can apply more generally to effective professional development and to providing professional development that specifically addresses the NGSS practices.

\section{Definition of Key Concepts}

- Physics First is a term used to describe a high school science course sequence that begins with physics at the $9^{\text {th }}$ grade. It often refers to the Physics, Chemistry, Biology course sequence, but that is not required. The term was coined due to Leon Lederman's (Lederman, 1998) call to teach physics before teaching chemistry and biology, 
- Inquiry-based teaching or inquiry-based instruction "is a student-centered pedagogy that uses purposeful extended investigations set in the context of reallife problems as both a means for increasing student capacities and as a feedback loop for increasing teachers' insights into student thought processes" Supovitz, Mayer, \& Kahle (2000). According to Bodzin and Beerer (2003), this occurs when students engage in scientific inquiry by asking questions, making hypotheses, designing investigations, grappling with data, drawing inferences, redesigning investigations and building or revising their theories.

- Traditional teaching has the following classroom characteristics as described by (Woolley \& Woolley, 1999): subjects are taught independently, curricula follows a textbook, students work independently, and students are assessed via traditional methods of homework, quizzes and tests. With regard to classroom discourse (Lewis, Baker, Watts, \& Lang, 2014) the norm is triadic dialogue, in which a teacher asks a question to the whole class, and one student responds, and then the teacher evaluates the response by affirming it or rejecting it by giving the correct answer.

- Professional Development (PD) includes a wide range of activities designed to improve teacher performance from formal classes or workshops, to informal book clubs, or teachers talking in the hallway (Desimone, 2009). The key concept is not based on the activity, but on "changes in knowledge and skills and classroom practice" (p. 183). In the context of my study, I use professional development to refer to a specific activity that is designed to change the knowledge and skills of the teacher, and ultimately, their classroom practice.

- Confidence is a construct used in this study to describe how successful teachers feel about their teaching. It encompasses both their assuredness about what they are trying to teach and the corresponding success of their students. According to Nolan \& Molla (2017), "confidence is about knowing one can successfully complete a task" and is "akin to self-efficacy" (p. 12). Self-efficacy, as defined by Bandura, are "beliefs in one's capabilities to organize and execute the courses of action" (as cited in Jones \& Leagon, 2014, p. 833).

Keywords

Patterns Physics, Physics First, Physics education, Model-based physics curriculum teacher beliefs, engineering design, science education, professional development, educative curriculum, science and engineering practices 


\section{Chapter 2: Literature Review}

In this chapter, I review the literature germane to understanding the context of this study. I begin with the theoretical framework. Then, I review the literature by identifying key changes in teaching practice required for teachers to successfully implement the NGSS in their classrooms. I then review the research on the Physics First movement to provide a context for how this particular Physics First program fits within the larger context of the movement. Finally, I review the literature related to supporting teacher change towards innovative teaching practices, including what role professional development can play in supporting teacher change towards innovative, and NGSS congruent, teaching practices. The purpose of the study is to examine the impact of the implementation of Patterns Physics on teacher practice and beliefs about science teaching. Does this new approach facilitate teacher classroom practices and beliefs congruent with those expressed in A Framework for K-12 Science Education (NRC, 2012) and Next Generation Science Standards (NGSS Lead States, 2013)?

\section{Theoretical Framework}

The primary focus of this study is to learn about the impact of a Physics First initiative on science teacher beliefs about $9^{\text {th }}$ grade physics and teacher views of the NGSS science and engineering practices. This study is an attempt to elicit the "teacher voice" about this initiative, both as it reflects on the current practice, but also in how the Physics First initiative has changed their beliefs. Therefore, in the context of this study, a theoretical framework should be teacher-centered, while also allowing for a multitude of 
different inputs and processes that can take into account the complexity of a teacher's experience. The Interconnected Model for Professional Growth (IMPG) (Clarke \& Hollingsworth, 2002) depicted in Figure 3 provides such a framework.

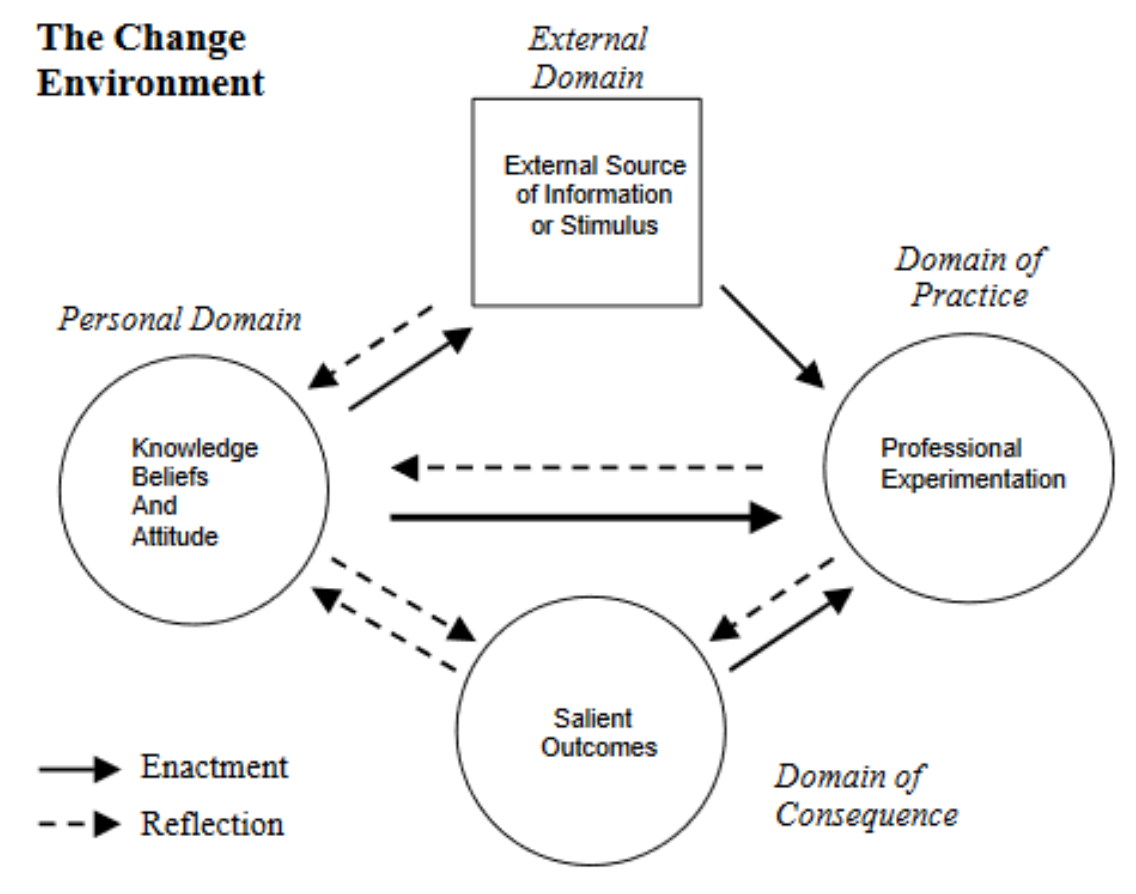

Figure 3. The interconnected model of professional development

From "Elaborating a model of teacher professional growth," by D. Clark and H. Hollingsworth, 2002, Teaching and Teacher Education, 18, p. 951

Based on the work of Clarke and Peter (1993) this model was developed by the Teacher Professional Growth Consortium in 1994. The framework consists of four domains: the Personal Domain, the External Domain, the Domain of Practice, and the Domain of Consequence. These domains represent different areas of a teacher's "world" (Clarke \& Hollingsworth, 2002). The Personal Domain consists of a teacher's 
knowledge, beliefs, and attitudes. The Domain of Practice involves the implementation or experimentation of teaching practices; while this likely occurs in the classroom, this model allows for this to occur in any setting in which the teacher is engaging in a teaching practice. The Domain of Consequence comprises the salient outcomes of a teacher's practice. This can include student learning, but also how well students respond to instruction, or how engaged they are in the instruction. While the Personal Domain, the Domain of Practice and the Domain of Consequence all function within the teacher's personal experience, the External Domain exists outside of the teacher's experience.

For example, for a teacher who participates in a workshop on the NGSS engineering practices, the workshop experience and materials are part of the External Domain. It is not until the teacher processes that information, either through reflection (the dashed arrows in Figure 3) or implements specific activities or strategies from that workshop that change takes place. This is called enactment in the diagram, represented with the solid arrows. This change can take the form of a teacher's change of knowledge, beliefs, or attitudes or it could be that the teacher enacts what was covered in the professional development into their classroom. Or, it could be that the teacher engages with other teachers in focused work around the NGSS science and engineering practices that could lead to the development of a new learning activity in the Domain of Practice. The Domain of Consequence is what is observed as the result of the professional experimentation. Did the activity improve student engagement and learning? What aspects of the teacher meeting was effective for influencing learning? And again, through the processes of enaction and reflection, this could lead to additional experimentation, 
and or changes in a teacher's knowledge and beliefs about teaching and learning. In this model, the domain of practice encompasses all forms of professional experimentation, not just experimentation that happens in the classroom.

One might think that this model with multiple domains is more complex than what is needed to explain the process by which teachers implement new instructional strategies or curriculum. According to Guskey (1985), “despite differences in context and format, most staff development programs share a common purpose to bring about change" (p. 58). This change is often about student outcomes, but can be a variety of things including teaching strategies, learning activities, assessment strategies, etc. The traditional (and simplistic) view of professional development is that teachers first participate in a professional development activity that changes their beliefs, attitudes, and perceptions about their teaching practice. This leads to teachers changing or modifying their instructional practices, which can then result in improved student learning. However, Guskey (1985) indicates that this model is likely inaccurate when applied to experienced teachers.

Guskey $(1985,1986)$ found that the traditional model misses something very important to understanding the change process in teacher practice. That is that teachers' beliefs and attitudes towards their teaching practice do not change as a result of participation in professional development, but only after implementing the strategies taught in the professional development and observing the effect on student learning. Guskey (1986) noted that teachers "beliefs and attitudes about teaching and instructional practices are similarly derived, largely from classroom experience" (p. 7). Therefore, 
“...evidence of improvement (positive change) in the learning outcomes of students generally precedes and may be a prerequisite to significant change in the beliefs and attitudes of most teachers" (p. 7). This model is shown in Figure 4 and illustrates its linear form. First, is the intervention or staff development. This is followed by a change in teachers' practices, followed by a change in student learning outcomes. It is only on observing these outcomes, that the teacher may have a change in beliefs and attitudes.

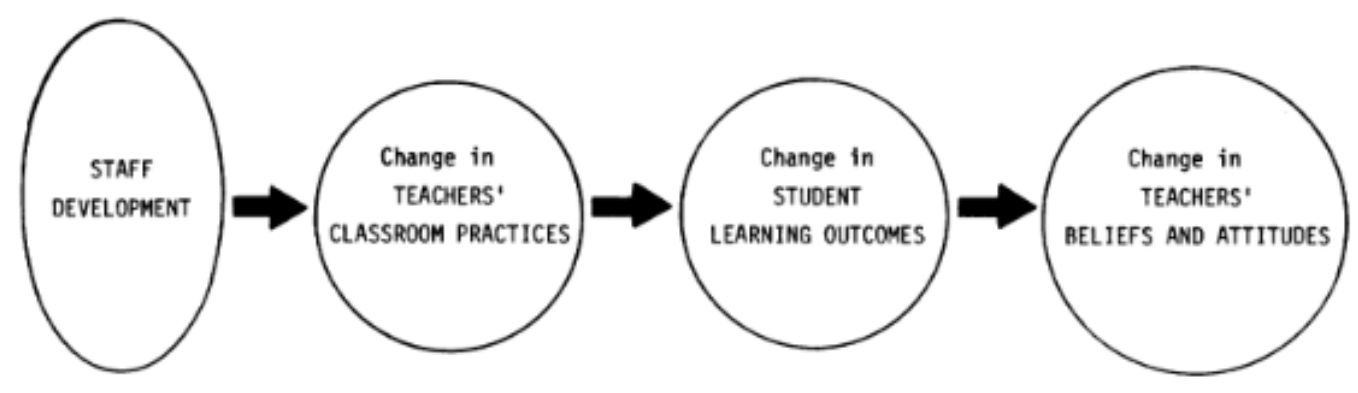

Figure 4. Linear model of teacher change due to a staff development intervention. From "Staff Development and the Process of Teacher Change" by Thomas R. Guskey, 1986, Educational Researcher, 15, p.7.

This model signifies the importance of the implementation of new classroom practices as critical to the desired changes in student learning and teachers' attitudes and beliefs. That it is the action of implementing the new teaching practice and then observing its effectiveness that is of utmost importance, not the participation in the staff development. While not embedded in the model, Guskey $(1985,1986)$ is clear that teachers need time to work with new ideas and have opportunities for follow-up support, as well as receive regular feedback on student learning, in order to achieve change. A more complete model would take these factors into account. Also, the linear nature of 
Guskey's model does not provide for the complexity of the processes involved, or identify the processes involved in that change.

The Interconnected Model for Professional Growth (IMPG) builds on the strengths of Guskey's model. It utilizes similar constructs to identify areas of teacher practice, called Domain in the IMPG. However, it adds to the model by providing the mechanisms for change, either reflection or enaction, and provides multiple pathways for change to occur (i.e. it is not a linear model). Also, in this model the Domains of Practice are considered more broadly to include all forms of professional experimentation, not just classroom teaching, or all forms of external inputs (e.g. teacher to teacher discussions of practice, journal articles, etc.) that relate to a teacher's practice. A strength of this model is that it recognizes the complexity of professional growth though the identification of multiple growth pathways between the domains. Also, there is a philosophical shift from professional development being designed to change teachers to one that views teachers as active learners who are engaged in professional growth opportunities (Clarke \& Hollingsworth, 2002, p. 950).

Coenders \& Terlouw (2015), used the IMPG in studying teacher change with the development and implementation of a new high school chemistry curriculum. They found that the process of developing curriculum was important for teachers to effectively enact the innovation in their classrooms, and suggested that in the process of phasing-in an innovation, it was important for new teachers to participate in a re-development phase, where they interact with the curriculum and redevelop it (by making minor modifications) and then having teachers enact lessons in their classrooms. 
In the context of this study, the IMPG provides a model to analyze the third research question: What aspects of Professional Development and curriculum for Patterns Physics do teachers find most impactful to their teaching practice [and how do these align with the NGSS practices]? The IMPG model provides for a variety of inputs, whether from formal professional development, or from the informal interactions between teachers, as well as other options such as the analysis of student work, or one's reflection on their own teaching practice.

\section{Review of the Research Literature}

In this next section, I review the literature identifying key changes in teaching practice that will be required for teachers to successfully implement the NGSS in their classrooms. While the focus of my study investigates the impact of a Physics First program on teacher practice, the goals, objectives, and standards related to that program all fall under the auspices of the NGSS. Here, I review the research on the Physics First movement to provide a context for how the Physics First program being studied fits within the larger context of the movement. Finally, I review literature related to supporting teacher change towards innovative teaching practices, including the role that professional development can play in supporting teacher change towards innovative, and NGSS congruent teaching practices.

\section{Change in Teaching Practice Due to NGSS}

In chapter one I explained how the NGSS differs from past standards and described common high school course sequences. This section will focus on what teacher 
classroom practices are required for the successful implementation of the NGSS, particularly related to the science and engineering practices.

To review, the NGSS promote significant reform of science education in the U.S. With roots based on standards released in the 1990s, the NGSS takes advantage of the latest research on how students learn science. Although much of the scientific content included in the NGSS is similar to that found in past standards (i.e. Benchmarks for Science Literacy, 1993; National Science Education Standards, 1996), the new standards differ from former standards in significant ways. First, these standards explicitly distinguish between scientific content, called Disciplinary Core Ideas (DCI), scientific processes, called Science and Engineering Practices (SEP), and general scientific concepts found throughout science, called Crosscutting Concepts (CCC). Second, these three areas - DCI, SEP, and CCC — are integrated into each standard. The integration of these three dimensions is necessary to provide "students with a context for the content of science, how science knowledge is acquired and understood, and how the individual sciences are connected through concepts that have universal meaning across [scientific] disciplines" (NGSS Lead States, 2013, p. xv). The explicit integration of these areas as students engage in understanding phenomena or engaging in science and engineering practices is called three-dimensional (3-D) learning.

\section{What is the Relationship Between Science and Engineering?}

In the NGSS, science is defined as the traditional natural sciences: physics, chemistry, biology, earth and space science, and environmental science. Engineering is defined as "any engagement in a systematic practice of design to achieve solutions to 
particular human problems" and engineering design is defined as "a systematic practice for solving engineering problems" (A Framework for K-12 Science Education, as cited in NGSS Lead States, 2013, p. 103). According to NGSS (2013) engineering design involves three key components:

- Defining and delimiting engineering problems involves stating the problem to be solved as clearly as possible in terms of criteria for success and constraints or limits;

- Designing solutions to engineering problems begins with generating a number of different possible solutions, then evaluating potential solutions to see which ones best meet the criteria and constraints of the problem;

- Optimizing the design solution involves a process in which solutions are systematically tested and refined and the final design is improved by trading off less important features for those that are more important (p. 104).

Engineering practices, as defined by NGSS, are the skills and knowledge that "engineers use as they design and build systems" (NGSS Lead States, 2013, p. xv). Scientific practices involve "the major practices that scientists use as they investigate and build models and theories about the world" (NGSS Lead States, 2013, p. xv). These practices are broken down into steps as shown in Table 3, which demonstrate that while the goals of engineering and science are different, many steps in each process are the same. In the engineering practices, the first step is defining problems, while in science practices, it is asking questions. The next steps in processes are the same, but the products of these practices are different. Whereas in engineering the product is designing solutions, in science it is constructing explanations (see Table 3). 
Table 3

Comparison of Engineering and Science Practices

\section{$\underline{\text { Engineering Practices }}$}

Defining Problems

Developing and Using Models

Planning and Carrying Out Investigations

Analyzing and Interpreting Data

Using Mathematics and Computational

Thinking

Designing Solutions

Engaging in Argument from Evidence

Obtaining, Evaluating, and Communicating

Information

\section{$\underline{\text { Science Practices }}$}

Asking Questions

Developing and Using Models

Planning and Carrying Out Investigations

Analyzing and Interpreting Data

Using Mathematics and Computational Thinking

Modified from A Framework for Science Education: Practices, Crosscutting Concepts, and Core Ideas (2012), p. 42.

\section{Educational Significance}

For the past 20 years reform in science education has revolved around the National Science Education Standards (NRC, 1996) and Benchmarks for Scientific Literacy (Project 2061, 1993). These standards identified what students should know and be able to do-with an emphasis on both science content and scientific inquiry. Scientific inquiry was developed for students to actively participate in the practice of science, but was often treated as an add-on, and conducted separately from identified science content 
(Pruitt, 2014). According to Pruitt (2014), "For many years state science education standards have focused more on discrete facts... as opposed to using any of these facts to understand bigger concepts" (p. 149), and "state standards have traditionally kept inquiry and content standards separate" (p. 146). By contrast, Pruitt (2014) explains the more integrated approach of NGSS:

The vision of the Framework and the NGSS is to use scientific and engineering practices as a means for students to show evidence they are able to apply knowledge...it is through this integration that students are able to show their mastery of content, but also an understanding of the accumulation of scientific knowledge. In using the practices, students are able to use their grasp of scientific knowledge in new and unique situations. (p. 149)

Pruitt's statement emphasizes that the NGSS ask students to have a higher level of engagement with and understanding of science and engineering content than was previously required. Pruitt also implies that instruction must provide students with opportunities to actively engage in activities that require them to explore, understand, and apply science and engineering content and practices.

This focus on engaging students in science and engineering practices also addresses issues of equity in science education. While these changes should benefit all students, they particularly provide improved opportunities for traditionally underserved students—English Language Learners (ELL), ethnic minorities, students with disabilities, students from economically disadvantaged backgrounds, female students, talented and gifted students, and students in alternative education programs (NGSS Lead States, 2013, p. 26). The science and engineering practices provide a context for all students, regardless of background, to engage their own knowledge and understanding of the world, including 
language and cultural experiences. This occurs in their execution of each science or engineering project and in their communication about the project.

Historically underserved students, such as English Language Learners (ELL), have been at a disadvantage in learning science precisely because they have not been as able to make connections to scientific content and language. While specifically addressing the needs of English Language Learners (ELL), the NGSS provides an excellent explanation of how this approach supports all students learning science:

Engagement in any science and engineering practices involves both scientific sense-making and language use. Students engage in these practices for the scientific sense-making process, as they transition from their naïve conceptions of the world to more scientifically based conceptions. Engagement in these practices is also language intensive and requires students to participate in classroom science discourse.... By engaging in such practices, moreover, they simultaneously build on their understanding of science and their language proficiency. (NGSS Lead States, 2013, p. 29)

Therefore, through participation in science and engineering practices and by engaging in classroom discourse about the experience, students utilize and build both science and language skills and understanding.

\section{The Challenges of Implementing the Engineering Practices}

The ability to achieve the goals of NGSS through the implementation of meaningful engineering activities is not guaranteed, and it will not be easy. One major hurdle will be in effectively training teachers to integrate engineering activities into their classroom practice. As mentioned earlier, at this time, most science educators have little or no background in engineering and engineering practices (Cunningham \& Carlsen, 2014; Purzer, Strobel, \& Cardella, 2014; Wilson, 2013). Teacher self-efficacy (belief in 
one's capabilities) is closely tied to instructional practices. Research conducted by Jones and Leagon (2014) demonstrated that students who have teachers with high self-efficacy outperform students whose teachers have low self-efficacy. It is therefore critical that teachers receive the knowledge and experience necessary to feel efficacious in their work. In order to address science teachers' lack of pedagogical knowledge of engineering standards and processes, professional development is imperative to effectively implement the engineering component of the NGSS.

Although classroom time for science is relatively consistent at the middle school and high school levels, activities that implement engineering and science practices require a significant amount of time. While the authors of the NGSS worked hard to limit the amount of material to meet the time constraints of a typical classroom (NGSS Lead States, 2013, p. 7) one could argue that there is still a significant amount of science content that needs to be covered. For many teachers, managing the time spent on science content versus that spent on science and engineering practices will be a significant challenge- especially since the science content needs to be integrated with the science and engineering practices and crosscutting concepts.

The culture of their school and that of the larger educational community both have a major impact on the level of each teacher's self-efficacy (Jones \& Leagon, 2014). According to Jones and Leagon (2014), "when they [science teachers] plan, work, and assess their science education program together, their beliefs related to the capability of their colleagues promote a belief that, as individuals, they can be successful in future efforts to change their instructional practices" (p. 834). Therefore, for successful 
implementation of engineering practices in a school setting, teachers will need structured time to work together in a productive manner. This collaboration not only addresses current needs, but also builds capacity for individual teachers to further reform or refine their teaching practice.

\section{High School Science Course Sequences and Physics First}

The 2012 National Survey (Banilower et al., 2013), a national survey that collected data on U.S. school course offerings in science and math, showed that almost all of the surveyed high schools taught Biology and Chemistry courses, while only $85 \%$ taught Physics courses. Additional classes taught at the high school level included Integrated Science (68\%), Environmental Science/Ecology (48\%), Earth and Space Science (48\%), and Engineering (24\%). The survey also found that $47 \%$ of high schools offer at least one Advanced Placement (AP) science course, with Biology being the most common AP science course.

As mentioned in chapter one, how high schools organize their science course sequences is not standardized across the U.S.; course sequences are determined by individual schools or school districts. However, the most common sequence in the U.S. is for $9^{\text {th }}$ grade students to take Biology, $10^{\text {th }}$ grade students to take Chemistry, and in $11^{\text {th }}$ and $12^{\text {th }}$ grade students take Physics or other science courses (Gaubatz, 2013). This is

commonly referred to as the BCP (Biology, Chemistry, Physics) sequence. This sequence has its roots based on the recommendations from the Committee of Ten in 1893 in which course sequences for college were recommended (Sheppard \& Robbins, 2002). The Committee of 10 was organized by the National Education Association and tasked with 
making recommendations for what should be taught at the high school level so that students from around the country would have similar preparation for college. While there was a call at the time from a sub-committee for the importance of physics, the primary concern was that the mathematical rigor required for physics necessitated that it be taught towards the end of high school.

Courses in Botany or Zoology (now combined into Biology) or Geology, or Astronomy (now often called Earth Science), which were largely descriptive in nature, were encouraged for earlier in high school (Sheppard \& Robbins, 2002). This reasoning, and the resulting implementation led to the tradition of having physics be an $11^{\text {th }}$ or $12^{\text {th }}$ grade course, which over time was embedded into the culture of schools in the U.S.

The first call to teach physics before biology and chemistry was made by Uri Haber-Schaim (1984) who justified this recommendation by reviewing the topics in the common textbooks for each discipline and illustrating that many of the chemistry concepts were required to understand the biology content, and that physics concepts were required to understand the chemistry content. In 1998, Project ARISE (Lederman, 1998) outlined goals for the results of effective science education:

- Science and mathematics literacy for all students;

- Citizens able to understand issues based in science and technology;

- Citizens able to discriminate between scientific understanding and personal belief;

- A capable work force for a modern technological society;

- People with a joy and pleasure in understanding a complex universe and the individual's role in it (p. 1). 
The authors of the Project ARISE report argued that "It is essential that science education programs address the needs of students as future workers and citizens. Nothing short of a bold initiative and a vigorous, high profile, sustained national commitment will enable us to reach this goal" (p. 2). The authors emphasized the problem that schools were falling very short of these goals.

The solution to addressing these goals is that the high school science curricula should be involve at least three years of instructional time (at the time most school often required only two years of science) and should have the first-year focus on physics, the second year of high school science instruction focus on chemistry, and the third-year focus on biology. In addition to this call to reorganize the content, there was also a call to modify instructional practices to engage students in authentic science experiences and supports the inquiry-based (reform-based) instructional strategies outlined in the National Science Education Standards (NSES, 1996) and the Benchmarks for Scientific Literacy (AAAS, 1993).

With the release of the National Science Education Standards (1996), states and school districts were making changes to meet the new standards. Lederman (1998) noted that the timing was right for change, "There is a golden opportunity here for a complete reworking of the high school science sequence: new content, new instructional materials, laboratories, assessment tools and teacher preparation requirements" (p. 7). Once again, with the release of the NGSS in 2013 schools and districts are reevaluating their course offerings, movement that provides another golden opportunity for the Physics First movement. 
Enrollment in Physics First programs. The number of Physics First schools has increased from an initial estimate of at least a few dozen in 1998 (Lederman, 1998) to at least a few hundred in 2002 (ARISE, 2002) to approximately 2000 high schools (three percent of public high schools and fourteen percent of private high schools) by 2013 (White \& Tesfaye, 2014a). In looking at the enrollment of individual students, the most recent data on physics enrollments (from the 2012-2013 school year) show that forty percent of all high school students have taken a physics course by graduation. This is the largest percentage of students taking high school physics on record. Indeed, this percentage has been rising since 1991, the last year of a 20 -year period of record low enrollment in which only seventeen percent of students took physics in high school. Of the students taking physics, six percent are taking physics as $9^{\text {th }}$ graders, identified as Physics First, 23\% are taking conceptual physics, or using a conceptual physics textbook, $36 \%$ are identified as taking regular physics, $18 \%$ in honors physics, and $17 \%$ in AP (Advanced Placement) or in a second year physics course.

Physics First was first identified in the American Institute of Physics (AIP) survey in 2009 (it is given every four years) and showed little change in enrollment from 2009. The overall growth in physics enrollments (all high school grade levels) was 5.1\% per year (White \& Tesfaye, 2014b), which was mostly in second year or AP physics programs. The survey also showed that physics enrollment is much higher in private schools than in public schools, where $22 \%$ physics students in private schools are in a Physics First program. Private school students are also more likely to enroll in AP and second year physics courses (White \& Tesfaye, 2014b). The larger percentage of private 
schools teaching Physics First is likely due to the independent nature of private schools, making it much easier to make course sequence changes at the school level.

As schools either evaluate their own course sequence or look into changing their course sequence to a Physics First program, it makes sense that they would look to research as well as other schools with Physics First programs to inform their decisionmaking process. One likely question is how, if at all, Physics First programs have an impact on student learning. Before discussing research on Physics First and student learning, I will discuss several innovations from Physics education research that have informed several Physics First programs.

Influence of educational research on Physics First. Starting in the mid-1970's, research into the teaching and learning of Physics began at the University level. The findings were dismal as studies found that the traditional lecture method of teaching, the primary teaching method at the time, was not effective in teaching students' physics (McDermott, 1993). McDermott (1993) summarized physics education research conducted up to 1993 by presenting the following conclusions:

a. Facility in solving standard quantitative problems is not an adequate criterion for functional understanding (Questions that require qualitative reasoning and verbal explanations are essential);

b. A coherent conceptual framework is not typically an outcome of traditional instruction. (Students need to participate in the process of constructing qualitative models that can help them understand relationship and differences among concepts;

c. Certain conceptual difficulties are not overcome by traditional instruction. (Persistent conceptual difficulties must be explicitly addressed by multiple challenges in different contexts); 
d. Growth in reasoning ability does not usually result from traditional instruction. (Scientific reasoning skills must be expressly cultivated);

e. Connections among concepts, formal representations, and the real world are often lacking after traditional instruction. (Students need repeated practice in interpreting physics formalism and relating it to the real world);

f. Teaching by telling is an ineffective mode of instruction for most students. (Students must be intellectually active to develop functional understanding).

To address these deficiencies, physics education researchers focused on student learning and developing strategies to address the deficiencies. Two significant results from this effort that directly impact the high school physics classroom are: the development of conceptual-based assessments to assess student learning and the development of inquiry-based instructional strategies and activities to engage students in scientific thinking.

The Force Concept Inventory (FCI) was developed to assess students understanding of basic Newtonian concepts (Hestenes, Wells, \& Swackhamer, 1992). A concept inventory is a "research-based assessment instrument[s] that probe[s] students' understanding of particular physics concepts (Madsen, McKagan, \& Sayre, 2014). The FCI is designed to make students choose between the correct Newtonian answers and commonsense alternatives. While at face value many physics teachers might view the FCI as too trivial, it has been shown to be good detector of scientific thinking, forcing students to choose "between Newtonian concepts and commonsense alternatives" (Hestenes et al., 1992, p. 2). Many students who had traditional instruction did poorly and showed little gains between pre- and post-tests, while students using a method addressing 
conceptual understanding (later identified as the modeling method in Wells, Hestenes, Swackhamer, 1995) showed significant gains (Hestenes et al., 1992).

The FCI has been used to assess several Physics First programs; it has been shown that $9^{\text {th }}$ grade students who have studied physics with the modeling method outperform $11^{\text {th }}$ and $12^{\text {th }}$ grade and college physics students who have studied physics with the traditional lecture format (Wells, et al., 1995). Additional concept inventories have been developed in physics and astronomy and can be found at PhysPort.org. I will not name them here as they have not been used in assessing Physics First projects in the literature I read.

The development of teaching and learning strategies designed to address the deficiencies in student learning as measured by the concept inventories is the next significant development. These strategies applied in an organized framework provide the foundation of inquiry-based instruction. Supovitz, Mayer, \& Kahle (2000) explained that “inquiry-based instruction is a student-centered pedagogy that uses purposeful extended investigations set in the context of real-life problems as both a means for increasing student capacities and as a feedback loop for increasing teachers' insights into student thought processes" (p. 332). Inquiry-based instruction involves engaging students "in the kinds of cognitive processes used by scientists when asking questions, making hypotheses, designing investigations, grappling with data, drawing inferences, redesigning investigations, and building as well as revising theories" (Bodzin \& Beerer, 2003, p. 44). 
Based on the results of concept inventories, traditional instruction changed the conceptual understanding of only 5-to-15 percent of the students, while inquiry-based instruction changed the conceptual understanding of up to $90 \%$ of students (Laws, Sokoloff, \& Thornton, 1999). The concept inventories provided a better measurement of student learning, evidence useful to inform instructional decision making. Inquiry-based instruction has been shown to be more effective than traditional methods, hence having instructional resources to support this pedagogical approach is critical.

The Active Physics (Eisenkraft, 1999) and CPO Physics (Hsu, 2004) textbooks were specifically designed to be an inquiry-based textbook and curriculum. CPO Physics utilized the 5E instructional model, structuring student activities for students to work through the following phases: "Engagement, Exploration, Explanation, Elaboration, and Evaluation" (Bybee et al., 2006, p. 1). Eisenkraft (2003) expands on this model in Active Physics by adding two new phases. The first addition elicits student prior knowledge and the second phase extends learning by having students apply what they have learned to new context. Both of these textbooks, in addition to Conceptual Physics (Hewitt, first edition 1971/ currently on the $12^{\text {th }}$ edition, 2015) are commonly used in Physics First programs. Conceptual Physics (Hewitt, 2015) is a traditional textbook-not inquiry based-written with a conceptual focus.

Another significant development is a technique called Modeling Instruction (Wells et al., 1995). Largely developed by high school physics teacher Malcolm Wells in response to his students' poor performance on the Mechanics Diagnostic (an early concept inventory), Wells realized that there was something missing in his instructional 
method. In conjunction with colleagues at the University of Arizona, Wells developed a modeling cycle in which students used data from experiments to develop mathematical models from experiments, and then had opportunities to test and correct their ideas. The three phases of the modeling cycle are model development, model evaluation, and model application. Through each phase, students engaged in discourse, guided by the teacher, that focused on "the formulation, elaboration, evaluation, and application of well-defined models"' (p. 609). Through this discourse, the teacher addressed both qualitative and quantitative elements. In contrast to traditional methods of instruction, Wells focused on the "postmortem," (p. 609) or the end-of-activity discussion, as the most important part of the lesson - where students had a chance to reflect, analyze, and consolidate what was learned in the activity.

This modeling instruction method is found in many Physics First programs and has been shown to be effective in improving student learning in physics (Jackson, Dukerich, \& Hestenes, 2008). Since its development in the early 1990's, advocates of this approach created the American Modeling Teachers Association (AMTA) to promote and support the modeling instruction method through workshops and research. As of 2017, over 7000 science teachers had participated in Modeling Instruction summer workshops and it was estimated that approximately ten percent of all U.S. high school physics teachers had participated in a summer Modeling Instruction Workshop (AMTA, n.d.)

Research on the impact of Physics First. Since the early days of the Physics First movement there has been a call for research into the impact of Physics First (Pasero, 2003; Physics First, 2009; Lulai, 2005). Despite this early call, there is a dearth of studies 
that can be considered generalizable to other schools due to the large number of variables involved at the implementation level. The following section reviews the limited number of studies I was able to find on Physics First; these studies are listed below in Table 4.

I found 13 studies of Physics First programs, six smaller studies that involved one or two high schools and seven larger studies that involved three or more high schools. Three of the larger studies were on the effectiveness of the Active Physics curriculum and involved $9^{\text {th }}$ grade implementations as well as traditional $11^{\text {th }}$ and $12^{\text {th }}$ grade implementations. One large study was on the CPO-Physics curriculum, and another using the Glencoe Physics: Principles and Problems (2015) text-a traditional physics textbook. The larger studies did not measure easily translatable assessment data. Mary (2015) found that the course sequence did not impact mathematics scores or end-of-course assessment. The most significant results from these studies is that $9^{\text {th }}$ grade students were shown to achieve at the level of $11^{\text {th }}$ and $12^{\text {th }}$ grade physics students, particularly if they received instruction with the Modeling Instruction method.

The smaller studies showed the most significant benefits from a Physics First approach, however, this may be due to the unique nature of the schools involved in the studies as several were private schools or unique public schools. Results from these smaller studies demonstrated that enrollment in upper level science electives increased after implementing Physics First programs. These studies demonstrated that not only did Modeling Instruction have an impact on student performance, teachers involved in these studies indicated that they preferred the inquiry-based approach of most Physics First curriculums over traditional physics pedagogies. 
A study conducted by Gaubatz, (2013) showed impressive results . This mid-west high school developed a modified-PCB sequence that had been in place for five years at the time of the study. The sequence was modified because $9^{\text {th }}$ graders were tracked into two different physics courses based on their $9^{\text {th }}$ grade math class. Those students who were in algebra were placed in a course that combined physics and earth science concepts (65\% of students), and students who were in Geometry or a higher-level math class were placed in Honors Physics (35\% of students).

What was most impressive in this study was that students who participated in the modified PCB sequence enrolled in AP courses in significantly greater numbers than those cohorts who did not. Enrollment in AP Biology, a junior year course, increased by three times while both AP Chemistry and AP Physics saw enrollments double.

However, one final measurement of this project was in comparing students' $8^{\text {th }}$ grade EXPLORE science assessments with $11^{\text {th }}$ grade ACT scores. This study showed no significant difference between the pre-PCB cohorts and the PCB cohorts. Moreover, while this study demonstrated an impressive degree of change in student engagement with science courses, it did not show a change in student achievement in science as measured by the EXPLORE and ACT exams. 


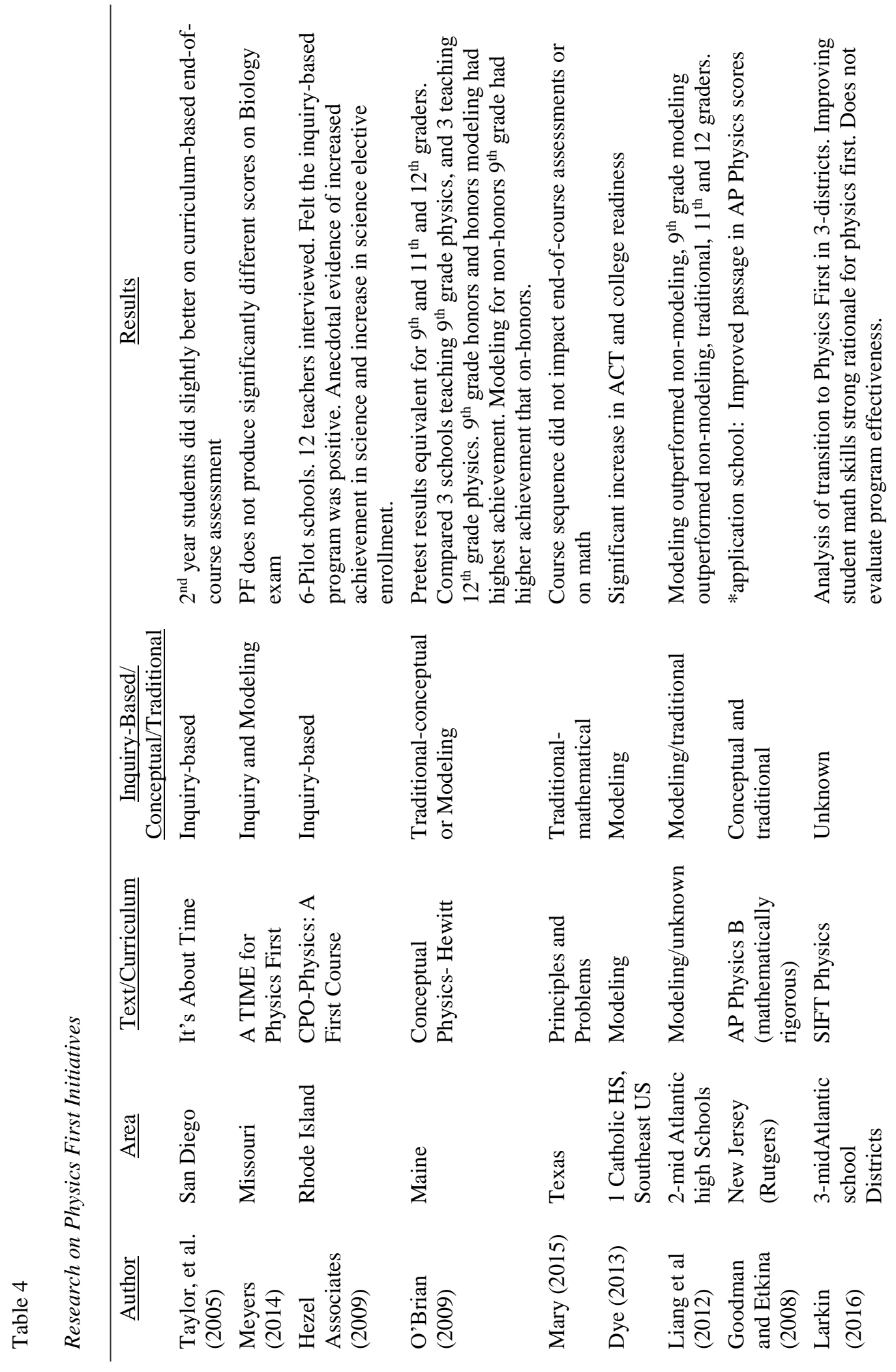




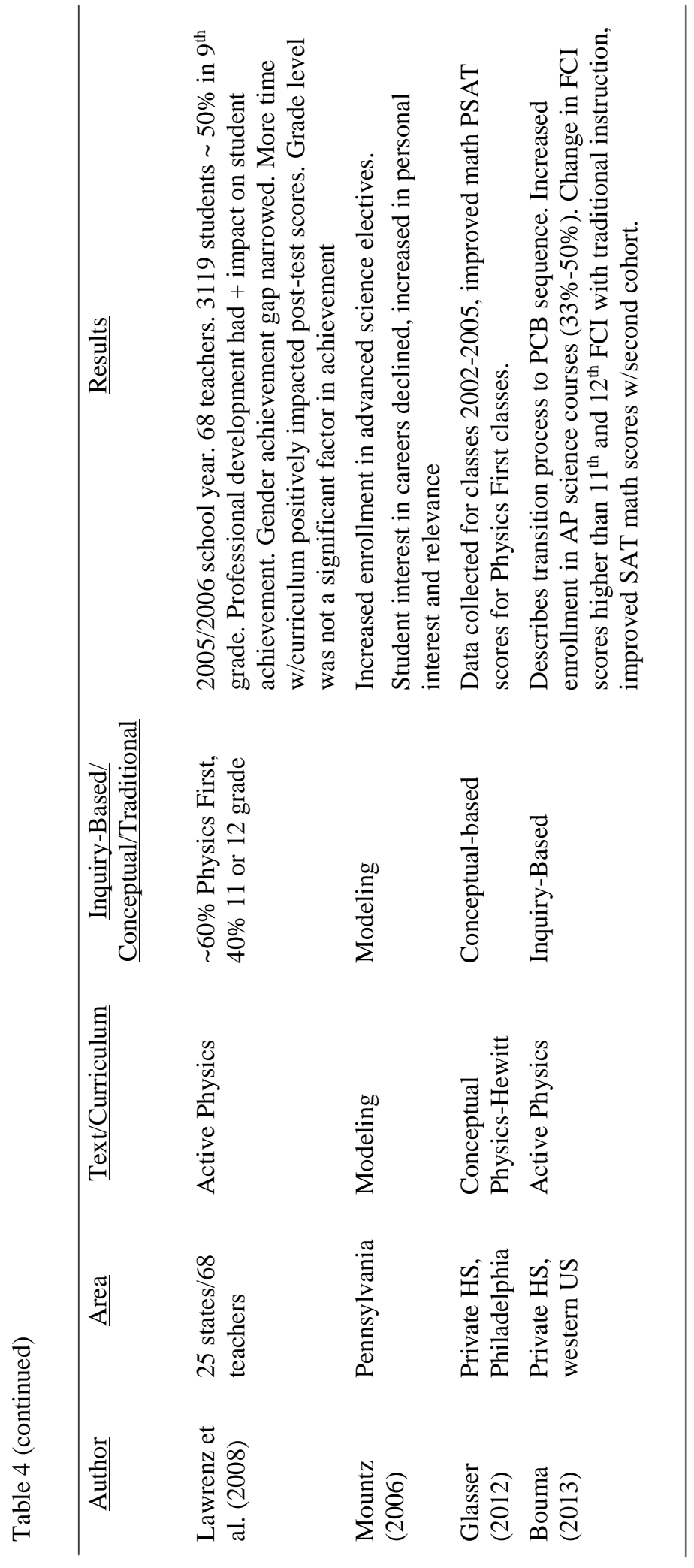


Patterns Physics in the Context of Physics First. The move towards the Physics First program in District A was the solution to a series of issues. Starting with the graduating class of 2012, the state increased the high school graduation requirement for science from two credits of lab-based science to three credits (one credit $=$ one full academic year). However, there was little guidance for students on what science courses to take and in what order to take them. As previously mentioned above, an evaluation of the courses students were taking at that time found that there were 188 different science course sequences that students were taking across the district (Manning, 2012). Only 11\% of students took Biology, Chemistry, and Physics classes, the course sequence that addressed most of the state science standards.

Patterns Physics is a curriculum designed with NGSS Science and Engineering Practices as its focus. The curriculum consists of five main units: Patterns and Computational Thinking, Engineering and Energy, Forces and Interaction, Energy Transfer and Computational Thinking, and Waves and Technology.

Recall that Patterns Physics begins with a unit on Patterns that engages students in three foundational activities in which they discover the mathematical pattern in the data for each activity (linear, inverse, and quadratic) (Hill, 2013). These are the foundational patterns in the course as these patterns will reveal themselves in further science and engineering activities throughout the course. This introductory unit is followed by units on Engineering \& Energy, Forces \& Interaction, Energy Transfer and Computational Thinking, and Waves \& Technology. The program uses Hewitt's Conceptual Physics as a 
supplementary text. Also, the techniques involved in modeling instruction (Wells, et al., 1995) are embedded into the program.

What distinguishes the Patterns Physics course from other Physics First programs is that the curriculum is developed within the school district to connect specifically to the NGSS and 3-D learning, encompassing the disciplinary core ideas (DCI), crosscutting concepts (CCC), and the Science and Engineering practices. Within the Science and Engineering (S\&E) practices, Patterns Physics places emphasis on arguing from evidence.

Each unit consists of science and engineering activities and focuses on using data to highlight linear, inverse, and quadratic patterns. Also, there are specific activities for students to develop computational reasoning through the use of spreadsheets and graphing software. This curriculum embeds activities with an inquiry focus, as well as modeling instruction. It is rather a hybrid of these approaches as described in the research review.

Regarding student placement in a $9^{\text {th }}$ grade science class (i.e. tracking), District A allowed for some variation. Some schools offered a $9^{\text {th }}$ grade physics course for all $9^{\text {th }}$ grade students, called Physics 1, while other schools also offered an honors level course called STEM Physics. Both courses were based on the same Patterns Physics curriculum but modified for the different levels. Students who attended schools that did not offer STEM Physics could do additional course work to earn the STEM Physics course designation. Some $9^{\text {th }}$ grade students who were considered advanced or planned to take IB Physics (a junior/senior elective in the International Baccalaureate Program) could 
skip ahead and enroll in Chemistry as $9^{\text {th }}$ graders. The district guidelines were that all students should take Physics, Chemistry, and Biology for graduation. According to Hill (personal communication, 2018), approximately $90 \%$ of all $9^{\text {th }}$ grade students in the district were taking a physics course using the Patterns Physics curriculum.

Figure 5 depicts a Physics First Continuum I developed based on my review of the literature. The left side begins with traditional, problem-solving based physics and then moves towards a traditional conceptual-based curriculum, moving towards an inquiry-based physics curriculum, and ending at the far-right with Modeling Instruction, as the most open, student-centered option. I believe Patterns Physics exists between Inquiry-based Physics and Modeling Instruction, as it has significant characteristics of both. I should add that through the instructional practices of individual teachers, the classroom experience of the student could be moved in either direction along the continuum.

\begin{tabular}{|lllll|}
\hline $\begin{array}{l}\text { Traditional } \\
\text { Problem-Solving- } \\
\text { Based Physics }\end{array}$ & $\begin{array}{l}\text { Traditional } \\
\text { Conceptual-Based } \\
\text { Physics }\end{array}$ & $\begin{array}{l}\text { Inquiry-Based } \\
\text { Physics }\end{array}$ & Patterns Physics & $\begin{array}{l}\text { Modeling } \\
\text { Instruction }\end{array}$ \\
\hline & & & \\
\hline $\begin{array}{l}\text { Traditional } \\
\text { Instruction }\end{array}$ & & & Innovative \\
\hline
\end{tabular}

Figure 5. The Physics First Continuum

While it would be optimal to be able to compare all of the studies, due to the differences in curriculum and instructional strategies used throughout the U.S., there are too many differences to make fully accurate comparisons. Also, the degree of alignment 
between the Physics First course learning goals and the learning goals of other science courses is unclear. This is important because, as noted above, what is predicted to make a long-term impact in student learning is not content alone. It is that learning from courses build on one another in a coherent way (Lederman, 1998). While the studies of Physics First programs do not provide direct evidence of overall student achievement in science, they are a good start in studying the student learning based on different curricular models and the possible broader impacts that these models might have on student achievement.

\section{Describing the Challenges, and Teacher Beliefs and Professional Development}

In 2001 the San Diego School District adopted a Physics First program in 18 high schools as part of an effort to improve student academic achievement and provide a more equitable education for students. The new district policy required all $9^{\text {th }}$ grade students to take physics followed by $10^{\text {th }}$ grade chemistry and then $11^{\text {th }}$ grade biology.

There were several reasons for this change that included meeting the new threeyears of lab-based science requirements of the State of California as well as preparing all students to meet the entrance requirements for California's universities, particularly low income and minority students. A review of District data showed that only $32 \%$ of their students met the college entrance requirements (Bess \& Bybee, 2004).

Prior to this change, physics was taught to only the district's top students using a mostly calculus-based approach and there was no standardized science course sequence. While a few schools had well regarded science programs, many did not, and the course offerings were not equitable across the district (Bess \& Bybee, 2004). The adoption of an 
inquiry-based Physics First program was an innovative solution to address the district's needs.

The shift to Physics First for all was therefore a significant change and required an amazing shift of teacher resources where previously only $20 \%$ of the district's students took physics or chemistry courses. To meet the needs for classroom physics teachers, the experienced $11^{\text {th }}$ and $12^{\text {th }}$ grade teachers needed training to shift their practices to use the Physics First approach and 40 out-of-discipline teachers required professional development support to teach the $9^{\text {th }}$ grade physics course (Bess \& Bybee, 2004). Also, the new curriculum was an inquiry-based program that required teachers to "change from a more traditional teacher-directed practice to an inquiry-based approach that incorporated an established instructional model..." (Taylor et al., 2005, p. 102). To meet these needs, the San Diego School District implemented a robust professional development program for 80 teachers from diverse content and area backgrounds to teach the new Physics First, inquiry-based program (Taylor et al., 2005).

Early results looked promising. After the first year, Taylor et al. (2005) found that most teachers felt that the professional development was valuable and had confidence in their understanding and ability to teach science as inquiry. Also, $72 \%$ supported the idea that all students should have the opportunity to take physics in the $9^{\text {th }}$ grade, which is significantly more than previous surveys of physics teachers in the district (p. 105). However, this early success was largely internal to these schools and teachers. The requirement for all $9^{\text {th }}$ grade students to take physics was dropped after a five-year effort, 
largely due to outside pressure, which included shifts in school board leadership based on opposition to the Physics First initiative.

This example provides a context for how difficult it is to make significant change in an educational program. Thinking about the change required of the teachers in this study illustrates how important it is to take into account both teacher beliefs about their teaching practice as well as providing on-going professional development opportunities necessary to support teacher change if there is any hope for success. The shift to the NGSS, whether it is in the form of a Physics First sequence, or something different, will require most teachers to make significant changes to their teaching practice, and it is the responsibility of all parties in the education community (schools, districts, states, and other science education stakeholders) to support teachers in making these changes.

\section{Teacher beliefs about inquiry-based practices}

One of the most significant factors in the quality of science education is the science teacher (Jones \& Leagon, 2014). After all, it is teachers who are the interface between students and student learning and the curriculum, standards, and other elements of the educational system. Teachers guide instruction, assessment, and the overall climate in their classrooms. In dealing with the complexity of the school setting, "the beliefs and attitudes they [science teachers] hold shape the way they interpret and respond to changes and challenges" (p. 830).

As the science education field moves towards supporting the goals and standards outlined in the NGSS it is therefore important to understand how teachers' beliefs and attitudes intersect with these goals for instructional practice and with the professional 
development required to assist teachers in reaching these goals. Jones and Leagon (2014) warn that "One of the powerful pitfalls that challenges the effectiveness of professional development is the failure to address teachers' attitudes and beliefs about their instructional practices" (p. 830), and that "providing teachers with new models of instruction or a new curriculum without addressing the underlying belief systems can lead to little meaningful change (p. 830).

According to Milner, Sondergeld, Demir, Johnson, and Czerniak (2012)

“Teachers' beliefs can be described as their convictions, philosophy, tenants, or opinions about teaching and learning” (p. 113). Teachers' beliefs are built up over through one's professional practice, as well as one's experience as a student. Beliefs about professional practice have been shown to be stable and difficult to change. Unfortunately, "the beliefs of teachers are not necessarily consistent with the literature about best practice in teaching...[and] appear to be stable and resistant to change" (p. 113). This can make reform much more difficult to implement. It has also been shown that "teachers rely on their core belief systems rather than academic knowledge when determining classroom actions" (Wallace \& Kang, 2004, p. 938).

In the context of science education reform, whether it is in implementing an effective Physics First program, or in training teachers to engage with the NGSS, teacher beliefs are an important consideration in supporting teachers in their current effective practices as well as working to modify practices to improve instruction. Cronin-Jones (as cited in Haney, Lumpe, Czerniak, \& Egan, 2002) found four factors that have a significant impact on how teachers implement a new curriculum: (a) "how students learn; 
(b) the teacher's role in the classroom; (c) the abilities of students in a particular age group; and d) the relative importance of content topics" (p. 173). In addition. teachers significantly alter curriculum to line up with their own beliefs and teaching contexts (Cronin-Jones, 2002).

In a study of high school teachers, Wallace \& Kang (2004) found several beliefs that supported inquiry instruction and several that impeded inquiry instruction. They noted that these beliefs created tension within the teacher when deciding on instructional practice. In support of inquiry, they found that teachers "believed that inquiry could foster independent thinking, deep thinking, and problem solving” (p. 957). In tension with this was teachers felt that they needed to cover a certain amount of curriculum, that inquiry required too much time, and that some students were too immature or lazy to learn via an inquiry approach.

In addition, a teacher's beliefs about the nature of learning have a significant impact on their approach. In a study examining teacher beliefs and science education reform, Czerniak \& Lumpe (1996) found that a large majority of science teachers did not believe that constructivism was necessary for teaching science. Even in the case of teachers who claim to have a constructivist view of learning, many may still not implement constructivist practices due to a variety of barriers. These obstacles may include time constraints, the science teaching practices of other teachers in their building, or the teacher's individual capacity to plan and design constructivist-based lessonsleading teachers to default toward a teacher-centered, transmission learning model. Windschitl (2002) acknowledges that the implementation of constructivist instruction has 
been a difficult challenge, and that teachers do face barriers in creating constructivist classrooms. Therefore, professional development should not only address constructivism in the contexts of learning and teaching, but also provide support for teachers in addressing the challenges and barriers in implementing constructivist strategies.

Veal, Riley Lloyd, Howell, \& Peters (2016) studied the connection between teacher beliefs and teacher practice. Seventy-eight science teachers completed online surveys used to measure their beliefs about science teaching and details about their classroom practice. Twenty-four teachers were observed using the Reformed Teacher Observation Protocol (RTOP) (Sawada et al., 2002) to measure innovative classroom teaching practices. This study is unique in that it collected and analyzed data on teacher beliefs about practice (identified in the study as normative beliefs), their self-report data on their actual teaching practice (identified in the study as discursive claims), and then observations of actual teaching practice using RTOP. The purpose of the study was to find relationships between teachers' beliefs, claims and actions. The responses were scaled on a continuum of traditional verses innovative beliefs and practices.

One might assume that teacher-reported innovative beliefs and innovative discursive claims would result in innovative teaching practice as measured by RTOP; this research showed that this was indeed the case in some cases. Classroom observations showed that teachers in fact implemented instruction as they said they would in the selfreport survey. However, what is most interesting is that the researchers found that whether or not a teacher had traditional or innovative normative beliefs about the norms, 
it was the teachers' innovative discursive claims (description of innovative teaching practices) that led to innovative classroom practices.

The researchers found that higher innovative beliefs did not necessarily mean that teachers actually implemented innovative teaching practices. In situations wherein the teacher had a belief in the effectiveness of innovative teaching but did not know how to effectively implement innovative strategies, innovations were not used in the classroom. This study demonstrated that while teacher beliefs about teaching practice is important, it is not directly linked to actual classroom practice. A point the importance of providing teachers opportunities to receive professional development support to develop practical skills necessary to implement innovative teaching practices.

Opfer \& Pedder (2011) described a more complex model that embeds beliefs and practices into the larger framework of teacher learning. They noted that "teacher learning must be conceptualized as a complex system rather than as an event” (p. 378). With regard to changing teachers' practice through professional development, they identified work done by Desimone (2009) that showed that a change in a teacher's beliefs can lead to a change in practice, which can then lead to a change in student achievement. However, Guskey $(1986,2002)$ showed that teacher beliefs changed only after they implemented the innovative practice and observed a change in student achievement, which then resulted in a change in teacher beliefs. For those involved in teaching, whether as a classroom teacher or as a professional developer, both scenarios have a certain face validity dependent on the context and on the individual participants. 
Therefore, understanding how to develop and implement effective professional development is critical in supporting teachers in science education reform.

\section{Professional Development}

In reviewing the literature on effective professional development, Rogers, Abell, Lannin, Wang, Musikul, Barker, and Dingman (2007) asserted that the goal of effective PD is to "provide teachers with PD opportunities to engage in the practice of science and mathematics themselves, reflect on this practice with respect to their classroom teaching and interactions with students, and improve their content and pedagogical content knowledge" (p. 511). A major relevant issue is how to design and implement professional development so that it has the desired effect on science teacher knowledge and practices. While the focus of my research study is on a Physics First program, the program is also part of the larger effort of implementing the NGSS, therefore, much of the research in the following section addresses professional development in the context of inquiry-based learning and the NGSS.

Since the 1990s, when the National Science Education Standards (NRC, 1996) and the Benchmarks for Science Literacy (Project 2061, 1993) were released, a major focus of professional development and instructional practice has been on the importance of scientific inquiry in the teaching and learning of science in $\mathrm{K}-12$. Yet the latest research on $\mathrm{K}-12$ science education indicates that in fact, science teachers are not effectively implementing scientific inquiry into their classrooms (Capps et al., 2012; Demir \& Abell, 2010; Marshall et al., 2009; Ozel \& Luft, 2013). Moreover, this lack of success in teaching scientific inquiry is a harbinger of the difficulty in changing science 
teacher practices to those spelled out by NGSS now and in the future. If the reforms of the last 20 years still have not been adopted by the majority of science teachers in the field, how long will the new reforms take to be effectively implemented?

In order to successfully implement the Next Generation Science Standards (NGSS), science teachers will need to modify their teaching practices to meet the new standards. This endeavor, particularly with regards to the engineering standards and practices, will require teachers to learn new things and adopt new frameworks for how they view their teaching practices. The need to provide extensive professional development to help teachers meet the expectations of NGSS is broadly recognized (e.g. Cunningham \& Carlsen, 2014; Sneider, 2012; Wilson, 2013). To be successful, it is critical for teachers and professional developers to have a well-developed understanding of how their students learn as well as how they themselves learn (NRC, 2000).

Research shows that many science teachers hold a behaviorist view of teaching and learning (NRC, 2003; Woolley \& Woolley, 1999), whereas the requirements of the new standards require a more constructivist view of learning. While behaviorist strategies can certainly be used in the classroom, they must not dominate the constructivist strategies that are more effective in developing student understanding of science and engineering concepts. With the new standards, students are expected to engage in experiences to build an understanding of science and engineering that includes not only science and engineering content, but also an understanding of the interrelatedness of the science practices and crosscutting concepts that exist amongst and through all of the disciplines (Pruitt, 2014). 
This change in practice will be difficult because while the shift towards a constructivist model of teaching and learning began with the National Science Education Standards in 1996, many science teachers have not yet shifted to this earlier model (Capps et al., 2012; Demir \& Abell, 2010; Marshall et al., 2009; Ozel \& Luft, 2013). I believe that one reason for this is that many teachers have not adopted a constructivist philosophy of learning, but instead have held onto a more behaviorist, or teacher-centered view of learning. In a study examining teacher beliefs and science education reform, Czerniak \& Lumpe (1996) found that a $81 \%$ of science teachers did not believe that constructivism was necessary for teaching science.

For teachers with a constructivist view of learning, many may still not implement constructivist practices due to a variety of barriers. These obstacles may include time constraints, the science teaching practices of other teachers in their building, or the teacher's individual capacity to plan and design constructivist-based lessons-leading teachers to default toward a teacher-centered, transmission learning model. Windschitl (2002) acknowledges that the implementation of constructivist instruction has been a difficult challenge and that teachers do face barriers in creating constructivist classrooms. Therefore, professional development should not only address constructivism in the contexts of learning and teaching, but also provide support for teachers in addressing the challenges and barriers in implementing constructivist strategies.

Adult learning theory provides guidance for science teachers and professional developers to plan, implement, and carry out professional development to help teachers shift their teaching to meet the new standards. Recognizing that adults bring their 
background knowledge and experiences, biases, and skills to the learning process is critical in planning professional development. Kolb's experiential model provides a simple framework for organizing professional development, either by an individual pursuing his or her own learning experience, or by a facilitator running a workshop. Providing learning experiences for the individual to engage in the material, followed by time for reflection, allows the learner to then make sense of the learning and put the learning into practice. It is interesting to note that this is primarily a constructivist approach to learning.

Research on effective professional development over the past 20-years is providing guidance to improve program design. While outlining the changes in practice required to implement the NGSS, Reiser (2013) noted, "These shifts in practice cannot be accomplished by learning about NGSS or by developing a collection of isolated techniques. Instead it requires fundamental attention to what we now know about how to support teachers changing their practice" (p. 2). To move beyond a superficial understanding of the NGSS, teachers need to engage with the NGSS on multiple levels. This requires time, an alignment with long-term goals, a focus on content, and a focus on both teaching practices and student work.

The following features have been shown to be part of effective professional development (NAP, 2016,): (a) "Active participation of teachers who engage in the analysis of examples of effective instruction and the analysis of student work; (b) a content focus; (c) alignment with district policies and practices, and; (d) sufficient duration to allow repeated practice and/or reflection on classroom experiences" (p. 3). 
This is an exciting time to be a science educator. I believe that the learning required to change teaching practices to meet the NGSS goals will be transformative for many teachers, as I believe it is for me. "Transformative learning has to do with making meaning out of experiences and questioning assumptions based on prior experience" (Cranton, 2006, p. 8). While I believe that many teachers are reflective practitioners by nature, shifting our practice towards the NGSS will create new opportunities for all science teachers to reflect on their current practices and beliefs as we figure out what the new standards mean and will look like in practice in our classrooms.

\section{Review of the Methodological Literature}

Luft \& Hewson (2014) emphasized that for those researching professional development programs, "it is important to reject the notion that these programs and the developers who run them are active providers, while the teachers are passive recipients. On the contrary, it is of the utmost importance to recognize that the teachers themselves are responsible for their own professional development” (p. 889). It is with that very perspective that I undertook this dissertation research. The goal was to find and report the teacher voice about the Patterns Physics implementation.

In the general sense, I searched for their beliefs on whether they think it is an appropriate curriculum for $9^{\text {th }}$ grade students, and further, how this course, either through receiving training or through teaching it, impacted their teaching practice. I have had my own journey with Patterns Physics and it has impacted my view of my teaching practice as I implement its activities and teaching strategies, but I am aware that my viewpoint is unique. I am curious as to the experience of others and hope that what I learned through 
conducting this study can be used to inform improvements to the curriculum and the training.

Studies that attempt to examine the teacher professional development process utilize a variety of approaches: quantitative, qualitative methodologies, and mixed methods (Luft and Hewson, 2014). The types of questions asked require different sets of methodologies in order to inform particular inquiries.

Creswell (2014), explained that quantitative designs are effective for comparing the relationship between variables that can be measured numerically. These numbers can then be analyzed using statistical tools. Two typical approaches are the experimental design in which one looks for the impact of an intervention or set of interventions and the non-experimental design that seeks to describe "trends, attitudes, or opinions of a population" (p. 11).

Fischer, Boone, \& Neumann (2014) identified four criteria for determining the trustworthiness of data, irrespective of whether it is a quantitative or qualitative measurement. These are: 1) “objectivity, 2) reliability, 3), validity, and 4) significance” (p. 21). Objectivity refers to the idea that when a measurement is made by multiple researchers, the procedures utilized by the researchers is such that they obtain the same measurement. Reliability refers to the potential errors in making a measurement. In some cases, this can be due to random errors (i.e. mistakes in making the measurement) or systemic errors (i.e. some error in the procedure or measuring tool). So, reliability is correlated to how reproducible a measurement is when used to measure similar or the same set of variables. Validity is the concept that what is being measured is what is 
supposed to be measured. This can be addressed by having multiple measurements or other methods to compare data. Finally, significance "refers to the trustworthiness of the results obtained through procedures of data reduction" (p. 23). In the context of quantitative research, this significance factor is determined mathematically as a probability that the results are correct rather than due to chance.

While quantitative research can provide valuable information, it is limited in scope. Science education has traditionally preferred a quantitative approach, but over the past thirty years qualitative research has provided new perspectives in understanding curricular policies and practices (Taylor, 2014). Qualitative research "seeks to improve science education through developing and understanding the complexity of the teaching and learning of science, often starting with highly selected and isolated cases" (Fischer et al., 2014, p. 18).

Guba \& Lincoln (1989) outlined a process called “constructive inquiry” (p. 174). In this process, the researcher seeks to learn about the claims, concerns, and issues about those involved in a program. They use the term constructive inquiry because the researcher does not know what the answers are or even all of the questions to ask. In addition, program evaluation is a largely human endeavor, thus there can be multiple realities depending on the perspectives of individuals involved. In essence, the constructive inquiry term is used because the researcher is, in effect, constructing an understanding based on their research. Due to the human component, Guba \& Lincoln (1989) argued that qualitative methods are best.

Humans collect information best, and most easily, through the direct employment of their senses: talking to people, observing their activities, reading their 
documents, assessing the unobtrusive signs they leave behind, responding to their non-verbal cues, and the like. It is for this reason that qualitative methods are preferred... (p. 175).

According to Merriam (2009), "qualitative researchers are interested in understanding the meaning people have constructed, that is, how people make sense of their world and the experiences they have in the world" (p. 13). Since I am interested in teachers' experiences and understanding of their teaching practice due to Patterns Physics, my research employed several qualitative components, including surveys and semi-structured interviews.

Case studies have been shown to be an important research approach in studying curricular innovations (NRC, 2004). While case studies are not appropriate in assessing the direct effects of a program on student achievement, "case studies provide insight into mechanisms at play that are hidden from a comparison of student achievement" (p. 167). Further, "case studies provide useful information on how program components interact with implementation factors at the level of classroom practices, and therefore can provide insight into the reason for whatever level of curricular effectiveness occurred" (p. 172).

Case study research can use both qualitative and quantitative methods (Yin, 2014). Using mixed methods allows the researcher to "combine[s] elements of qualitative and quantitative research approaches (e.g., use of qualitative and quantitative viewpoints, data collection, analysis, inference techniques) for the broad purposes of breadth and depth of understanding and corroboration" (Johnson, Onwuegbuzie, \& Turner, 2007, p. 123). Creswell (2014) advises that using mixed methods is appropriate when neither the quantitative nor qualitative approach alone is adequate to meet the needs of the study. 
Surveys are a common method in collecting both quantitative and qualitative data, and the survey developed for this study collects both types of data. Krathwohl (2009) outlined the steps in developing and analyzing a survey. The key steps in developing a survey are: 1) Determine the purpose; 2) decide on trade-offs (example: time, number of questions, internal integrity vs external generality); 3) develop a sampling plan; 4) get feedback from the target population and modify survey; 5) develop the instrument; 6) develop the coding scheme; 7) consider interviews about the survey with a few participants to query about their interpretation; and 8) compile, analyze, and interpret results.

Giving surveys through an online format provides many advantages, including the speed with which the survey can be given, and the ability to quickly organize data for analysis. While the quality of the survey may vary (does it provide the data desired by the researcher?) there are other potential caveats. The following is a summary of issues identified by Jaeger (1984), as cited in Krathwohl, 2009, p 599 that highlight potential issues: 1) Is the sample representative of the population and large enough? 2) did respondents understand, interpret, and willing to respond to the questions, as well as have the knowledge to respond? 3) would the responses have change based on the rewording or reordering of questions? 4) were the respondents honest? This list of issues can be mitigated by the researcher paying close attention to the data collected, close attention to the development of the survey, and some follow-up with several respondents. 


\section{Summary}

My research project is a case study of high school science teachers in District A and used both quantitative and qualitative methods to address my research questions. A survey was designed to collect both quantitative and qualitative data from participants. The survey was distributed to District A high school science teachers via email and surveys were completed voluntarily. Follow-up interviews were conducted with the survey participants who volunteered to participate in the follow-up interviews.

Participants indicated informed consent within the survey, and prior to being interviewed. In chapter three, I will discuss details of the methods used in this study as well as the analysis procedures. 


\section{Chapter 3: Methods}

The adoption of the Next Generation Science Standards (NGSS) has caused teachers, administrators, and school district leaders to reexamine their K-12 science courses and offerings. At the high school level (grades 9-12) this means that school and district leaders are reevaluating both science course sequences and the learning targets for those courses to best meet the requirements of the standards. As discussed in chapter one, the NGSS is significantly different than past standards, particularly with the equalized emphasis of core content, crosscutting concepts, and science and engineering practices. The increased emphasis on crosscutting concepts and science and engineering practices is a significant change from past standards and requires a significant change in instructional practice. The current set of challenges for science educators are how to best meet the goals of the NGSS.

To address these and other challenges, several District A high school science teachers and science specialists, also known as Teachers on Special Assignment (TOSAs), developed three new science courses to be taught as a three-year sequence at the high school level. The overarching theme for these courses is the crosscutting concept Patterns. The sequence of these courses followed the physics first approach, known as the PCB (physics, chemistry, biology) course sequence, with physics taught at the $9^{\text {th }}$ grade, chemistry at the $10^{\text {th }}$ grade and biology at the $11^{\text {th }}$ grade.

Since implementation in District A in the 2012-2013 school year, the Patterns Physics course and the Patterns PCB course sequence have gained popularity in the local region. Over 150 science teachers from outside the district have participated in a one- 
week professional development summer workshop to support adoption of the PCB courses and several districts in our region have adopted the Patterns Physics course for their $9^{\text {th }}$ grade science offering, including the largest district in the state. However, the reasoning behind these decisions has been largely based on the high degree of facevalidity of the curriculum with NGSS (because the learning targets match those in NGSS) and anecdotal evidence from teachers that the curricula is a success rather than rigorous research providing evidence to support the PCB adoption.

The purpose of the study is to examine the impact of the implementation of Patterns Physics on teacher practice and beliefs about science teaching. Does this new approach facilitate teacher classroom practices and beliefs congruent with those expressed in A Framework for K-12 Science Education (NRC, 2012) and Next Generation Science Standards (NGSS Lead States, 2013)? The specific research questions are:

\section{Research Questions:}

1. To what extent have the Professional Development (PD) and teaching experiences affected teachers' confidence in engaging students in the practices of science and engineering?

2. Which aspects of the Professional Development (PD) and teaching experiences have made the greatest difference in teachers' confidence and self-reported changes in their practices?

3. How have the Professional Development (PD) and teaching experiences changed teachers' perceptions about the value of physics first?

To inform these research questions, the literature in chapter two was used to better understand the problem and to develop and determine appropriate methods for this study. In chapter three, I first outline the research methods with an explanation for why I chose 
these methods. Next, I describe the participants and present rationale for selecting this particular group for this study. I discuss the development of the instruments used in this study detailing key aspects of the processes and decisions throughout the development cycle. What follows is a brief discussion of my role as the researcher, the data collection and analysis procedures and I conclude with a summary.

\section{Research Methods}

In planning a study, Creswell (2014) said that “...researchers need to think through the philosophical worldview assumptions that they bring to the study, the research design that is related to this worldview, and the specific methods or procedures of research that translate the approach into practice" (p. 4). Worldviews are "a general philosophical orientation about the world and the nature of research that a researcher brings to a study" (p. 6).

\section{Research paradigm}

The term paradigm is often used interchangeably with worldview. Four prominent philosophical research paradigms are post-positivism, constructivism, transformative, and pragmatism. Pragmatism is unique in that it is not "committed to any one system of philosophy and reality" (Creswell, 2014, p.9) but utilizes all available resources to understand problems and find solutions. Morgan (2014), who based his understanding of pragmatism on the work of John Dewey, notes that pragmatism emphasizes the nature of expertise, the focus on the outcomes of action, and on shared beliefs (p. 28).

I chose pragmatism, or the pragmatic paradigm for this study because this problem-centered worldview is oriented towards examining real-world practice. My 
focus was to learn about the impact of Patterns Physics on teacher practice. Not only did I want to learn about science teachers' experience with Patterns Physics and their professional opinions on how this curriculum works within the context of their classroom practice, I also sought to measure the aspects of their classroom practice that related to their use and comfort with the NGSS science and engineering practices (that are embedded into the Patterns Physics curriculum) as objectively as possible. I posit that this knowledge can be used to improve the Patterns Physics curriculum and accompanying professional development and provide empirical data on the successes and challenges of implementing Patterns.

\section{Research design and rationale}

When studying contemporary events where behaviors cannot be manipulated, Yin (2014) recommended using a case study approach. The case study is used when the researcher seeks to "understand a real-world case and assume that such an understanding is likely to involve important contextual conditions pertinent to your case" (p. 16). Merriam (2009) defined a case study as "an in-depth description and analysis of a bounded system" (p.40). The bounded system is "a single entity, a unit around which there are boundaries...(and) could be a single person who is a case example of some phenomenon, a program, a group, an institution, a community, or a specific policy study of a new science curriculum..." (p. 40).

Merriam stated that a case study is appropriate when "the researcher aims to uncover the interaction of significant factors characteristic of the phenomenon" (p. 43). Both Merriam and Yin indicated that a case study is an appropriate method when 
studying a system that has clear boundaries and where the context and characteristics in which the case resides are important factors.

The process of determining the optimum research approach to investigate the impact of Patterns Physics on teacher practice and beliefs about science teaching led to important questions. As mentioned previously, since its implementation in District A in the 2012-2013 school year, most of the teachers in District A and over 150 teachers outside of the district have completed the Patterns Physics summer workshops. The Patterns Physics curriculum, at the time of this study, was being implemented in at least four school districts. While doing a study that involved teachers from outside of District A would have been possible — and indeed may be the focus of a larger study at a later time - the differing contexts in which these teachers taught (i.e. levels of administrative support, the nature of professional development, attention to implementation fidelity) would be additional variables to consider.

Roehrig, Kruse, \& Kern (2007) found that systemic curricular change requires more than just resources (e.g., textbooks and supplies) and professional development. Systemic change also requires structured time for teachers to work together, ideally with trained teacher leaders who can "support or constrain the work of teachers implementing the curriculum" (p. 904) and plan and adaptively guide conversations between teachers on how to best implement the curriculum. The science teachers in District A consistently received the level and quality of support for systemic curricular change as identified by Roehrig, et al. (2007); it is unlikely that teachers who implemented Patterns Physics in other school districts received the same level of support. 
In light of these considerations, I decided to conduct a case study that only involved high school science teachers in District A. These teachers had a unique set of characteristics that made them the preferred choice as a focus for an initial stage of research. First, given that the PCB curriculum was developed in District A, many current teachers have been involved since its inception. Second, the district has provided significant ongoing resources, including professional development, science TOSAs to coordinate and support the implementation of the new curriculum, and continued administrative support. Third, there had been a significant amount of time since implementation (in its $6^{\text {th }}$ year at the time of his study), thus several initial difficulties had been worked through. Also, teachers who taught science courses other than Patterns Physics could provide a meaningful perspective based on their observations of their current students who had taken Patterns Physics versus students who had not taken Patterns Physics (i.e. Were these students more or less prepared than previous students who did not take Patterns Physics? Did they have stronger or different knowledge and skills? Were they as successful in the current course as previous classes of students?)

Because the implementation effort was focused on the six large comprehensive high schools in this district (that have impacted the largest number of district students) there would still be sufficient diversity of implementations to make the case interesting while still manageable for dissertation level research.

This study is a bounded case study of District A science teachers and uses both quantitative and qualitative methods to address the research questions (Yin, 2018). Morgan (2014) identifies triangulation as an effective way to check multiple data sources 
for consistency, providing a better sense of the accuracy of the data, and the conclusions drawn from them. In keeping with Morgan's observation, due to the nature of my research questions, I determined that both quantitative and qualitative methods were needed to provide opportunities to triangulate data to create a more nuanced, in-depth description of the impact of Patterns Physics on the science teachers in District A. As depicted here in Figure 6, I collected data in phases:
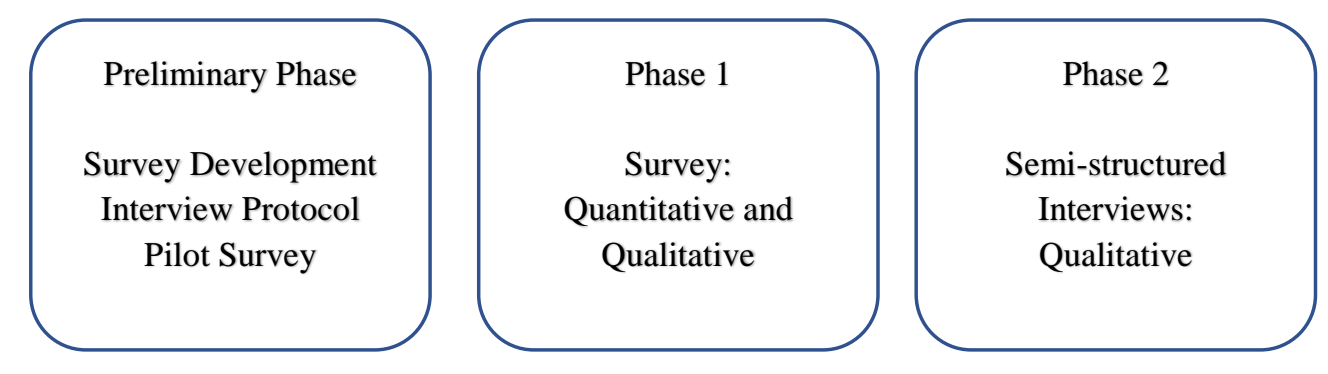

Figure 6. Three phases of the research design

Prior to administering the survey with actual study participants, I piloted the questions with a small number of teachers who would not be involved in the study. This pilot was conducted to ensure that the meaning of each survey item could be accurately understood in the intended manner and would elicit data needed to inform the research questions.

In phase one, teacher participants completed a locally developed survey called the Patterns Physics Impact Survey (see Appendix A). I used Qualtrics, a web-based survey platform, for this survey that involved both quantitative and qualitative items. Several of the items elicited data about participants' preference for a high school science course sequence and were nominal in nature. Another series of questions used a five-point Likert scale response style approach to probe participants about specific aspects of their teaching practice. The survey also involved several open-ended questions wherein 
teachers provided explanations and descriptions of their beliefs and experiences with Patterns Physics.

The multiple choice and Likert scale responses were uploaded from Qualtrics into SPSS for analysis using descriptive and basic statistical analysis techniques. The qualitative, open-ended responses were downloaded into a spreadsheet and organized by item.

Each open-ended response was coded using the two-cycle coding approach recommended by Saldaña (2009). The first cycle codes were descriptive or in-vivo to accurately interpret the essence of the intended meaning each response. For the second cycle of coding, I developed themes that best described the subsets of first cycle codes. Saldaña (2009) referred to this stage as focused coding. According to Saldaña, "the primary goal during Second Cycle coding, if needed, is to develop a sense of categorical, thematic, conceptual, and/or theoretical organization from the array of First Cycle codes" (p. 149). The themes developed in the second cycle coding provided the basis for the analyses of the qualitative responses in preparation for interviews.

Phase two involved a series of nine interviews with participants who responded positively to an invitation issued in the survey. The purpose of these interviews was to gain a more in-depth understanding of teachers' views and experiences. According to Yin (2018), "one of the most important sources of case study evidence is the interview....Interviews can especially helpful by suggesting explanations (i.e. the "hows" and "whys") of key events, as well as the insights reflecting participants' relativist perspectives" (p. 118). The semi-structured interviews (see Appendix B) provided 
teachers an opportunity to expand upon and explain their responses to the survey questions and to draw on examples from their teaching practice to describe their perceptions.

To summarize, phase one of this study collected quantitative and qualitative data through a survey. Teachers responded to items that inquired about their views of physics at the $9^{\text {th }}$ grade, their perceptions of the impact that the professional development had on their teaching practices, and what aspects of the professional development most impacted their confidence in teaching the NGSS practices in science and engineering. Phase two of this study collected qualitative data through interviews with teachers who volunteered to be interviewed by responding to an invitation embedded in the survey. This set of nine interviews elicited more in-depth descriptions of teachers' beliefs and practices.

\section{Participants}

The participants in this study were high school science teachers who taught in one of the six large, comprehensive high schools in District A. At the time of this study, District A consisted of six large comprehensive high schools and four alternative high schools with a total enrollment of over 12,000 students. Initial estimates indicated that there were approximately 100 science teachers in the district with 35 science teachers teaching a Patterns Physics course. Due to variability in teaching assignments and professional development opportunities between science teachers in the alternative and comprehensive high schools, it was determined to limit the unit of analysis to involve science teachers who taught in the district's large comprehensive high schools. A total of 
68 science teachers were identified as teaching in those schools and 27 teachers taught one or more sections using the Patterns Physics curriculum.

While this project had a focus on those teaching Patterns Physics, all science teachers who teach in these schools were impacted by the Patterns Physics program; I was interested in collecting perspectives from all of the teachers in order capture the variety of perspectives. Therefore, all 68 science teachers were invited to participate in this study.

There were 32 respondents to the survey (47\% response rate of science teachers overall) with 19 respondents indicating that they taught Patterns Physics at the $9^{\text {th }}$ grade level (70\% response rate of Patterns Physics teachers). Ten teachers indicated in the survey that they would be available to participate in a follow-up interview.

Nine interviews were conducted, as one person decided not to participate at the end of the interview timeframe. If more than 12 teachers volunteered to be interviewed, a selection process to achieve maximum variation (Guba \& Lincoln, 1989) would have been implemented. However, this selection process plan was not implemented given that only nine teachers followed through and participated in the interviews.

The interviewees represented five of the six comprehensive high schools; eight of the nine interviewees taught Patterns Physics. These teachers represented 37\% of the total number of Patterns Physics teachers in District A.

\section{Procedures}

Data collection was conducted in two phases. Phase one was completed during the late fall of the 2017-2018 school year. After receiving approval from District A to 
conduct this study, I met with five of the six comprehensive high school science departments during scheduled department meetings and gave a short presentation introducing the study and inviting the teachers to participate. A district science Teacher on Special Assignment (TOSA) acted as a proxy to provide information to the science department at the sixth school. The district TOSA followed a protocol to make clear that the TOSA was not conducting the survey and would not have access to raw data (Appendix F).

To arrange the meeting times, science department chairs were contacted in each school via email in coordination with a district science TOSA, to determine the best time to schedule the presentation. The goal of the presentation was to present the purpose and scope of this study to these teachers, explain the connection between my research study and the work they have been doing in the district, and provide an opportunity for them to ask questions.

At the conclusion of each participant recruitment meeting, the teachers in each school were sent an email that provided a brief description of the project and a link to the Patterns Physics Impact Survey (Appendix A). The survey was created using Qualtrics, a web-based survey platform, and was housed on a university server.

The first page of the survey included an invitation to participate, a brief description of the project, confidentiality information, contact information to address concerns, problems, or questions about the study, and a place for participants to indicate active informed consent before moving forward to take the survey or to opt-out of participating. 
The survey was open for responses for a period of two-weeks. At the conclusion of the first week and again one day before the survey closed, I emailed reminders to noncompleters (i.e. teachers who had not accessed the survey or had not indicated that they did not want to participate).

Within each survey, participants were asked whether they would be willing to participate in a 30-45-minute follow-up interview. Three meeting options were offered: meeting at a place of mutual convenience, completing the interview over the telephone or using an on-line conferencing application called Zoom. If interested, there was a place for participants to enter their contact information (name and preferred email address).

In early January 2018, consenting teachers were contacted via email thanking them for completing the PPIS and for their interest in being interviewed as part of this study. In that email, teachers were directed to a Google form where they indicated whether or not they still wanted to participate in an interview, their preference for meeting in person or via an online conference app. If they preferred a meeting in person, they were asked where they would like to meet. These teachers also indicated the best day(s) of the week for the interview to take place as well as any preferred times or dates. The interviews were scheduled from mid-January through early February 2018.

The phase two involved a semi-structured interview protocol (Appendix B) to interview the ten teachers who volunteered to be interviewed. At least one teacher from each of the six high schools volunteered. Because this was less than the maximum number of interviews I was prepared to do $(n=12)$, arrangements were made to interview all of these teachers. One teacher, the only representative from one of the schools, 
dropped out at the time of the scheduled interview, so a total nine teachers were interviewed. Four teachers were interviewed in person at their school and five interviews were conducted via Zoom. All interviews were digitally audio recorded.

At the beginning of each interview, the Interview Consent Form was provided to the participant who then decided whether or not to continue to participate in the study (Appendix D). Those interviewed in person signed a copy of the form. Those interviewed using the Zoom conferencing application were emailed the Interview Active Informed Consent Form prior to the interview, were offered an opportunity to ask any questions about the interview or the study. At the beginning of each interview, teachers using the Zoom application provided their verbal consent to participate in the interview for the study. This exchange was recorded as part of the interview audio recording. The interviews then proceeded using the interview protocol as a guide.

Interview transcripts were created by uploading the digital recordings to Rev.com. The researcher then reviewed each transcript for accuracy and made minor corrections to the transcripts as needed by simultaneously listening to the audio file and reading the prepared transcript through the Rev.com web interface. Completed transcripts were then loaded into Atlas.ti, a qualitative data analysis software (QDAS), for initial coding. The coding process is described in more detail in the data collection and analysis section.

Maintaining data. All electronic data and records from this study are stored in a password protected online account. All paper files are in a locking file box in my home office. All data will be stored for three-years and then destroyed or deleted. 
Instruments and measures. Two instruments were developed for this study. The Patterns Physics Impact Survey (PPIS, Appendix A) is an online survey on the Qualtrics web-based survey platform. The semi-structured interview protocol was designed for follow-up interviews (Appendix B). The PPIS was developed in a little over a year in consultation with District A TOSAs and research collaborators in my graduate school program.

I chose the online survey design because it was easy to distribute to my target group. The survey was accessible to participants over a two-week period, an approach that afforded teachers the opportunity to take the survey when it was most convenient for each individual to do so within this limited timeframe. This approach also allowed for the quantitative and qualitative data to be captured and stored in a digital format. The semistructured interview questions were designed to provide more in-depth responses to questions addressed in the PPIS, obtain descriptions from teachers about their teaching practice, and to "elicit views and opinions from the participants" (Creswell, 2014). In the following section, I will describe the development of the PPIS and the semi-structured interview process.

\section{Background}

When this study was in the development phase, one goal was to find or develop some objective measure of teacher practice or proficiency in using the NGSS practices. A search of the literature found several quantitative instruments that had been used to measure the impact of reform-based practices. Two of these, the Science Teaching Efficacy Belief Instrument A (STEBI-A) (Riggs \& Enochs, 1990) and the Teachers' 
Sense of Efficacy Scale (TSES) (Tschannen-Moran \& Hoy, 2001) focused on teachers' self-efficacy. Only two survey instruments were found that specifically addressed the NGSS, the NGSS Readiness Survey (Haag \& Megowan, 2015) and the Science Instructional Practice Survey (SIPS) (Hayes, Lee, DiStefano, O’Connor, \& Seitz, 2016). The lack of applicable surveys was not surprising considering that the NGSS was only released in 2013.

The NGSS Readiness Survey (Haag \& Megowan, 2015) and the SIPS (Hayes et al., 2016) are different in fundamental ways. The NGSS Readiness Survey addresses teachers' motivation and confidence in having students engage in the NGSS science and engineering practices, while the SIPS survey asks teachers to record the frequency of specific classroom practices from a provided list of reform and traditional instructional practices.

As mentioned in chapter one, one key difference between the NGSS and past science standards is the elevation of engineering (both content and practices) to be on equal footing with science. Unfortunately, the SIPS survey did not specifically address engineering. Since engineering is a key component NGSS, as well as the Patterns Physics curriculum, the SIPS survey did not meet the needs of this study.

The NGSS Readiness Survey (Haag \& Megowan, 2015) was developed to collect data from K-12 teachers on their ability to engage their classes in the science and engineering practices. The NGSS Readiness Survey consists of five sections, followed by several demographic and short response questions about the NGSS (Figure 7). Developed from a pilot study of 45 teachers, the NGSS Readiness Survey was a national online 
survey administered in March and April 2013. Sections one through three of the survey contained many of the same items as those in the STEBI-A assessment, while section four and five were questions related to teachers' motivation and success in teaching the NGSS practices.

Haag and McGowen (2015) reported that 710 middle and high school science teachers completed their NGSS Readiness Survey and that $51 \%$ of those teachers were trained in Modeling. Modeling is an instructional technique that "expresses an emphasis on the construction and application of conceptual models of physical phenomena as a central aspect of learning and doing science" (Jackson et al., 2008, p. 10). The fact that so many of the participants were trained in Modeling was particularly relevant to this study as Patterns Physics embraces aspects of this approach (Hill, 2013). It is important to note that Modeling is an instructional approach for science inquiry that does not necessarily address engineering.

Haag and Megowen (2015) found that high school teachers were more motivated and prepared to teach the NGSS science and engineering practices than middle school teachers. Furthermore, they found that teachers trained in Modeling ( $>90$ hours of training for high school teachers and $>64$ hours of training for middle school teachers) were more motivated and prepared to teach the NGSS science and engineering practices than those teachers without Modeling training. High school teachers trained in Modeling indicated the highest level of preparedness to the science and engineering practices, middle school teachers trained in Modeling scored similarly to high school non-modeling teachers, and middle school teachers not trained in Modeling showed the lowest level of 
preparedness. They also found that many teachers indicated the need for additional training in engineering.

Haag \& Megowan (2015) did not include results from the self-efficacy (STEBIA) items in their survey. The report of their findings only addressed the sections specifically targeting teacher readiness and motivation to teach NGSS science and engineering practices. It is not clear why the STEBI-A results were not included in their study, but it could be because those questions were not relevant to their research questions.

The STEBI-A was developed to measure the self-efficacy of elementary school teachers in science. Indeed, much of the research on self-efficacy has been done with elementary and pre-service teachers (Riggs \& Enochs, 1990). Herrington, Yezierski, \& Bancroft (2016) compared self-efficacy measurements with classroom observations and found a disconnect, as self-efficacy scores did not "appropriately capture teachers' knowledge or enactment of classroom practices" (p. 1075). In addition, they found that self-efficacy scores for experienced teachers were stable and not significantly impacted by PD. These finding supported that of an earlier study conducted Ross (1994). Based on these factors, I decided not to include self-efficacy items in this study.

In the early stages of this study, I decided to focus on teachers and their beliefs and experiences that relate to their teaching of the NGSS science and engineering practices. The items Haag \& Megowan (2015) cited in their article that addressed teacher motivation and readiness to teach the NGSS science and engineering practices were aligned with my goals of learning if teacher confidence in teaching the science and 
engineering practices had changed since the implementation of the Patterns Physics course, and if so, what contributed to that change in confidence. Haag \& Megowan's survey was also effectively used with teachers trained in Modeling; an instructional approach similar to that found in the Patterns Physics curriculum.

I contacted Susan Haag in the spring of 2016 to request permission to use some of the items from the STEBI-A survey. Haag provided this consent and sent me the NGSS Readiness Survey. The STEBI-A items were not included in my study, as several studies indicated that the items may not be effective with my target population (Herrington et al., 2016; J. A. Ross, 1994). While the NGSS Readiness Survey provided a meaningful foundation for a survey instrument, it did not meet all of the needs for this study. Therefore, additional questions were developed, modified, and integrated into the final version of the survey instrument developed for this study, the Patterns Physics Impact Survey (PPIS).

Figure 7 shows the key components of the NGSS Readiness survey, the first version of the PPIS (v1) and the final version of the PPIS (v. Final). A timeline of these developments can be found in Table 5. Next, I explain how the PPIS v1 was developed and then the final modifications that were made for the PPIS v. Final. 


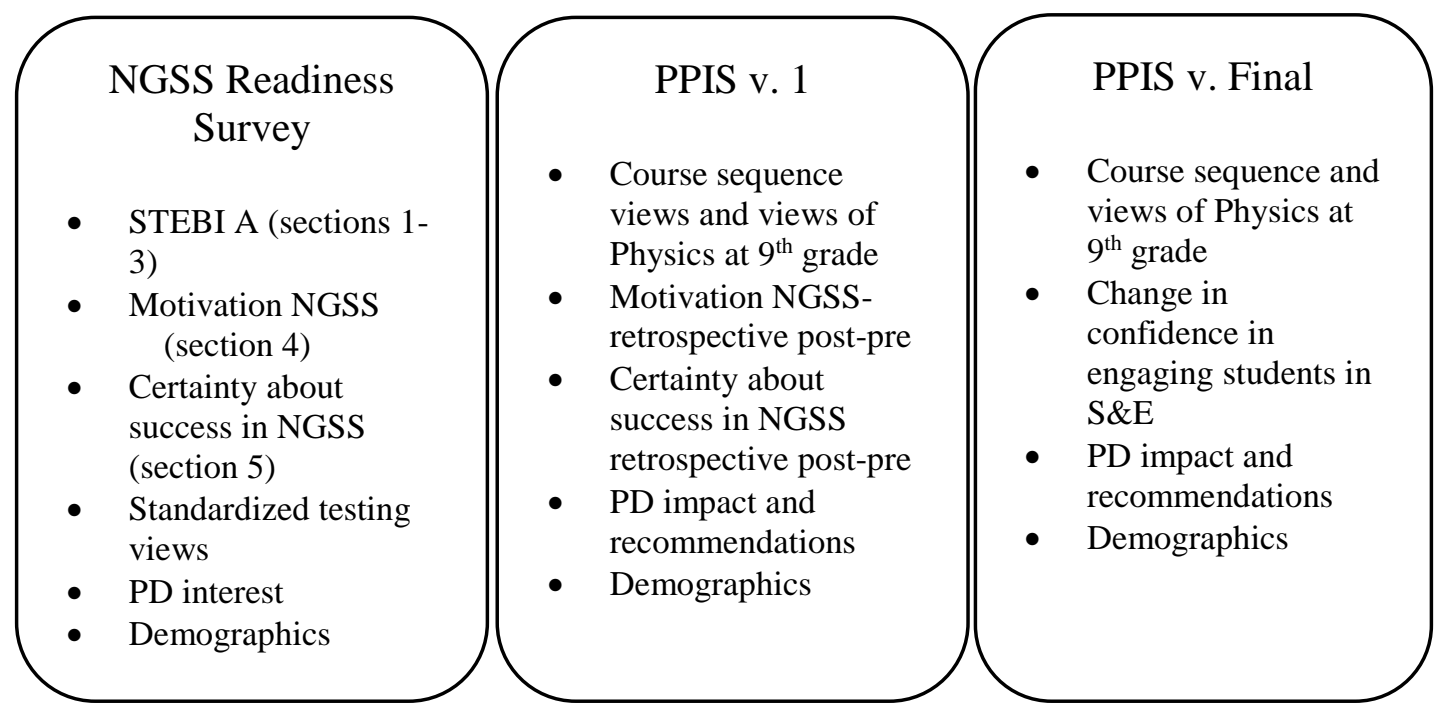

Figure 7. Development of the patterns physics impact survey (PPIS)

Development of the Patterns Physics Impact Survey (PPIS). As a primary

measurement tool in this study, the quality of the survey is critical. In developing a

survey, Krathwohl (2009) wrote, "important considerations in instrument construction are what to ask, how to ask it, how to order the questions, how to format the instrument, and how to improve it (p. 575). The development and optimization of the survey instrument was an extended process that evolved over time. In making iterative improvements, I followed the recommendations of Krathwohl and responded to feedback from colleagues and mentors consulted throughout the development phase.

In addition to teachers' engagement with the NGSS science and engineering practices, two key objectives of this study were to investigate teachers' views of the value of Physics First (teaching physics at the $9^{\text {th }}$ grade) and aspects of PD and their teaching experience they perceived most impacted their teaching practice regarding the NGSS science and engineering practices. The NGSS Readiness Survey did not reference Physics 
First or course sequencing at all and the section on professional development was limited. Therefore, I developed additional items in the PPIS instrument to address these areas of concern.

Krathwohl (2009) said that in designing a survey "the order of the questions is important. The opening of the instrument sets the tone for the respondents regarding the motivation and purpose" (p. 578). Table 5 shows how each item in the survey matches with each research question.

Course sequence and views of Physics at the 9th grade. Because this study examined teachers' perceptions related to the impact of Patterns Physics, the PPIS (both versions) began with questions intended to elicit each teacher's opinion on what high school science course sequence they thought best, provided an opportunity for respondents to explain their reasoning, and asked whether or not their views changed over time, and if so, to describe their changing perspectives. Several additional items inquired more in depth about their beliefs about a $9^{\text {th }}$ grade physics course. 
Table 5

Phases of Survey Development

$\underline{\text { Timeline }}$

1. Preliminary Phase: SpringSummer 2016, PPIS Initial Draft

(37 questions*)

2. PPIS v1: Spring 2017 (40 questions*)

3. PPIS-final version-

Summer 2017

(31 questions*)

Submitted to IRB

4. Pilot Survey: October 2017

5. PPIS to District A: December 2017 $\underline{\text { Characteristics }}$

- Review literature

- Obtained NGSS Readiness Survey (Haag and McGowen, 2015).

- Met with District A TOSA-brainstorm

- Initial drafting of items, NGSS Readiness Survey as the base: NGSS-Motivation; Certainty of Success

- Development of course sequence and views on physics first questions.

- Begin with demographics-include gender, educational attainment.

- $\quad$ PD-Science and Engineering practices-blended

- Demographics moved to the end of the survey

- Lead with best sequence/physics at $9^{\text {th }}$ grade

- Retrospective pre-post, NGSS Motivation and Success in engaging students in NGSS S\&E.

- Short response-How has workshop impacted NGSS science and engineering practices

- Short response-How has teaching impacted NGSS science and engineering practices

- Piloted multiple times with colleagues for feedback and logic testing.

- Combined motivation and confidence about success prepost into, how has your confidence changed.

- Short response items simplified

- Simplified demographics-removed gender, years of education

Modified for summer workshop participants (sent to 81 teachers), 26 questions ( $\mathrm{n}=24$ completed surveys)

Distributed to District A high school science teachers. (sent to 68 teachers), 31 questions ( $\mathrm{n}=32$ completed surveys)

* Due to logic items, participants do not respond to all questions.

\section{Change in confidence in engaging students in science and engineering. The}

following sub section is based on the two sets of multiple choice questions from the

NGSS Readiness Survey (Haag \& Megowan, 2015). The first set of questions was used 
to measure teacher perceptions of their motivation in teaching the NGSS practices and the second set was used to measure teacher perceptions of their success (or readiness) in teaching the NGSS practices. In PPIS v. 1, two of the NGSS Readiness survey sub-items were slightly modified to provide additional clarification. This sub-item: "How certain are you of success in: Constructing Explanations (for science) and Designing Solutions (for engineering)," was split into two individual questions to delineate a distinction between science practices and the engineering practices. This was needed because while there is much overlap between the science and engineering practices, there are indeed important distinct differences. Also, while teachers should be implementing both engineering and science activities in their science courses, there is no guarantee that this is in fact the case. Therefore, having distinct questions specific for engineering practices and for science practices provided the opportunity to elicit data relevant to each practice.

To determine whether District A teachers' motivation and readiness had changed since the implementation of Patterns Physics, a strategy known as the retrospective pretest was used. In this particular study, pre-test data was not possible to collect as the curriculum adoption intervention began years prior to the start of this study.

According to Allen and Nimon (2007), "a retrospective pre-test is a pre-test administered post-intervention, asking individuals to recall their behavior prior to an intervention" (p. 29). For example, in the case of the PPIS v.1, the question was arranged using the Post-Then model. Teachers were first asked to rate their current practice and then asked to rate their past practice: "Rate how certain you are about your success in engaging students in the following task." Teachers provided this rating for each of the ten 
science and engineering practices listed. The next item prompt then asked, "Think back to your teaching practice before you took the Patterns Physics workshop, rate how certain you were about your success in engaging students in the following task," in which teachers responded for each of the ten science and engineering practices. This allowed for a comparison between perceived current practice and perceived past practice.

The retrospective pre-test has been shown to be as effective as traditional pre-tests and post-tests in determining the impact of professional development (Allen \& Nimon, 2007; D’Eon, Sadownik, Harrison, \& Nation, 2008; Hoogstraten, 1982; Lam \& Bengo, 2003). Little, Chang, Gorrall, Waggenspack, \& Fukuda (in press) argued that the retrospective pre-test "design is ideally suited to minimize response shift bias and to capture person-level perceived change" and is preferred to the traditional pre-test, posttest when "quantifying person-level change in program evaluation research" (p. 27).

To simplify the survey and improve alignment of the items with the research questions, the Post-Then approach was replaced with the "perceived change" approach in the retrospective pre-test (Lam \& Bengo, 2003). In the perceived change approach, teachers were asked to estimate the degree of change directly versus answering two separate items as in the Post-Then approach (Lam \& Bengo, 2003). For the PPIS v. Final, the motivation and success items were combined into a new construct called 
"confidence," and the Post-Then approach was replaced with the perceived change approach to the retrospective pre-test (Figure 8).

Allen \& Nimon (2007) identified two issues with the retrospective pre-test approach regarding validity: the implicit theory of change (Ross, 1989) and impression management (Pearson, Ross, \& Dawes; 1992), also identified as “satisficing” (Lam \&

\section{PPIS v.1. NGSS Readiness}

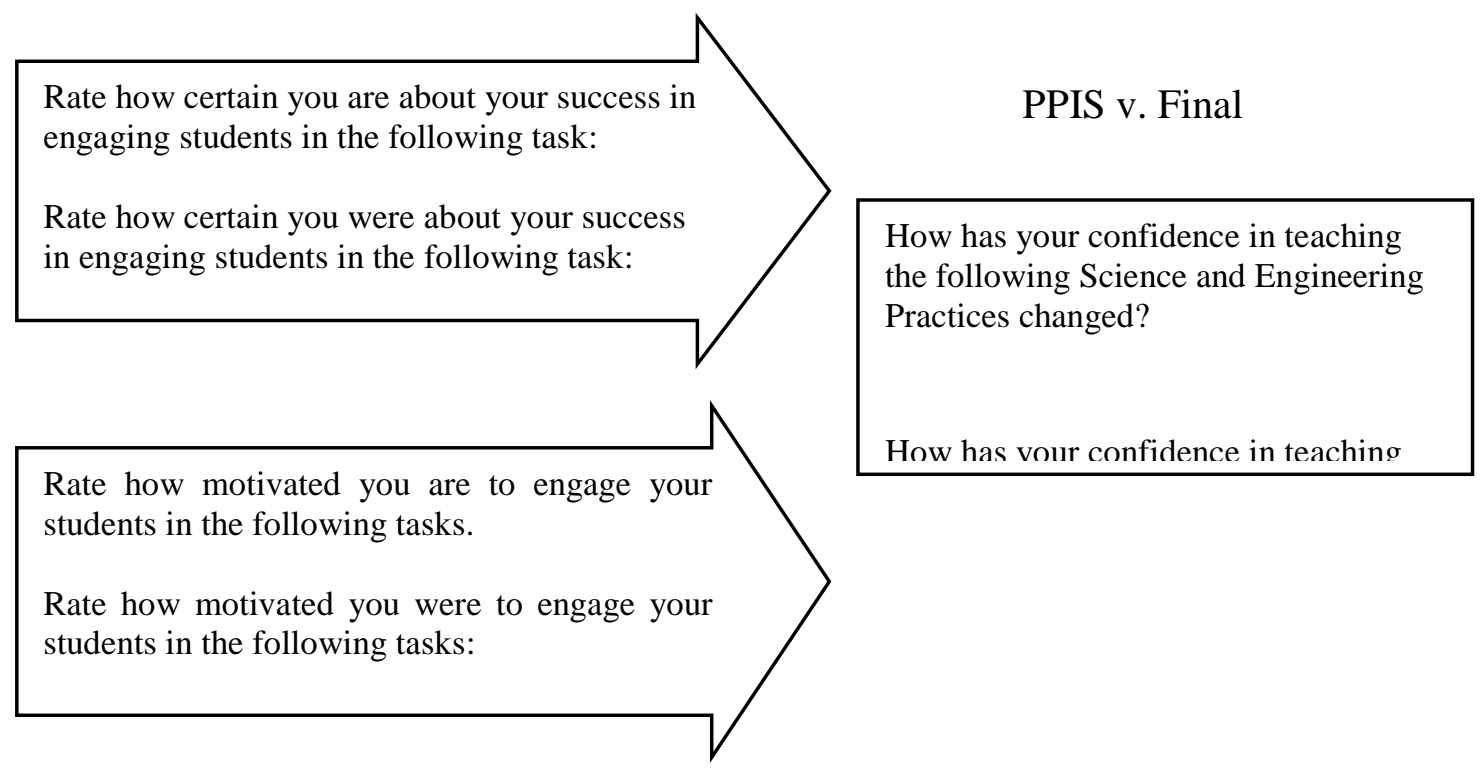

Figure 8. Integration of success and motivation items to confidence construct.

Bengo, 2003). Impression management and satisficing are the idea that respondents will respond in a manner intended to impress the survey giver or seek to provide socially desirable responses. In this study, impression management was likely minimized as respondents did not have a direct relationship to me or this study and participation was voluntary. 
Implicit theory of change is the concept that people apply biases when recalling past events. While these biases can't be avoided in this context, research indicates that the retrospective pre-test provides a more accurate measure than traditional pre-test, post-test arrangements. This is largely because participants may not have enough knowledge to accurately assess themselves prior to an intervention, and according to Allen, "tend to overstate their level of functioning" (p. 30). This difference due to an overstatement or understatement is called response shift bias (Allen \& Nimon, 2007).

Lam \& Bengo (2003) warned that that the perceived change approach can lead to a larger self-reported change in practice than the Post-Then approach, largely due to satisficing. Despite this potential threat, the perceived change approach was used for several reasons. First, the perceived change approach simplified the survey to be more manageable for participants. Second, the survey did not actually measure the change in confidence in response to a specific intervention. This is because participants responded based on their varied backgrounds and experiences that occurred since the PCB curriculum reform effort began in District A over a period of six years. Some of the teachers involved in this study were not involved in the reform effort over the entire sixyear period. Therefore, the instrument measured teachers perceived change in confidence since they began their own involvement with implementation of this new curriculum. In addition to the Likert items on the NGSS science and engineering practices, most teachers completed several short response items that addressed perceived change in practice. The short response style prompts provided respondents opportunities to describe the context to their responses to Likert-scale items. 
Third, participants' responses were used to compare teachers' perceptions to develop descriptions of patterns and themes found throughout the data sets. This approach controlled for individual biases found within the group. Finally, the retrospective pre-test approach was the only viable method to elicit teachers' perceptions related to change in practice given that this study took place years after the initial implementation of Pattern Physics in District A.

PD Impact and recommendations. The NGSS Readiness survey involved several items of limited scope regarding professional development. Therefore, several short response items were developed for the PPIS v1 contained in a single section. They were reorganized in the PPIS v. Final to better fit within relevant sections of the survey to improve the flow of the survey items. In the PPIS v. Final, teachers were asked a series of distinct questions that prompted them to describe experiences that were most impactful to their understanding of the NGSS science and engineering practices as well as make recommendations for future professional development.

Demographics. The demographics section in the NGSS Readiness survey were originally adopted in the PPIS v.1 and several others were added to address specific needs of this target group. This list of demographic items from the NGSS Readiness survey was modified in the PPIS v. Final by reducing the total number of items and adding a few items specific to this study (eg. What school do you teach in?). The goal was to only ask for demographic information that was germane to the study. Table 6 shows the demographic categories used in this study. 
Table 6

Demographics of District A Survey Participants

Building: School identifier A-F

Content Expertise: self-identified-physics, chemistry, biology, earth science, other

Career band: Early-career 2-5 years; Mid-career 6-19 years; Late-career 20+ years

Courses taught:

Patterns Physics, Patterns other (Patterns Chemistry or Biology), Other

Follow-up Interviews. Morgan (2014) described using both quantitative and qualitative methods to inform a research question as an effective way to address triangulation — having multiple viewpoints to address the research question — to provide a stronger base of evidence to support conclusions. I followed Morgan's advice and applied each method independently and conducted analysis of results from each instrument independently first before triangulating data so that one method did not influence another.

The semi-structured interview protocol (Appendix B) was used with nine interview participants. Table 7 describes which interview questions were designed to elicit data to inform each research question. These follow-up interviews questions were explicitly designed to elicit data to develop a more in-depth, nuanced description of participants' perceptions than that provided by the survey alone (Morgan, 2014). 
Table 7

PPIS Survey items and interview items utilized for each research question

Category

Demographics

Research Question 1:

To what extent have the PD and teaching experiences affected teacher confidence in engaging students in the practices of science and engineering?

Research Question 2:

Which aspects of PD and experience have made the greatest difference in teachers' self-reported changes in their practices?

Research Question 3:

How have the PD and teaching experiences impacted teachers' perceptions of the value of physics first?
Survey Items and Interview Questions

Descriptive: $2.1-2.5,2.10 ; 5.1-5.5$

Interview Question: 1

Likert: 3.2-3.4

Short response: 4.1-4.3

Interview Questions: 3-5
Short response: $4.1-4.3$

Interview Questions: 6-8

Likert: 2.13

Short response: $2.6-2.9 ; 2.12,2.14-2.15$

Interview Questions: 2, 9-11

\section{Role of the Researcher}

I bring to this project a background of over twenty-five years of experience as a high school science educator with a curricular focus on physics and chemistry. I have participated in many professional development activities and workshops as a participant and as a facilitator. In addition, I have presented and facilitated workshops at many conferences with a focus on physics and engineering for K12 teachers throughout my career.

Although I do not teach in District A, I have been involved with Patterns Physics for several years beginning by taking the one-week Patterns Physics summer workshop during June of 2014 with two of my school colleagues. Since then, I have been one of three-to-four teachers in my high school teaching Patterns Physics as a $9^{\text {th }}$ grade science 
course and facilitated or co-facilitated several one-day or half-day Patterns Physics summer workshops.

Due to my experiences, I brought a unique perspective and potential bias to this study. It is in fact my involvement with Patterns Physics that drove my interest in conducting this piece of dissertation research. I was very curious to learn of others' experiences and interested in conducting research useful for improving the Patterns Physics curriculum and professional development workshops, as well as to learn about what factors support teacher change.

To mitigate bias or conflict of interest, I conducted this research with participants outside of my working environment, the high school science teachers in District A. I did not have any working knowledge of most of these science teachers, including their background experience or beliefs about Patterns Physics. To minimize selection bias, the survey instrument was sent to all science teachers in District A (six comprehensive high schools) to obtain as large a cross-section of these teachers as possible. The Patterns Physics Impact Survey was anonymous; therefore, I had no knowledge of individual responses. There was an optional demographic survey question that asked respondents to provide the name of the school they taught in, however, given that multiple teachers from each school responded to the survey I had no way of linking survey responses to individuals.

Regarding the interviews, "the aim of the interview... is to minimize the impact of the interviewer on what the respondent says" (Krathwohl, 2009, p. 306). While I brought my own lens and experience to each interview, my goal was to elicit authentic responses 
from the interviewees. To support this, the semi-structured interview protocol was used to guide the interview. The interviews were digitally audio recorded and I took hand-written notes throughout each conversation. The recordings were transcribed and then initially analyzed using Atlas.ti. (Creswell, 2014). No actual names were used in the transcriptions. Interviewees were given a codename for the recordings, Atlas.ti files, and printed transcripts.

To check my coding and analysis procedures, I met several times with a member of my committee, Cary Sneider, Ph.D., and separately with my dissertation writing instructor Joanne Cooper, Ph.D., and former colleague Jennifer Wells, Ed.D. In those consultations I received guidance and clarifications about my techniques and analysis. While I am aware that I bring potential bias to this study, these consultations supported my best efforts to accurately code and analyze the qualitative data and to minimize the bias I brought to this study.

\section{Data collection and Analysis}

In this next section, I describe how data was collected and analyzed.

Data Collection. As mentioned above, data collection was conducted in two phases. Phase one involved the use of the Patterns Physics Impact Survey. The survey participant group involved all science teachers who taught in one of the six of the large comprehensive high schools in District A. The Science Teacher on Special Assignment (TOSA) provided a preliminary email list that I cross referenced against each school's website to ensure that all eligible teachers were contacted. 
Participants completed the survey using their preferred device, which could have been a computer, digital tablet, or smartphone. This method of data collection was appropriate given that the teachers were geographically dispersed in six different schools and the web based format allowed teachers to complete the survey at their convenience over a two-week period (Sue \& Ritter, 2012).

Sue and Ritter (2012) identified several potentially problematic issues with online surveys; coverage bias, the reliance on technology, and that desired respondents may not participate due to instrument fatigue or overload (i.e., being asked to participate in too many surveys). Archer (2008) reported that response rates for online surveys related to workshop evaluations, needs assessments, and impact evaluation range from 39\%-57\%. Prior to recruiting participants, a district TOSA estimated that I could expect a response rate of about $20 \%$.

To maximize the number of teachers involved in this study, I personally recruited teachers by providing a presentation that described the planned study and asked them to participate during science department meetings at five of the six high schools. A District A TOSA, acting as a proxy, provided the participant recruitment presentation at the sixth high school. This pre-scripted recruitment presentation argued that this study would provide teachers with opportunities to reflective on their perceptions about the professional development and implementation of Pattern Physics in their schools and that themes and patterns that emerged from these data would be of value to participants themselves and to school decision makers within and beyond District A and not simply to me as a dissertation researcher. 
Coverage bias, in which the targeted respondents are not representative of the population (Sue \& Ritter, 2012), was difficult to address since individual participant locations were not known until after the survey was completed and only if the teacher volunteered to provide their teaching location (an optional survey item). The effort to involve as many District A high school science teachers as possible was meant to increase the quality of the sample and to minimize coverage bias. The survey was open for two full weeks; reminders were sent to non-completers at the conclusion of the first week and a day before the survey closed. Again, the Qualtrics platform allowed the PPIS to be completed either on a computer or mobile device providing for maximum convenience to reduce coverage bias.

Data Analysis. This case study utilized both quantitative and qualitative analysis techniques to inform the research questions. Phase one of this study, the Patterns Physics Impact Survey, involved both quantitative and qualitative items. The semi-structured interviews conducted in phase two of this study produced qualitative data and the twostep coding process allowed for both quantitative and qualitative data analysis.

To explain the data analysis procedures for this study, I will first describe the procedures used to analyze the Patterns Physics Impact Survey (PPIS) followed by the procedures used to code and analyze the semi-structured interviews. For quantitative analyses, SPSS version 25 was used to conduct descriptive statistical analysis using ttests and chi-square. The qualitative analyses of survey items were done by copying responses into a Google Sheet and organized by question and participant number. Coding was done within the Google Sheet by adding columns for each round of coding. Google 
Sheets was then used to organize themes and codes for further analysis. (Creswell, 2014). Atlas.ti was used for the initial coding and theme development of the interviews. Printed transcripts and Google Sheets were also used for additional coding, organization and analyses of the data.

Table 8 depicts the PPIS item numbers, interview protocol question number, and analysis technique organized by each research question. This table shows that each research question was inform from both the survey and the interview data sets. Research question one and three were informed by both qualitative and quantitative data.

Table 8

PPIS Survey and interview items utilized for each research question and description of analysis technique

\begin{tabular}{lcc}
\hline Category & $\begin{array}{c}\text { Survey Items and } \\
\text { Interview Questions }\end{array}$ & Data Analysis \\
\hline
\end{tabular}

Demographics

Research Question 1

To what extent have the PD and teaching experiences affected teacher confidence in engaging students in the practices of science and engineering?

Research Question 2

Which aspects of PD and experience have made the greatest difference in teachers' self-reported changes in their practices?

Research Question 3

How have the PD and teaching experiences impacted teachers' perceptions of the physics first?

Descriptive: $2.1-2.5,2.10 ; 5.1-5.5 \quad$ Descriptive Statistics

Interview Question: 1

Likert: $3.2-3.4$

Short response: 4.1-4.3

Interview Questions: 3-5

Short response: 4.1-4.3

Interview Questions: 6-8

Likert: 2.13

Short response:

2.6-2.9; 2.12, 2.14-2.15

Interview Questions: 2, 9-11
Descriptive Statistics, t-test Focused coding

Focused coding

Focused coding

Focused coding

Descriptive Statistics, Chi-square

Focused coding

Focused coding 
Two important criteria in assessing the quality of a case study design are construct validity and reliability (Yin, 2014). Construct validity is "identifying correct operational measures for the concepts being studied" (p. 46). In this study, the PPIS went through several review processes and a pilot test to verify construct validity. Additional strategies to address validity were used as recommended by Creswell (2014). These involved using data from multiple sources to triangulate the data, providing "rich, thick description to convey the findings" (p. 201) and clarifying the bias the researcher brings to the study. Here, Figure 9 depicts the approach used for qualitative data analysis in this study.

Raw Data (short answer/survey)

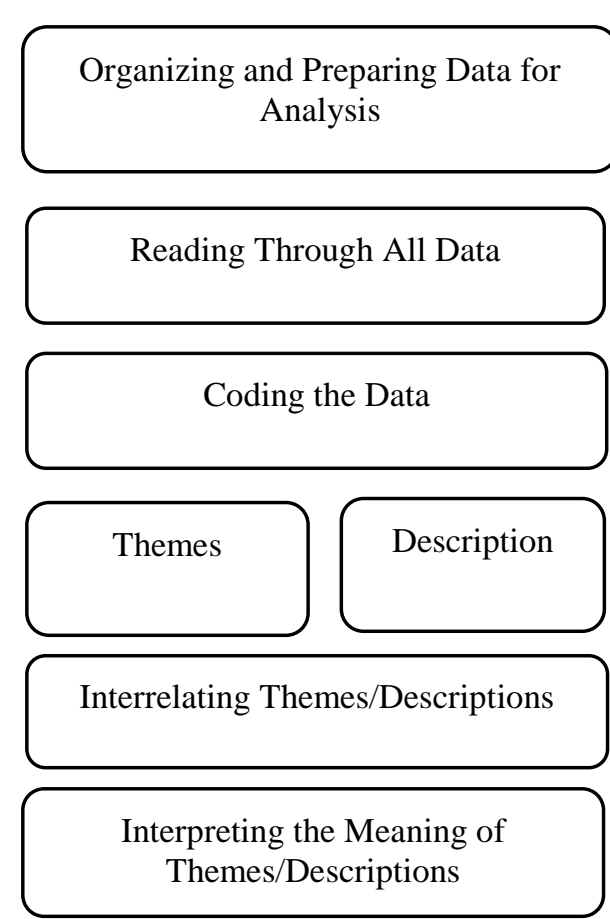

Figure 9. Data analysis process (Creswell, 2014, p. 195) 
Phase One: PPIS. The PPIS provided several opportunities for quantitative analysis using two descriptive statistics tools, a t-test and chi-square. Demographic data were used to structure the analyses to see if there were differences between groups; the demographic categories are shown in Table 9. The PPIS consisted of four sections: Physics First and Patterns Physics, NGSS Science and Engineering Practices, Professional Development and Demographics. Descriptive statistics were used to determine the distribution of teachers across school buildings, content expertise and career-band (based on years of teaching), courses taught, and type of workshop(s) taken.

The first items of the survey elicited teachers' views of the best science course sequence for high school. This involved collection of quantitative and qualitative data. Teachers chose from several multiple-choice options (quantitative data) and then provided their reasoning to further explain their response (qualitative data). Descriptive statistics were used to show the range of responses.

A chi-square analysis was done to compare demographic groups to see whether there were any statistically significant differences between groups. The chi-square test compares the frequency of responses and determines whether there is a statistically significant relationship between categorical variables (Field, 2009). The qualitative data was not coded but shown in-vivo as the number and type of responses were clear to understand and interpret.

The next quantitative survey items were about the qualities of the $9^{\text {th }}$ grade Patterns Physics course. Teachers responded to several prompts with agree, disagree, and no opinion. These items were treated as categorical variables; the chi-square test was 
used to determine if there was any relationship between responses and the demographic traits. Teachers also responded to several open-ended, short-response items that provided key qualitative data useful for providing context critical for correctly interpreting meaning.

Table 9

Demographic Categories of District A Survey Participants

Building: School identifier A-F

Content Expertise: self-identified-physics, chemistry, biology, earth science, other

Career band: Early-career 2-5 years; Mid-career 6-19 years; Late-career 20+ years

Courses taught: Patterns Physics, Patterns other (Chemistry or Biology), Other

Workshop attended

Hours of PD outside of district

The next group of questions in the PPIS addressed teachers' confidence in teaching the NGSS science and engineering practices. There were ten survey items that used a Likert scale response pattern ( $5=$ Greatly improved to $1=$ less confident). These items were modified to be a retrospective pre-test using the perceived change model approach. Descriptive statistics were used to determine the mean and standard deviation for all of the participants' responses to these items. An independent t-test was done to compare scores of Patterns Physics teachers with those who did not teach Patterns Physics. A dependent t-test was done to analyze responses from five teachers that taught both Patterns Physics and one or more Patterns-Other course (i.e., Patterns Chemistry and Patterns Biology. All short response items were downloaded into a Google 
spreadsheet and coded using Saldana's two-cycle coding approach. These results were then compiled, triangulated and reported.

Phase Two: Interview Analysis. Interview transcripts were uploaded into Atlas.ti and four interviews were initially analyzed using in-vivo and open coding. Invivo coding directly copies a word or phrase from the qualitative data (Saldaña, 2009) and is particularly important when the intent is to "honor the participant's voice" (p. 74). Open coding in Atlas.ti allowed any code to be assigned to the text. Saldaña (2009) referred to this step of the coding technique as initial coding. The second cycle coding method was focused coding (Saldaña, 2009), which is "the development of major categories or themes from the data" (p. 155). I developed 150 initial codes that were placed into 11 categories as a result of focused coding. At that point, I switched from Atlas.ti to a Google spreadsheet where I created a table based on the 11 categories. This format allowed me to more easily view, organize and manipulate the data (Appendix $H$ ). Saldaña (2009) explained that coding is a cyclical act. In other words, the coding process involves multiple iterations of coding and analysis. After the initial coding with Atlas.ti, I printed the five remaining transcripts and coded those based on the initial categories. I was able to type codes or cut/paste codes from a digital copy of each transcript into the spreadsheet. I found that coding the printed transcript gave me a better connection to the narrative of each interview and that it was easier to organize notes and memos as they could be easily written on the hard copy of the transcript or researcher $\log$. 
The transcripts originally coded with Atlas.ti were reviewed to be sure that all applicable information was obtained. Krathwohl (2009) recommended organizing data in tables or matrices to organize data, find relationships, and eliminate alternative hypotheses (p. 329). With the organizational structure in place, all interviews were reread with codes entered onto the spreadsheet. The transcripts were reviewed several times with the goal recording all relevant data. One category was called "other" to collect data that did not fit into a distinct category but was deemed relevant to the study.

The resulting spreadsheet was used to look for patterns in the data that led to the development of themes. The initial 11 categories were reduced to seven, which resulted in the development of five themes. These themes, and the underlying codes, were then used to inform the research questions.

\section{Summary}

In chapter three I began by introducing my research proposal and presenting my research questions. This was followed by a presentation of research methods in which I explained my reasoning for approaching this research project as a case study. I provided information about the participants for my study, my procedures, and measurement instruments. The Patterns Physics Impact Survey can be found in Appendix A and the semi-structured interview questions can be found in Appendix B. I concluded with an explanation of the data collection and data analysis procedures. In chapter four, I discuss the results and analysis from phase one and phase two of this study and then provide the findings from this study. I conclude with a discussion of the limitations of the study and a summary. 


\section{Chapter 4: Results}

The purpose of this study was to examine the impact of the implementation of Patterns Physics on teacher practice and beliefs about science teaching at the high school level. Two focus questions that influenced this study were: 1) How does this new approach facilitate teacher classroom practices and beliefs? 2) Is this approach congruent with those expressed in A Framework for K-12 Science Education (NRC, 2012) and Next Generation Science Standards (NGSS Lead States, 2013)?

This case study examined high school science teachers from District A, a district in which the Patterns Physics curriculum was initially developed and implemented at the $9^{\text {th }}$ grade level in the 2012-2013 school year. This study participants were chosen due to their unique position of being part of the development of the Patterns curricula as well as being first adopters. Another key reason for this selection is that there has been a significant investment in making the initiative work in District A. The district has funded teachers on special assignment (TOSAs) to organize and lead professional development, TOSAs have worked to improve the curriculum based on teacher feedback and resources and teachers have extensively collaborated to invest time and effort to implement and improve this initiative over time.

Compared with other large Physics First initiatives, this one was developed and supported by internal efforts within District A. This was not an initiative coming into the district from an outside, third-party entity such as has been the case in San Diego, California and in the state of Rhode Island. 
In addition, compared with other smaller Physics First initiatives that were developed within schools by an individual or small number of teachers, this initiative has been implemented district-wide with significant support and resources provided to support all teachers involved in the initiative. These reasons make the Patterns initiative in District A unique and worthy of study.

As mentioned above, data were collected in two phases. In phase one, a survey was completed by 32 high school science teachers in District A (participation rate=47\%). In phase two, nine high school science teachers in District A who took the survey and volunteered to be interviewed participated in a 30-45 minutes individual interview (28\% of survey respondents; $13 \%$ of teachers invited to participate).

In this chapter, I will first discuss the results and analysis from the first phase of the study, the Patterns Physics Impact Survey (PPIS), followed by a presentation of the findings from phase one. Next, I will present the results and analysis of the second phase, the interviews with nine District A science teachers, followed by the findings from phase two.

\section{Results and Analysis}

\section{Phase One: Patterns Physics Impact Survey}

Inspired by the NGSS Readiness Survey (Haag \& Megowan, 2015), the Patterns Physics Impact Survey (Appendix A) was developed to investigate the impact of this Physics First initiative on teachers' views of this instructional approach. In addition, this study sought to elicit teachers' perceptions of impact of the Patterns curriculum on teachers' confidence in implementing the NGSS science and engineering practices. 
Finally, this survey sought to elicit data concerning teachers' views and experiences about professional development associated with this educational reform effort.

The Patterns Physics Impact Survey (PPIS) was distributed to high school science teachers in District A via an email containing the invitation with a link to the web-based survey. The email was sent after I, or a proxy (I met with five schools and a proxy met with one school), met with each school's science department to introduce the study, answer questions, and invite teachers to participate by completing the survey and participating in an individual interview. The formal invitation for participating in the interviews was placed at the end of the survey. Interested teachers opted into the interview and provided their contact information in the survey. The survey was anonymous except for the teachers who opted in to be interviewed at a later date.

The survey instrument is comprised of four main sections outlined in Table 10: Demographics, Physics First and Patterns Physics, the NGSS Science and Engineering Practices, and Professional Development. Specific survey item numbers are listed in the table. The next section outlines the demographics of the participants.

Table 10

PPIS Items Per Topic

\begin{tabular}{ll}
\hline \multicolumn{1}{c}{ Topic } & $\underline{\underline{\text { Item Numbers }}}$ \\
Demographics & $2.1-2.3 ; 5.1-5.5$ \\
Physics First and Patterns Physics & $2.4-2.15$ \\
NGSS Science and Engineering Practices & $3.2-3.4 ; 4.1-3$ \\
Professional Development & $4.1-4.3$ \\
\hline
\end{tabular}


Demographics of District A Survey Participants. For this study, I used the following information to define different characteristics of the participant recruitment sample:

- Building: The teachers' school identifier, 6 different schools, labeled A-F;

- Content expertise: Teachers self-identified their area(s) of content expertise: physics, chemistry, biology, earth science, other;

- Career band: Teachers indicated how many years they had been teaching, which was categorized as follows: early-career $=$ two to five years (there were no first-year teachers in the sample) of science teaching experience, mid-career $=$ six-nineteen years of experience, and late-career $=$ twenty-plus years of experience;

- Courses taught: Teachers identified which high school science courses they taught and categorized as follows: Patterns Physics, Patterns Other (either Patterns Biology or Patterns Chemistry); and Other (all other science courses).

As shown in Table 11, thirty-two District A high school science teachers completed the survey. At least two participants from each school participated and three participants did not identify a school (this item was optional). The science department in each school employed a range of six-to-fourteen teachers. Respondents self-identified their areas of science content expertise. Twenty-four teachers indicated expertise in physics; 17 in chemistry, 20 in biology, eight in earth science and six in other (this could be any other science content area). Respondents could choose more than one response. 
Table 11 also depicts the number of teachers in each career band. Sixteen (50\%) participants were mid-career teachers, eight (25\%) were late career teachers, and seven (22\%) were early-early career teachers with two-to-five years of experience. One respondent $(3 \%)$ did not indicate their years of experience teaching science.

Table 11

Survey Respondents

\begin{tabular}{|c|c|c|c|c|c|c|}
\hline Building & $\begin{array}{c}\text { Number of } \\
\text { Respondents }\end{array}$ & $\begin{array}{c}\text { Content } \\
\text { Expertise* }\end{array}$ & $\begin{array}{l}\text { Number of } \\
\text { Responses }\end{array}$ & $\begin{array}{c}\text { Career } \\
\text { Band }\end{array}$ & $\begin{array}{c}\text { Number of } \\
\text { Respondents }\end{array}$ & $\underline{\text { Percent }}$ \\
\hline A & 3 & Physics & 24 & $\begin{array}{c}\text { Early (2- } \\
5)\end{array}$ & 7 & $22 \%$ \\
\hline B & 5 & Chemistry & 17 & $\begin{array}{l}\text { Mid (6- } \\
19)\end{array}$ & 16 & $50 \%$ \\
\hline $\mathrm{C}$ & 7 & Biology & 20 & $\begin{array}{l}\text { Late } \\
(20+)\end{array}$ & 8 & $25 \%$ \\
\hline $\mathrm{D}$ & 5 & Earth Science & 8 & $\begin{array}{c}\text { Not } \\
\text { indicated }\end{array}$ & 1 & $3 \%$ \\
\hline $\mathrm{E}$ & 2 & Other & 6 & & & \\
\hline $\mathrm{F}$ & 7 & & & & & \\
\hline $\begin{array}{c}\text { Not } \\
\text { indicated }\end{array}$ & 3 & & & & & \\
\hline Total & 32 & & & Total & 32 & 100 \\
\hline
\end{tabular}

*Self-identified content areas of expertise; participants could choose more than one content area.

Table 12 depicts the science courses that each of the teachers taught and which Patterns professional development workshop(s) they attended. There are three Patterns workshops available: Patterns Physics, Patterns Biology, and Patterns Chemistry. These workshops were typically offered during the summer months. The date at which each 
teacher participated in the workshop was not collected but could have occurred at any point over the past six years.

At the time that the survey was administered (2017), 19 teachers taught Patterns Physics, 10 teachers taught either Patterns Biology or Patterns Chemistry, and three teachers taught science courses other than Patterns Biology, Patterns Chemistry, or Patterns Physics. In addition, the type of Patterns training-Patterns Physics, Patterns Chemistry, and Patterns Biology is listed. Since this study focused on teachers' perceptions related to Patterns Physics, I combined the Patterns Chemistry and Patterns Biology categories into a category called Patterns Other.

In total, 25 of the 32 study participants who completed the survey had participated in the Patterns Physics Workshop. Of that total number of survey respondents, 14 had participated in the Patterns Physics Workshop alone while 11 respondents had participated in both Patterns Physics and in either or both of the Patterns Chemistry and Patterns Biology workshops.

At the time of the survey, 14 of the 19 Patterns Physics teachers had only participated in the Patterns Physics workshop. In other words, 14 of the 19 teachers had not participated in a Patterns Chemistry or Patterns Biology workshop.

As indicated in Table 12, of those teaching Patterns Physics, twelve indicated that they used $80-100 \%$ of the curriculum, two used $60-79 \%$ of the curriculum, and four used $40-59 \%$ of the curriculum. One teacher did not indicate the percentage of the curriculum used in his or her courses. 
Table 12

Survey Teachers' Course Assignments and Workshop Attendance

\begin{tabular}{lcclcc}
\hline \multicolumn{1}{c}{ Courses Taught } & \multicolumn{5}{l}{ Workshop Attendance } \\
\hline & $\underline{\text { Number }}$ & $\underline{\text { Percent }}$ & & $\underline{\text { Number }}$ & $\underline{\text { Percent }}$ \\
$\begin{array}{l}\text { Patterns } \\
\text { Physics* }\end{array}$ & 19 & $59 \%$ & Patterns Physics Only & 14 & $44 \%$ \\
Patterns Other & 10 & $31 \%$ & $\begin{array}{l}\text { Patterns Physics and Patterns } \\
\text { Other }\end{array}$ & 11 & $34 \%$ \\
Other & 3 & $10 \%$ & Patterns Other & 6 & $19 \%$ \\
& & & None & 1 & $3 \%$ \\
Total & 32 & $100 \%$ & Total Workshops & 32 & $100 \%$ \\
& & & Total Patterns Physics & 25 & $78 \%$ \\
\hline
\end{tabular}

*Of the Patterns Physics teachers, twelve used $80-100 \%$ of the curriculum, two used $60-79 \%$ of the curriculum, four used $40-59 \%$ of the curriculum, and one is unknown.

Another component of this study was to investigate the impact of professional development on teachers' practice. One of the survey questions inquired about the amount of professional development each teacher had participated in over the past two years that was outside of the regular school district professional development activities. Of the 32 respondents, 25 (78\%) responded "yes" to additional professional development outside of the school district, and seven responded "no" (22\%). There were 23 "yes" respondents that estimated the number of hours of PD they had participated in. While there were six outliers with 100+ hours, the mean number of hours of PD, not including the outliers, was 32 hours with a standard deviation of 16 hours.

While the purpose or structure (e.g. one summer workshop for 32 hours, or four 8-hour sessions throughout the school year) was not indicated, a majority of teachers were pursuing PD outside of opportunities provided by their district. Again, due to the 
survey design, respondents provided data for two-years of PD. To give some context to these numbers, in a national sample of K12 teachers, over a 12 -month period $26 \%$ of teachers participate in 33 or more hours of PD in their content area and 53\% participate in 9-33 hours, and the remaining 21\% with 0-8 hours (which may include PD offered by the districts) (NCES, 2012). Compared to the national sample indicating the number of PD hours taken in one-year, District A teachers likely partake in more PD than the average teacher in the national sample, particularly since the District A teachers did not include in-district provided PD in their estimates.

\section{Survey item analysis}

The demographic data provided context as to some of the qualities of the participants who took the Patterns Physics Impact Survey (PPIS). Here, I will address analysis of each section of the survey-Physics First and Patterns Physics, NGSS Science and Engineering Practices, and Professional Development.

Recall that the first set of survey items addressed teachers' views on Patterns Physics and Physics First. The second set addressed teachers' views and self-reported changes in confidence in engaging students in the NGSS Science and Engineering Practices. The third section addressed teachers' views about what professional development and teaching experiences where most impactful to their understanding and/or instruction of the NGSS science and engineering practices.

Patterns Physics and Physics First. Teachers were asked the following: For a variety of reasons, high schools across the United States offer different science sequences. Based on your experience, which of the following high school science 
sequences is best for students to learn science? The answers to this question can be found in Figure 10. The most common response was the PCB sequence, with 19 (59\%). The next most common response was both "the sequence does not matter" and "other," with 5 (15.6\%) responses each. Only three $(9.4 \%)$ respondents indicated a preference for the BCP sequence.

Respondents were asked to provide a brief explanation for their choice. Here, I present Figure 10 that provides a summary of these responses for each of the sequence options, followed by a brief summary of the reasoning.

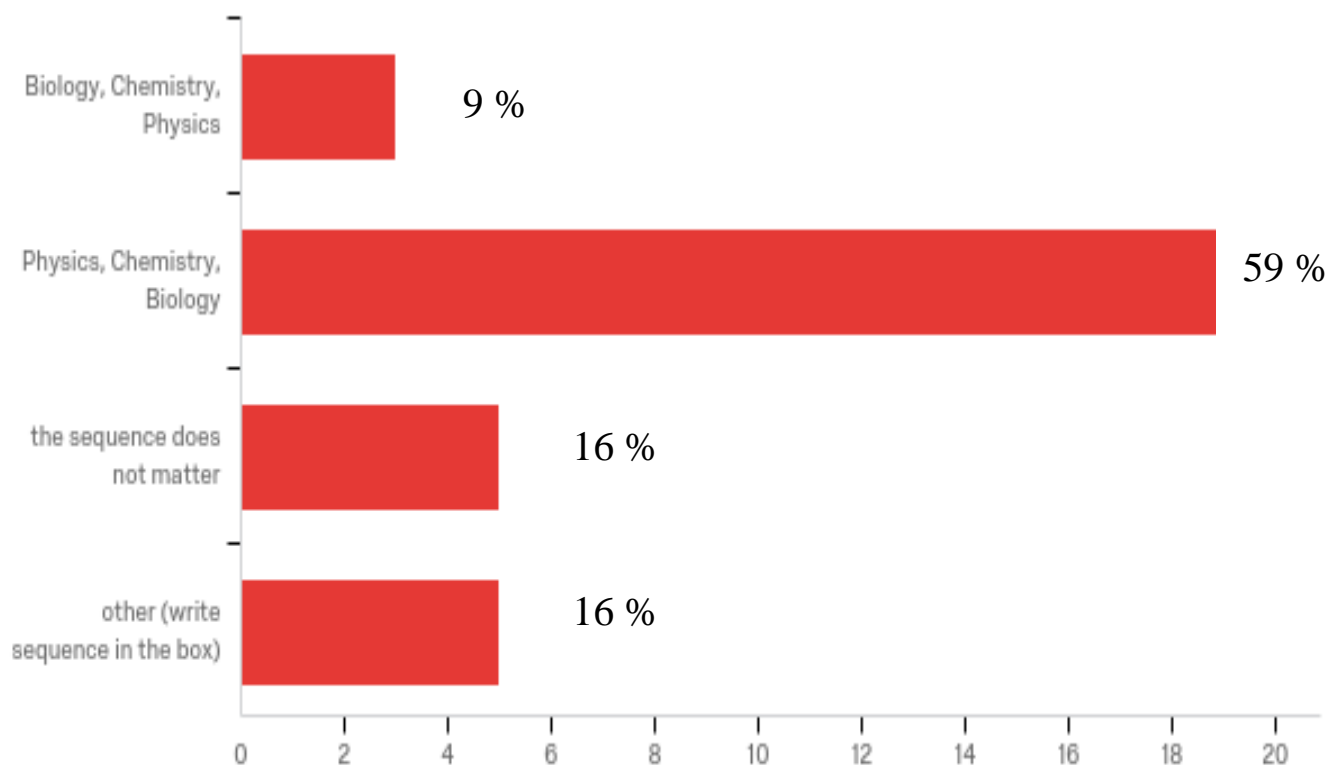

Figure 10. Preferred Course Sequence 
Other sequence: For those who answered “other," responses included:

- Integrated, bio, chem, physics but wish it weren't so;

- I think developmental readiness is most important. I would like to see $9^{\text {th }}$ grade; physics students choose Bio or chem. I see some students who could take STEM chemistry if they waited until Junior year;

- As always, it's more about how it is done than the order. There are benefits to both...I personally miss our Integrated Science where students got a bit of each subject through their sophomore year;

- Earth Space Science, Biology, Chemistry, Physics (optional);

- Physical science, chemistry, biology, physics.

To summarize these choices, two respondents preferred an integrated approach at the $9^{\text {th }}$ grade level and one respondent preferred a physical science class at the $9^{\text {th }}$ grade level; which indicates that these teachers believe that some physics content is appropriate at the $9^{\text {th }}$ grade level. Three of the respondents listed physics as a fourth-year course, which would be optional for students in this setting due to the state requirement for only three years of science. Two of the respondents provided reasoning that the developmental readiness of the student or how the class is taught is more important than the subject matter of the course.

DNM sequence: For those who answered, "the sequence did not matter," there were four relevant responses:

- I think that as long as students are receiving information on how to collect and analyze data and apply it to patterns, it doesn't matter which science sequence students take;

- I just feel that I cannot really state that learning science is sequence dependent. A good science course will stimulate student minds and make them want to engage in inquiry no matter where they start. I think that logically physics makes the most sense, but not all students base their learning off of the physics foundation of content knowledge;

- Different interests should be allowed to explore the sciences at their own pace and order of choice. I do not believe that biology requires chemistry and 
physics as prerequisites; I do believe that whatever course is tailored for freshmen will be of far lesser rigor in terms of math and complexity.

- Students should be able to take classes in whatever order they choose, perhaps trying out their first interest. If we want to get more kids interested in science, we need to provide high interest electives.

These responses can be broken down into two categories of reasoning. First is the idea that a good science course that engages students in scientific practices is independent of content. Second is the idea that students should be able to choose a course based on the student's interests.

BCP sequence: For those who answered "Biology, Chemistry, Physics" as the preferred course sequence, their reasoning was:

- I have noticed that an integrated approach worked best. For physical science, the ISP program seemed the most beneficial. I have found that physics first has dramatically decreased the interest in science for students who are borderline or struggle, rather than increase as promised;

- Biology isn't as math intensive and should theoretically be easier for 9th graders to do, especially if they've had biology content in middle school. Chemistry is the next most technical course and is at sophomore level. Physics is the most mathintensive and should be taken later.

One respondent mentioned the Integrated Science Program (that involves units on Biology, Chemistry and Physics in a one-year course) as the preferred sequence. Two respondents reported that since adopting Patterns Physics, they have observed a decrease in science interest amongst students who struggle in science. The second respondent indicated that math is a barrier for ninth grade students and therefore biology is "easier for ninth graders to do."

PCB sequence. For those respondents who answered "Physics, Chemistry, Biology," there were 17 comments regarding PCB sequence. The most common reasoning was that 
the sequence matters, as in physics prepares students for chemistry, and then physics and chemistry prepare students for biology (ideas referenced in eight of the 17 responses).

The second most common response was that a physics course is appropriate in that it allows for hands-on, macroscopic activities that allow students to engage in scientific inquiry and engineering. One teacher indicated that these qualities made physics less abstract and more accessible to English as a Second Language students than other science content areas.

Several related teacher responses are listed here:

- Patterns physics is a great introductory course for freshmen. They learn the basics of high school science including inquiry and engineering design. They are taught to use data to make informed predictions, and they learn in the style of write claim evidence, reasoning. Chemistry continues improving these skills. By teaching chemistry before biology, students are able to understand the phenomenon we experience in more detail because they have already studied molecular properties and interactions. Biology is the ideal course to combine the three areas of high school science. At the junior year, the biology course can include more depth and detail because physics and chemistry have already been taught.

- When implemented correctly, and with full buy-in from faculty, physics provides a strong foundation for chemistry, which in turn supports biology. Students should be able to engage in deeper meaning-building in biology (and chemistry) if they already have this foundation. Algebra-based physics offers more opportunities for students to really confront their preconceptions about how the world works and understanding how to recognize and use patterns in nature can lead to a deeper understanding of further science disciplines. It makes sense to start with physics, because most of what we study in 9th grade is macroscopic and topics students deal with on a daily basis (motion, forces, energy). Plus, it sets students up to take even more advanced physics, but I'm a physics teacher, so...

- Physics provides hands-on, visible and "feelable" experiences with nature that students can easily relate to and allows them to strengthen their basic algebra skills within the context of their science studies. Chem[istry] is invisible, harder to conceptualize, and Biology requires keeping track of multiple, interdependent systems with a lot of memorization. 
To expand on the question of which science sequence was best, a follow-up question asked whether teachers had changed their opinion since they had started teaching, and if so, why. Seventeen respondents (53\%) had changed their opinon of the best science course sequence over their teaching careers. From that list, 12 had originally thought that the BCP sequence was best with nine now preferring the PCB sequence and three said that the sequence does not matter. Only one teacher indicated changing from an initial view that the PCB sequence was best to "other," where they identify a preferred sequence to be integrated science at $9^{\text {th }}$ grade, followed by chemistry, biology, and then physics.

Table 13 depicts the choice for Best Sequence in the categories Teaching Location and teaching Experience Career Band. A chi-square analysis was done to see if there were any significant differences between responses and the school in which they taught (Teaching Location) and their years of teaching experience (Career Band). The analysis shows that there were no significant differences in responses based on teaching location $\left(\chi^{2}(18, N=32)=11.1, p=.89\right.$.) or years of experience $\left(\chi^{2}(9, N=32)=\right.$ $11.9, p=.22)$ 
Table 13

Best Sequence Choices by Location and Experience

\begin{tabular}{|c|c|c|c|c|c|c|}
\hline \multirow[b]{3}{*}{ Teaching Location-coded* } & \multirow[b]{3}{*}{ Not indicated } & \multicolumn{4}{|c|}{ Best Sequence } & \multirow[b]{2}{*}{$\underline{\text { Total }}$} \\
\hline & & $\underline{\mathrm{BCP}}$ & $\underline{\mathrm{DNM}}$ & $\underline{\text { Other }}$ & $\underline{\mathrm{PCB}}$ & \\
\hline & & 0 & 0 & 1 & 2 & 3 \\
\hline \multirow[t]{7}{*}{ (School) } & $\mathrm{A}$ & 0 & 1 & 0 & 2 & 3 \\
\hline & $\mathrm{B}$ & 0 & 0 & 1 & 4 & 5 \\
\hline & $\mathrm{C}$ & 1 & 1 & 0 & 5 & 7 \\
\hline & $\mathrm{D}$ & 1 & 1 & 1 & 2 & 5 \\
\hline & $\mathrm{E}$ & 0 & 0 & 0 & 2 & 2 \\
\hline & $\mathrm{F}$ & 1 & 2 & 2 & 2 & 7 \\
\hline & Total & 3 & 5 & 5 & 19 & 32 \\
\hline \multirow{5}{*}{$\begin{array}{l}\text { Teaching Experience** } \\
\text { (Career Band) }\end{array}$} & Not indicated & 0 & 0 & 1 & 0 & 1 \\
\hline & Early (2-5) & 0 & 1 & 2 & 4 & 7 \\
\hline & Late $(20+)$ & 1 & 2 & 2 & 3 & 8 \\
\hline & Mid (6-19) & 2 & 2 & 0 & 12 & 16 \\
\hline & Total & 3 & 5 & 5 & 19 & 32 \\
\hline
\end{tabular}

Table 14 shows the choice for Best Sequence broken down by courses taught and workshop. A chi-square analysis was done to see if there were any significant differences between responses and the courses that they taught (Patterns Physics: 
Physics; Patterns Chemistry and/or Patterns Biology: Pother; any other science course: Other). The analysis shows that there were no significant differences in responses based on Courses Taught $\left(\chi^{2}(6, N=32)=3.15, p=.79\right)$ or Workshop Type $\left(\chi^{2}(9, N=32)=\right.$ $15.3, p=.08)$

Table 14

Best Sequence Choices by Courses Taught and Workshops Taken

\begin{tabular}{|c|c|c|c|c|c|c|}
\hline \multirow[t]{4}{*}{ Courses Taught* } & & $\underline{\mathrm{BCP}}$ & $\underline{\mathrm{DNM}}$ & Other & $\underline{\mathrm{PCB}}$ & $\underline{\text { Total }}$ \\
\hline & Other & 0 & 1 & 1 & 1 & 3 \\
\hline & Patterns Other & 1 & 2 & 2 & 5 & 10 \\
\hline & Patterns Physics & 2 & 2 & 2 & 13 & 19 \\
\hline \multirow[t]{5}{*}{ Workshop** } & Pattern Physics & 0 & 2 & 2 & 10 & 14 \\
\hline & Pattern Physics & 3 & 0 & 3 & 5 & 11 \\
\hline & \& Patterns-Other & & & & & \\
\hline & Patterns Other & 0 & 3 & 0 & 3 & 6 \\
\hline & None & 0 & 0 & 0 & 1 & 1 \\
\hline
\end{tabular}

$* \chi^{2}(6, N=32)=3.15, p=.79$.

$* * \chi^{2}(9, N=32)=15.3, p=.08$.

Table 15 depicts the choice for Best Sequence with Expertise, where expertise is either Physics or Not-physics. A chi-square analysis was done to see if there were any significant differences between responses and the teacher's expertise (self-identified). 
The analysis shows that there were no significant differences in responses. $\left(\chi^{2}(3, N=\right.$ $32)=4.49, p=.21)$

Table 15

Comparison of best sequence and Expertise

\begin{tabular}{llcccccc}
\hline Expertise & BCP & $\underline{\text { DNM }}$ & $\underline{\text { Other }}$ & & $\underline{\text { PCB }}$ & $\underline{\text { Total }}$ \\
\cline { 3 - 6 } & Physics & 3 & 2 & 4 & 15 & 24 \\
Not-physics & 0 & 3 & 1 & 4 & 0 \\
Total & 3. & 5 & 5 & 19 & 32 \\
\hline
\end{tabular}
$\chi^{2}(3, N=32)=4.49, p=.21$.

Summary. A majority of teachers preferred the PCB sequence to other sequences and when including teachers who believed the sequence does not matter, a large majority of teachers indicated support for the PCB sequence. The chi-squared analysis was used to determine if there were differences between the demographic groups: Location, Content Expertise, Career-band, Courses Taught. The analysis showed no statistical difference between demographic groups.

Qualities of a 9th grade Physics Course. An additional survey item was designed to elicit teachers' views about a $9^{\text {th }}$ grade physics course with the following prompt: The following questions are specifically about a $9^{\text {th }}$ grade physics course. Please indicate your belief about the following statement: 1) A physics course is not appropriate for the $9^{\text {th }}$ grade. 2) A physics course for the $9^{\text {th }}$ grade should focus mostly on conceptual understanding with minimal mathematics. And 3) A physics course for $9^{\text {th }}$ grade should utilize mathematics to find patterns in experimental data. Teachers indicated their belief in each statement using a five-point Likert scale. Responses were compiled into three 
groups: agree, disagree, and no opinion. Table 16 below shows the results broken down into the following groups: all respondents, those with physics expertise verses notphysics expertise, and career band.

The results from question one showed that a majority $(>80 \%)$ of teachers believed that physics is appropriate at the $9^{\text {th }}$ grade level. The responses for question two showed that about half of the teachers thought that a $9^{\text {th }}$ grade physics course should minimize mathematics, while the other half of the teachers thought that mathematics should not be minimized. Further analysis showed that neither years of teaching experience nor content area expertise correlated with the opinion about the extent to which mathematics should be included. This indicates that there was no clear consensus, even accounting for teacher expertise and years of teaching experience. This result is particularly interesting considering teachers' responses to question three, A physics course for $9^{\text {th }}$ grade should utilize mathematics to find patterns in experimental data.

Responses to question three showed that a majority of teachers believed that a $9^{\text {th }}$ grade physics course should utilize mathematics to find patterns in experimental data $(>80 \%)$. A statistical test found no statistically significant difference in responses between content expertise or years of teaching experience. 
Table 16

Belief about $9^{\text {th }}$ Grade Physics Course

\begin{tabular}{|c|c|c|c|c|c|c|c|c|c|c|}
\hline \multirow[t]{2}{*}{ Category } & & \multicolumn{3}{|c|}{ Item 1} & \multicolumn{3}{|c|}{ Item 2} & \multicolumn{3}{|c|}{ Item 3} \\
\hline & & \multicolumn{3}{|c|}{$\begin{array}{l}\text { A physics course is not } \\
\text { appropriate for the } 9 \text { th } \\
\text { grade }\end{array}$} & \multicolumn{3}{|c|}{$\begin{array}{l}\text { A physics course for } \\
\text { 9th grade should focus } \\
\text { mostly on conceptual } \\
\text { understanding with } \\
\text { minimal mathematics }\end{array}$} & \multicolumn{3}{|c|}{$\begin{array}{l}\text { A physics course for } \\
\text { 9th grade should utilize } \\
\text { mathematics to find } \\
\text { patterns in experimental } \\
\text { data }\end{array}$} \\
\hline \multirow{3}{*}{$\begin{array}{l}\text { All } \\
\text { responses }\end{array}$} & Agree & \multicolumn{3}{|c|}{5} & \multicolumn{3}{|c|}{16} & \multicolumn{3}{|c|}{26} \\
\hline & Disagree & \multicolumn{3}{|c|}{25} & \multicolumn{3}{|c|}{15} & \multicolumn{3}{|c|}{5} \\
\hline & $\begin{array}{l}\text { No } \\
\text { Opinion }\end{array}$ & \multicolumn{3}{|c|}{2} & \multicolumn{3}{|c|}{1} & \multicolumn{3}{|c|}{1} \\
\hline \multirow[t]{3}{*}{ Expertise* } & & Physics & \multicolumn{2}{|c|}{ Not-physics } & Physi & \multicolumn{2}{|c|}{$\begin{array}{c}\text { Not- } \\
\text { physics }\end{array}$} & Physics & \multicolumn{2}{|c|}{$\begin{array}{c}\text { Not- } \\
\text { physics }\end{array}$} \\
\hline & Agree & 4 & \multicolumn{2}{|c|}{1} & 12 & & 4 & 21 & \multicolumn{2}{|c|}{5} \\
\hline & Disagree & 19 & \multicolumn{2}{|c|}{6} & 11 & & 4 & 3 & \multicolumn{2}{|c|}{2} \\
\hline \multicolumn{11}{|l|}{ Career } \\
\hline & Agree & 1 & 2 & 2 & 4 & 8 & 4 & 6 & 13 & 6 \\
\hline & Disagree & 6 & 5 & 14 & 3 & 8 & 4 & 1 & 3 & 1 \\
\hline
\end{tabular}

* Expertise $=$ Disciplinary focus, physics teacher or not a physics teacher

** Career Band $=$ Year of teaching experience

Juxtaposing the results from question two and three, it is likely that teachers have differing views of the definition of mathematics in the context of a $9^{\text {th }}$ grade physics course. For example, one teacher might define mathematics in the context of a traditional model of teaching physics that emphasizes standard quantitative problem solving (McDermott, 1993), while another may define mathematics in the context of finding patterns in experimental data as found in Patterns Physics (Hill, 2013) and the Modeling 
Instruction method (Jackson, et al., 2008; Wells, et al., 1995). For example, a teacher comfortable with the current level of mathematics in Patterns Physics that align with the former definition would likely answer "disagree" to question two, but if their perspective aligned with the latter definition, they would answer "agree" to question two. In contrast to the no consensus response to question two, the consensus response to question three indicated that teachers have differing views of how to define mathematics in the context of a $9^{\text {th }}$ grade physics course.

NGSS Confidence. The next series of survey items asked teachers to indicate how their confidence in engaging students in the science and engineering practices has

\section{PPIS NGSS Confidence prompts.}

1. Asking questions that can be answered with data

2. Developing and using models

3. Planning and carrying out rigorous scientific investigations (collect accurate data)

4. Analyzing and interpreting data

5. Using mathematics and technology to make sense of data

6. Constructing explanations (for science)

7. Designing solutions (for engineering)

8. Engaging in argument from evidence

9. Obtaining, evaluating, and communicating information

10. Effectively using engineering (i.e. designing and building) problems to help students understand concepts

Likert scale

$5=$ greatly improved confidence

4=moderately improved confidence

$3=$ slightly improved confidence

$2=$ Did not change confidence

$1=$ Less confidence

Figure 11. Prompts for PPIS confidence items 
changed due to their training and teaching experience. Item prompts and the applied Likert scale can be found in Figure 11.

Of the 32 teachers who took the survey, 18 of 19 Patterns Physics teachers provided responses to this question, 12 of the teachers of Patterns Chemistry and Patterns Biology, and five teachers who had taken the Patterns Physics workshop and the Patterns Biology or a Patterns Chemistry workshop or both of these workshops.

Results showing the average score for each item with the standard deviation are found below in Table 17. Also, an independent sample t-test was conducted to compare the groups. While the average score for the Patterns Workshop participants was higher on all items compared with the Patterns Biology and Patterns Chemistry workshop participants, with the exception of responses to one item, the only statistically significant difference was for item two that involved the prompt: Developing and Using Models. The exception was item seven, where the Patterns Physics teachers score $(\mathrm{M}=3.39, \mathrm{SD}=$ 1.46) was lower than the Patterns Biology and/or Chemistry teachers $(\mathrm{M}=3.50, \mathrm{SD}=$ 1.00).

For the Patterns Physics teachers, the two most greatly improved items were item one $(\mathrm{M}=4.11, \mathrm{SD}=0.96)$, Asking questions that can be answered with data; and item two $(\mathrm{M}=4.33, \mathrm{SD}=0.69)$, Developing and using models. Except for item seven, all the Patterns Physics teachers had a higher average score than the teachers who taught Patterns Chemistry and Patterns Biology. 
Table 17

Comparison Between All teachers, Pattern Physics teachers and Patterns Biology/Chemistry teachers

\begin{tabular}{|c|c|c|c|c|c|}
\hline & $\underline{\text { All Teachers }}$ & $\begin{array}{c}\text { Patterns Physics } \\
\text { Teachers }\end{array}$ & $\begin{array}{l}\text { Patterns Biology } \\
\text { and/or Chemistry } \\
\text { Teachers*** }\end{array}$ & $\underline{\mathrm{t} \text {-test }}$ & p-value \\
\hline Question & $\mathrm{M}(\mathrm{SD}) \mathrm{n}=30$ & $\mathrm{M}(\mathrm{SD}) \mathrm{n}=18$ & $M(S D) n=12$ & & \\
\hline 1 & $3.83(1.11)$ & $4.11(0.96)$ & $3.42(1.24)$ & $\mathrm{t}(28)=1.7$ & .096 \\
\hline 2 & $3.87(1.04)$ & $4.33(0.69)$ & $3.17(1.11)$ & $t(28)=3.6$ & $.001 *$ \\
\hline $3(s)$ & $3.53(1.31)$ & $3.78(1.35)$ & $3.17(1.19)$ & $\mathrm{t}(28)=1.3$ & .215 \\
\hline 4 & $3.70(1.21)$ & $3.94(1.21)$ & $3.33(1.15)$ & $\mathrm{t}(28)=1.4$ & .179 \\
\hline 5 & $3.77(1.10)$ & $3.83(1.20)$ & $3.67(0.98)$ & $\mathrm{t}(28)=0.4$ & .693 \\
\hline $6(s)$ & $3.40(1.13)$ & $3.55(1.25)$ & $3.25(0.97)$ & $\mathrm{t}(28)=0.6$ & .263 \\
\hline 7 (e) & $3.43(1.28)$ & $3.39(1.46)^{* *}$ & $3.50(1.00)$ & $\mathrm{t}(28)=-0.2$ & .820 \\
\hline 8 & $3.57(1.04)$ & $3.78(1.11)$ & $3.25(0.87)$ & $\mathrm{t}(28)=1.4$ & .178 \\
\hline 9 & $3.43(0.94)$ & $3.61(0.92)$ & $3.17(0.94)$ & $\mathrm{t}(28)=1.3$ & .208 \\
\hline $10(\mathrm{e})$ & $3.40(1.24)$ & $3.50(1.29)$ & $3.25(1.22)$ & $\mathrm{t}(28)=0.5$ & .600 \\
\hline
\end{tabular}

*statistically significant

**Patterns Physics teacher < Patterns Biology or Chemistry teacher

Levene's test $>.05$; equal variances assumed.

$(\mathrm{s})=$ targeted science item; $(\mathrm{e})=$ targeted engineering item

***teachers who also teach patterns physics not included

Table 18 shows a comparison of scores for the five teachers who teach Patterns Physics and completed both the patterns workshop and the Patterns Biology or the Patterns Chemistry workshop or both workshops. A paired sample t-test was performed 
to identify any statistically significant differences. While all the scores for the Patterns Physics workshop were higher than the Patterns Biology or Chemistry workshops, none of the differences were statistically significant.

Table 18

Paired Samples T-Test Comparison for Teachers who teach both Pattern Physics and Patterns Biology/Chemistry

\begin{tabular}{|c|c|c|c|c|}
\hline & $\underline{\text { Patterns Physics }}$ & $\begin{array}{l}\text { Patterns Biology or } \\
\text { Chemistry }\end{array}$ & $\underline{\mathrm{t} \text {-test }}$ & p-value \\
\hline Question & $M(S D) n=5$ & $M(S D) n=5$ & & \\
\hline 1 & $3.80(1.30)$ & $3.60(1.52)$ & $t(4)=1.0$ & .374 \\
\hline 2 & $4.40(0.89)$ & $3.60(1.52)$ & $\mathrm{t}(4)=1.37$ & .242 \\
\hline $3(s)$ & $3.80(1.64)$ & $3.20(1.64)$ & $\mathrm{t}(4)=1.0$ & .374 \\
\hline 4 & $4.20(1.30)$ & $3.80(1.30)$ & $\mathrm{t}(4)=0.59$ & .587 \\
\hline 5 & $4.20(1.30)$ & $3.60(1.52)$ & $\mathrm{t}(4)=1.0$ & .374 \\
\hline $6(s)$ & $3.60(1.52)$ & $3.40(1.34)$ & $\mathrm{t}(4)=0.41$ & .704 \\
\hline 7 (e) & $4.00(1.73)^{*}$ & $3.40(1.34)$ & $\mathrm{t}(4)=0.89$ & .426 \\
\hline 8 & $4.00(1.23)$ & $3.40(0.89)$ & $\mathrm{t}(4)=1.0$ & .374 \\
\hline 9 & $3.80(0.45)$ & $3.40(0.89)$ & $t(4)=1.0$ & .374 \\
\hline $10(\mathrm{e})$ & $4.20(1.30)^{*}$ & $3.40(1.82)$ & $\mathrm{t}(4)=1.37$ & .242 \\
\hline
\end{tabular}

While the number of teachers in this sample was small $(n=5)$, all of the scores from the Patterns Physics workshop were higher than from the Patterns Biology or Chemistry workshops. Also, as compared to the entire data set depicted in Table 17, the 
average scores for all items were larger. Interestingly, for this group of teachers, the change in confidence was higher for the items specific to engineering (items seven and ten) compared with the items specific to science (items three and six). The higher confidence scores may be due to having more PD targeting the science and engineering practices. Also, experiencing engineering projects, particularly in multiple disciplines may deepen teachers understanding of the engineering practices, thus leading to higher levels of confidence.

Also, in comparison with the Patterns Physics Teachers (Table 17) the scores for items seven and 10, questions specific to engineering, were 0.7 and 0.6 higher than the Patterns Physics Teachers as a cohort (*due to small sample size, I did not analyze statistically). This could indicate that regarding engineering, the additional PD from attending both workshops provided teachers with additional experience, and possibly different contexts, that positively impacted their confidence in teaching engineering, and in recognizing the value of the PD.

Summary. Teachers reported improved confidence in all items assessing aspects of the NGSS science and engineering practices. The level of improved confidence was higher for the teachers who taught the Patterns Physics course versus those who taught Patterns Biology or Patterns Chemistry courses except for question number seven, Designing solutions for engineering. The differences were only statistically significant for question two, Developing and using models.

Teachers who took the Patterns Physics workshop and the Patterns Chemistry or the Patterns Biology workshop or both reported higher confidence on each survey item 
based on their experiences with Patterns Physics. Also, in comparison with teachers who only participated in the Patterns Physics workshop, they showed a significantly higher average score (>0.5) for the items specific to engineering.

Professional Development. The final section of the survey asked teachers what has been most impactful to their understanding of NGSS science and engineering practices and instruction as well as their recommendations for future professional development. This section consisted of two short answer items. The first question was in specific reference to the engineering practices and the second was in specific reference to the science practices. There were 25 responses to the question specifically about the engineering practices and 24 responses to the item specifically about the science practices. These responses were reviewed and coded, with the most common codes listed here in Table 19 that depicts the number of instances each code appeared.

Table 19

Impactful experiences for science and engineering practices

NGSS Engineering Practices?

8-Targeted Engineering PD w/expert

(within district or outside of district)

6- Doing engineering projects with students

6- Patterns Physics Workshops

4-Working with colleagues (in-building)
NGSS Science Practices?

5 Working with colleagues

5 Targeted Science PD

4 Patterns Physics Workshops

3-other professional experience

2-Doing science projects with students 
Regarding the engineering practices, responses fit into four main categories. The most common impactful experience was targeted PD on engineering that occurred either within offerings presented by District A or outside of the District. Common responses also involved doing engineering projects with students, the Patterns Physics workshops, and working with colleagues within the building.

For example, one teacher wrote, "Common planning time has lead [sic] to creative and engaging engineering practices.” While another said, "My PD's at [school name] have been super helpful in designing and implementing NGSS engineering problems for my students to solve." While a majority of teachers provided responses that fit these codes, there were several teachers that did not provide examples or indicated that they were not very familiar with the standards.

Regarding the science practices, working with colleagues and targeted PD were the most common responses, followed by the Patterns Physics workshops, other professional experiences, and doing science projects with students. For example, one teacher wrote, "Working closely and collaboratively with the physics team at [school name] has made all the difference in this program's success." Another respondent wrote, "PD time during summer 2012, and occasional learning team meetings with physics teachers throughout the district."

As was the case on the question related to engineering practices, there were several teachers who indicated that they were not familiar with the standards or that the standards had not had an impact in practice. One teacher explained the lack of impact this way, 'I have 36 years' experience as a science teacher, so I don't feel that I changed my 
instruction on science practices much. I have never taught Physics or Engineering, so it was the engineering practices that were new to me."

Regarding suggestions for future professional development, there were 23 responses covering a range of activities. There was no strong consensus on future professional development, but there were three themes that emerged from the responses. The first theme was to continue work in aligning curriculum to the NGSS. The second theme was to continue work on best practices/instructional strategies, and the third theme was continued work to address struggling students. While there was consensus on continuing to align curricula to the NGSS and to work on best practices and instructional strategies, consensus for how to address issues related to struggling students was less present in the data. However, what was clear was that addressing the needs of struggling students was on the mind of many of the teachers who responded to the survey.

When analyzing responses for preferred course sequence, one reason some teachers supported the BCP sequence over the PCB sequence was that physics was too hard, particularly with the mathematics requirements, for some students to be successful. In contrast other teachers indicated that physics was accessible to all students. One respondent explained it this way, "Physics provides a platform for easy data collection and graphical analysis." Another teacher recommended "Keep the math simple until student understanding of mathematics is understood by the teacher. Then more complex concepts can be discussed that challenge the students but do not overwhelm them." A recommendation by another respondent was to, "Align the work and concepts being 
covered in the Freshman algebra class with the Physics math component. Common language and a focus on graphing and interpretation is key to success."

\section{Phase One Summary}

The Patterns Physics Impact Survey (PPIS) was completed by 32 high school science teachers representing all six comprehensive high schools in District A. From this group, 25 participants completed a Patterns Physics Workshop and 19 taught Patterns Physics. In this section, I will summarize the findings from the survey.

\section{Finding one: District A high school science teachers strongly support}

Patterns Physics and the PCB course sequence. Most teachers indicated that the Physics, Chemistry, Biology (PCB) was the best sequence for teaching high school science while five also indicated that the sequence does not matter. A small number of teachers preferred the Biology, Chemistry, Physics (BCP) or indicated that students should be able to choose their courses. Most teachers who changed their view on the best sequence $(n=9)$ changed to the PCB sequence.

\section{Finding two: Teaching experience and district training in Patterns Physics} improved confidence in teaching the NGSS science and engineering practices.

Teachers showed an increase in confidence in all areas addressing teaching the NGSS science and engineering practices. Teachers in the Patterns Physics Workshop showed greater improvement in all areas except Designing solutions (for engineering), but the difference was not statistically significant. The most significant change in confidence was the Patterns Workshop participants in Developing and using models (mean=4.29). 
Finding three: Multiple opportunities for Professional Development provided over a significant timespan were critical in supporting Patterns Physics and NGSS implementation. Teachers indicated several common PD opportunities: targeted PD (toward science and/or engineering), the Patterns Workshops, working with colleagues (in-building), and working with students. While there was no single best answer, this list indicated that multiple opportunities (over time) and the ability to engage with colleagues and with students in the classroom was impactful to teacher practice.

Finding four: Whatever sequence they prefer, teachers are aware of the need to adjust the curriculum to meet the needs of struggling students. Teachers were aware that some students struggled with Patterns Physics, primarily with mathematics skills. Several respondents saw the Patterns Physics curriculum as being able to support students learning of mathematics, particularly algebra. They indicated that the teacher needs to be aware of individual students' math abilities and make adjustments as needed so as not to overwhelm students.

\section{Phase Two: Interview Analysis and Results}

Semi-structured interviews were conducted with nine teachers in January and February. The interview questions can be found in Appendix C. These individual interviews were conducted either in-person or via the online video conferencing app Zoom. The interviews were digitally audio recorded and then transcribed with Rev.com. Data about each interview including the school the interviewee taught in, the date of the interview, the type of interview, the career-band of the interviewee, and their experience with Patterns Physics can be found in Table 20 below. 
In total, I interviewed nine teachers from five of the six high schools. Eight of the teachers were teaching a physics course (Physics 1, STEM Physics) at the time of the interview, and one teacher taught Patterns Chemistry. In the next section, I present a brief description of each interview participant.

Table 20

Phase Two-Demographics of Interviewees

\begin{tabular}{|c|c|c|c|c|c|}
\hline Interviewee & $\begin{array}{c}\text { School } \\
\text { Location* }\end{array}$ & $\begin{array}{c}\text { Interview } \\
\text { Date }\end{array}$ & $\begin{array}{c}\text { Type of } \\
\text { Interview }\end{array}$ & $\underline{\underline{\text { Career }}}$ & $\begin{array}{c}\text { Experience w/Patterns } \\
\text { Physics }\end{array}$ \\
\hline $\begin{array}{c}1 \\
\text { Steve }\end{array}$ & $\mathrm{D}$ & $1 / 19$ & Online & Mid-career & $\begin{array}{c}\text { Patterns Physics and } \\
\text { Other }\end{array}$ \\
\hline $\begin{array}{c}2 \\
\text { Donna }\end{array}$ & $\mathrm{C}$ & $1 / 21$ & Online & Early-career & $\begin{array}{c}\text { Patterns Physics and } \\
\text { other }\end{array}$ \\
\hline $\begin{array}{c}3 \\
\text { Robert }\end{array}$ & $\mathrm{C}$ & $1 / 22$ & In person & Mid-career & $\begin{array}{c}\text { Patterns Physics and } \\
\text { Other }\end{array}$ \\
\hline 4 & $\mathrm{C}$ & $1 / 23$ & In person & Early Career & Patterns Physics Only \\
\hline Gayle & & & & & \\
\hline $\begin{array}{c}5 \\
\text { Avery }\end{array}$ & $\mathrm{F}$ & $1 / 24$ & In person & Early-career & $\begin{array}{c}\text { Patterns Physics and } \\
\text { other }\end{array}$ \\
\hline 6 & $\mathrm{~F}$ & $1 / 24$ & In person & Mid-career & Patterns Physics Only \\
\hline Marie & & & & & \\
\hline $\begin{array}{c}7 \\
\text { Shawn }\end{array}$ & $\mathrm{E}$ & $1 / 29$ & Online & Mid-career & $\begin{array}{c}\text { Patterns Chemistry and } \\
\text { Other }\end{array}$ \\
\hline $\begin{array}{c}8 \\
\text { Jaime }\end{array}$ & $\mathrm{C}$ & $2 / 2$ & Online & Late-career & $\begin{array}{c}\text { Patterns Physics and } \\
\text { Other }\end{array}$ \\
\hline $\begin{array}{c}9 \\
\text { Alex }\end{array}$ & A & $2 / 7$ & Online & Mid-career & $\begin{array}{c}\text { Patterns Physics and } \\
\text { Other }\end{array}$ \\
\hline
\end{tabular}

* Schools randomly assigned a letter designation

**Early-career (2-5); Mid-career (6-19); Late-career (20+) years of science teaching experience ***These teachers were interviewed together due to scheduling constraints. 
Experience and Views of Interview Participants. The purpose of the interviews was to elicit a more in-depth perspective about teacher practices, experiences, and beliefs about Patterns Physics to inform the research questions. The following descriptions were developed from the interviews and are presented here to provide context to the reader about the experience and views of these teachers. Pseudonyms were used to identify each participant; I intentionally used gender-neutral pronouns when gender was not clearly identified.

Interviewee 1. After having taught in a PCB program for a few years in a different state, Steve is in his first year in District A and teaching Patterns Physics. In his previous school, Steve participated in PD on the Modeling Method and participated in the development of a 9th grade physics curriculum based on that method. Engineering was not a component of that curriculum, so that has been a significant difference from his previous practice.

Steve supports the PCB sequence and the patterns approach to teaching physics. Based on his previous experience, Steve said that a $9^{\text {th }}$ grade physics course needs to be tailored to the skills and developmental level of the students and cannot be a simplified version of an $11^{\text {th }}$ and $12^{\text {th }}$ grade physics course. About their current position, Steve said that a significant number of students did not seem to have the pre-requisite mathematics skills required to be easily successful with the Patterns Physics curriculum and that this situation posed a challenge.

Interviewee 2. Donna taught science in a different state for a few years, took several years off, and is now back in the classroom in her first year of teaching in District 
A. Donna teaches one section of STEM physics as well as several sections of astronomy for $11^{\text {th }}$ and $12^{\text {th }}$ grade students. Donna has a strong understanding of science standards from earlier work with Project 2061 but is new to the NGSS.

Based on prior experiences, Donna supports the PCB sequence because she thinks it better supports student learning in the scientific practices of collecting and analyzing data compared with their earlier experience teaching biology to $9^{\text {th }}$ grade students where inquiry was difficult for their students. Donna is having a positive experience with teaching Patterns Physics and works hard to maintain a positive classroom environment where students can learn from failure and engage in inquiry.

Interviewee 3. Robert is a mid-career teacher who has taught in several different school districts including schools in a different state prior to teaching in District A. He has been teaching Patterns Physics since its adoption and currently teaches Physics 1 and Chemistry1 and has experience teaching science courses for ESL (English as a Second Language) students.

Robert supports the PCB sequence but believes that the scaffolding of learning is more important than sequencing. Robert also works with children outside of the District A setting and has made connections between how younger children engage in science inquiry and how high school students do so. In both cases, he believes that students need opportunities to explore and experiment in answering their questions. Robert thinks that both Patterns and the NGSS are moving in the right direction-with a decreased emphasis on factual knowledge and a greater emphasis on the processes of science and engineering. 
Interviewee 4. Gayle is in her fifth year of teaching and working in District A and has only taught with the PCB sequence. Gayle teaches Physics 1 for ESL students and makes some modifications to the curriculum to support these students. In addition to Physics, Gayle teaches an Ecology course and a non-science course. Gayle says that the Patterns Physics course has been extremely successful with the ESL students. Gayle has expertise as a chemistry and biology teacher and indicated that her strength in teaching the Patterns Physics course is in developing students' science and engineering skills. Gayle has found that the structure of patterns physics, repeating patterns throughout the curriculum, and in structuring science inquiry and engineering design is very helpful for the ESL students.

Interviewee 5. Avery has been teaching for six years, is in their second year in District A, and has taught in several other school districts. Avery has a background in engineering and in teaching CTE (career-technical-education). Avery teaches Patterns Physics and an Astronomy class with $11^{\text {th }}$ and $12^{\text {th }}$ grade students.

Avery indicated that the biggest challenge is student motivation, as they have some students who do not engage in the coursework. Avery is supportive of the PCB sequence because of how knowledge and skills can be developed and applied to the next course. They suggested that an introductory $9^{\text {th }}$ grade course, a "pre-science or integrated science", that would focus on developing math skills and writing lab reports might be a solution for students who lack pre-requisite skills. This teacher really likes the patterns approach in that students develop the equations from experimental data. They also value engineering as a way for students to systematically make design decisions. 
Interviewee 6. Marie is in her fourth year of teaching in District A after teaching in another district. Her current teaching assignment is split between physics and chemistry, but her background has been in environmental science.

Marie is a strong proponent of the NGSS and identifies teaching the NGSS and using proficiency grading as a strength. The patterns approach to physics has impacted Marie's understanding of scientific inquiry. She said that she now recognizes how prior to patterns, she had a very teacher-directed approach whereas she has now shifted to a more student-centered approach. Marie highly values the engineering projects for how they engage students and provide opportunities for class discussion. Marie understands the reasoning behind the PCB sequence, but is open to other options, particularly based on her observations that some student struggle with mathematics. Marie indicated that Biology as defined by NGSS is now a very difficult discipline to teach and learn and the Biology would not be appropriate in the $9^{\text {th }}$ grade.

Interviewee 7. Shawn is a mid-career teacher who teaches four sections of Patterns Chemistry $\left(10^{\text {th }}\right.$ grade $)$ and one section of Engineering ( $9^{\text {th }}$ and $10^{\text {th }}$ grade). They are relatively new to District A and was a science TOSA in their previous district. This teacher has extensive experience with the NGSS and has led many PD sessions for high school teachers in science and engineering.

Shawn described a significant shift from a teacher-centered approach to a studentcentered approach after adopting the Pattern curricula as being a significant change in their teaching practice. As a chemistry teacher at the $10^{\text {th }}$ grade, having students enter chemistry with knowledge of energy as well as a foundation in data collection and 
analysis has been a big benefit of having physics at the $9^{\text {th }}$ grade. Shawn is a strong proponent of the PCB sequence.

Interviewee 8. Jaime teaches several sections of STEM Physics, the honors level $9^{\text {th }}$ grade physics course in their school, and several sections of IB Physics $\left(11^{\text {th }}\right.$ and $12^{\text {th }}$ grade). Jaime has taught in District A for almost 20 years and has mostly taught AP and IB Physics $\left(11^{\text {th }}\right.$ and $12^{\text {th }}$ grade). Jaime had a previous career in engineering.

Jamie reported that a big challenge in teaching STEM physics was in adjusting to an appropriate level of mathematics; it took about three years for Jamie to become confident teaching the Patterns Physics program. This teacher views the hands-on and macro-scale qualities of the activities as well as the engineering projects positively. Jaime is a proponent of the PCB sequence.

Interviewee 9. Alex teaches two sections of Physics 1 , the $9^{\text {th }}$ grade Patterns Physics course. They also have one section of a non-science class and with their remaining time as a TOSA focused on standards-based assessment. Alex has been teaching at the same school longer than 10 years and taught the previous Integrated Science course at the $9^{\text {th }}$ grade wherein students took a course called Inquiry A that involved physics and earth science, then Inquiry B that involved biology and chemistry.

Alex shared that there were not many students who went on to take physics in their junior or senior year prior to the switch to Patterns. They observed an increase in the number of juniors and seniors who take physics since the implementation of Patterns Physics. Alex has also taught engineering classes and contributed to early engineering projects in the Patterns Physics curriculum. Alex is a proponent of the PCB sequence. 


\section{Phase Two: Findings through Categories and Themes}

Method of Analysis. To analyze the interviews, I first used Atlas.ti, a qualitative

data analysis and research software package (QDAS), to code four of the interviews using in-vivo and open coding. This process resulted in the development of 150 individual codes. I then reviewed the codes and began to organize them into categories. The initial analysis resulted in 11 categories.

I then transitioned to using a spreadsheet to organize the codes with each interview as it was easier for me to track and organize the codes. I reread printed and digital copies of the transcript and placed data and comments into individual categories. I was able to combine several categories to reduce the data to five distinct categories, with sub-categories that I will refer to herein as themes.

Table 21 depicts the categories and themes developed from the interviews. Then, in the following sections, I will define each category, provide examples of the range of responses, and conclude with a summary of the findings. 
Table 21

Categories and Themes for the interviews

\section{$\underline{\text { Categories }}$}

1. Descriptions of Practice

2. Considerations about Patterns Physics and Physics First

3. Professional Development

4. The role of NGSS.

5. Impact on practice (beliefs)

\section{Themes}

1A: Patterns

1B: Inquiry

$1 \mathrm{C}$ : Engineering

2A: Nature of the course and sequence considerations

2B: Role of mathematics and challenges

3A: Culture of collaboration through multiple opportunities

3B: Qualities of effective PD.

4A: Guiding instructional practice

4B: Moving science education forward

5A: Patterns as an instructional model

5B: Student-centered instruction

Category 1: Descriptions of Practice. Teachers provided descriptions of their classroom practice, particularly their approaches to activities, units, and lessons that address the science and engineering practices. Here is a list of the related themes followed by a brief description of each:

- Theme 1A, Patterns: Teachers described the use of "Patterns," the finding of mathematical relationships between variables in the experiment(s), as an overarching theme of their classroom practice.

- Theme 1B, Inquiry: Teaches described their approach to science inquiry — finding patterns (mathematical) in phenomena and using those patterns to better understand the phenomena to make predictions. 
- Theme 1C, Engineering: Teachers described their approach to engineering, particularly a focus on iteration and using data to make design decisions.

Theme 1A: Patterns. All interviewees provided similar descriptions of using patterns as the overarching theme of their approach to addressing patterns in multiple experiments. Key patterns (i.e. linear, inverse, quadratic) and the approach to inquiry are introduced at the beginning of the school year and then those patterns are used to address and understand new phenomenon throughout the school year. Alex described them this way:

We set the scene with the idea that all scientists are looking for cause and effect, or relationships that exist because of one thing interacting with another. And then through that we set that menu of four, five, [or] six patterns that kind of encompass most of the experience you would have in a physics class at this level. And that creates that toolkit ... [and then we can ask students] does this fit a relationship that you already know about? And it's not always direct, sometimes it's an inverse of something that we know. Or we flip the axis on you, or there's a constant in there that's kind of hidden (Interviewee 9, personal communication).

Jamie described work with patterns in this way:

...the first month you're picking up these four mathematical patterns that keep repeating - that's consistency for students. So, I appreciate that we're always going back... how does that relate to those four patterns. Is it one of them? Or something different? And so that continuity, I think is a strength that overarches throughout the year.

The approach was to introduce the key patterns at the beginning of the school year, and then refer to those patterns to help students structure new learning in new contexts. Teachers highlighted that a key benefit of this approach is that the patterns can reveal themselves in different experiments. For example, Donna stated, “And look, you 
think electricity is like completely different from a ball rolling down a hill, but really it's not, and here's what it looks like." Donna went on to point out that even if the pattern is not explicitly revealed in a particular lesson, it can be used for further analysis as students work to figure out what is going on.

Teachers indicated that there was real educational power to thinking in terms of patterns in that this approach provides continuity throughout the school year and multiple opportunities for students to make connections to previous concepts. As Robert explained, "When we do multiple different experiments, each time reinforcing the pattern, I think their understanding is also reinforced." And Shawn said, “And so that continuity, I think is a strength that overarches throughout the year."

Theme 1B: Inquiry. The second theme, inquiry, reflects participants' approach to engaging students in science practices. Students first explore a phenomenon then use their background knowledge to make a prediction (sometimes referred to as a wild guess prediction). Then students engage in inquiry to collect and analyze data to determine a pattern between the variables. This is followed by some activity for students to review and discuss what they found, and then apply the patterns they discovered to make additional predictions that can be tested, to develop a conclusion or both. Each of the teachers described utilizing this process, but Gayle provided the most detailed description of this procedure:

When we do things like the ball and ramp lab where we look at acceleration of the ball down the ramp in order to predict the speed that it would have at the end or the distance it would go ..., the students are given a problem, "Can you predict how far this is going to go? Take a wild guess." Even before they've ever seen the lab, just imagine it happening. 
What do you think? Then we form a research question so that they can identify idea of what they're going to be looking at. Then we go over procedure and then they're off. They're in the hallway... with the ramp. They are trying to control for the variables that we've already discussed. I give them suggestions and I really try to let them manage the equipment to isolate those variables. Then they're out in groups and they do independent work that entire time on collecting the distance and time that a ball is rolling down the ramp and across the floor.

Then we come back in together and they are doing calculations and doing their whiteboard presentations to each other. Then we do a, "what do you notice type of thing" between different groups. Then I ask them to come up with some ideas of why the graph are slightly different or whatever we're noticing. We try to have a discussion about so that I'm never standing up there saying, "This one's good. This one's bad." I'm trying to get them to look at it and see if there's something about the graph that the group has created that might generate some ideas on what could've changed between all of the lab set-ups.

Then we talk about the meaning of the variables and the patterns that we see. Then we talk about all of the relationships between the variables. Then they sit down and write a claim evidence, explanation, some repair graph for me and that's about it. That's the general set-up of any lab that we do. We just repeat that every time we are sitting down for a lab.

In brief, the common process they describe is: Explore Phenomenon $\rightarrow$ Wild Guess Prediction $\rightarrow$ Procedure/Analysis $\rightarrow$ Concept Development and Arguing from Evidence $\rightarrow$ Additional predictions and Conclusion or both. This is the general format followed for science experiments.

Avery explained that this process is empowering for students as they apply skills and tools to develop an understanding of physical phenomena before learning a formal scientific explanation:

The systematic and repeated approach to creating these equations- that I never got a chance to [do] - If you, theoretically, follow this system you can almost figure out anything. It's very empowering. Rather than you are handed information, you are creating information. You are, in theory, creating these 
equations.... We realize they've been created before. We don't even tell them that [the name of the phenomena] .... It's this thing like "Oh, it happens to be that Newton came up with this. That's pretty cool, but we did it."

Teachers indicated that this approach wherein students developed the mathematical model and an understanding of how the variables were connected through their experimental results was helpful for students to develop a more in-depth understanding of relevant scientific concepts and the scientific process of discovery.

Theme 1C: Engineering (Data, Iteration, Constraints). Interview participants referred to several engineering activities found in the curriculum. Their descriptions were less detailed than those for science, but there were three common sub-themes in the approach to engineering. The first was the use of data, often a result of a science experiment, in making design decisions. The second was the emphasis for students to iterate their designs. Donna provided an example of this:

"We've done some labs about tension and compression, and now we're putting it all together..., actually using our data to drive our design decisions...And, see what happens? Okay, this one didn't work, why didn't it work? We're doing some failure analysis and going back and correcting."

In addition, engineering projects were often set up with additional constraints that could be material or costs constraints. Alex explained this in describing a project with wind turbines:

We have the students take some data on the relationship between the ability to do work, transfer energy based on blade angle, blade size, blade shape, blade area. And then they integrate all of those into an optimized design. There are some cost constraints, materials constraints, and they have to work within that framework to get to this optimized design and then explain where that comes from.

Each participant described several engineering projects when summarizing their practice (each instructional unit included an engineering project) indicating that students 
are getting multiple opportunities to do engineering. Shawn commented on the benefit of this, "With regards to the curriculum: I think it's great that they do so many engineering projects, because I think physics lends itself...for doing all those projects. They get a real solid foundation in the engineering process".

Summary. The teachers described a similar approach in using patterns as an overarching theme for the course, their approach to inquiry, and their approach to engineering. While this may not be surprising in that these teachers were all teaching Patterns Physics (or patterns chemistry for the chemistry teacher), it is important to note that these teachers, from five different schools were in fact describing similar approaches to their classroom practice. This is evidence that there was a measure of fidelity in the instruction of Patterns Physics.

\section{Category 2: Considerations about Patterns Physics and Physics First.}

Participants described the unique characteristics of Patterns Physics and its appropriateness for the $9^{\text {th }}$ grade. Each of the nine interviewees made statements that reflected each of these themes.

- Theme 2A, Nature of the course and sequence considerations: Teachers provided descriptions of what makes Patterns Physics unique and revealed important course qualities in addition to content as well as reasoning for science course sequence based on their experiences.

- Theme 2B, Role of mathematics and challenges: All interviewees discussed mathematics as a key component of patterns physics but provided details to give insight into what is meant by mathematics and its role in the course. 
Theme 2A Nature of the course and Sequence Matters. In category one, Descriptions of Practice, I provided evidence of how Patterns Physics is implemented through the teachers' description of their classroom practice. These descriptions provided evidence for how teachers viewed Patterns Physics as a unique approach to teaching $9^{\text {th }}$ grade physics and how they saw the placement of the course in the high school course sequence. Teachers described the Patterns approach as being a unique way to structure student learning throughout the school year and that this approach was effective in supporting student learning.

The larger context was to use these patterns to support student learning in science inquiry and engineering. Teachers described how students utilized patterns to make scientific predictions, test predictions, and to structure their understanding of phenomena. In engineering, students were drawing on the patterns to make and analyze design decisions. It was through these contexts that teachers defined the nature of the Patterns Physics course. It was not content driven, with delivering content being the ultimate goal of the course. Instead it was connection driven wherein students engaged in the science and engineering practices to discover patterns in nature and to make connections to scientific content to understand natural phenomena. It was with this background that teachers described their reasoning behind the best science course sequence. All of the interviewees referenced the development of science process skills as key to the Patterns Physics course in addition to providing students with knowledge and skills that would support their learning in future science courses. 
There were some differences among the interviewees about the best science course sequence. All of the interviewed teachers supported the PCB sequence in theory, but several had difficulties in practice. I will first describe their theoretical reasons in support of the PCB sequence, followed by issues interviewees said they found in practice with the PCB sequence.

Teacher reasoning in support of the PCB sequence can be summarized this way. Physics provides an appropriate context for students to engage in science and engineering at the $9^{\text {th }}$ grade level because it is macro-scale (versus micro-scale) and thus, largely tangible to students - they can see, touch, and hear what is going on. This provides a context for students to engage in the science and engineering practices where they can see and modify procedures and results. This experience also provides a context for the application of mathematics or other reasoning skills in analyzing data and developing conclusions or in making design decisions. Teachers indicated that this is appropriate for most $9^{\text {th }}$ grade students. As an example of the difference between macro- and microscaled experiments, Jaime said:

We used to start with some chemistry stuff about atoms that they can't physically relate to, whereas watching the ball go across the floor and measuring length and time and calculating velocity. The concepts in mechanics and even into waves and electricity and magnetism tend to be more large scale rather than small scale. And gives kids the opportunity to connect physical observations with mathematical processes.

Alex explained how conceptualizing phenomena at macro-scale is more accessible for students to develop the skills of data collection, graphing, and data analysis, which support larger science and engineering practices as well as math skills: 
Now that I've been doing it for a while, I totally appreciate having physics first. The idea of them having a foundation for where to put their math, as they're getting into algebra, why it matters when they can use it. That really helps. And then the workaround data analysis and recognizing trends and relationships really seems to help them lock stuff in to chemistry and biology better. The data really is, I would say, pending. We haven't had this out there long enough I think to really see a shift. But, anecdotally, looking at it from the ground, I think that it's been beneficial to the kids.

While these quotes show that one strength of the Patterns Physics curriculum was that students could use and develop their mathematics and algebra skills, it turns out that students' pre-requisite math skills were important in their success in Patterns Physics. This next section will explore the issue of mathematics skills.

Theme 2B: Role of Mathematics and Challenges. As indicated in the previous section, teachers viewed the application of mathematics as a positive attribute of Patterns Physics. All of the teachers interviewed indicated that the application of the algebraic skills in discovering the algebraic relationships in the four patterns was positive, and that returning to those patterns throughout the curriculum was helpful for student learning. In addition, the application of these skills is embedded into the patterns approach to inquiry. Gayle expressed support for this approach this way:

...but I would argue for our freshman physics student those early skills of graphing, understanding a graph, using the claim evidence explanation model, and practicing those basic algebra skills, I feel like that sets them up for more success, because those are really fundamental skillset every science student needs to have. The way that we're doing it now, the physics not so much the content, but the skills that they're learning I feel like is appropriate for the freshman. Then also, I would argue that the level of engagement is high, because we do so many handson labs.

This view that the mathematics involved in the Patterns Physics curriculum is a fundamental component of science skills was supported by all interview participants. 
However, there was a difference between theory and practice, as several teachers indicated that students' lack of algebra skills made the course difficult to teach and impacted student success in science. Alex said that it was difficult to teach "the low kids that just don't understand the basic algebraic relationships and functions, it's tough... Whether that's in math class or physics or probably reading and writing as well - they don't seem to be mutually exclusive, and it's a tough thing to deal with".

Steve, a teacher who was new to the district, said this about Patterns Physics and math:

The Patterns curriculum as it exists currently is a train headed somewhere awesome, but the ticket is basic algebra, and many of the kids just don't get on... and I've heard this from the other pattern teachers, if you've got the math you crush the course. If you don't have the math you don't.

Steve gave the following example to describe student difficulties with mathematics:

So [the equation] $\mathrm{s}=\mathrm{k}^{*} \mathrm{~m}$. If I give you $\mathrm{k}$ and I tell you that $\mathrm{m}$ is 5 , you should be able to figure out what $\mathrm{s}$ is. Most of the kids can do that, but if I give you the stretch [s] and I give you k, can you find out what mass [m] that was? Forty percent of my students can't do that.

In this example, the students could do the simplest form of problem solving but were not able to manipulate equations. Most of the interviewees indicated the need to address students' skills in mathematics. However, it was only when a significant number of teachers' students struggled with the mathematics, that it became an issue where teachers questioned the appropriateness of the Patterns Physics curriculum. Steve said:

...but you have to face reality at a certain point that if a large enough population of your students are not meeting middle school standards, you are the last line. There's no one after you that is going to teach them these things if you don't. 
Therefore, Steve felt it was important to meet the needs of the students where they were, instead of where they were expected to be academically. In discussing possible solutions to this problem, Steve said:

I am really pushing toward non-algebra stuff to start the year with that still involves analytical thinking, so they still learn to think. But it also means you're gonna pull back on the lab work a bunch. I don't have a full vision yet, but I gotta find a way to buy the kids more time so they can get to algebra. Or alternatively, we just keep using the proportion circles. [a technique they implemented this year to support student problem solving].

Steve also discussed other strategies to support student learning by modifying some of the curriculum to be more conceptually focused and removing some of the mathematics early in the course. Steve emphasized the importance of meeting the learning needs of the students where they were academically and to not just move through the curriculum and let students struggle.

Individual schools also had different systems in place to handle struggling students. One teacher indicated that in their school they had a program where low-level students took a support class during their $9^{\text {th }}$ grade year that addressed foundational math and science skills. Several schools had specific sections for ESL students that allowed teachers to target language in a way that is more appropriate for those students. Several schools tracked high-level math students into STEM Physics while the rest of their students took Physics 1. In other schools, all students took Physics 1 where additional opportunities were made available for students to earn STEM physics credit.

Summary. Patterns Physics is a unique approach to teaching physics with a strong emphasis on the development of mathematical patterns that describe phenomena. 
Students typically determine these patterns through a science inquiry process. Students further apply these patterns for further inquiry experiments or in making design decisions in engineering projects. Students who are algebra ready, as in they understand basic algebraic concepts, are typically successful in negotiating the necessary skills and knowledge. Students who struggle with basic algebra struggle with Patterns Physics; teachers reported it is difficult to teach these students. While teachers viewed a strength of patterns physics to be its mathematical focus based on recurring patterns, this was also a weakness for students who struggled with mathematics.

While I will provide more details in the section on Professional Development, interviewees provided descriptions of their professional interactions with colleagues that indicated that many science teachers were implementing with fidelity. In addition, these teachers indicated strong support for the patterns approach to scientific inquiry. They liked the cyclical, repetitive nature of using the patterns with science inquiry and engineering and indicated that the repetitive nature is helpful for student learning.

Category 3: Professional Development. Teachers indicated that District A provided professional development (PD) targeting the Patterns curriculum (physics or chemistry) was important in supporting their teaching. While several teachers discussed participating in PD offered by out-of-district groups such as the National Science Teachers Association, all teachers commented on their participation in district provided professional development targeted towards implementing the Patterns curriculum. Two themes emerged from the interviews - qualities of effective PD and multiple opportunities and a collaborative culture. 
- Theme 3A, Qualities of Effective PD: Teachers discussed attributes of PD that were most effective for them.

- Theme 3B, Multiple opportunities and a collaborative culture:

Teachers described a variety of professional development opportunities targeted towards supporting Patterns Physics that provided both immediate support in their teaching of Patterns Physics and facilitated collaborative relationships. These opportunities were organized and implemented by district science TOSAs.

Theme 3A. Qualities of Effective PD: The most common participant response for effective PD was to "be in the role of the student." A secondary response was for teachers to have time to discuss the unit and assessment. Not explicitly stated, but implicit in their responses was the importance of PD that was targeted towards their teaching of Patterns Physics.

Alex, a mid-career teacher who had helped facilitate PD sessions had this to say about the organization of the PD:

The patterns physics PD courses are basically a carbon copy of what we do in class...It's nice because you get to see what it looks like.... Any trainings I've been a part of, I've made sure it feels, it tastes, it smells just like it does in a classroom...

The result was for teachers to get a complete experience, so in addition to the experience of doing the activities, the goal was to give teachers the tools and experiences to successfully implement the unit with their students. Alex added,

All those trainings have been very hands on. They're very interactive. You walk away with curriculum, assessments, rubrics, some material sometimes. You're kind of set to get started on teaching that stuff. Across the board we've gotten 
really good feedback on that and I certainly agree with that feedback. I had the same experience when I went through it.

Donna, a teacher new to Patterns Physics stressed the importance of doing the unit from the student perspective and explained her experience this way:

Actually, the way that we've done the workshops, going in and doing the labs and doing the projects. Seeing it from a student's point of view. Because we can get, you know, the lesson plans, here's the standards, here's the plans, this is what we're going to do. But, actually, like, doing it has been helpful...feeling like a student in the workshop has helped me in terms of presentation. How organized I feel I need to be.

However, teachers experienced with teaching Patterns Physics expressed different needs. Marie, an early-career teacher who has taught Patterns Physics for several years said:

I feel like around NGSS and the curriculum that we're teaching at the high school level, I feel like most of us have it under control, and it's just fine-tuning stuff, making it more engaging or fitting it to your kids, or making it more relevant, or whatever. I would like to see a lot of the PD go to the middle school and elementary school level [with regards to their current work]. Just sitting down, talking about the standards, and then having time, after we'd talked about the standards and the facets of how we can reach them, having the time to sit down, as a collective group, and create a finished product.

Theme 3B: Multiple opportunities and a collaborative culture. In addition to

the qualities of a particular workshop or PD session, another quality emerged that may be unique to this district — offering PD in support of the Patterns curricula over multiple years so that every interested teacher could obtain additional support. This longitudinal PD facilitated more in-depth relationships amongst teachers and the district TOSAs. In addition, ongoing PD provided opportunities for teachers to collaborate and share their own ideas and experiences on best-practices that had an important impact on teacher 
practice. Gayle, an early-career teacher described their participation in the monthly PD sessions this way.

My first two or three years of teaching the physics curriculum ..., [the lead TOSA] would host professional development opportunities for just physics teachers. We would walk through the curriculum and talk about the different labs. We would analyze the rubrics and try to align our expectations for student mastery of those concepts, how they would demonstrate it, and to what level are we looking. That was extremely helpful for my first two years of teaching, because it was previewing what was coming up and allowing me to adapt that mindset for those skills that we're developing.... I think I went pretty regularly to the PD the first two years and then the third year [it] drops a little bit, but that was extremely helpful.

Shawn indicated that while they thought the summer workshop was most important, the conversations and worktime within the building were also critical to supporting thoughtful adaptations to the curriculum to fit the unique context of their school.

And then having a couple of colleagues that I teach it with, where we together can make it [the lessons] our own in our building. And that was important. So time for teachers ... to collaborate and talk about what's working, what's not working, what skills do they bring to the table within their own department, within their own building? I think it does need to be a program that gets adopted and adapted.

There were several teachers who referenced the need to "make it their own," which refers to minor changes to the lesson or handouts to adjust for teacher preferences, classrooms expectations, and culture. Shawn explained it this way, "I think it does need to be a program that gets adopted and adapted." This adaptation process allowed teachers to modify the curriculum to better fit their programs and schools. 
In addition to the workshops and in-building PD, Shawn described the online tools developed by the lead science TOSA that provided opportunities for teachers to view or revisit these resources at their convenience:

[The lead science TOSA] has put together on Teacher Source, a ton of support if you take the time to look at it. There're videos of what's going on in the classrooms so you can get a sense of what we're aiming for. Student interaction with the content and there's also some videos about just teacher talk about how to go about this.... [the TOSA] calls it the "Eye on the Prize" ... what's the big thing that we're overarching here. And I think he does a good job with that....

In accessing the TOSAs, one teacher described calling the lead TOSA on the

phone to discuss a project. Robert described how the lead science TOSA came to his classroom to model a lesson for an engineering activity:

He developed the bridge unit... when I was interested in teaching it, he actually would come over and take over my class for a period, or a half a period, so I could watch how he does it. Then, I could modify it, I could make it my own with his support. So it introduced a whole new realm of something I could do in the classroom, in a very practical sense.... Personally, I felt very supported in that.

Robert later developed an electrochemistry unit with a unique approach and was then able to share with colleagues in a district PD session.

It was a very short professional development that I put on when teachers saw how simple the structure was, and that the process could be used to engage in a variety of different types of instruction. It just opened a lot of possibilities. So now we have teachers who are using the same experimental design to teach things about electricity. We also have teachers using it to teach reaction series, so a variety of different ways.

Within this highly collaborative environment this teacher developed an innovative way to teach a unit from the current curriculum and share it with others and then the innovation was applied to new contexts by others. This is a wonderful example of how 
having a culture that prioritizes time for collaboration could have an impact on classroom instruction.

Summary. Teachers perceived that they benefitted from the PD offered in the district in support of Patterns Physics. The summer workshop, monthly meetings, and the in-building departmental meetings supported collaborative relationships that contributed to the success of the program. The interviewees clearly communicated that they felt listened to and well-supported. The district science TOSAs provided consistency in the professional development program and fostered a culture of collaboration by supporting teachers through the multi-year PD sessions, site-visits, personal communication, modeling instructional strategies, and providing web-based materials. Having a flexible PD structure allowed teachers to engage at different times and in different ways, thus different teachers responded to different types of PD strategies based on their own professional needs, availability.

Category 4: Role of the NGSS. Interviews revealed that the NGSS played a meaningful role in teachers' practice. Initial coding addressed teachers' level of knowledge (basic knowledge, knowledgeable, and very knowledgeable) and perception of value - do they value the standards (+), or not value the standards (-)? Each participants knowledge level was determined by self-description and the amount of detail provided in relation to the NGSS. All interviewees had at least basic knowledge, indicating that they were familiar with the standards associated with the courses that they taught, but did not provide specific details of the standards. 
While all interviewees expressed a positive view of the standards, their level of knowledge varied. Two teachers were categorized as having basic knowledge, five as knowledgeable, and two as very knowledgeable (see Appendix H).

Teachers also indicated that the Patterns Physics curriculum and the NGSS were well-aligned. For example, Jaime said:

I know that the curriculum that has been built and is being used here...had the next gen standards in mind as they shaped it. I am not a memorizer of standards, so I could not tell you what the next gen science standards are from memory. I reviewed them and looked at them maybe four times in the last four years. They are what we ought to be having kids working on, real-life problems with real-life science skill.

An early-career teacher noted that, "[district TOSAs are doing work to] make sure that the topics covered in the freshman physics curriculum are aligned to that [NGSS]" (Gayle, personal communication). Steve, an experienced physics teacher relatively new to the district addressed the connection between the NGSS and Patterns Physics, as well as a larger goal in teaching science, which was having students actually "do" science to learn science.

...the philosophy behind patterns and the philosophy behind NGSS I think are one-to- one; and NGSS really struck me as a "Guys, remember that we need to teach kids how to do science, so that they can do science to find out more science."

While several more experienced teachers described how the NGSS was different than past standards, several early-career teachers indicated that the NGSS were familiar to them because they were part of their teacher preparation. Marie, an early career teacher relatively new to District A specifically described her background with the NGSS this way: "I'm a new-enough teacher that I was raised on it. I was brought up to think through 
the lens of NGSS.... I feel my understanding of NGSS is strong." Marie later described the induction experience as a new-hire as a positive one, and that there was explicit connection between their current physics course and the NGSS.

Coming into this [district] I was so impressed... [district science TOSAs] were really helping people....'You're teaching physics, okay. Here's the suggested curriculum and here's how it lines up with NGSS.' It just ticked all the boxes, and it was really thoughtful. You see that at physics, you see that in chemistry, and see it at biology [referring to the PCB sequence in the district], that there's a plan and there's a suggested curriculum, a road map.

While the teachers interviewed had different levels of knowledge with the NGSS, their views on the role of the NGSS emerged as two themes, guiding instructional practice, and moving science education forward.

- Theme 4A, Guiding instructional practice: Teachers discussed how the NGSS informed them about what to do in the classroom as well as a framework to facilitate meta-discussions about what and how they teach. They saw the NGSS as a guide, or roadmap towards the what and how to teach and to facilitate conversations amongst colleagues in improving practice.

- Theme 4B, Moving science education forward: Teachers discussed how the NGSS move science education to be more engaging and relevant for students and was what we should be doing.

These two themes were often intertwined in teacher comments, so some of the following comments show both themes. To illustrate what he referred to as guiding instructional practice, Alex explained that the NGSS were used in designing and evaluating new units of instruction: 
I think the standards are strong. I think that they're well thought out, they're well laid out....we definitely keep our eye on them as we think of how we want to teach things, when we introduce new units or new projects into the curriculum, how they fit? Do they move us closer to those standards?

Marie provided another example:

I think NGSS is a beautiful road map, a great suggestion of where we should be and what we should be doing and having that very thought-out plan that I think does prepare the kids for the next step. NGSS does this fabulously.

Shawn, a mid-career teacher with extensive knowledge of the NGSS, explained

the differences between the NGSS and past science standards and practices:

What's really new and different about the NGSS standards is that they are intertwining learning the content with doing that with a practice and focusing on a crosscutting concept. That's pretty new, where our old ... content standards were all very content driven, and so I think therefore teachers were allowed to kind of do "the" inquiry lab, or "the" engineering project, and so students weren't using that as a means to actually learn the content. They were separated rather than intertwined like they are now. Or like they should be.

This quote illustrates that the connection between content, the crosscutting concepts and the science and engineering practices as expressed in the NGSS are both novel to science education and a logical progression in organizing instruction. Robert, a mid-career teacher, explained the evolution of standards in a different way and how he viewed that the standards can connect student learning to disciplines outside of science:

I think the Patterns and NGSS are moving in the right direction, that we're less interested in explicit answers and more interested in the process of what we're doing and generalizing what we're teaching.... I think they're [the NGSS] a good idea. I think for too long science teachers were left to their own devices, to just teach whatever they thought was important. I think that the next reasonable step came in being very specific in what was to be taught [referencing earlier standards], and more or less how it was to be taught. And I think that this is the next reasonable step in that evolution: to be looking at broader processes, and I think less on division of things between physics, biology, and chemistry. .... And I think depending on how the teacher interprets them it could relate to art, or biology, or to physics, or to a variety of other disciplines. So, I see a lot more 
cross-disciplinary things where hopefully students will be able to hang their hat on more than just these very specific things.

Steve highlighted how the NGSS support the meta-conversations between teachers about their practice:

I remember looking at them and thinking that they were really very good, especially as a way for a science department to have a conversation around "What is it that we are trying to produce? What does it mean to have someone who is scientifically literate, even if they're not even gonna (sic) go into science professionally?

The engineering components of the NGSS were also seen as moving science education forward. Marie explained that left to their own devices, many science teachers would not implement engineering units of instruction on their own. However, "they've forced a lot of teachers that are paying attention to NGSS and trying to address those standards, [it] has forced us to be like, 'Wait a second. How do I get this engineering standard in here?' and this teacher thought engineering was great."

Alex explained their past practice and how engineering had impacted their physics class. "[Engineering] was something that we didn't do before, we used to just blast from one topic to another with little short labs." However, after doing engineering as part of their course, they described the impact this way:

Because of the engineering projects, I think it is more engaging for kids. But those projects require us to slow down, not get to as many topics but get into the depths of not only the engineering process but applying the physics that we're studying.

The addition of engineering was a challenge for many teachers due to their lack of training or background in addition to the classroom challenges of time and materials. 
However, it did provide learning opportunities for students that were more engaging and allowed for learning at a deeper level.

Summary. Interview participants expressed positive views about the NGSS and shared that they were using the NGSS to inform their teaching practice. The NGSS were viewed as a goal to work towards and a guide for both discussions among teachers about classroom practice and in the words of Alex, the NGSS are, "what we ought to be having kids working on, real life problems with real life science skill”.

In addition, the NGSS provides a structure with that teachers and their colleagues use to discuss and plan their units of instruction. Teachers in District A made a significant effort in implementing the Patterns Physics curriculum and the NGSS over the past sixyears. As illustrated in the quotes above, teachers involved in the interview have embraced the NGSS as it relates to their practice. The next section is an analysis of the interviews that highlights the impact this effort has had on teachers' beliefs about their teaching practice.

Category 5: Impact on Practice: Seven of the nine interview participants indicated that teaching with the Patterns approach (either Patterns Physics or Patterns Chemistry) impacted their teaching practice. In reviewing their responses two themes emerged related to how teachers incorporated certain qualities of the Patterns Physics into an instructional model and transitioning from a teacher-centered classroom to a studentcentered classroom. 
- Theme 5A, Patterns as an instructional model: This theme involves specific techniques from Patterns Physics, such as connecting learning to central themes and explicitly connecting future learning to those themes.

- Theme 5B, Student-centered instruction: This approach was seen by several teachers as more effective for supporting student learning. It was described by one teacher as "letting go of the reins."

Theme 5A: Patterns as an Instructional Model. As addressed in categories one and two, teachers related that they embraced the Patterns approach because they believed it was more effective than their previous methods of teaching science. One of the reasons for this belief expressed through the interviews was the positive effects of having a recurring theme of several patterns that can be applied across a multitude of phenomena. The four types of patterns served to scaffold student learning by providing opportunities for the reinforcement of key ideas and building connections between concepts and practices.

Robert, a mid-career teacher said: "I think I'd always appreciated the importance of scaffolding. But I think patterns gave it a new and simplistic way of actually putting it in front of the students." Gayle, another mid-career teacher, expanded on this idea beyond the content of the course to include their overarching instructional approach toward science inquiry:

Let your method also be a pattern... Make it very apparent to the student that this is the process that we're doing and make it repetitive. Make it a pattern. It should be something that they [the students] can predict what's coming next when you start into those types of projects. 
Other teachers explained that they were applying the Patterns approach to other courses. One teacher had applied the mathematical patterns to their astronomy course. This teacher used the approach outlined in the Patterns Physics curriculum but applied the patterns concepts to astronomy content.

Alex described how the Patterns learning arc approach to organizing instruction over a unit with a focus on using patterns to understand relationships impacted thinking in a non-science class:

That mindset of unit arcs that revolve around a theme of relationships through patterns or, call it what you will, central themes, that has worked ... it rings true in my mind. I can't separate that way of designing lessons and curriculum any longer. It's just how I do it all.... It's interesting, the AVID class that I teach, that's a pretty canned curriculum that's given to us by a national organization. It's college prep, but still my physics, patterns brain seeps in there. We look at behavioral patterns, work habits, the way you devote time and the effects that that has. It all ends up coming back to this idea of these relationships, these patterns, these correlations whether they're positive or negative, how they're having an effect on each other.

These teachers had internalized the patterns approach, using it as a means for planning lessons, even in different subjects.

Theme 5B: Student-centered instruction. Several teachers indicated that through their teaching with the Patterns approach (Patterns Physics or Patterns Chemistry), they saw their teacher role differently. They expressed that their mind-sets had shifted towards facilitating a more student-centered classroom culture that emphasizes student engagement and student thinking. Gayle, a mid-career teacher, described the transition toward being more student-centered as follows:

When I first was delivering the Patterns curriculum, I held on tightly to the reins...I was delivering the curriculum.... That was...where I was comfortable. As 
I've experienced it, I've let go a little bit and said, "No, this is something that they can puzzle over. Yeah, I don't need to give them the solution before I even give them the problem." That flip of the switch-let them wonder for a little while. Let them observe something.... Give them an opportunity to actually think about it before you are revealing the answer....I was a first year teacher, so I think that I was really also just nervous about what they would do if they had a moment of ... It's intimidating to be a first-year teacher and have 36 freshmen in front of you.

It is clear from this description that being comfortable with teaching $9^{\text {th }}$ grade students was important in shifting learning away from a teacher-focus and more towards a student-focus. Shawn, a mid-career teacher, described a noticeable change in practice from the stand-and-deliver strategies they were taught as a teacher candidate to a more student-centered approach:

I definitely think that before I was like a sage-on-the-stage, standing up in front and lecturing like I was taught... Now it's more like I'm wandering around the room, I'm stopping in at tables, I'm talking to kids, they're talking to each other, they're asking questions, I'm answering, so it's really more of a conversation rather than a one-way dialogue of information just going from myself to them. I think that it's much better because they're experiencing what they're doing, and so I think the learning is a little bit longer lasting. I think in a traditional lecture setting, they're watching you and you're talking about this, or you're doing a problem, and it totally makes sense to them. Then they're going to leave your class and go to like three other classes today, and so then by the time a day or two or five or 10 have passed, even though it made sense to them in that moment, since they didn't really experience it, it doesn't stay with them very long.

Shawn further explained that for learning to be lasting and meaningful, students must be engaged "in doing the work" and that it is critical for students to experience the work. Shawn share that it was experience in teaching Patterns Chemistry has led them to this conclusion.

The last example illustrates how the patterns approach really changed the way Marie viewed physics and in how best to teach it: 
I thought, when I first started teaching, my content knowledge is strong, and not just in physics. I feel like I'm really well rounded; I'm exceptionally good at chemistry, biology, physics, and environmental science. My confidence in my ability to understand the stuff, and then, eventually, over the years, learn how to teach it, I thought was great. Then, once I realized, after patterns, there's a big fundamental piece of science that I'm not teaching the kids, or haven't natively been great at teaching the kids, and that's the one, I didn't think of, for instance, physics in terms of patterns so much. I thought of chemistry that way, and biology that way, but for some reason, I never really thought of physics as being so patterns-based, so it changed the way I thought about physics. And it changed the way I taught it to be more ...It's hard to get it student-led, but definitely studentenabled. I can enable the students to find the science, find the laws, find the physics. So, I think, of science, not just as a body of knowledge, but as a practice.

This teacher described coming from a solid content and teaching background and the experience of shifting to seeing the importance of moving towards a student-centered classroom, as thinking of "science, not just as a body of knowledge, but as a practice."

Summary. Teacher interviews indicated that through teaching the Patterns curriculum (Physics or Chemistry) their teaching practice had changed. Some teachers described the positive impact of using patterns, or the recurring "patterns" themes within their classrooms, but also in how they structured their units to reinforce student learning. Other teachers described shifting their practice from being more teacher-centered to more student-centered because they found it was more effective for student learning.

\section{Limitations of Study}

This study had several limitations due to the nature of case study research, the approach to data collection, and due to the data collected. While case study research is effective in studying phenomena that are "anchored in real-life situations" (Merriam, 2009 , p. 51), it is not appropriate to generalize the results to different groups. Because the results of this study are based on a sample of high school science teachers in District A, 
the results of this study are not necessarily generalizable to other schools or districts interested in either implementing the Patterns Physics or a Physics First program.

Merriam (2009) also stated that "it is the reader, not the researcher, who determines what in a particular case can be transferred to similar situations" (p. 51). With this in mind, the intent of this study was to describe teachers' beliefs and changes to practice as a result of involvement in the Patterns approach with the hope what is to be learned from this set of teachers' reflective perceptions and beliefs can be utilized by others in a meaningful way.

Regarding the approach to data collection, respondents to both the survey and the interviews were self-selected. There was no tangible benefit for participating in the study outside of the desire to reflect upon and share perceptions related to the Patterns approach to teaching science and engineering.

Another limit is that in this particular participant sample there were several teachers who had only taught the PCB sequence and with the NGSS. Thus, these teachers lacked experience necessary to draw comparisons of the impacts of multiple course sequences or science teaching approaches on learning prior to the foci required by the NGSS.

While there was a relatively high interview response rate $(47 \%)$ and the data indicated that there was a range of responses from the six high schools, it was not possible to determine whether the responses were statistically representative of the entire high school science teacher population in District A. While nine teachers completed the 
interviews, one school was not represented in the interviews and one school was overly represented with four interview participants.

The interviewees provided data and perspectives related to their own teaching and professional development practices plus they sometimes referenced the experiences of their colleagues. Again, while these data were helpful in examining the practices and experiences of science teachers within District A, these data are not necessarily representative of all of the science teachers in the district.

Finally, the data collected in this study were limited to the self-report style survey and nine individual interviews. Due to the scope of this study, it was not possible to observe teachers either teaching or participating in PD. Nor was it possible to observe teacher or student artifacts that would be relevant to the goals of this study.

\section{Summary}

Patterns Physics and the Patterns PCB sequence was widely accepted by District A science teachers as the preferred approach to teaching high school science. Teachers found the Patterns approach, wherein students engaged in inquiry to discover or verify mathematical patterns found in physical phenomena and then revisiting those patterns through additional investigations, as beneficial to student learning. Teachers reported success with this approach for all students except for those who struggle with basic math or algebraic concepts. Several strategies were discussed by interviewees on how to address this issue.

Professional development that was directly targeted towards classroom practice was identified as being critical in supporting teachers implementing the Patterns 
curriculum. Professional development was not only provided before teachers began teaching the course, there was ongoing professional development offered district-wide on a monthly basis, as well as within individual school buildings during building-wide professional development. The science TOSAs were critical in the planning and implementing district-wide PD, as well as working with individual teachers on an on-call basis.

This ongoing PD system (in place for six years at the time of this study) supported a culture of collaboration between teachers and TOSAs. Teachers credited the TOSA's work supporting teacher learning as critical to well-conceived development and modification of curricula resources and assessments to suit the needs of students. Results from this study indicate that the professional development and positive experiences teaching Patterns curricula increased teachers' confidence in teaching the NGSS science and engineering practices. In addition, teachers in this study indicated that they embraced the NGSS as important to science teaching and set up worthy goals to strive to implement in their own practices.

Interviewees discussed the impact of this program on their teaching practice and beliefs. Many teachers reported that they had adopted the Patterns approach in how they thought about their teaching. For example, several teachers had applied the Patterns approach to how they structured and organized classes in other subject areas. It is clear that many teachers had embraced the Patterns approach to teaching and that they viewed this approach as being a valuable teaching tool. 
Interviewee nine, Alex, provided a summary that I think accurately represents the general position that District A teachers expressed in relation to Patterns Physics:

It's not a panacea. It's not going to revolutionize test scores and send your STEM, or STEAM program through the roof. It's an accessible, workable piece of the puzzle [emphasis mine]. I think most kids leave the physics classes at the end of their freshman year liking science or not disliking science. I don't get a lot of kids who hated that class. If you're moving kids on with a positive relationship and a positive outlook on a subject, you're setting them up for the possibility of being more successful. And I think it's done a really good job of changing the narrative around what science is at our school, and at other schools that have been involved with it. I think it's a positive thing.

Teaching is a complex endeavor influenced by a myriad of factors. Having a curriculum that supports the teacher in teaching science to students needs a combination of quality, appropriateness, and flexibility. Interviewee nine, Alex, said, "Patterns Physics is accessible, workable, has positively impacted the narrative around science teaching. However, it is still is only one piece of the puzzle."

In chapter five, I synthesize the findings of this study and address each of the research questions. I situate what is to be learned from this study within the larger context of science education in the U.S. I discuss implications of this study for practice and provide suggestions for further research. I conclude with an overall summary of the study. 


\section{Chapter 5: Conclusions}

Patterns Physics is a novel physics curriculum developed in District A by several science teachers in the role of Teacher on Special Assignment (TOSAs), with contributions from various colleagues, as part of an effort to create a more equitable and effective high school science course sequence that meets the goals described in the Framework for K12 Science Education and the NGSS. Patterns Physics is meant to be a foundational course designed to be taught at the $9^{\text {th }}$ grade level followed by Patterns Chemistry- $10^{\text {th }}$ grade and Patterns Biology- $11^{\text {th }}$ grade. As the foundational course, emphasis is placed on supporting students with the practices of science and engineering and to develop the skills and content knowledge to support further learning in science throughout high school. The course used the NGSS crosscutting concept patterns as the overarching theme and combined content and instructional strategies in science and engineering activities.

It has been acknowledged that the NGSS is significantly different from past standards and that it requires a sustained, coordinated effort over multiple years to meet the goals of these standards (Bybee, 2014; NRC, 2015; Penuel, Harris, \& DeBarger, 2015; Pruitt, 2014). The Physics-Chemistry-Biology (PCB) course sequence has proponents who believe that it is the preferred course sequence for building students' scientific knowledge in high school (Glasser, 2012; Goodman \& Etkina, 2008; Larkin, 2016), particularly if the Modeling Instruction method is used (Jackson et al., 2008; Liang et al., 2012; Wells et al., 1995). The Patterns PCB initiative in District A was 
designed to meet the challenges embedded in the NGSS and shares characteristics of Modeling Instruction method (Hill, 2013) .

The purpose of this study was to examine the impact of the implementation of Patterns Physics on teacher practice and beliefs about science teaching. A key motivation for pursuing this line of research was this focus question; how does this new approach facilitate teacher classroom practices and beliefs congruent with those expressed in A Framework for K-12 Science Education (NRC, 2012) and Next Generation Science Standards (NGSS Lead States, 2013)? The following research questions were developed to guide this study.

\section{Research Questions:}

1. To what extent have the Professional Development (PD) and teaching experiences affected teachers' confidence in engaging students in the practices of science and engineering?

2. Which aspects of the Professional Development (PD) and teaching experiences have made the greatest difference in teachers' confidence and self-reported changes in their practices?

3. How have the Professional Development (PD) and teaching experiences changed teachers' perceptions about the value of physics first?

These research questions were designed to connect the lived experience of high school science teachers in District A with three current issues in science education: teaching the NGSS - particularly the science and engineering practices, effective professional development, and the Physics First initiative. The literature review in chapter two explored the current research on these issues. Chapter three presented methods used in this study and chapter four presented the analysis and results of 
quantitative and qualitative data from phase one of this case study, the Patterns Physics Impact Survey (PPIS), and phase two, interviews with nine District A science teachers.

Here, in Chapter 5, I discuss the major findings in the context of the research questions and situate these findings in a larger context. I conclude with a discussion of implications for practice and suggestions for further research.

\section{How the Data and Analysis Informs the Research Questions}

\section{Research question one}

Recall that the first research question was: To what extent have the PD and teaching experiences affected teachers' confidence in engaging students in the practices of science and engineering? The results from the Patterns Physics Impact Survey (PPIS) indicate that most teachers had improved confidence in all areas of the science and engineering practices as a result of participating in the Patterns Physics curriculum reform initiative. Teachers of the Patterns Physics course indicated a larger change in confidence in nine of the ten areas compared with those who did not teach the course (Patterns Chemistry or Patterns Biology). The most significant changes for Patterns Physics teachers were found in the following items Asking questions that can be answered with data (4.11) and Developing and Using Models (4.33). While the most significant change for the teachers of Patterns Biology or Patterns Chemistry (nonPatterns Physics teachers) or both was Using mathematics and technology to make sense of data (3.67) and Designing solutions (for engineering) (3.50).

The only statistically significant difference between Patterns Physics teachers and the teachers of Patterns Biology or Patterns Chemistry or both was for Developing and 
Using Models $(\mathrm{M}=4.33, \mathrm{M}=3.17 \mathrm{p}=.001)$. This difference may be due to the explicit development of mathematical models to describe physical phenomena (i.e., a linear pattern for constant velocity for the motion of a ball) and the utilization of these models to describe the physics principles throughout the Patterns Physics course, while the use of the mathematical patterns is less of a focus in the Patterns Chemistry or Patterns Biology courses.

The qualitative data obtained from the interviews provided some detail about individual teacher's confidence in teaching the science and engineering practices through their descriptions of their teaching practice. Teachers indicated confidence through their descriptions of science and engineering activities they conducted with students. They highlighted key learning progressions that students worked through as they applied science and engineering practices. All interviewees indicated that the underlying structure of the Patterns Physics curriculum, specifically the cycling of several common mathematical patterns derived from the foundational experiments (linear, quadratic, and inverse patterns), and then applying those patterns to new phenomena was an effective approach to support student learning. Teacher beliefs about the developmental appropriateness of theses learning activities and teaching process contributed to their sense of self-confidence.

While teachers indicated confidence with the patterns approach and activities, teacher confidence in their abilities to help students succeed in the Patterns Physics course was more nuanced. Although teachers described an overall confidence, some indicated a lack of confidence in teaching students who were not "algebra ready" who 
struggled with the mathematical and proportional reasoning components of the curriculum. While student skills in mathematics was acknowledged as a challenge by most teachers interviewed, it was only when a significant number of students in a class were not successful before teacher confidence began to wane. As Steve explained:

If $80 \%$ of your students can hack it, well then you can intervene for the $20 \%$, and that's fine. But in some cases, it is a majority of my class that just can't do that math. I'm not going to have interventions with them. It's my class.

Another teacher indicated a lack of confidence in dealing with students who were not motivated to participate in the learning activities and engage in the coursework. While these teachers indicated confidence in their understanding the content and methods of the Patterns Physics course, they were not confident in engaging all students in the science and engineering practices within the context of the Patterns Physics course.

Haag \& Megowan (2015) connect confidence to teachers' motivation and level of preparedness to teach the science and engineering practices. They found that teachers trained in Modeling Instruction (MI) are more confident in teaching the science and engineering practices. The Patterns Physics curriculum and training share many qualities found in MI in that "teachers use multiple representations to make sense of studentdesigned experiments, apply those understanding to novel situations and problems, and then discuss how they know what they know" (Hill, 2013, p.39). Patterns differs from MI in that there is a "greater emphasis on comparing and contrasting low evidence-based to high evidence-based predictions... and explicitly integrates physics and mathematics" (Hill, 2013, p. 39). 
A limitation of the survey was that it did not measure teachers' perceived confidence in teaching each of the science and engineering practices, just the change in confidence in each of the practices. For example, it is possible a teacher felt confident in some of the science and engineering practices prior to the implementation of Patterns Physics, in which case the professional development or experiences teaching Patterns Physics did not change their confidence in each area. In other words, there may have been a ceiling effect at play. Interestingly, there was no significant difference in responses to survey items that specifically addressed the engineering practices compared with those that specifically addressed the science practices, despite that the engineering practices were relatively new to many teachers.

To summarize, most teachers demonstrated an increase in confidence in all areas of engaging students in the NGSS science and engineering practices. The teachers of Patterns Physics showed greater gains in all areas except Designing Solutions (for engineering). Interviews indicated that teacher confidence was related to student engagement and success, their understanding of the patterns approach, and their belief that the activities and teaching approach were appropriate. The next research question explores this issue of confidence in more depth by detailing the data analysis related to factors that teachers' perceived to have increased their confidence.

\section{Research question two}

What aspects of the PD and teaching experiences have made the greatest difference in teachers' confidence and self-reported changes in their practice? The purpose of this question was to identify key components of PD and teacher experiences 
that teachers identified as being significantly impactful to their practice. These key components can be used to understand the effectiveness of particular components of the current implementation effort, as well as identifying key elements to be included or emphasized in future professional development to positively impact teacher practice. Both the survey and the interviews provided evidence about changes in teachers' confidence. Only the interviews provided evidence for self-reported changes in practice. I will first address teacher confidence drawing on evidence from both the survey and the interviews. This will be followed by teachers' self-reported changes in practice. I will conclude with a summary of the results.

Results from the survey. Teachers provided a variety of responses in the survey about what was most impactful to their understanding of, or to, their instruction of the NGSS science and engineering practices. Several teachers indicated that the most impactful PD they experienced was through attending PD sponsored by professional organizations (e.g. National Science Teachers Association conferences). A few teachers indicated their prior experience as scientists or engineers had been most impactful and a few teachers indicated that they had limited knowledge of the science and engineering practices as described in the NGSS. However, most of the teachers identified PD activities that were part of their work within the district.

The responses from these teachers fit into four categories: Targeted PD; working with colleagues; doing projects with students; and the introductory, summer Patterns workshops. Many of the responses combined several of these categories. For example, in responding to what experience(s) were most impactful, one teacher wrote, "After 
experiencing the PD where teachers worked through each of the student investigations and projects, spending three-to-four years modifying the activities." This response indicates that not only was the PD with teachers important, but also doing the experience of actually conducting experiments with students and making modifications over several iterations was highly impactful on practice.

Another teacher identified the importance of working with colleagues who were leaders in the curriculum implementation. "Working directly with the people who have generated the 'big ideas' of the Patterns sequence has been most impactful. I am not a 'big ideas' person but am an effective implementer of others' ideas.” This teacher emphasized the importance of having TOSA leaders who are accessible and able to support teachers in implementing the curriculum.

Another teacher shared, "PD time during summer 2012 (five years prior to taking the survey) and occasional learning team meetings with physics teachers throughout the district was critical". The teacher also stressed the importance of follow-up meetings with district physics teachers over the ensuing years.

While there were a variety of responses, the consistent themes were that for many teachers, impactful professional development was directly connected to classroom practice, collaboration with colleagues, including those with expertise in the patterns approach (i.e. teacher leaders and TOSA's), and occurred over longitudinal time-frame (three or more years was indicated several times).

Results from interviews. The results from the interviews support these findings while providing more detail about teachers' experience. For example, in discussing 
targeted PD, several interviewees indicated that it was important for teachers to be in the role of the student, to actually do the activity to get the same experience as a student. In addition to that experience, teachers described the importance of discussing the "big ideas" and reviewing additional curriculum resources, assessments, and scoring rubrics. Interviewees mentioned that after this common experience, they could work with their inbuilding colleagues to make modifications or adjustments to fit their individual school situations.

Making the curriculum "their own" was an important component message that arose both in the survey responses and in interviews. This involved individual teachers making modifications to lessons and more commonly, entire school science departments working in teams to modify Pattern Physics lessons to fit their classroom needs such as adjusting for differences in equipment, technology, or materials, and modifying lessons to emphasize different skills based on student needs.

In addition to this $\mathrm{PD}$, the science TOSAs and teacher leaders who were contributing to curriculum development were critical in providing support to classroom teachers. Most of the interviewees discussed contacting these individuals for additional information or guidance. These relationships and the interactions gave teachers on-going support as they engaged with the new curriculum.

Another finding from the interviews was the importance of the NGSS in providing guidance in their teaching practice. While there was a range of expertise in the NGSS, from basic knowledge to highly knowledgeable, teachers indicated that the NGSS was an important guide or roadmap for instructional practice. They saw the NGSS as 
moving science education forward. As one teacher said, the NGSS is "what we ought to be having kids working on, real life problems with real life science skill."

While the science and engineering practices were emphasized, teachers also referred to the importance of the crosscutting concepts and the disciplinary science content. The theme "Patterns" and how it is structured within the curriculum had a significant impact on teachers' confidence, as well as an impact of their teaching practice. Their confidence improved because the same structure and instructional strategies were utilized over several instructional units giving teachers opportunities to utilize the structures and strategies multiple times - in essence practicing. Using patterns as an overarching theme provided a mental framework for how teachers viewed the connections between the content and practices within the curriculum. This is different than traditional science teaching that is more focused on content and the delivery of content with the content being largely viewed as siloed information versus knowledge and skills connected to larger issues.

Unique to the interviews was teachers' descriptions of how the Patterns Physics initiative has impacted their views on teaching and changes in their own teaching practices. Several teachers described how they had changed from having a teachercentered approach toward a more student-centered classroom. As one interviewee, Shawn, said moving from "sage on the stage to guide on the side."

Teachers described their focus and the focus of the curriculum as being one where students were engaging in data collection and analysis with a structured space for student discussion. This discussion happened in a formalized environment, such as the 
whiteboard meetings (described by Gayle, interviewee four), or in a less formalized environment when groups of students were making design decisions. This put students in a position to engage in discussion with each other to discuss, analyze, and ask questions. Teachers described student discourse as being a key component of their instruction with the Patterns Physics curriculum with greater emphasis on student engagement than in traditional science teaching.

Many of the interviewees indicated a change in practice based on their application of the Patterns Approach as an instructional model. They embraced this approach because they believed it was more effective than other models. In essence, the approach scaffolds learning through the application of several patterns that are applied over a multitude of phenomena. Several teachers indicated that they used the patterns approach in thinking about their instruction over time, making connections between concepts and utilizing similar approaches to provide students with multiple opportunities for practice and mastery. Several teachers indicated that they are utilizing this instructional approach in other classes that they taught as a way to organize their instruction.

Summary. The implementation of Patterns Physics has impacted teacher confidence in teaching science and in how they engaged in their teaching practice. Regarding the steps undertaken to support this initiative, teachers found targeted PD, working with colleagues, doing projects with students, and the introductory summer workshop were important in supporting their teaching practice. Responses to the survey indicated that having multiple opportunities to engage with the curriculum —in the role of a student, in professional discussions with colleagues (including expert teachers, TOSAs, 
and co-teachers within a building) over several years were critical components that supported the change in practice towards the NGSS. The NGSS also played a key role by providing guideposts and a roadmap that was used to monitor and assess their changes in practice.

\section{Research question three}

How have the PD and teaching experiences changed science teachers' perceptions about the value of physics first? The intent of this question was to investigate teachers' thinking about the Physics First approach and how their views changed based on their teaching experience within the district. While most participants had taught a high school course sequence other than the current PCB (Physics, Chemistry, Biology) sequence, either within the district or in other school districts, there were several teachers who had only taught in this district with the Physics First model. This was a limitation, as these teachers did not have a different experience to compare to. However, all respondents were able to provide reasoning about their views of the best science course sequence, which was meaningful in determining participants' perceptions of the value of the Physics First approach.

At the time of this study, in the sixth year of implementation, there was broad support by District A teachers for Patterns Physics and the PCB course sequence. The survey showed that $78 \%$ of respondents believed that physics was an appropriate topic to teach at the $9^{\text {th }}$ grade level, with $12 \%$ indicating no opinion. Furthermore, $81 \%$ of respondents indicated that the physics course should utilize mathematics to find patterns in experimental data, while 3\% had no opinion. Starting with this baseline, the surveys 
and interviews provided a more nuanced story of teachers' perceptions about physics first and how/if they had changed and why.

In this section, I review the data from the survey and interviews regarding teachers' preferred course sequence. I discuss how these teachers define Physics First, provide teachers' reasoning in support of and against $\mathrm{PCB}$, including the role of mathematics, and conclude with a summary.

Teachers indicated that teaching physics at the $9^{\text {th }}$ grade level is a viable approach to teaching high school science as $78 \%$ of respondents indicated that physics was appropriate for the $9^{\text {th }}$ grade level. However, just because it is viable does not mean that all of the respondent believed that Physics First is the preferred course sequence. While the results showed a preference for the PCB sequence, there was some variation. Of the teachers surveyed $(n=32), 60 \%$ preferred the PCB sequence and $15 \%$ said that the sequence does not matter, indicating a strong preference for the PCB sequence by district science teachers. Only $10 \%(n=3)$ of the respondents preferred the BCP sequence. The remaining respondents preferred to return to the integrated science sequence in place prior to the adoption of the PCB sequence, adopt a different course sequence (though this was not described), or they thought that students should be able to choose their courses based on individual interest.

Of the 32 survey participants, 17 indicated that they had changed their view of their preferred science course sequence over time. Of the 12 respondents who initially preferred the BCP sequence, nine shared that they had changed their minds in support of the PCB sequence. Their reasons for changing to the PCB sequence overlapped the 
reasoning many teachers provided in support of the PCB sequence discussed in the next section. A chi-squared analysis was conducted to determine if there were any differences based on teachers' teaching location, years of teaching experience, content area expertise, and courses taught, but no statistical differences were found.

Qualitative responses within the survey indicate that having a working definition of a Physics First course was important. The teachers in this study were mostly referring to their experience with the Patterns Physics curriculum, but also made comments about a physics class in general. Several teachers were clear that teaching a physics course designed for $11^{\text {th }}$ or $12^{\text {th }}$ grade students to $9^{\text {th }}$ grade students was "a recipe for disaster" and not recommended, particularly with respect to the level of mathematics involved and the course workload. Several teachers were specific in stating that a $9^{\text {th }}$ grade physics course needs to be taught at a level that is accessible for students, with a focus on developing skills and involving a developmentally appropriate level of mathematics.

Regarding Patterns Physics, teachers indicated that while physics content is taught in Patterns Physics, an important aspect of the course was to use physics as a vehicle for teaching students about the science and engineering practices, the crosscutting concepts, and connecting to students understanding of mathematics through the use of basic algebraic patterns.

Many teachers provided reasons in support of the PCB sequence, with the Patterns Physics as the $9^{\text {th }}$ grade curriculum, in these main categories. First, the physics content taught in Patterns Physics provided students with opportunities for hands-on experimentation that are macro (students can see and touch the experimental materials) 
verses micro scale (materials are too small to see, i.e., atomic and molecular interactions found in chemistry and biology). Second, these experiments provided opportunities for students to engage in the science and engineering practices in ways that they can tangibly experience (i.e., measuring the stretchiness of springs, and then designing a bungee cord). Third, the curriculum provided opportunities for students to apply and develop mathematics skills (i.e., determining the spring constant of a rubber band and using that data to determine how much a bungee cord will stretch). Finally, these teachers viewed the Patterns Physics course as a foundational course in high school science that helps prepare students for chemistry and biology. As one survey participant teacher explained:

Patterns physics is a great introductory course for freshmen. They learn the basics of high school science including inquiry and engineering design. They are taught to use data to make informed predictions, and they learn in the style of write claim evidence, reasoning. Chemistry continues improving these skills. By teaching chemistry before biology, students are able to understand the phenomenon we experience in more detail because they have already studied molecular properties and interactions. Biology is the ideal course to combine the three areas of high school science. At the junior year, the biology course can include more depth and detail because physics and chemistry have already been taught.

Teachers made it apparent that many of the teachers in District A do not simply view the Patterns Physics course in isolation, but as one part of a three-year science sequence where physics supports learning in chemistry, and physics and chemistry supports learning in biology. Also, several teachers indicated success with ESL students, as physics was the least abstract of the science courses.

Another survey participant, a teacher who initially did not believe the course sequence mattered but is now a supporter of the PCB sequence described it this way. 
Physics provides hands-on, visible and "feelable"[sic] experiences with nature that students can easily relate to and allows them to strengthen their basic algebra skills within the context of their science studies. Chem is invisible, harder to conceptualize, and Biology requires keeping track of multiple, interdependent systems with a lot of memorization.

Teachers opposed to the PCB sequence provided several reasons. One reason was that they did not view Patterns Physics as a legitimate physics course. They expressed that while more students were now taking so-called physics, these students did not really understand, or gain exposure to the same topics covered in a traditional physics course. Several teachers indicated that enrollment in upper-level physics courses had declined since the implementation of Patterns Physics, while several other teachers indicated they thought enrollment in upper-level courses had improved.

Another reason given for not supporting the PCB sequence was that these teachers did not think many students had the mathematical capabilities required for them to be successful in physics at the $9^{\text {th }}$ grade level. Students' lack of math skills was a common reason given in support of teaching Biology at the $9^{\text {th }}$ grade, as it was therefore more accessible to more $9^{\text {th }}$ grade students. Interestingly, several teachers argued that with the NGSS standards, biology was now too rigorous to be taught at the $9^{\text {th }}$ grade level as it now requires more complex thinking and complex applications of science skills and content. One thing was clear from both the interviews and the surveys, mathematics plays an important role in Patterns Physics and it is viewed as both a benefit of the curriculum and a barrier.

The survey respondents indicated that teachers' views of the role of mathematics in a $9^{\text {th }}$ grade physics class varies. When responding to the following prompt: A physics 
course for $9^{\text {th }}$ grade should focus mostly on conceptual understanding with minimal mathematics, there was no consensus on an answer. An almost equal number of participants agreed with the statement $(n=16)$ as disagreed $(n=15)$, and one teacher reported no opinion. Upon further analysis, there was no discernable pattern based on respondents' content area of expertise, career band, or teaching location.

While there is not a clear view of the role of mathematics, teachers did provide data about how they handle mathematics in the Patterns Physics course. First, teachers indicated that students who have functional algebra skills are successful with the course. Second, several teachers indicated that it is especially important for teachers to assess and monitor student's mathematics skills at the beginning of the year in order to inform necessary adjustments to support student success.

Teachers who had a significant number of students who were not algebra-ready indicated more difficulty in teaching the Patterns Physics course as outlined and needed to develop additional materials to support student learning. While dealing with the mathematics in the course was identified as a challenge, teachers felt that the course supported students in improving their skills and understanding of mathematics and believed that this was a benefit. Teachers only expressed difficulty in teaching the course if they had a significant number of students who struggled with basic algebra.

Summary. The science teachers in District A were supportive of the PCB sequence they had been implementing over the past six years with Patterns Physics as the $9^{\text {th }}$ grade physics curriculum. There was overwhelming agreement that a $9^{\text {th }}$ grade physics class needs to be tailored to the needs of $9^{\text {th }}$ grade students and should also be viewed not as a 
stand-alone physics course, but as a foundational course that can be used to support students' development in science thinking as outlined in the NGSS science and engineering practices and crosscutting concepts. These skills, in concert with the development of mathematical reasoning, can contribute to students' understanding of science and help prepare them for deeper learning and success in chemistry and biology.

\section{Additional Findings}

There were two significant findings that fell outside of the boundaries of the research questions. First, as a consequence of the extended professional development and collaborative opportunities that specifically targeted teachers' classroom practice, a culture of collaboration developed among district science teachers and between district science teachers and TOSAs. Second, the culture of collaboration surrounding curricula that supported the goals of the NGSS successfully changed teachers' classroom practice to implement 3D learning - the synthesis of science and engineering content, crosscutting concepts, and practices. These findings are significant as they address key questions about the mechanisms, methods, and qualities of professional development needed to support teachers in changing their practice to meet the goals of the NGSS (Wilson, 2013).

Results from this study indicate that a culture of collaboration developed within District A and that the culture was a significant factor in supporting teacher changes in practice. Survey results showed that teachers valued the collaboration with colleagues that targeted effective implementation of the curriculum. Interviews provided additional confirmation as teachers described the processes and value of working collaboratively both within their schools and in district teams. 
The science TOSAs played a critical role in developing PD and supporting teachers, individually and in team settings. Teachers felt that they could access additional support if needed and were provided opportunities to contribute to the implementation effort in a variety of ways. These factors contributed to teacher confidence.

In sum, the results indicate that teachers are communicating and learning from one another with the goal of improving their classroom practice, while also striving to improve the overall quality of science education for District A's students. It is the interactions between and among science teachers and TOSAs, and the changes that took place because of those interactions that created the culture of collaboration. These interactions amongst colleagues supported teacher learning, coherence in implementation, and changes in classroom practice. These results are in agreement with those found by Garet, Porter, Desimone, Birman, Yoon, (2001).

It is widely acknowledged that the NGSS, particularly the implementation of 3D learning, requires a departure from traditional approaches in teaching science and that PD is a key component to facilitate this change (Bybee, 2014; NRC, 2015; Wilson, 2013). Wilson (2013) claimed that developing PD that will prepare teachers to meet the challenges of the NGSS is one of the "grand challenges" in the field of science education. In the latest report on the field of K12 science education, Banilower et al., (2018) found that "despite the inclusion of engineering in the NGSS and many states' standards, relatively few science teachers across the grade ranges have had professional development that emphasized deepening their understanding of how engineering is done" 
(p. 75) and only about a third of science courses provide students opportunities to engage in engineering (p. 109).

Also, while many high school science teachers engage their students in some aspects of the science practices, very few provide students the opportunity to engage in "evaluating the strengths/limitations of evidence and the practice of argumentation" (p. 114). This study demonstrates that by using a curriculum that emphasizes the science and engineering practices in concert with PD to support teachers in both engaging in these practices in the role of learners, as well as focusing on instructional approaches to teach these practices, teachers can and will implement innovative practices in the classroom.

In addition, the teachers in this study valued the embedded nature of the science and engineering practices, the crosscutting concepts, and the core content, and they recognized that this instructional approach reflects a core aspect of the NGSS. They have embraced these teaching practices as not only consistent with their professional responsibilities of implementing the NGSS, but also as critical to helping their students learn science as a meaningful and useful set of knowledge and skills that will serve them well in life, whatever their chosen profession may be.

\section{Situated in a Larger Context}

The purpose of this study was to examine the impact of the implementation of Patterns Physics on teacher practice and beliefs about science teaching at the high school level. Does this new approach facilitate teacher classroom practices and beliefs congruent with those expressed in A Framework for K-12 Science Education (NRC, 2012) and Next Generation Science Standards (NGSS Lead States, 2013)? 
The answer to this question was yes. The results of this study show that teachers involved in this study changed classroom teaching practices and embraced the goals of the NGSS, particularly the crosscutting concept patterns and the science and engineering practices. However, results also indicate that the change of beliefs and practices is a work in progress; that while this new approach has facilitated changes in classroom practices and beliefs, teachers were still in transition. Results also show strong support for the PCB sequence with Patterns Physics as the $9^{\text {th }}$ grade physics course.

In the following section, I will situate the findings of this study in three contexts: 1) the recent history of science education reform, 2) the context of the Physics First movement, and 3) the literature on science professional development. This section will conclude with an overview of how the theoretical framework, the Interconnected Model for Professional Growth (Clarke \& Hollingsworth, 2002), relates to this study.

\section{Recent history of science education reform}

The NGSS is the latest iteration of national efforts to prepare K-12 students for success in college, careers, and citizenship (NGSS Lead States, 2013). It builds on past efforts by addressing advances in science and utilizing what has been learned in the field of science education. Patterns Physics was designed to meet the goals outlined in A Framework for K-12 Science Education (NRC, 2012) and has been modified to meet the NGSS.

According to Bybee (2011), science inquiry was a major emphasis beginning in the 1960's and developed through the 1990's. Science inquiry “emphasized learning science concepts and using the skills and abilities of inquiry to learn those concepts" ( $\mathrm{p}$. 
38). This emphasis, in addition to the emphasis on the nature of science (Lederman, 1995), were integral in the standards documents published in the 1990's: Project 2061 (AAAS, 1993) and the National Science Education Standards (NRC, 1996). While the intent of these standards documents was to emphasize the importance of both science content and science inquiry was often treated as an add-on and conducted separately from identified science content, if at all (Pruitt, 2014).

According to Pruitt (2014), the focus of the previous standards was on students knowing discrete facts versus understanding the larger concepts of science. "The vision of the Framework and the NGSS is to use the scientific and engineering practices as a means for students to show evidence they are able apply knowledge" (p. 149). It is the focus on engaging students in science and engineering practices that also addresses issues of equity in science education as the engagement in these activities provides improved opportunities for all students, including historically underserved students, to engage their own knowledge and understanding of the world.

Results of this study indicate that these teacher participants largely embraced the 3D learning approach outlined in the NGSS. Teachers indicated that using Patterns as a key crosscutting concept throughout the curriculum was helpful in supporting student learning and in their own planning and implementation of course activities. Teachers also described the importance of science and engineering projects and in engaging students in the science and engineering practices. None of the teachers described these activities as one-off activities, but as integrated into the instructional units. Teachers described the benefits of 3D learning on student engagement and in student learning. 
Several teachers explained that this process of 3D learning helped them move from a teacher-centered classroom to a more student-centered classroom. They indicated that having consistent patterns in the instructional approach provided both students and teachers multiple opportunities to practice and improve. While students had additional practice in engaging in the science and engineering practices outlined in the NGSS, teachers had additional practice in supporting student learning with this approach. Overall, teachers found this approach helpful in supporting student learning.

\section{Within the context of the Physics First movement}

Chapter two summarized research literature about the Physics First movement that advocates for physics to be taught at the $9^{\text {th }}$ grade, often to be followed by Chemistry in the $10^{\text {th }}$ grade and Biology in the $11^{\text {th }}$ grade. While rarely implemented in schools across the country ( $\sim 3 \%$ of public schools and $\sim 9 \%$ of private schools in 2005 , AAPT, 2006), there has been an effort to increase this number since the late 1990's (Lederman, 1998, AAPT, 2006).

The reasoning for teaching physics in the $9^{\text {th }}$ grade has primarily been based on the idea that physics concepts underlie those taught in chemistry and biology, and for students to understand those topics, students need to understand basic physics concepts (Lederman, 1998; Wilt, 2005; AAPT, 2006). Additional work with the Modeling Approach to teaching physics (Wells, Hestenes, \& Swackhamer, 1995) has been effective in integrating the scientific inquiry approach to learning and has found improved student achievement when implemented (Dye, Cheatham, Rowell, Barlow, \& Carlton, 2013). There were two physics first initiatives on the scale of the physics first initiative in 
District A and worthy of comparison. While a more detailed summary of these projects is provided in $\mathrm{Ch}$ 2, I will highlight the similarities and differences.

Taylor et al. (2005) reported on a Physics First initiative in the San Diego City Schools that began implementation in the 2001-2002 school year supported by a National Science Foundation grant. Similar to the District A Patterns Physics initiative, it began with a summer training and there was a comprehensive professional development program for all ninth-grade physics teachers $(80+$ teachers). The PD program addressed the implementation of the new curriculum, instructional practices, and provided content knowledge and other strategies to address the needs of non-content teachers as well as veteran physics teachers who would be transitioning from teaching $11^{\text {th }}$ and $12^{\text {th }}$ grade students to $9^{\text {th }}$ grade students. The professional development was based on the Active Physics curriculum. Professional development was provided throughout the school year with monthly meetings and common planning periods for most of the $9^{\text {th }}$ grade physics teachers. At the end of the first year, survey data showed that a large majority of teachers felt that students should have the opportunity to take physics in the $9^{\text {th }}$ grade and that students gained a better appreciation for the processes of science with inquiry-based instruction versus direct instruction. Student achievement on an end-of-course assessment showed improvement in the second year versus the first year.

The overall tenor of the article indicates that this initiative was successful, but the initiative was disbanded in 2006. According to Tomsho (2006), the reasoning behind the Physics First initiative was to "raise the performance of minority, low-income and immigrant students" and was initiated by the superintendent. As was the situation in 
District A, before the Physics First initiative there was no specific course sequence for students to reach college readiness and teachers were often free to teach what they wanted.

Tomsho (2006) reported that while some teachers liked the new physics course other teachers did not. Students' mathematics readiness was also an issue as one teacher indicated that many students had not passed $8^{\text {th }}$ grade algebra and were therefore not ready for physics. However, the article described a large resistance to the initiative from parents, particularly those in affluent areas, and that the issue became so controversial that it became a school board election issue. Cavanagh (2006) reported that the Physics First requirement was dropped in June of 2006 due to the school board responding to critics of the program who said that the math was too difficult and that the curriculum "presented watered-down science".

Physics First Rhode Island was an initiative in six high schools beginning in 2006 with the support of a National Science Foundation grant. Hezel Associates LLC (2009) evaluated the program in 2009 three years after the initial implementation and provided a description of the implementation effort. Similar to District A, this initiative was to implement a three-year PCB sequence with the physics course being implemented in year one, the chemistry course in year two and the biology course in year three.

As with District A and the San Diego initiative, this approach required biology teachers and other non-physics trained teachers to teach ninth grade physics. Like other Physics First initiatives, it began with a summer workshop to train teachers about the 
curriculum and instructional strategies. The curriculum were designed to be inquirybased.

The report indicated that teachers were largely pleased with the Physics First curriculum and the inquiry approach. That said, the report also indicated that several schools were going to discontinue their Physics First initiative due to other priorities within their school districts and it seemed that any organized effort in supporting the initiative ended in the spring of 2009. The report does provide some insight into the initiative and an opportunity to compare with District A. Positive aspects noted in the report and in this study were:

- Communication between teachers in a building resulted in development of common tasks, assignments, and assessments. This helped ensure that students in different classes were learning the same materials;

- Several schools provided common planning time and this supported teacher collaboration;

- The scaffolding in the curriculum was helpful for student learning. Teachers felt that the PCB course progression helped student understanding of science with focus on scientific modes of thinking and data organization. They were able to address upper-level topics with more depth than prior to the implementation;

- The inquiry-based approach was regarded favorably. Hands on learning increased engagement. Repetition through the scaffolding method was believed to increase student understanding and retention of knowledge;

- There was anecdotal evidence of improved student achievement. 
Negative aspects include that there was "no formal system ... in place for teachers to exchange ideas about [the] course sequence implementation with others also using the program" (Hezel Associates LLC, 2009, p. 8). The report indicated that teachers desired this connection.

This point highlights the importance of the monthly meetings provided by District A in maintaining opportunities for teachers to get together to discuss the curriculum and the implementation cycle.

Also identified in this report was the issue of the lack of math skills as an obstacle for student learning. There were two other significant issues identified with the initiative:

- Chemistry curriculum was in development during the first three-years and not finalized until the completion of year three. Chemistry teachers had to supplement the lesson materials;

- No biology curriculum was developed so there was no third course.

So why did the San Diego and Rhode Island experiments with Physics First initiatives fail while the initiative in District A is still ongoing and has significant support from its teachers? All of these initiatives were undertaken to solve problems of equity, low-student achievement, and to implement a consistent course sequence between schools in the districts (District A had five comprehensive high schools and San Diego had 18 schools) (Taylor, 2005). Districts were also transitioning to new graduation requirements increasing from requiring only two years of science to three years, and districts were trying to address low levels of student achievement. While it appears that there was a great deal of strong resistance from parents and the community in San Diego 
about the Physics First initiative (Tomsho, 2006), according to Holveck (personal communication, April 4, 2017), there was no resistance from parents or the community in District A.

The views of the parents and community in Rhode Island are unknown. External community pressure does not appear to have been a deciding factor in the continuation of Physics First in the state.

What distinguishes the District A initiative from the others was that it was largely a bottom-up approach introduced as it was under development by district TOSAs and science teachers and voted on by the district's science teachers as the best approach to meet their challenges. The San Diego initiative was instituted by the superintendent and the Rhode Island's participation was influenced by an invitation to participate in a large curriculum research study — so these initiatives were decided by administrators and therefore were both top-down decisions.

Another significant difference is that the curricular materials for Patterns Physics were being developed by TOSAs and district teachers and therefore connected directly to district needs and resources. Initiative leaders intentionally provided teachers within the district opportunities to participate in its development, while both the San Diego and Rhode Island initiatives used a commercial curriculum and therefore less modifiable with minimal opportunities to contribute to the development.

The professional development model used in San Diego during the first few years of implementation identified by Taylor (2005) is similar to that implemented by District A, but it is not clear whether that PD support continued or was stopped after a certain 
number of years. The District A PD model was still being implemented at the time of this study, six years after the initial implementation, and therefore provided continuous support to teachers.

A final difference is one of timing. While the San Diego initiative came towards the end of the era wherein the topic of science inquiry dominated the narrative, Patterns Physics was implemented at the beginning of the age of the NGSS with the threedimensional (3D) approach to teaching and learning. The NGSS required changes by all subjects and the Patterns Physics initiative was able to be implemented in the context of broader changes in science education and could be developed as the foundational course of a three-year sequence to meet those goals. However, the San Diego initiative did not require other science teachers to change beyond the status quo.

In commenting on the repeal of the Physics First initiative in San Diego, Leon Lederman said that they had not given it enough time. "They couldn't take the growing pains of the revolution. Revolutions come hard" (as cited in Cavanagh, 2006). It is unclear what happened to the Rhode Island physics first initiative. According to (Hezel Associates LLC, 2009), two of the six high schools were planning to leave the program in 2010 due to decisions made by building administrators, as the high schools involved in the Physics First pilot were not all in the same district. Therefore, there was no central support to maintain the initiative.

In contrast, the district-level support provided by District A, funding for PD and TOSAs to support the initiative, in addition to accountability measures (i.e., all schools accessing the same curriculum and common learning targets and assessments) has 
provided a necessary structure to support the Patterns PCB initiative. Key differences worth noting when comparing possible reasons for the longevity of the program in District A versus the other school systems.

Summary. Patterns Physics has several fundamental differences from other largescale Physics First initiatives that have likely led to its success whereas others were discontinued. First, Patterns Physics was a bottom-up initiative (versus top down) that required district science teachers and administrators to make the commitment to the program. Second, the curriculum was developed in-house, so teachers had opportunities to contribute to its development and by its nature, there was some flexibility for teachers to make minor modifications to "make it their own." Third, the long-term commitment by the district to fund science TOSAs, provide monthly PD focused on support implementation of upcoming units, and in supporting in-building PD for further collaboration time. Fourth, the Patterns Physics curriculum is viewed as step one in a three-year course sequence to teach fundamental science concepts. It is not a stand-alone course. These reasons combine to give the Patterns Physics continued support over time, as it is modified and further integrated into the District A high school science program.

\section{Within literature on science professional development}

One of the lessons to learn from examining reform efforts in science education in the U.S. over the last 30 years is that change is hard. There are many moving pieces in schools including teachers' expertise, beliefs and practices, the influence of school demographics and parents, and administrative support. 
In chapter two, I reviewed the research on professional development in relation to supporting reform efforts in science education. Reforms involving embedding science inquiry into science teachers' instructional practice showed that many teachers were not effectively implementing science inquiry into their classrooms (Capps, Crawford, Constas, 2012; Demir \& Abell, 2010; Marshall, Horton, Igo, Switzer, 2009; Ozel \& Luft, 2013). In addition, the need for extensive professional development to support engineering in the NGSS is becoming broadly recognized (Cunningham \& Carlsen, 2014; Sneider, 2012).

District A took on these challenges in the implementation of Patterns Physics and the Patterns PCB sequence using best practices identified by the research. The results of this study provide further evidence that these elements of best practice should be done in concert with one another.

Through research on professional development in schools, a consensus has developed about what constitutes effective professional development. According to Loucks-Horsley, Stiles, Mundry, Love, and Hewson (2009):

Professional development: needs to be directly aligned with student learning needs; is intensive, ongoing, and connected to practice; focuses on the teaching and learning of specific academic content; is connected to other school initiatives; provides time and opportunities for teachers to collaborate and build strong working relationships; and is continuously monitored and evaluated (p. 5).

The professional development effort in support of Patterns Physics addressed each of these requirements as the PD was targeted towards the specific content and teaching practices that teachers would be teaching. Patterns Physics and associated PD were considered an important part of the district-wide effort towards providing equitable 
learning experiences for all students, in tandem with the initiative towards supporting teachers to implement standards-based assessment practices.

Time was provided for the planning and implementation of Patterns Physics through common planning periods in some schools, in-building professional development workshops, and district-wide monthly professional development sessions that targeted the next instructional unit. District TOSAs monitored and evaluated (using exit slips) the ongoing lesson planning.

In addition to these aspects of the professional development, the Patterns initiative in District A also provided opportunities for individual teachers to be involved in this effort at a variety of levels. Responses from the survey and interviews indicated a range of responses from teachers. For example, a survey participant who wrote, "I am not a 'big ideas' person but am an effective implementer of others' ideas," while interviewee 9 , Alex, who is now leading trainings after being part of the initial implementation effort said:

I'm glad I was at a place where somebody was brave enough to take the classic physics curriculum and say, it's not working; and to try something else. I don't know that I would have been that person, but I'm really glad I was close to that person and was able to jump on. As I've taught longer, I think I can be more of that person now, but I don't know if I would have been if somebody hadn't shown me or given me the opportunity to do it. I certainly appreciate that. I feel like I was kind of [in the] right place, [at the] right time

Teachers who worked in teams on designing and implementing curriculum developed professional relationships and changed their beliefs about their teaching practice. Voogt, et al, (2011) also found that collaborative work had a positive impact on teachers' job satisfaction and self-confidence. Furthermore, Coenders and Terlouw 
(2015) found that the process of modifying a curriculum before implementing it in the classroom was important for effective implementation. In keeping with this finding, the Patterns Physics professional development provided opportunities for teachers to engage with the curriculum and activities and provided space for them to make modifications to best fit their individual classroom or school situations.

The ongoing professional development model offered by District A supports prior studies regarding the benefits of collaborative work. In addition, it is distinct from other initiatives in that this professional development model was internal to the district; it was the long-term practice of this district to provide longitudinal, personalized support to teachers working in a collaborative manner. This contrasts with other professional development initiatives which were sponsored or led by an outside organization, such was the case with the Physics First initiatives in San Diego and Rhode Island.

Another feature of the Patterns Physics curriculum is that it was explicitly designed to help teachers implement the NGSS and therefore introduced teachers to new instructional practices called for in the new standards. Davis and Krajcik, (2005) defined educative curriculum materials as "curriculum materials that are intended to promote teacher learning" (p. 3)... "educative curricula help teachers make connections between general principles and specific instructional moves - to integrate their knowledge base and begin to use their knowledge flexibly in the classroom" (p. 7). Based on the definitions and descriptions by Davis and Krajcik (2005), I argue that Patterns Physics is an educative curriculum, and therefore that has been a contributing factor in teachers' support for the Patterns PCB sequence. 
The extensive professional development model that was implemented to support the Patterns Physics curriculum and the PCB sequence has improved teacher confidence. Nolan and Molla (2017) stated "confidence is about knowing one can successfully complete a task" and is "akin to self-efficacy" (p. 12). Nolan \& Molla (2017) indicated that teachers are "more confident when they have a strong knowledge base, a collegial network and decisional capacity" (p. 17). These factors were supported in the professional development program for Patterns Physics and may be a contributing factor in teachers support of the program.

\section{Theoretical Frame}

As discussed in chapter two, the Interconnected Model for Professional Growth (IMPG) (Clarke \& Hollingsworth, 2002) (Figure 3) was chosen as the theoretical frame for this study. While the IMPG was originally intended to study the professional growth of individual teachers, Voogt, et al. (2011) used the IMPG to identify "learning patterns that occur in professional development arrangements" (p. 1234). Voogt studied the learning that took place in teacher design teams (TDTs) — teams that consisted of two or more teachers who were working on designing or re-designing curriculum materials with the goal of improving instructional practice. While I did not explicitly study the impacts of curriculum modification on student learning aspect of teachers' experience with Patterns Physics but rather teachers' perceptions and beliefs, this study contributes to the body of literature that demonstrates that the IMPG model can been used to study various aspects of individual teacher learning, as well as learning done in teams. 
Coenders and Terlouw (2015) used the IMPG model to study small teams of teachers who were developing and implementing a high school chemistry curriculum. They found that teachers who participated in the development of the curriculum were much more effective at implementing the curriculum than those who received PD on the curriculum but did not participate in the development. To address the increased learning of the curriculum developers, Coenders and Terlouw (2015) extended the IMPG by adding what they called the Developed Material Domain (DMD). Because many teachers in District A have had an opportunity to develop or modify components of the Patterns Physics curriculum, this additional component is relevant to this study.

Based on the experience of conducting this study, I believe that the Interconnected Model for Professional Growth (IMPG) can be applied to better understanding teacher confidence. Applying the IMPG framework to this study, I propose that teacher confidence stems from the connection between the Personal Domain (knowledge beliefs and attitudes) and the Domain of Consequence (salient outcomes). When the salient outcomes match, or are in line with the teacher's knowledge, belief, and attitude, then the teacher will feel confident.

When they are not in-line then the teacher will feel less confident. For the Patterns Physics teachers who were working with students who were not successful in the course, due to either a deficiency in their mathematics skills or with motivation to engage in the coursework, the teachers' confidence in working with these groups of students was diminished. Interestingly, a teacher trying to address the needs of students who were struggling with the mathematics in the course was already in the process of professional 
experimentation with several ideas and the teacher dealing with students who expressed a lack of motivation was seeking an external source for advice. In both cases, these teachers were aware that the salient outcomes were not acceptable and therefore looked to the external domain for guidance. They drew on that guidance in the domain of practice and then assessed the salient outcomes to inform practice. Those interactions would then contribute to the teachers' personal beliefs and attitudes. In all, I believe that all teachers want to feel confident in their ability to teach and engage students in meaningful learning, and given the appropriate support structures, work through the IMPG model to achieve congruence to be confident in their teaching practice.

Based on the findings of this study, I would extend the IMPG with one additional component, the social constructivist filter (Figure 12). Key to teacher learning is the "social construction of knowledge through cooperative and collaborative interactions is critical to overall learning" (Davis, 2003, p. 24). Through the structured PD supports afforded teachers in District A, it was clear that the interactions through collaborative work provided teachers opportunities to learn from each other and modify their understanding of the what and why of what they were doing. In a context in which teachers participate and engage in reflective practice with colleagues and other specialists (in this case, science TOSAs), there is opportunity for discussion and reflection. The experiences of others, in the context of science teacher practice have an impact.

For example, when a teacher is engaging in a new activity, even if it does not go as planned, if there is feedback about another experience and outcome, or support to keep trying, or strategies to improve the practice for next time, then the teacher may be open to 
continued efforts with the new activity without unexpected outcomes directly impacting their personal beliefs and attitudes. It is clear from this study that the social interactions between colleagues was an important contributor to engagement with the Patterns Physics implementation and that it took several years of effort before teachers were truly comfortable with its implementation. Due to the social constructivist filter, teachers were able to give the initiative the time and effort, both individually and together as colleagues, to make the Patterns Physics initiative a success. As a result of this, many teachers have changed their knowledge, beliefs, and attitudes (the personal domain) to be supportive of Patterns Physics and the PCB sequence and confident in their teaching of Patterns Physics and the NGSS science and engineering practices.

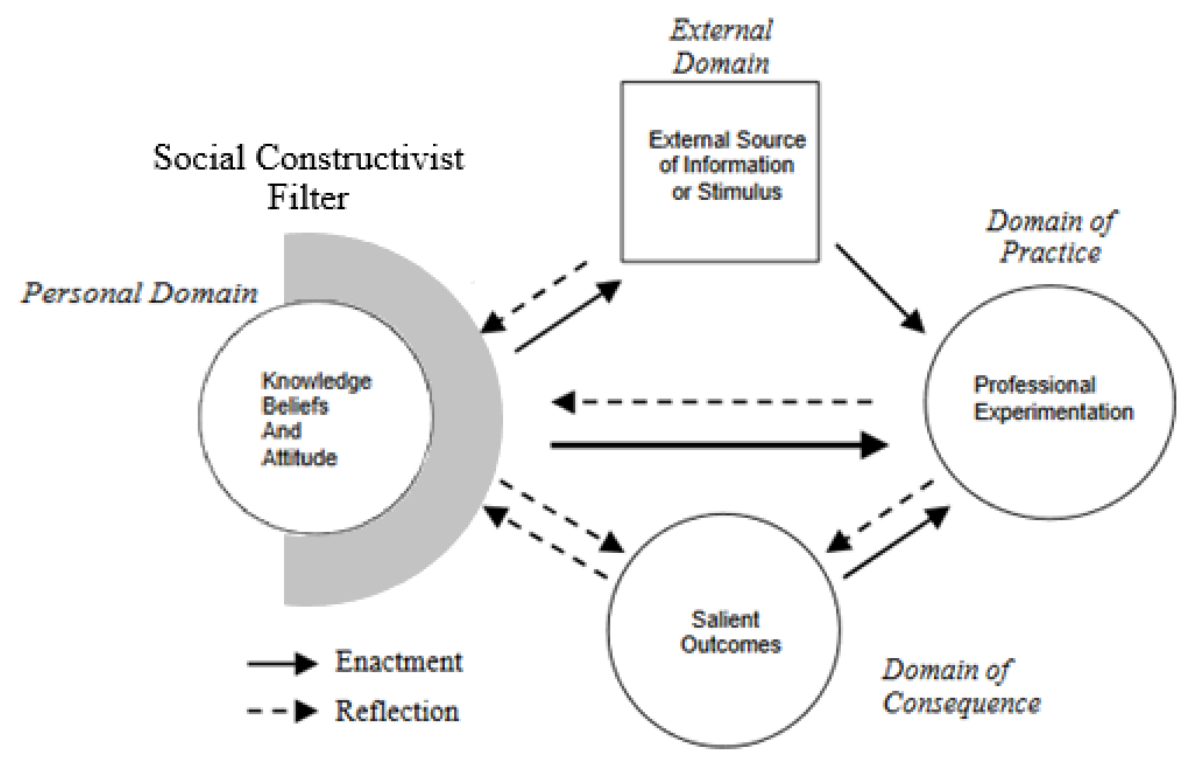

Figure 12. Interconnected Model for Professional Growth diagram inspired by Clark and Hollingsworth (2002) 


\section{Implications}

The results of this study indicate that the implementation process required a significant change in teachers' classroom practice, which was supported with a significant professional development initiative with consistent long-term support from the district administration. The success of the Patterns Physics course and Patterns initiative has implications for practice for those implementing science curricula at the high school level, whether it is a PCB sequence, or to support instructional changes required to meet the NGSS. This study also has implications for policy makers who wish to support science educators in meeting the NGSS. Finally, this study has implications for further research

\section{Implications for practice}

This study supports the recommendations of Loucks-Horsley, Stiles, Mundry, Love, \& Hewson (2009) that professional development needs to be connected to teachers' practice, focused on the teaching and learning of specific content, consist of enough time and opportunity for collaboration and the development of working relationships, and be monitored and evaluated. When a school or school district makes plans for adopting a new curriculum, it is typical for it to plan for only a one-or two-year implementation timeline (Holveck, personal communication, April 4, 2017). However, this study —in line with other research (e.g. Cunningham \& Carlsen, 2014; Davis, 2003), indicates a longer time commitment is needed. Several teachers in this study indicated that it took three years or so before they were confident in their ability to teach the 
curriculum and that additional refinements continued to be made after that initial threeyear period.

This finding is consistent with research conducted by Cunningham and Carlsen (2014), who indicated, "that it can take three to six years before teachers are genuinely comfortable engaging in engineering practices with their students" (p. 209). Also, after reaching an acceptable level of confidence, teachers' participation in the optional monthly PD sessions dropped off, but they would attend sessions when they felt they needed a refresher. As mentioned above, newer teachers in the district would regularly attend these monthly PD sessions and bring back information to their school to share with their departments. This illustrates that the continued PD impacted not only the teachers in attendance but also their colleagues in the individual schools. As engineering is a relatively new component to high school science, teachers find it very important to have PD to work through these activities and to discuss and modify them with colleagues. These consistent supports were identified as important to teachers in developing confidence in teaching the units, including the embedded science and engineering projects.

It is important to note that District A science teachers chose the Patterns PCB sequence from several choices in adopting a common course sequence for district high schools. This was part of the school district's effort to provide a more equitable experience for students. Holveck said that teachers need to participate in the decision for curriculum change, 'because if they don't have the buy in, it's not going to work...it's the teacher who has to change what they're doing every day in the classroom. If they 
don't buy into that, it's not going to happen" (personal conversation, April 4, 2017). Engaging teachers in such decisions allows teachers to participate as professionals and have buy-in, either because they believe in the initiative, or because they are supporting colleagues.

After engaging in the Patterns PCB initiative for several years, Holveck said that the professional communities were highly valued. While skeptical at first, after teachers had a chance to work collaboratively, they were very satisfied with working in teams. Therefore, it is critical that teachers be part of the decision-making process when changing curricula or the course sequence or both.

Regarding the implementation of a Physics First course sequence, this study demonstrates there is broad support from district teachers for this approach with the condition that the curriculum is appropriate for ninth grade students. The support for Patterns Physics arises because teachers see how the course fits within a larger curricular framework - the physics course fits as a good introductory course that can address the science and engineering practices with hands-on experiments, it provides students with a course content that supports learning in chemistry and biology, and the biology standards are viewed by many as too advanced for ninth grade students. The point here is that teachers need to see how the implementation will work for their school setting.

While some teachers indicated that students' mathematical skills could be an issue, most teachers indicated that adapting instruction to support all levels of learners was manageable with their students. This is an issue that needs to be thought through for each individual setting. In addition, the proper supports with PD, materials, and 
assessments need to be provided. District A had several science TOSAs who planned PD, organized and provided materials, and contributed expertise for the classroom teachers. This support and the relationships that developed were critical to the success of the implementation.

A key conclusion from this study is that over time, a collaborative culture developed between many high school science teachers in the district and with the science TOSAs. Teachers found these relationships very helpful in understanding the goals and objectives of the curriculum as well as instructional strategies. Some teachers were happy with the support they received in improving their instruction in their classrooms, while others were able to participate in other capacities such as contributing the design of lessons and entire instructional units or assisting with PD sessions. Teachers valued the collaboration work and many indicated that these experiences improved their classroom practice.

In addition to fostering healthy development of collaborative culture, the platforms provided by district leadership created opportunities for teachers within the district to step into leadership roles, a situation that positively contributed to professional growth for teachers and for the Patterns initiative. In other words, this PD model not only supported the professional growth and capacity of science teachers, it built a network for that professional capacity to developed and shared amongst the teachers to the benefit of the Patterns initiative and the overall district-wide education reform initiative. 


\section{Implications for policy}

From an education policy perspective, it is important to note that District A is one of the largest districts in the state and had the administrative support and financial and human resources available to implement the professional development program. In this state, only 9\% of districts are considered large (enrollment over 7000 students) and enroll $55 \%$ of the state's students. The remaining students are in medium-sized districts (10006999 students and 34\% of school districts) and small districts (1-999 students and 57\% of school districts) (Blumenstein, 2017). This means that a large number of teachers work in schools that may not have the financial and human resources (i.e., not enough teachers in a school or district) to undergo a professional development program similar to that implemented in District A. Therefore, education policy makers need to provide resources and opportunities, particularly for teachers in medium and small school districts, to connect with others for meaningful professional development. With the new focus on the NGSS, it may not be reasonable to support individual course curricula at this level, but subject area or common units in physics, chemistry, biology, and earth and space science designed to meet the NGSS could be modeled.

This study showed that when teachers had an overarching theme or approach to teaching, some teachers applied them to new contexts. With quality, on-going PD that was focused on instructional strategies and units designed to meet the NGSS, teachers could gain expertise needed to translate to their own teaching contexts. Providing platforms wherein teachers could network with other teachers, including teacher leaders, 
in similar teaching situations could provide meaningful opportunities for professional growth.

\section{Implications for research}

The establishment of Pattern Physics in District A and its more recent adoption in other school districts provides several opportunities for research into the impact of Physics First and the impact of the Patterns (PCB) sequence on student achievement as measured by standardized assessments, including state-level assessments. While several small studies have shown some impact on student achievement in standardized assessments, there is a lack of research involving large-scale projects. In addition, standardized assessments have not necessarily been aligned with the goals of these projects, making it difficult to utilize these as a meaningful measures of student achievement.

At the time of this writing, the state is implementing new science assessments designed to assess students on the NGSS. These new assessments may provide a tool with which to measure specific impacts of the Patterns approach on student achievement relates to the NGSS and, depending on which courses and course sequences are taught in schools throughout the state, the impact of the Physics First approach. Due to the timeframe of the implementation in District A, the size of the district, and the adoption of the Patterns Physics curriculum in other districts, it should be possible to address some of the larger questions associated with the Physics first movement as well as the impact of the Patterns (PCB) sequence. 
Potential future research questions include: Does the physics first approach/Patterns (PCB) sequence...

1) Improve science and math assessment scores?

2) Impact the number of students taking advanced science courses?

3) Impact the rates of college and career readiness

4) Impact the achievement of historically underserved students?

These questions build on the work of Sadler, Sonnert, Hazari, and Tai (2014) who found that the number of years a student takes science or math in high school is associated with "significant increases in STEM career interest" (p. 1). The increase was dependent on the subject: in addition to calculus, or a second year of chemistry, one or two years of physics predicted a large increase. Biology or life sciences did not impact STEM career interest.

Bridges (2017) completed a study (in District A) investigating the impact of the Physics First initiative on historically underserved students and their science collegereadiness test scores, rates of science college and career-readiness, and student interest in STEM careers and found a small positive effect. A limitation he acknowledged was that the study encompassed students who took Patterns Physics during the first two years of implementation. Bridges inquired as to whether or not the effect would be different after the curriculum had been in place for a longer period of time to overcome the implementation effect. Some teachers in this case study indicated that they thought achievement and STEM interest had increased since the adoption of the Patterns initiative, while several others felt that it was worse. 
Another group that may find the Patterns approach to be of interest would be mathematics researchers due to its explicit approach to utilizing mathematics. According to NCTM (2009) there is a shift underway in the approach to high school mathematics that "make reasoning and sense making foundational to the content that is taught and learned in high school" (p. 1). Student achievement in mathematics has long been an issue and recent efforts at reform in mathematics education have not had an impact on student achievement in international assessment (NCTM, 2018). A new national effort to reform mathematics education is underway and outlined in Catalyzing Change in High School Mathematics (NCTM, 2018). According to this report,

Students should leave high school with the quantitative literacy and critical thinking processes needed to make wise decisions in their personal lives. Students should be able to determine whether or not claims made in scientific, economic, social, or political arenas are valid. (p. xi)

This statement about what students should know and know how to do from the mathematical perspective is very much in line with how Patterns Physics approaches mathematics. Therefore, I think it would be valuable for mathematics education researchers to observe how math is used in Patterns Physics and see how science teachers are using math. Doing so might provide science educators with valuable input on how Patterns Physics can better support mathematics learning for students.

Finally, the biggest issue regarding student success in Patterns Physics is the lack of algebra skills for some students. I strongly recommend a research and development project to develop a means of teaching those skills in the context of Patterns Physics. Such a research project should determine methods to assess prerequisite skills and knowledge for success in Patterns Physics as well as to develop additional unit(s) and 
modifications or both to the current curriculum to support student development of those skills required for success in the course. This would also provide necessary guidance and materials for teachers who have students or classes in need of additional supports for success in Patterns Physics. Leveraging what is happening in the science classroom to support student learning in mathematics is an opportunity to support student skill development in quantitative literacy and critical thinking; skills that are helpful in life.

\section{Conclusion}

The Next Generation Science Standards (NGSS, 2013) set a new standard for how students should experience science learning, which required teachers to significantly change their teaching practices in order to provide meaningful learning experiences to support students to meet the NGSS. District A undertook a herculean project, near the time of the NGSS release, to reorganize their high school science course offerings. This was done to address two specific needs: the lack of students that were college and career ready in science, and to address identified inequities in the science course offerings within the district.

With a small, but dedicated group of science educators, Patterns Physics and the Patterns PCB course sequence was developed to address the district needs and the goals outlined in A Framework for K-12 Science Education (NRC, 2012), the foundational document of the NGSS. Instituting the Patterns Physics course for all $9^{\text {th }}$ graders required training many teachers without training or experience in teaching physics — as there were not nearly enough physics-trained teachers in the district to teach all $9^{\text {th }}$ grade students' physics. In addition, the Patterns Physics course was designed to integrate the 
crosscutting concepts, science practices and engineering practices, which required all teachers to adopt new teaching strategies. After six years, at the time of this study, the Patterns PCB initiative was still supported, and because of its success, many other districts had sent teachers to Patterns PD workshops for training, and several other had adopted the Patterns curricula.

The aim of this study was to examine the impact of Patterns Physics, the foundational course of the Patterns PCB sequence, on teacher practices and beliefs about science teaching. Results from this study showed that the implementation of Patterns Physics had positively impacted teacher confidence in providing instruction that supported the NGSS science and engineering practices. Teachers found targeted PD, working with colleagues, doing projects with students, and the introductory summer workshop important to supporting their teaching practice. The Patterns PCB sequence was viewed as an appropriate course sequence, with strong agreement that a ${ }^{\text {th }}$ grade physics course needs to be tailored to the needs of those students. Having multiple opportunities to engage with the curriculum - in the role of a student, in professional discussions with colleagues (involving expert teachers, TOSAs, and co-teachers within a building) over several years were critical to support a change in practice towards the NGSS. The multiple opportunities supported a culture of collaboration that has broad implications for improving practice both within the Patterns initiative and beyond, and the NGSS played a key role as a guidepost and roadmap toward teacher professional growth. 


\section{References}

A Framework for K-12 Science Education: Practices, Crosscutting Concepts, and Core Ideas. (2012). Retrieved from http://nap.edu/catalog/13165

AAAS (Ed.). (1993). Benchmarks for science literacy, Project 2061. New York: Oxford University Press.

AAPT. (2006). Physics First: An Informational Guide for Teachers, School Administrators, Parents, Scientists, and the Public. AAPT.

Allen, J. M., \& Nimon, K. (2007). Retrospective Pretest: A Practical Technique for Professional Development Evaluation Jeff M. Allen, Ph. D. University of North Texas. Journal of Industrial Teacher Education, 44(3), 27-42.

AMTA. (n.d.). What is AMTA? [website]. Retrieved from https://modelinginstruction.org/

Archer, T. M. (2008). Response Rates to Expect from Web-Based Surveys and What to Do About It. Journal of Extension, 46(3). Retrieved from https://www.joe.org/joe/2008june/rb3.php

ARISE : American renaissance in science education. Implementation resource book suggestions from the field. (2002).

Banilower, E. R., Smith, P. S., Malzahn, K. A., Plumley, C. L., Gordon, E. M., \& Hayes, M. L. (2018). Report of the 2018 NSSME+. Retrieved from Horizon Research, Inc website: http://horizon-research.com/NSSME/2018-nssme 
Banilower, Eric R., Smith, P. S., Weiss, I. R., Malzahn, K. A., Campbell, K. M., \& Weis, A. M. (2013). Report of the 2012 National Survey of Science and Mathematics Education. Retrieved from http://eric.ed.gov/?id=ED548238

Bess, K., \& Bybee, R. W. (2004). Systemic reform of secondary school science, A review of an urban U. S. school district: San Diego City Schools. Retrieved March 31, 2017, from http://ehrweb.aaas.org/UNESCO/pdf/SystemicReform_Bess.pdf

Blumenstein, B. (2017). High School Math and Science Course Taking Patterns. Retrieved from Office of Accountability, Research, \& Information Service website: https://www.oregon.gov/ode/reports-and-data/Pages/AccountabilityData-Briefs.aspx

Bodzin, A. M., \& Beerer, K. M. (2003). Promoting inquiry-based science instruction: The validation of the Ccience Teacher Inquiry Rubric (STIR). Journal of Elementary Science Education, 15(2), 39. https://doi.org/10.1007/BF03173842

Bridges, J. (2017). Preparing Historically Underserved Students for STEM Careers: The Role of an Inquiry-based High School Science Sequence Beginning with Physics. Dissertations and Theses. https://doi.org/10.15760/etd.3413

Bybee, R. W. (2011). Scientific and Engineering Practices in K-12 Classrooms. Science Teacher, 78(9), 34-40.

Bybee, R. W. (2014). NGSS and the Next Generation of Science Teachers. Journal of Science Teacher Education, 25(2), 211-221. https://doi.org/10.1007/s10972-014$9381-4$ 
Bybee, R. W., Taylor, J. A., Gardner, A., Scotter, P. V., Powell, J. C., Westbrook, A., \& Landes, N. (2006). The BSCS 5E Instructional Model: Origins, Effectiveness, and Applications. 19.

Capps, D., Crawford, B., \& Constas, M., (2012). A Review of Empirical Literature on Inquiry Professional Development: Alignment with Best Practices and a Critique of the Findings. Journal of Science Teacher Education, 23(3), 291-318. https://doi.org/10.1007/s10972-012-9275-2

Cavanagh, S. (2006a, June 7). San Diego School Board Retreats From 9th Grade Physics Course - Education Week. Education Week. Retrieved from https://www.edweek.org/ew/articles/2006/06/07/39physics.h25.html?r=52656223 0\&intc=eml-contshr-shr-desk\&mkey=403ABE96-B257-11E8-BBF5ECCEC819EBCD\&print=1

Cavanagh, S. (2006b, September 6). 'Physics First' Is Moving Slowly Into Nation's High Schools - Education Week. Education Week. Retrieved from http://www.edweek.org.proxy.lib.pdx.edu/ew/articles/2006/09/06/02physics.h26.h tml

Clarke, D., \& Hollingsworth, H. (2002). Elaborating a model of teacher professional growth. Teaching and Teacher Education, 18(8), 947-967. https://doi.org/10.1016/S0742-051X(02)00053-7

Coenders, F., \& Terlouw, C. (2015). A Model for In-service Teacher Learning in the Context of an Innovation. Journal of Science Teacher Education, 26(5), 451-470. https://doi.org/10.1007/s10972-015-9432-5 
Council, N. R. (2003). What Is the Influence of the National Science Education Standards?: Reviewing the Evidence, A Workshop Summary (K. S. Hollweg \& D. Hill, Eds.). Retrieved from http://www.nap.edu/catalog/10618/what-is-theinfluence-of-the-national-science-education-standards

Cranton, P. (2006). Understanding and promoting transformative learning: a guide for educators of adults (2nd ed.). San Francisco, CA: Jossey-Bass.

Creswell, J. (2014). Research Design: Qualitative, Quantitative, and Mixed Methods Approaches (4th ed.). SAGE Publications.

Cunningham, ChristineM., \& Carlsen, WilliamS. (2014). Teaching Engineering Practices. Journal of Science Teacher Education, 25(2), 197-210. https://doi.org/10.1007/s10972-014-9380-5

Czerniak, CharleneM., \& Lumpe, AndrewT. (1996). Relationship between teacher beliefs and science education reform. Journal of Science Teacher Education, 7(4), 247266. https://doi.org/10.1007/BF00058659

Davis, E. A., \& Krajcik, J. S. (2005). Designing Educative Curriculum Materials to Promote Teacher Learning. Educational Researcher, 34(3), 3-14. https://doi.org/10.3102/0013189X034003003

Davis, K. S. (2003). "Change is hard": What science teachers are telling us about reform and teacher learning of innovative practices. Science Education, 87(1), 3-30. https://doi.org/10.1002/sce.10037

Demir, A., \& Abell, S. K. (2010). Views of inquiry: Mismatches between views of science education faculty and students of an alternative certification program. 
Journal of Research in Science Teaching, 47(6), 716-741.

https://doi.org/10.1002/tea.20365

D’Eon, M., Sadownik, L., Harrison, A., \& Nation, J. (2008). Using Self-Assessments to Detect Workshop Success: Do They Work? American Journal of Evaluation, 29(1), 92-98. https://doi.org/10.1177/1098214007312630

Desimone, L. M. (2009). Improving Impact Studies of Teachers' Professional Development: Toward Better Conceptualizations and Measures. Educational Researcher, 38(3), 181-199. https://doi.org/10.3102/0013189X08331140

Dye, J., Cheatham, T., Rowell, G. H., Barlow, A., \& Carlton, R. (2013). The Impact of Modeling Instruction within the Inverted Curriculum. Electronic Journal of Science Education, 17(2). Retrieved from http://ejse.southwestern.edu.proxy.lib.pdx.edu/article/view/11231

Eisenkraft, A. (1999). Active physics (Teacher's ed edition). It's About Time, Inc.

Eisenkraft, A. (2003). Expanding the 5E model: a proposed 7E model emphasizes"transfer of learning" and the importance of eliciting prior understanding.(science teaching model). The Science Teacher, 70(6), 56-59.

Field, A. (2009). Discovering Statistics Using SPSS (3rd ed.). Thousand Oaks, California: SAGE Publications.

Fischer, H. E., Boone, W. J., \& Neumann, K. (2014). Quantitative research designs and approaches. Handbook of Research on Science Education, 2, 18. 
Garet, M. S., Porter, A. C., Desimone, L., Birman, B. F., \& Yoon, K. S. (2001). What makes professional development effective? Results from a national sample of teachers. American Educational Research Journal, 38(4), 915-945.

Gaubatz, J. (2013). Evaluation of a Secondary School Science Program Inversion: Moving from a Traditional to a Modified-PCB Sequence. Science Educator, $22(1), 19-25$.

Glasser, H. M. (2012). The Numbers Speak: Physics First Supports Math Performance. The Physics Teacher, 50(1), 53. https://doi.org/10.1119/1.3670088

Goodman, R., \& Etkina, E. (2008). Squaring the Circle: A Mathematically Rigorous Physics First. The Physics Teacher, 46(4), 222. https://doi.org/10.1119/1.2895672

Guba, E. G., \& Lincoln, Y. S. (1989). Fourth generation evaluation. Newbury Park, Calif.: Sage Publications.

Guskey, T. R. (1985). Staff Development and Teacher Change. Educational Researcher, $42(7), 57-60$.

Guskey, T. R. (1986). Staff Development and the Process of Teacher Change. Educational Researcher, 15(5), 5-12. https://doi.org/10.2307/1174780

Guskey, T. R. (2002). Professional Development and Teacher Change. Teachers and Teaching, 8(3), 381-391. https://doi.org/10.1080/135406002100000512

Haag, S., \& Megowan, C. (2015). Next Generation Science Standards: A National Mixed-Methods Study on Teacher Readiness. School Science and Mathematics, 115(8), 416-426. https://doi.org/10.1111/ssm.12145 
Haber-Schaim, U. (1984). In my opinion: High school physics should be taught before chemistry and biology. The Physics Teacher, 22(5), 330-332. https://doi.org/10.1119/1.4807675

Haney, J. J., Lumpe, A. T., Czerniak, C. M., \& Egan, V. (2002). From beliefs to actions: The beliefs and actions of teachers implementing change. Journal of Science Teacher Education, 13(3), 171-187.

Hayes, K. N., Lee, C. S., DiStefano, R., O’Connor, D., \& Seitz, J. C. (2016). Measuring Science Instructional Practice: A Survey Tool for the Age of NGSS. Journal of Science Teacher Education, 27(2), 137-164. https://doi.org/10.1007/s10972-0169448-5

Heller, J. I., Daehler, K. R., Wong, N., Shinohara, M., \& Miratrix, L. W. (2012). Differential effects of three professional development models on teacher knowledge and student achievement in elementary science. Journal of Research in Science Teaching, 49(3), 333-362. https://doi.org/10.1002/tea.21004

Herrington, D. G., Yezierski, E. J., \& Bancroft, S. F. (2016). Tool trouble: Challenges with using self-report data to evaluate long-term chemistry teacher professional development. Journal of Research in Science Teaching, 53(7), 1055-1081. https://doi.org/10.1002/tea.21323

Hestenes, D., Wells, M., \& Swackhamer, G. (1992). Force concept inventory. The Physics Teacher, 30(3), 141-158. 
Hezel Associates LLC. (2009). Physics First Rhode Island: School Personnel and Stakeholder Interviews. Retrieved from http://www.hezel.com/images/resourcelibrary/physics-first-rhode-island.pdf

Hill, B. (2013). The Patterns Approach. Science Teacher, 80(3), 38-42.

Hoogstraten, Joh. (1982). The Retrospective Pretest in an Educational Training Context. The Journal of Experimental Education, 50(4), 200-204.

Hsu, T. (2004). Physics, A First Course. Nashua, NH: Delta Education.

Jackson, J., Dukerich, L., \& Hestenes, D. (2008). Modeling instruction: An effective model for science education. Science Educator, 17(1), 10.

Johnson, R. B., Onwuegbuzie, A. J., \& Turner, L. A. (2007). Toward a Definition of Mixed Methods Research. Journal of Mixed Methods Research, 1(2), 112-133. https://doi.org/10.1177/1558689806298224

Jones, M. G., \& Leagon, M. (2014). Science Teacher Attititudes and Beliefs. Handbook on Reasearch in Science Education.

Krathwohl, D., R. (2009). Methods of Educational and Social Science Research (3rd ed.). Waveland Press, Inc.

Lam, T. C. M., \& Bengo, P. (2003). A Comparison of Three Retrospective Self-reporting Methods of Measuring Change in Instructional Practice. American Journal of Evaluation, 24(1), 65-80. https://doi.org/10.1177/109821400302400106

Larkin, D. B. (2016). Putting Physics First: Three Case Studies of High School Science Department and Course Sequence Reorganization. School Science and Mathematics, 116(4), 225-235. https://doi.org/10.1111/ssm.12168 
Laws, P., Sokoloff, D., \& Thornton, R. (1999). Promoting Active Learning Using the Results of Physics Education Research. Retrieved May 4, 2017, from http://science.uniserve.edu.au/newsletter/vol13/vol13.pdf\#page=14

Lederman, L. (2001). Revolution in Science Education: Put Physics First! Physics Today, 54(9), 11-12. https://doi.org/10.1063/1.1420496

Lederman, L. M. (1998). ARISE: American renaissance in science education. FERMILAB-TM-2051. Retrieved from http://lss.fnal.gov/cgibin/find_paper.pl?tm-2051

Lederman, L. M. (2005). Physics First? The Physics Teacher, 43(1), 6-7. https://doi.org/10.1119/1.1845981

Lederman, N. G. (1995). Translation and Transformation of Teachers' Understanding of the Nature of Science into Classroom Practice. Retrieved from https://eric.ed.gov/?id=ED382474

Lewis, E., Baker, D., Watts, N. B., \& Lang, M. (2014). A professional learning community activity for science teachers: How to incorporate discourse-rich instructional strategies into science lessons. Science Educator, 23(1), 27.

Liang, L. L., Fulmer, G. W., Majerich, D. M., Clevenstine, R., \& Howanski, R. (2012). The Effects of a Model-Based Physics Curriculum Program with a Physics First Approach: a Causal-Comparative Study. Journal of Science Education and Technology, 2l(1), 114-124.

Little, T., Chang, R., Gorrall, B., Waggenspack, L., \& Fukuda, E. (in press). The Retrospective Pretest-Posttest Design Redux: On its Validity as an Alternative to 
Traditional Pretest-Posttest Measurement. International Journal of Behavioral Development.

Loucks-Horsley, S., Stiles, K. E., Mundry, S., Love, N., \& Hewson, P. W. (2009). Designing Professional Development for Teachers of Science and Mathematics. Corwin Press.

Luft, J., \& Hewson, P. (2014). Research on Teacher Professional Development in Science. In Handbook of Research in Science Education (2nd ed.). Routledge.

Lulai, P. (2005). Seeking Physics First Data. The Physics Teacher, 43(8), 485-485. https://doi.org/10.1119/1.2120368

Madsen, A., McKagan, S. B., \& Sayre, E. C. (2014). Best practices for administering concept inventories. ArXiv Preprint ArXiv:1404.6500. Retrieved from https://arxiv.org/abs/1404.6500

Manning, R. (2012, December 12). Beaverton Schools Push Reforms With Reduced Funds. $O P B$.

Marshall, J., Horton, R., Igo, B., \& Switzer, D. (2009). K-12 Science and Mathematics Teachers' Beliefs About and Use of Inquiry in the Classroom. International Journal of Science and Mathematics Education, 7(3), 575-596. https://doi.org/10.1007/s10763-007-9122-7

Mary, M. T. (2015). An investigation of the impact of science course sequencing on student performance in high school science and math. Retrieved from http://search.proquest.com/openview/d34b2d9d954b7c8be9438d6cc10add98/1?pq -origsite $=$ gscholar $\& \mathrm{cbl}=18750 \&$ diss $=\mathrm{y}$ 
McDermott, L. C. (1993). Guest Comment: How we teach and how students learn-A mismatch? American Journal of Physics, 61(4), 295-298. https://doi.org/10.1119/1.17258

Merriam, S. B. (2009). Qualitative Research: A Guide to Design and Implementation. San Francisco: Jossey-Bass.

Michaels, S. (2008). Ready, set, science!: putting research to work in K-8 science classrooms. Washington, D.C.: National Academies Press.

Milner, A. R., Sondergeld, T. A., Demir, A., Johnson, C. C., \& Czerniak, C. M. (2012). Elementary Teachers’ Beliefs About Teaching Science and Classroom Practice: An Examination of Pre/Post NCLB Testing in Science. Journal of Science Teacher Education, 23(2), 111-132. https://doi.org/10.1007/s10972-011-9230-7

Morgan, D. L. (2014). Integrating Qualitative and Quantitative Methods: A Pragmatic Approach. SAGE Publications Inc.

National Council Of Teachers Of Mathematics. (2009). Focus in High School Mathematics: Reasoning and Sense Making. National Council of Teachers of Mathematics1906 Association Drive, Reston, VA 20191-1502Tel: 800-235-7566; Tel: 703-620-3702; Fax: 703-476-2970; e-mail: orders@ nctmorg; Web site: http://wwwnctmorg/.

National Council of Teachers of Mathematics. (2018). Catalyzing change in high school mathematics: initiating critical conversations. Reston, VA: The National Council of Teachers of Mathematics, Inc. 
National Research Council. (1996). National Science Education Standards. Retrieved from http://www.nap.edu/catalog/4962/national-science-education-standards

National Research Council. (2004). On Evaluating Curricular Effectiveness: Judging the Quality of K-12 Mathematics Evaluations. https://doi.org/10.17226/11025

National Research Council. (2012). A Framework for K-12 Science Education: Practices, Crosscutting Concepts, and Core Ideas. The National Academies Press. Washington DC.

National Research Council. (2015). Guide to Implementing the Next Generation Science Standards. Retrieved from https://www.nap.edu/catalog/18802/guide-toimplementing-the-next-generation-science-standards

NGSS Lead States. (2013). Next Generation Science Standards: For states, by states. National Academies Press Washington, DC.

Nolan, A., \& Molla, T. (2017). Teacher confidence and professional capital. Teaching and Teacher Education, 62, 10-18. https://doi.org/10.1016/j.tate.2016.11.004

NRC. (2000). How People Learn: Brain, Mind, Experience, and School: Expanded Edition. Retrieved from http://www.nap.edu/catalog/9853/how-people-learnbrain-mind-experience-and-school-expanded-edition

Opfer, V. D., \& Pedder, D. (2011). Conceptualizing Teacher Professional Learning. Review of Educational Research, 81(3), 376-407. https://doi.org/10.3102/0034654311413609 
Ozel, M., \& Luft, J. A. (2013). Beginning Secondary Science Teachers’ Conceptualization and Enactment of Inquiry-Based Instruction. School Science and Mathematics, 113(6), 308-316. https://doi.org/10.1111/ssm.12030

Pasero, S. (2003). The State of Physics-First Programs. Retrieved April 30, 2017, from http://lss.fnal.gov/archive/2001/pub/Pub-01-206.pdf

Penuel, W. R., Harris, C. J., \& DeBarger, A. H. (2015). Implementing the Next Generation Science Standards. Phi Delta Kappan, 96(6), 45-49.

AAPT. (2009). Physics First: An Informational Guide for Teachers, School Administrators, Parents, Scientists, and the Public. Retrieved from http://eric.ed.gov/?id=ED505784

Pruitt, S. (2014). The Next Generation Science Standards: The Features and Challenges. Journal of Science Teacher Education, 25(2), 145-156. https://doi.org/10.1007/s10972-014-9385-0

Public School Data File, 2011-12. (2012). US Department of Education, National Center for Educatation Statistics.

Purzer, Ş., Strobel, J., \& Cardella, M. E. (2014). Engineering in pre-college settings: synthesizing research, policy, and practices. West Lafayette, Indiana: Purdue University Press.

Reiser, B. J. (2013). What Professional Development Strategies Are Needed for Successful Implementation of the Next Generation Science Standards? Invitational Research Symposium on Science Assessment, K-12 Center at ETS, 23. 
Riggs, I. M., \& Enochs, L. G. (1990). Toward the development of an elementary teacher's science teaching efficacy belief instrument. Science Education, 74(6), 625-637.

Roehrig, G. H., Kruse, R. A., \& Kern, A. (2007). Teacher and school characteristics and their influence on curriculum implementation. Journal of Research in Science Teaching, 44(7), 883-907. https://doi.org/10.1002/tea.20180

Rogers, M. P., Abell, S., Lannin, J., Wang, C.-Y., Musikul, K., Barker, D., \& Dingman, S. (2007). Effective professional development in science and mathematics education: Teachers' and facilitators' views. International Journal of Science and Mathematics Education, 5(3), 507-532.

Ross, J. A. (1994). The impact of an inservice to promote cooperative learning on the stability of teacher efficacy. Teaching and Teacher Education, 10(4), 381-394. https://doi.org/10.1016/0742-051X(94)90020-5

Ross, M. (1989). Relation of Implicit Theories to the Construction of Personal Histories. Psychological Review, 96(2), 341-357. https://doi.org/10.1037/0033295X.96.2.341

Sadler, P. M., Sonnert, G., Hazari, Z., \& Tai, R. (2014). The Role of Advanced High School Coursework in Increasing STEM Career Interest. 23(1), 13.

Sadler, P. M., \& Tai, R. (2001). Success in Introductory College Physics: The Role of High School Preparation. Science Education, 85(2), 111-136.

Saldaña, J. (2009). The coding manual for qualitative researchers. Los Angeles: Sage. 
Sawada, D., Piburn, M. D., Judson, E., Turley, J., Falconer, K., Benford, R., \& Bloom, I. (2002). Measuring Reform Practices in Science and Mathematics Classrooms: The Reformed Teaching Observation Protocol. School Science and Mathematics, 102(6), 245-253. https://doi.org/10.1111/j.1949-8594.2002.tb17883.x

Sheppard, K., \& Robbins, D. M. (2002). Lessons from the Committee of Ten. The Physics Teacher, 40(7), 426-431. https://doi.org/10.1119/1.1517887

Sneider, C. (2012). Core Ideas of Engineering and Technology. Science Teacher, 79(1), 32-36.

Sue, V., \& Ritter, L. (2012). Conducting Online Surveys (2nd ed.). Thousand Oaks, CA: SAGE Publications Ltd.

Supovitz, J. A., Mayer, D. P., \& Kahle, J. B. (2000). Promoting Inquiry-Based Instructional Practice: The Longitudinal Impact of Professional Development in the Context of Systemic Reform. Educational Policy, 14(3), 331-356. https://doi.org/10.1177/0895904800014003001

Taylor, J. A., Getty, S. R., Kowalski, S. M., Wilson, C. D., Carlson, J., \& Scotter, P. V. (2015). An Efficacy Trial of Research-Based Curriculum Materials With Curriculum-Based Professional Development. American Educational Research Journal, 52(5), 984-1017. https://doi.org/10.3102/0002831215585962

Taylor, J. A., Powell, J. C., Van Dusen, D. R., Schindler, B. J., Pearson, B., Lavine, D., \& Bess, K. (2005). Curriculum Reform and Professional Development in San Diego City Schools. The Physics Teacher, 43(2), 102. https://doi.org/10.1119/1.1855747 
Taylor, P. (2014). Contemporary qualitative research: Toward an integral research perspective.

Tomsho, R. (2006, April 13). Top High Schools Fight New Science As Overly Simple. Retrieved December 2, 2018, from WSJ website: https://www.wsj.com/articles/SB114488997269924686

Tschannen-Moran, M., \& Hoy, A. W. (2001). Teacher efficacy: capturing an elusive construct. Teaching and Teacher Education, 17(7), 783-805. https://doi.org/10.1016/S0742-051X(01)00036-1

Veal, W. R., Riley Lloyd, M. E., Howell, M. R., \& Peters, J. (2016). Normative beliefs, discursive claims, and implementation of reform-based science standards: IMPLEMENTATION OF REFORM-BASED SCIENCE STANDARDS. Journal of Research in Science Teaching, 53(9), 1419-1443. https://doi.org/10.1002/tea.21265

Voogt, J., Westbroek, H., Handelzalts, A., Walraven, A., McKenney, S., Pieters, J., \& de Vries, B. (2011). Teacher learning in collaborative curriculum design. Teaching and Teacher Education, 27(8), 1235-1244. https://doi.org/10.1016/j.tate.2011.07.003

Wallace, C. S., \& Kang, N.-H. (2004). An investigation of experienced secondary science teachers' beliefs about inquiry: An examination of competing belief sets. Journal of Research in Science Teaching, 41(9), 936-960.

https://doi.org/10.1002/tea.20032 
Wells, M., Hestenes, D., \& Swackhamer, G. (1995). A modeling method for high school physics instruction. American Journal of Physics, 63(7), 606-619. https://doi.org/10.1119/1.17849

White, S., \& Tesfaye, C. L. (2014a). Nearly 1.4 Million High School Physics Students Enrollments in AP and second-year courses up 26\% even though number of graduates down in 2012-13. The Physics Teacher, 52(5), 276-277. https://doi.org/10.1119/1.4872405

White, S., \& Tesfaye, C. L. (2014b). Nearly 1.4 Million High School Physics Students Enrollments in AP and second-year courses up 26\% even though number of graduates down in 2012-13. The Physics Teacher, 52(5), 276-277. https://doi.org/10.1119/1.4872405

Wilson, S. M. (2013). Professional Development for Science Teachers. Science, 340(6130), 310-313. https://doi.org/10.1126/science.1230725

Wilt, J. R. (2005). Ninth Grade Physics: A Necessity for High School Science Programs. Journal of Curriculum \& Supervision, 20(4), 342-362.

Windschitl, M. (2002). Framing constructivism in practice as the negotiation of dilemmas: An analysis of the conceptual, pedagogical, cultural, and political challenges facing teachers. Review of Educational Research, 72(2), 131-175.

Woolley, S. L., \& Woolley, A. W. (1999). Can We Change Teachers' Beliefs? A Survey about Constructivist and Behaviorist Approaches.

Yin, R. K. (2014). Case Study Research: Design and Methods (5 edition). Los Angeles: SAGE Publications, Inc. 
Yin, R. K. (2018). Case Study Research and Applications (6th ed.). Retrieved from https://us.sagepub.com/en-us/nam/case-study-research-andapplications/book 250150

Zhang, M., Parker, J., Koehler, M. J., \& Eberhardt, J. (2015). Understanding Inservice Science Teachers' Needs for Professional Development. Journal of Science Teacher Education, 26(5), 471-496. https://doi.org/10.1007/s10972-015-9433-4 


\section{Appendix A: Patterns Physics Impact Survey (PPIS)}

\section{Start of Block: Default Question Block}

Q1.1 Patterns Physics Impact Survey. You are invited to participate in a study conducted by Stephen Scannell, an Educational Leadership program doctoral student from Portland State University (PSU). The purpose of this dissertation research is to examine the impact of the implementation of Patterns Physics on teacher practice and beliefs about science teaching. The data will be used for research purposes and to inform teacher professional development for physics teachers.

To protect your identity, personal identifying information will be removed. You do not have to take part in this study; it will not affect your relationship with your school district or workshop leaders. You may withdraw from this study at any time.

If you have concerns or problems related to participating in this study, or your rights as a research subject, please contact the PSU Office of Research Integrity, 1600 SW 4th Ave, Market Center Bldg., Ste. 620, Portland, OR 97201; phone (503) 725-2227 or 1 (877) 480-4400; email hsrrc@pdx.edu.

If you have questions about the study itself, please contact Stephen Scannell at 503-5120231, scannell@pdx.edu.

O I have read and understand the above and agree to participate in this study by completing this survey. (1)

I do not wish to participate in this study. (2)

Skip To: End of Survey If Patterns Physics Impact Survey You are invited to participate in a study conducted by Stephen Sca... = I do not wish to participate in this study. 
Q2.1 Please indicate below which Patterns Professional Development workshops you have participated in. Choose all that apply.
口 Patterns Physics (1)
口 Patterns Chemistry (2)
口 Patterns Biology (3)
I I have not participated in a Patterns workshop (4)

Q2.2 Please indicate below which courses you teach. Choose all that apply.

9 9th grade Physics using Patterns Physics (1)

글 10th grade Chemistry using Patterns Chemistry (2)

길 11th grade Biology using Patterns Biology (3)

ㅁarth Science (4)

a AP/IB Physics (5)

a AP/IB Chemistry (6)

口 AP/IB Biology (7)

$\square$ Other-Please type in the course title (you may add multiple courses) (8)

\section{Display This Question: \\ If Please indicate below which courses you teach. Choose all that apply. = 9th grade Physics using Patterns Physics}

Q2.3 How many years have you taught 9th grade using Patterns Physics?

\section{Display This Question:}

If Please indicate below which courses you teach. Choose all that apply. = 9th grade Physics using Patterns Physics 
Q2.4 Every teacher makes modifications based on their own classroom with regards to curriculum. Based on your classroom, what percentage of the instructional materials that you use are part of the Patterns Physics curriculum?
O $0-19 \%(1)$
O $20-39 \%(2)$
O $40-59 \%(3)$
O $60-79 \%(4)$
O $80-100 \%(5)$

Q2.5 For a variety of reasons, high schools across the United States offer different science sequences. Based on your experience, which of the following high school science sequences is best for students to learn science?
O Biology, Chemistry, Physics (1)
O Physics, Chemistry, Biology (2)
O the sequence does not matter (3)
other (write sequence in the box) (4)
Display This Question:
If For a variety of reasons, high schools across the United States offer different science sequences... = Biology, Chemistry, Physics

Q2.6 Provide a brief explanation for why you chose Biology, Chemistry, Physics as the best sequence.

\author{
Display This Question: \\ If For a variety of reasons, high schools across the United States offer different science sequences... = \\ Physics, Chemistry, Biology \\ Q2.7 Provide a brief explanation for why you chose Physics, Chemistry, Biology as the best sequence.
}
Display This Question:
If For a variety of reasons, high schools across the United States offer different science sequences... = the sequence does not matter

Q2.8 Provide a brief explanation for why the science sequence does not matter. 


\section{Display This Question:}

If For a variety of reasons, high schools across the United States offer different science sequences... = other (write sequence in the box)

Q2.9 Provide a brief explanation for why your sequence is the best sequence.

Q2.10 Has your opinion of the best science course sequence changed over your teaching career?

Yes (40)

No (41)

\section{Display This Question:}

If Has your opinion of the best science course sequence changed over your teaching career? = Yes

Q2.11 Which science course sequence did you originally think was best?

Biology, Chemistry, Physics (1)

Physics, Chemistry, Biology (2)

the sequence does not matter (3)

other (write sequence in the box) (4)

\section{Display This Question:}

If Has your opinion of the best science course sequence changed over your teaching career? $=$ Yes

Q2.12 What led you to change your views? 
Q2.13 The following questions are specifically about a 9th grade Physics course: Please indicate your belief about each statement.

\begin{tabular}{|c|c|c|c|c|c|}
\hline & $\begin{array}{c}\text { Strongly } \\
\text { Agree (1) }\end{array}$ & Agree (2) & Disagree (4) & $\begin{array}{c}\text { Strongly } \\
\text { disagree (5) }\end{array}$ & $\begin{array}{c}\text { No Opinion } \\
(6)\end{array}$ \\
\hline $\begin{array}{l}\text { A physics } \\
\text { course is not } \\
\text { appropriate for } \\
\text { the 9th grade } \\
\text { (4) } \\
\text { A physics } \\
\text { course for 9th } \\
\text { grade should } \\
\text { focus mostly on } \\
\text { conceptual } \\
\text { understanding } \\
\text { with minimal } \\
\text { mathematics } \\
\text { (1) } \\
\text { A physics } \\
\text { course for 9th } \\
\text { grade should } \\
\text { utilize } \\
\text { mathematics to } \\
\text { find patterns in } \\
\text { experimental } \\
\text { data (2) }\end{array}$ & . & . & 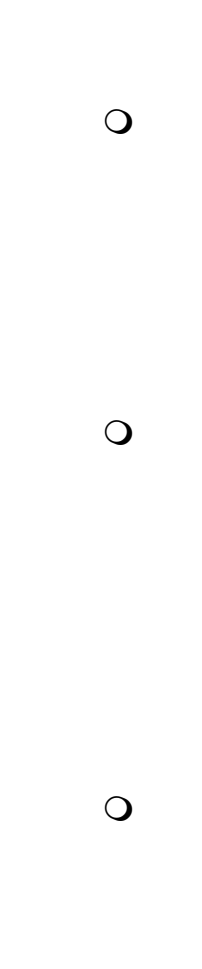 & 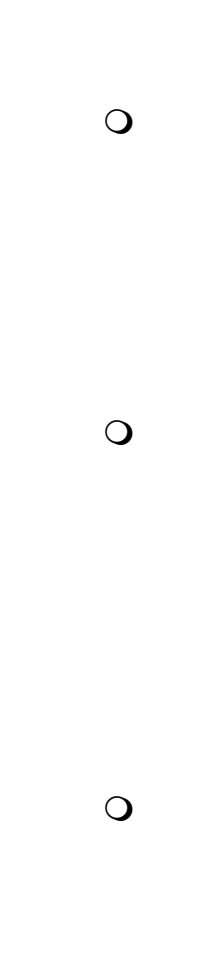 & 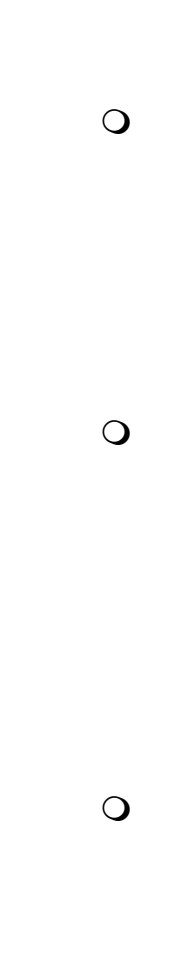 \\
\hline
\end{tabular}

Q2.14 Scenario: A group of science teachers from a different school district visit your school as they investigate whether or not they should adopt a Physics First approach and possibly the Patterns Physics curriculum. What advice would you give them about Physics First and Patterns Physics?

About Physics First, I suggest...

Q2.15 About Patterns Physics, I suggest...

Q3.1 The next series of questions are about the NGSS Science and Engineering Practices, particularly about your experiences in teaching science practices and engineering practices. 

Display This Question:
If Please indicate below which Patterns Professional Development workshops you have participated in.... = Patterns Physics
And Please indicate below which courses you teach. Choose all that apply. $=9$ th grade Physics using Patterns Physics

\section{Q3.2}

Given the training you received in the Patterns Physics Workshop and your experience in teaching the course, how has your confidence in engaging students in the following Science and Engineering Practices changed? Use the following scale 5=Greatly improved confidence, 4=Moderately improved confidence, $3=$ Slightly improved confidence, $2=$ Did not change confidence, $1=$ Less confidence

\begin{tabular}{|c|c|c|c|c|c|}
\hline & $\begin{array}{l}5=\text { Greatly } \\
\text { improved } \\
\text { confidence } \\
\text { (1) }\end{array}$ & $\begin{array}{l}\text { 4=Moderately } \\
\text { improved } \\
\text { confidence (2) }\end{array}$ & $\begin{array}{c}\text { 3=Slightly } \\
\text { improved } \\
\text { confidence (3) }\end{array}$ & $\begin{array}{l}\text { 2=Did not } \\
\text { change } \\
\text { confidence (4) }\end{array}$ & $\begin{array}{c}\text { 1=Less } \\
\text { confidence } \\
\text { (5) }\end{array}$ \\
\hline $\begin{array}{l}\text { Asking questions that can } \\
\text { be answered with data (1) }\end{array}$ & O & 0 & 0 & 0 & $O$ \\
\hline $\begin{array}{l}\text { Developing and using } \\
\text { models ( } 2 \text { ) }\end{array}$ & 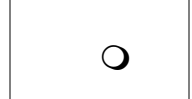 & 0 & 0 & 0 & 0 \\
\hline $\begin{array}{l}\text { Planning and carrying out } \\
\text { rigorous scientific } \\
\text { investigations (collect } \\
\text { accurate data) (3) }\end{array}$ & 0 & $O$ & O & 0 & 0 \\
\hline $\begin{array}{c}\text { Analyzing and interpreting } \\
\text { data (4) }\end{array}$ & 0 & 0 & 0 & 0 & 0 \\
\hline $\begin{array}{c}\text { Using mathematics and } \\
\text { technology to make sense } \\
\text { of data (5) }\end{array}$ & 0 & O & O & 0 & O \\
\hline $\begin{array}{l}\text { Constructing explanations } \\
\text { (for science) (6) }\end{array}$ & 0 & 0 & 0 & 0 & 0 \\
\hline $\begin{array}{l}\text { Designing solutions (for } \\
\text { engineering) (7) }\end{array}$ & 0 & 0 & $O$ & 0 & 0 \\
\hline $\begin{array}{l}\text { Engaging in argument } \\
\text { from evidence (8) }\end{array}$ & 0 & 0 & 0 & 0 & 0 \\
\hline $\begin{array}{l}\text { Obtaining, evaluating, and } \\
\text { communicating } \\
\text { information (9) }\end{array}$ & $O$ & 0 & 0 & 0 & O \\
\hline $\begin{array}{c}\text { Effectively using } \\
\text { engineering (i.e. designing } \\
\text { and building) problems to } \\
\text { help my students } \\
\text { understand science } \\
\text { concepts (10) }\end{array}$ & 0 & 0 & 0 & 0 & 0 \\
\hline
\end{tabular}




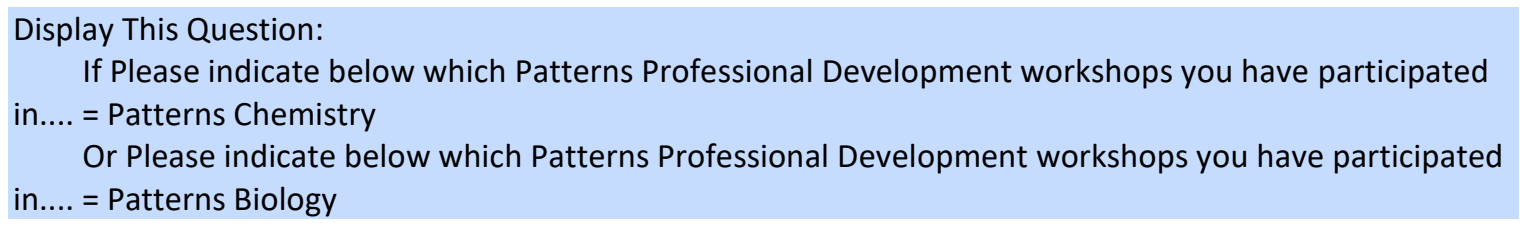

Q3.3 Given the training you received in the Patterns Biology and/or Patterns Chemistry Workshop, and your experience in teaching, how has your confidence in teaching the following Science and

Engineering Practices changed? Use the following scale 5=Greatly improved confidence, 4=Moderately improved confidence, $3=$ Slightly improved confidence, $2=$ Did not change confidence, $1=$ Less confidence

\begin{tabular}{|c|c|c|c|c|c|}
\hline & $\begin{array}{l}\text { 5=Greatly } \\
\text { improved } \\
\text { confidence } \\
\text { (1) }\end{array}$ & $\begin{array}{l}\text { 4= Moderately } \\
\text { improved } \\
\text { confidence (2) }\end{array}$ & $\begin{array}{l}\text { 3=Slightly } \\
\text { improved } \\
\text { confidence } \\
\text { (3) }\end{array}$ & $\begin{array}{c}\text { 2=Did not } \\
\text { change } \\
\text { confidence } \\
(4)\end{array}$ & $\begin{array}{c}\text { 1=Less } \\
\text { confidence } \\
\text { (5) }\end{array}$ \\
\hline $\begin{array}{c}\text { Asking questions that } \\
\text { can be answered with } \\
\text { data (1) }\end{array}$ & 0 & 0 & 0 & 0 & 0 \\
\hline $\begin{array}{l}\text { Developing and using } \\
\text { models ( } 2 \text { ) }\end{array}$ & 0 & 0 & 0 & 0 & 0 \\
\hline $\begin{array}{c}\text { Planning and carrying } \\
\text { out rigorous scientific } \\
\text { investigations (collect } \\
\text { accurate data) (3) }\end{array}$ & 0 & $\bigcirc$ & 0 & 0 & 0 \\
\hline $\begin{array}{l}\text { Analyzing and } \\
\text { interpreting data (4) }\end{array}$ & 0 & 0 & 0 & 0 & 0 \\
\hline $\begin{array}{l}\text { Using mathematics } \\
\text { and technology to } \\
\text { make sense of data (5) }\end{array}$ & 0 & 0 & O & O & 0 \\
\hline $\begin{array}{l}\text { Constructing } \\
\text { explanations (for } \\
\text { science) (6) }\end{array}$ & 0 & 0 & 0 & 0 & 0 \\
\hline $\begin{array}{l}\text { Designing solutions } \\
\text { (for engineering) (7) }\end{array}$ & 0 & 0 & 0 & 0 & 0 \\
\hline $\begin{array}{l}\text { Engaging in argument } \\
\text { from evidence (8) }\end{array}$ & 0 & 0 & 0 & 0 & 0 \\
\hline $\begin{array}{l}\text { Obtaining, evaluating, } \\
\text { and communicating } \\
\text { information (9) }\end{array}$ & 0 & 0 & 0 & 0 & 0 \\
\hline $\begin{array}{l}\text { Effectively using } \\
\text { engineering (i.e. } \\
\text { designing and } \\
\text { building) problems to } \\
\text { help my students } \\
\text { understand science } \\
\text { concepts (10) }\end{array}$ & 0 & 0 & 0 & 0 & 0 \\
\hline
\end{tabular}



Display This Question:
If Please indicate below which Patterns Professional Development workshops you have participated in.... = I have not participated in a Patterns workshop

Q3.4 Over the past three years, given whatever professional or experience may have had, how has your confidence in teaching the following Science and Engineering Practices changed? Use the following scale 5=Greatly improved confidence, 4=Moderately improved confidence, $3=$ Slightly improved confidence, $2=$ Did not change confidence, $1=$ Less confidence

\begin{tabular}{|c|c|c|c|c|c|}
\hline & $\begin{array}{c}\text { 5=Greatly } \\
\text { improved } \\
\text { confidence } \\
\text { (1) }\end{array}$ & $\begin{array}{l}\text { 4=Moderately } \\
\text { improved } \\
\text { confidence (2) }\end{array}$ & $\begin{array}{c}\text { 3=Slightly } \\
\text { improved } \\
\text { confidence } \\
\text { (3) }\end{array}$ & $\begin{array}{c}\text { 2=Did not } \\
\text { change } \\
\text { confidence } \\
\text { (4) }\end{array}$ & $\begin{array}{c}\text { 1=Less } \\
\text { confidence } \\
\text { (5) }\end{array}$ \\
\hline $\begin{array}{c}\text { Asking questions that } \\
\text { can be answered with } \\
\text { data (1) }\end{array}$ & 0 & 0 & $\bigcirc$ & 0 & 0 \\
\hline $\begin{array}{l}\text { Developing and using } \\
\text { models ( } 2 \text { ) }\end{array}$ & 0 & 0 & 0 & 0 & 0 \\
\hline $\begin{array}{c}\text { Planning and carrying } \\
\text { out rigorous scientific } \\
\text { investigations (collect } \\
\text { accurate data) (3) }\end{array}$ & 0 & 0 & 0 & 0 & 0 \\
\hline $\begin{array}{l}\text { Analyzing and } \\
\text { interpreting data (4) }\end{array}$ & 0 & 0 & 0 & 0 & 0 \\
\hline $\begin{array}{l}\text { Using mathematics } \\
\text { and technology to } \\
\text { make sense of data } \\
\text { (5) }\end{array}$ & 0 & 0 & 0 & 0 & $\bigcirc$ \\
\hline $\begin{array}{c}\text { Constructing } \\
\text { explanations (for } \\
\text { science) (6) }\end{array}$ & 0 & 0 & 0 & 0 & 0 \\
\hline $\begin{array}{l}\text { Designing solutions } \\
\text { (for engineering) (7) }\end{array}$ & 0 & 0 & 0 & 0 & 0 \\
\hline $\begin{array}{l}\text { Engaging in argument } \\
\text { from evidence (8) }\end{array}$ & 0 & 0 & 0 & 0 & 0 \\
\hline $\begin{array}{l}\text { Obtaining, evaluating, } \\
\text { and communicating } \\
\text { information (9) }\end{array}$ & 0 & 0 & 0 & 0 & 0 \\
\hline $\begin{array}{l}\text { Effectively using } \\
\text { engineering (i.e. } \\
\text { designing and } \\
\text { building) problems to } \\
\text { help my students } \\
\text { understand science } \\
\text { concepts (10) }\end{array}$ & 0 & 0 & 0 & 0 & 0 \\
\hline
\end{tabular}




\section{Start of Block: Default Question Block}

Q4.1 What experience(s) have you had (either PD, teaching, or other) that have been most impactful to your understanding or to your instruction of the NGSS engineering practices?

Q4.2 What experience(s) have you had (either PD, teaching, or other) that have been most impactful to your understanding or to your instruction of the NGSS science practices?

Q4.3 With the goal of improving science instruction toward the goals of the NGSS, what recommendations do you have for future professional development efforts for you and/or for your department?

\section{End of Block: Default Question Block}

\section{Start of Block: Block 6}

Q5.1 How many years have you taught science (K-12)? : (enter 0 if you have not yet started your first year teaching, 1 if you in your first year teaching, 2 for 2 nd year teaching, etc. )

Q5.2 Considering all of your academic, professional development, and teaching experience, which of the following content areas do you have expertise in teaching at the high school level? (choose all that apply)

口 Physics (1)

口 Chemistry (2)

口 Biology (3)

口 Earth Science (4)

$\square \quad$ Other (5) 
Q5.3 Have you participated in science teaching professional development outside of that provided by your school district in the past 2-years?
○ Yes (1)
No (3)
I don't remember (2)

\section{Display This Question: \\ If Have you participated in science teaching professional development outside of that provided by yo... = Yes}

Q5.4 Approximately how many hours of professional development outside of your school district have you participated in over the past 2-years?

Q5.5 What is the name of the school where you teach (most recent teaching assignment)?

Q6.1 If you are interested in being interviewed as part of this research project, please indicate that below by clicking-Yes, I am interested in being interviewed. Interviews will scheduled for a time and place of mutual convenience, and can be done via phone or google hangouts. Interviews will take approximately 30 minutes. Not all teachers will be interviewed, as a sample will be chosen from those who indicate yes.

Yes, I am interested in being interviewed. (1)

No, I am not interested in being interviewed. (2)

\section{Display This Question:}

If If you are interested in being interviewed as part of this research project, please indicate that... = Yes, I am interested in being interviewed.

Q6.2 Thank you for being willing to be interviewed. Please enter your contact information below. I will be contacting you in $~ 3-4$ weeks about being interviewed, and you can decline at that time if you choose.

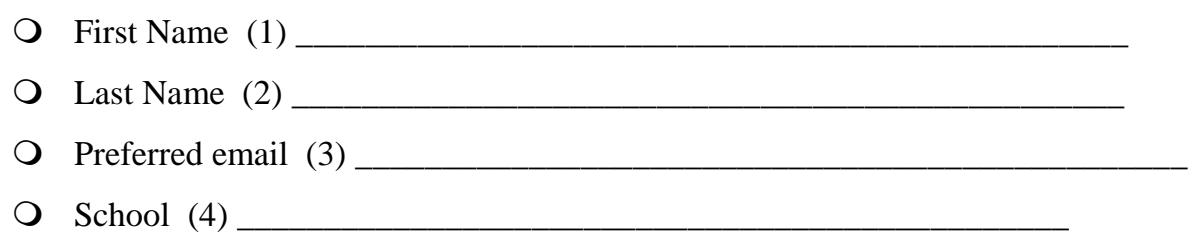

Q6.3 Thank you for completing this survey. If you have anything additional you would like to share, please type in the space below. Thank you. 


\section{Appendix B. Semi-structured Interview Questions}

Next Generation Science Standards and Physics First: A Mixed-methods Case Study of High School Teachers' Beliefs and Practices

1. Please tell me about your current teaching assignment (list of courses, schedules, etc.)

2. What science course sequence to you think is best at the high school level? Can you explain your reasoning?

3. What can you tell me about the NGSS? What are your strengths and weaknesses in trying to meet these standards?

4. Can you describe an activity/lesson/or unit you do that addresses the science practices?

5. Can you describe an activity/lesson/or unit that you do that addresses the engineering practices?

6. Please describe the PD that you have had that has been most helpful in addressing NGSS? Your teaching practice in general?

7. Please describe the PD that you would like to participate in to better meet that needs of NGSS?

8. Please describe the PD that you think is needed for your school, or district to better prepare teachers to meet the needs of NGSS?

9. In your opinion, what are the pros and cons of the Patterns Physics curriculum?

10. Do you think Patterns Physics supports NGSS? If so, how?

11. What would your recommendations be for teachers from other schools about Patterns Physics?

12. Is there anything else that you would like to share about how your address the NGSS science and engineering practices?

13. Is there anything else that you would like to share about Patterns Physics? 


\section{Appendix C. Interview Consent Form}

Next Generation Science Standards and Physics First: A Mixed-methods Case Study of High School Teachers' Beliefs and Practices

Interview Consent Form

Date

You are invited to participate in a study conducted by Stephen Scannell, an Educational Leadership program doctoral student from Portland State University (PSU).

The purpose of this dissertation research is to examine the impact of the implementation of Patterns Physics on teacher practice and beliefs about science teaching. The data will be used for research purposes and to inform teacher professional development for science teachers.

You indicated on the Pattems Physics Impact Survey (completed online) that you were interested in being interviewed as part of this research project. The interviews will be about $30-45$ minutes and will pertain to your experiences with the Patterns Physics curriculum, professional development activities to support science teaching, and the Next Generation Science Standards. Arrangements will be made to either conduct the interviews in person at your school, or mutually agreeable location, or to conduct the interviews via an online platform such as google chat or GoToMeeting. The interviews will be audio-recorded and transcribed for analysis. All data collected from this project will be stored on a password protected server accessible only to the researcher and all data will be destroyed in three years.

To protect your identity, all personal identifying information will be removed and your name will not be used in any published reports about this study. You do not have to take part in this interview, or in any aspect of this study. Your decision will not affect your relationship with your school or school district. You may withdraw from this study at any time.

If you have concems or problems related to participating in this study, or your rights as a research subject, please contact the PSU Office of Research integrity, 1600 SW 4th Ave, Market Center Bidg, Ste, 620, Portland, OR 97201; phone (503) 725-2227 or 1 (877) 480-4400; email hisrc@pdx.edu.

If you have questions about the study itself, please contact Stephen Scannell at 503512-0231; email scannellopdx edu. 


\section{Appendix D. Email Protocol}

\section{Email to High School Science Teachers in District A}

\section{To: District A High School Science Teachers}

Re: Invitation to participate in research project involving Patterns Physics

My name is Stephen Scannell, and I am currently teaching Patterns Physics at X High School, as well as a doctoral student at Portland State University in the Educational Leadership program. Also, I have been working as a co-facilitator for professional development for Patterns Physics. I am currently working on a dissertation to examine the impacts of the implementation of Patterns Physics on teachers' practices and beliefs about science teaching, particularly in how they relate to the Next Generation Science Standards.

As you likely know, the Patterns Approach- Patterns Physics, Patterns Chemistry and Patterns Biology- developed in the District A School District has had a significant impact on high school science in our region as several districts have already adopted the Patterns curricula, and many others have looked to adopt or integrate the Patterns Approach into their high school science programs.

You are invited to participate in this research because of your unique and valuable perspective from teaching Patterns Physics, teaching Patterns Chemistry or Patterns Biology, or your experience in teaching in a district that has been a long-time adopter of Patterns Physics. In addition, you have likely participated in professional development activities targeted towards the Patterns Approach and the Next Generation Science Standards.

If you choose to participate, you will be asked to complete an online survey that will take $\sim 30$ minutes. The survey is a combination of selected response and short answer questions. You do not need to participate in this research study, and you may withdraw at any time.

The online survey will be open for two weeks and you may access it through the link below. If you do not respond, I will send a reminder email in 1-week and again 1-day before the survey closes. If you do not want to participate and do not want to receive the reminder emails, please click on the survey link and indicate that you do not want to participate.

Please click the survey link below for more information and to begin the survey.

\section{Link to Survey}

If you have questions about the study, please contact me at 503-512-0231; email:

scannell@pdx.edu.

Thank you for your time and consideration in helping me research this important and timely topic.

Sincerely,

Stephen Scannell 


\section{Appendix E. Proxy (TOSA) Recruitment Script}

District A Science Teachers (If possible, given near the start of the 2017-2018 school year and presented by a surrogate):

As you likely know, the Patterns Approach-Patterns Physics, Patterns Chemistry and Patterns Biology-developed in the District A School District, has had a significant impact on high school science in our region as several districts have already adopted the Patterns curricula, and many others have looked to adopt or integrate the Patterns Approach into their high school science programs.

Stephen Scannell, a teacher of Patterns Physics at X High School, a co-facilitator of the summer Patterns Physics Workshops, and a doctoral student at Portland State University in the Educational Leadership program, is working on a dissertation to examine the impacts of the implementation of Patterns Physics on teachers' practices and beliefs about science teaching, particularly in how they relate to the Next Generation Science Standards.

You are invited to participate in this research because of your unique and valuable perspective from teaching Patterns Physics, Patterns Chemistry or Patterns Biology, or your experience in teaching in a district that has been a long-time adopter of Patterns Physics. In addition, you have likely participated in professional development activities targeted towards the Patterns Approach and the Next Generation Science Standards. This research project is being done independently of the school district and your participation is completely voluntary. However, the results of this project could be helpful for us in understanding the impact of Patterns Physics and the Patterns Approach on teacher practices and beliefs, as well as inform further professional development. If you choose to participate, you will be asked to complete an online survey. The survey is a combination of selected response and short answer questions and will take approximately 30 minutes. The survey also asks for volunteers who might be interested in being interviewed as part of this project. Participation is not required, and your decision to participate will not be used to evaluate you in any way. All personally identifiable information will be removed before data analysis, and individual responses will be kept confidential.

Stephen Scannell will be sending you an email with an invitation to participate in this project and a link to the online survey. The survey will be open for two weeks. He will send two reminder emails before the survey closes. If you do not wish to participate and do not want to receive the reminder email, please click on the survey link and indicate that you do not want to participate. Participation in the survey is completely voluntary and you can withdraw at any time.

The work you have done with the Patterns Approach is significant and worthy of study, as it is having a significant impact on science teaching in our region. Your participation in this project will be appreciated. Thank you for your time and consideration in addressing this important and timely topic. 


\section{Appendix F. Recruitment Script}

To District A Science Teachers (If possible, given near the start of the 2017-2018 school year):

My name is Stephen Scannell, and I am currently teaching Patterns Physics at X High School, as well as a doctoral student at Portland State University in the Educational Leadership program. Also, I have been working as a co-facilitator for professional development for Patterns Physics. I am currently working on a dissertation to examine the impacts of the implementation of Patterns Physics on teachers' practices and beliefs about science teaching, particularly in how they relate to the Next Generation Science Standards.

As you likely know, the Patterns Approach-Patterns Physics, Patterns Chemistry and Patterns Biology-developed in the District A School District has had a significant impact on high school science in our region as several districts have already adopted the Patterns curricula, and many others have looked to adopt or integrate the Patterns Approach into their high school science programs.

You are invited to participate in this research because of your unique and valuable perspective from teaching Patterns Physics, teaching Patterns Chemistry or Patterns Biology, or your experience in teaching in a district that has been a long-time adopter of Patterns Physics. In addition, you have likely participated in professional development activities targeted towards the Patterns Approach and the Next Generation Science Standards.

If you choose to participate, you will be asked to complete an online survey. The survey is a combination of selected response and short answer questions and will take approximately 30 minutes. In the survey, I will also ask for volunteers who might be interested in being interviewed. Participation is not required, and your decision to participate will not be used to evaluate you in any way. All personally identifiable information will be removed before data analysis, and individual responses will be kept confidential.

I will be sending you an email with an invitation to participate in the online survey. The survey will be open for two weeks. I will send a reminder email before the survey closes. If you do not wish to participate and do not want to receive the reminder email, please click on the survey link to indicate that you do not want to participate. Participation in the survey is completely voluntary and you can withdraw at any time.

The work you have done with the Patterns Approach is significant and worthy of study, as it is having a significant impact on science teaching in our region. Your participation in this project will be appreciated. I thank you for your time and consideration in helping me research this important and timely topic. 


\section{Appendix G. Interview Coding Matrix}

\begin{tabular}{|c|c|c|c|c|c|c|c|}
\hline \multicolumn{8}{|c|}{ Interview Categories and Summary of Resuits } \\
\hline Interviewee & Courge & $\begin{array}{l}\text { Classroom } \\
\text { Practice }\end{array}$ & $\begin{array}{l}\text { Sequence and Role } \\
\text { of Patterns } \\
\text { Physics } / \text { PF }\end{array}$ & $\underline{\mathrm{PD}}$ & Role of NGSS & Impact on Practice & Challenges \\
\hline 1 & $\begin{array}{l}\text { Patterns } \\
\text { Physics }\end{array}$ & $\begin{array}{l}\text { Implementing } \\
\text { Pattems } \\
\text { Physics }\end{array}$ & $\begin{array}{l}\mathrm{PCB}^{4} \text {. Needs to be } \\
\text { accessible to students } \\
\text { (math level), Bio } \\
\text { likely too hard for } 9^{\mathrm{k}} \\
\text { grade. Physics can be } \\
\text { about ideas and math }\end{array}$ & $\begin{array}{l}\text { Within dept; } \\
\text { modeling lessons } \\
\text { for colleagues }\end{array}$ & $\begin{array}{c}\text { Basic } \\
\text { knowledge; + }\end{array}$ & $\begin{array}{l}\text { Value of pattems } \\
\text { approach; importance of } \\
\text { conceptual supports for } \\
\text { beginning of the year; } \\
\text { spreadsheet modeling }\end{array}$ & $\begin{array}{l}\text { Dealing with } \\
\text { students' lack of } \\
\text { algebra skills. } \\
\text { Patterns is super- } \\
\text { essential- however } \\
\text { some kids are ready } \\
\text { for it, many are not. }\end{array}$ \\
\hline 2 & $\begin{array}{l}\text { Patterns } \\
\text { Physics } \\
\text { (STEM) }\end{array}$ & $\begin{array}{l}\text { Implementing } \\
\text { Patterns } \\
\text { Physics }\end{array}$ & $\begin{array}{l}\text { PCB: taught bio first- } \\
\text { lacked in addressing } \\
\text { science practices; } \\
\text { important for course } \\
\text { to support other later } \\
\text { "science" courses; } \\
\text { good opportunity to } \\
\text { teach, or strengthen } \\
\text { algebra skills }\end{array}$ & $\begin{array}{c}\text { Monthly } \\
\text { workshops, doing } \\
\text { labs from student } \\
\text { view } \\
\text {-would like more } \\
\text { big picture view } \\
\text { of whyl }\end{array}$ & $\begin{array}{c}\text { Basic } \\
\text { knowledge; + }\end{array}$ & $\begin{array}{l}\text { Value of patterns } \\
\text { approach; Importance of } \\
\text { uaing data in engineering } \\
\text { design decisions; } \\
\text { repetition of key patterns }\end{array}$ & $\begin{array}{l}\text { Being sure that } \\
\text { students confront } \\
\text { physics } \\
\text { misconceptions; }\end{array}$ \\
\hline 3 & $\begin{array}{l}\text { Patterns } \\
\text { Physics }\end{array}$ & $\begin{array}{l}\text { Implementing } \\
\text { Patterns } \\
\text { Physics }\end{array}$ & $\begin{array}{l}\mathrm{PCB} \text {; reference needs } \\
\text { to be both forward } \\
\text { and backward }\end{array}$ & $\begin{array}{l}\text { Science TOSA } \\
\text { visited classioom } \\
\text { to model lesson; } \\
\text { attend monthly } \\
\text { pd meetings }\end{array}$ & $\begin{array}{c}\text { Knowledgeable; } \\
+\end{array}$ & $\begin{array}{l}\text { Importance of } \\
\text { scaffolding and } \\
\text { addressing the broader } \\
\text { process of science; use of } \\
\text { simplistic models with } \\
\text { which to scaffold; adopt } \\
\text { pattems approach- }\end{array}$ & $\begin{array}{l}\text { We have to teach all } \\
\text { of the math that we } \\
\text { do. } \\
\text { Providing adequate } \\
\text { time for student } \\
\text { leaming and } \\
\text { processing. }\end{array}$ \\
\hline 4 & $\begin{array}{l}\text { Patterns } \\
\text { Physics }\end{array}$ & $\begin{array}{l}\text { Implementing } \\
\text { Pattems } \\
\text { Physics }\end{array}$ & $\begin{array}{l}\text { PCB-not sequence as } \\
\text { much as skill, } \\
\text { graphing, claim- } \\
\text { evidence-reasoning }\end{array}$ & $\begin{array}{l}\text { Monthly } \\
\text { meetings- } \\
\text { attended 2-yrs } \\
\text { In-building team } \\
\text { approach }\end{array}$ & $\begin{array}{c}\text { Basic } \\
\text { knowledge; + }\end{array}$ & $\begin{array}{l}\text { Importance of repetition } \\
\text { in lab activities-students } \\
\text { know what to do next; } \\
\text { Let your method be a } \\
\text { pattern; } \\
\text { Letting go of reigns }\end{array}$ & $\begin{array}{l}\text { (none explicitly } \\
\text { stated) }\end{array}$ \\
\hline \multicolumn{8}{|c|}{ Interview Coding Matrix (p.2) } \\
\hline Interviewee & Course & $\begin{array}{l}\text { Classroom } \\
\text { Practice }\end{array}$ & $\begin{array}{c}\text { Sequence and Role } \\
\text { of Patterns } \\
\text { Physics } / P F\end{array}$ & $\underline{\mathrm{PD}}$ & Role of NGSS & Impact on Practice & Challenges \\
\hline 5 & $\begin{array}{l}\text { Patterns } \\
\text { Physics }\end{array}$ & $\begin{array}{l}\text { Implementing } \\
\text { Patterns } \\
\text { Physics }\end{array}$ & $\begin{array}{l}\text { PCB-logically, } \\
\text { difficulties with } \\
\text { current students }\end{array}$ & $\begin{array}{l}\text { Summer } \\
\text { workshop; } \\
\text { meeting time } \\
\text { with other } \\
\text { physics and chem } \\
\text { teachers }\end{array}$ & $\begin{array}{c}\text { Knowledgeable; } \\
+\end{array}$ & $\begin{array}{l}\text { Implementing Patterns } \\
\text { strategies in other } \\
\text { science course }\end{array}$ & $\begin{array}{l}\text { Student } \\
\text { engagement, } \\
\text { Student readiness } \\
\text { for HS science, } \\
\text { pacing; addressing } \\
\text { ELL students }\end{array}$ \\
\hline 6 & $\begin{array}{l}\text { Patterns } \\
\text { Physics }\end{array}$ & $\begin{array}{l}\text { Implementing } \\
\text { Patterns } \\
\text { Physics }\end{array}$ & $\begin{array}{l}\text { PCB-logically, } \\
\text { difficulties with } \\
\text { current students }\end{array}$ & $\begin{array}{l}\text { Conversations } \\
\text { with district } \\
\text { Science TOSA } \\
\text { and team; }\end{array}$ & $\begin{array}{c}\text { Very } \\
\text { knowledgeable; } \\
+\end{array}$ & $\begin{array}{l}\text { Implementing S\&E } \\
\text { practices in other science } \\
\text { course; more student- } \\
\text { centered; changed } \\
\text { approach to physics }\end{array}$ & $\begin{array}{l}\text { Student readiness } \\
\text { for HS science; } \\
\text { addressing ELL } \\
\text { students }\end{array}$ \\
\hline 7 & $\begin{array}{l}\text { Patterns } \\
\text { Chem }\end{array}$ & $\mathrm{NA}$ & $\begin{array}{l}\text { PCB, use content to } \\
\text { build understanding, } \\
\text { build science and } \\
\text { engineering practices }\end{array}$ & $\begin{array}{l}\text { Hands-on, } \\
\text { provide skills and } \\
\text { strategies to } \\
\text { implement }\end{array}$ & $\begin{array}{c}\text { Very } \\
\text { knowledgeable; } \\
+\end{array}$ & $\begin{array}{l}\text { Move to student-centered } \\
\text { classroom; importance of } \\
\text { engineering; evolving } \\
\text { classroom }\end{array}$ & $\begin{array}{l}\text { Time to implement } \\
\text { engineering }\end{array}$ \\
\hline 8 & $\begin{array}{l}\text { Physics } \\
\text { (STEM) }\end{array}$ & $\begin{array}{l}\text { Implementing } \\
\text { Patterns } \\
\text { Physics }\end{array}$ & $\begin{array}{l}\text { PCB; tangible to } \\
\text { students i.e... hands- } \\
\text { on, macro, connect } \\
\text { physical with math } \\
\text { processes }\end{array}$ & $\begin{array}{l}\text { Summer } \\
\text { workshop key, } \\
\text { quarterly } \\
\text { workshops, in- } \\
\text { building } \\
\text { collaboration }\end{array}$ & $\begin{array}{c}\text { Knowledgeable; } \\
+\end{array}$ & $\begin{array}{c}\text { Love engineering } \\
\text { projects, make } \\
\text { mathematics digestible }\end{array}$ & Breadth vs. depth \\
\hline 9 & $\begin{array}{l}\text { Patterns } \\
\text { Physics }\end{array}$ & $\begin{array}{l}\text { Implementing } \\
\text { Patterns } \\
\text { Physics }\end{array}$ & $\begin{array}{l}\mathrm{PCB} \text {; foundation for } \\
\text { utilizing math-where } \\
\text { students can use it } \\
\text { and why it matters }\end{array}$ & $\begin{array}{l}\text { Workshops } \\
\text { (summer, } \\
\text { quarterly) }\end{array}$ & $\begin{array}{c}\text { Knowledgeable } \\
+\end{array}$ & $\begin{array}{l}\text { Learning arcs, cyclical } \\
\text { nature, chromebooks } \\
\text { student-centered } \\
\text { classroom }\end{array}$ & $\begin{array}{l}\text { Time constraints- } \\
\text { what to cover/leave } \\
\text { out; keep projects } \\
\text { current; math } \\
\text { abilities of students }\end{array}$ \\
\hline
\end{tabular}

